ICME-13 Monographs

Hans Niels Jahnke

Lisa Hefendehl-Hebeker Editors

Traditions in

German-Speaking

Mathematics

Education

Research

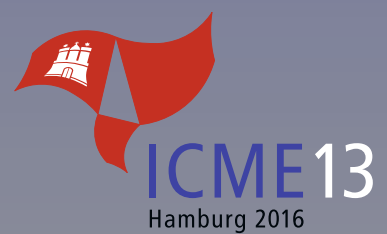

Springer Open 


\section{ICME-13 Monographs}

\section{Series editor}

Gabriele Kaiser, Faculty of Education, Didactics of Mathematics, Universität Hamburg, Hamburg, Germany 
Each volume in the series presents state-of-the art research on a particular topic in mathematics education and reflects the international debate as broadly as possible, while also incorporating insights into lesser-known areas of the discussion. Each volume is based on the discussions and presentations during the ICME-13 conference and includes the best papers from one of the ICME-13 Topical Study Groups, Discussion Groups or presentations from the thematic afternoon.

More information about this series at http://www.springer.com/series/15585 
Hans Niels Jahnke · Lisa Hefendehl-Hebeker Editors

\section{Traditions in \\ German-Speaking \\ Mathematics Education Research}

望 Springer Open 


\section{Editors}

Hans Niels Jahnke

Faculty of mathematics

University of Duisburg-Essen

Essen, Germany

\author{
Lisa Hefendehl-Hebeker \\ Faculty of mathematics \\ University of Duisburg-Essen \\ Essen, Germany
}

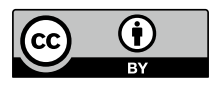

ISSN 2520-8322

ICME-13 Monographs

ISBN 978-3-030-11068-0

https://doi.org/10.1007/978-3-030-11069-7

Library of Congress Control Number: 2018966112
ISSN 2520-8330 (electronic)

ISBN 978-3-030-11069-7 (eBook)

(C) The Editor(s) (if applicable) and The Author(s) 2019. This book is an open access publication.

Open Access This book is licensed under the terms of the Creative Commons Attribution 4.0 International License (http://creativecommons.org/licenses/by/4.0/), which permits use, sharing, adaptation, distribution and reproduction in any medium or format, as long as you give appropriate credit to the original author(s) and the source, provide a link to the Creative Commons license and indicate if changes were made.

The images or other third party material in this book are included in the book's Creative Commons license, unless indicated otherwise in a credit line to the material. If material is not included in the book's Creative Commons license and your intended use is not permitted by statutory regulation or exceeds the permitted use, you will need to obtain permission directly from the copyright holder.

The use of general descriptive names, registered names, trademarks, service marks, etc. in this publication does not imply, even in the absence of a specific statement, that such names are exempt from the relevant protective laws and regulations and therefore free for general use.

The publisher, the authors and the editors are safe to assume that the advice and information in this book are believed to be true and accurate at the date of publication. Neither the publisher nor the authors or the editors give a warranty, express or implied, with respect to the material contained herein or for any errors or omissions that may have been made. The publisher remains neutral with regard to jurisdictional claims in published maps and institutional affiliations.

This Springer imprint is published by the registered company Springer Nature Switzerland AG The registered company address is: Gewerbestrasse 11, 6330 Cham, Switzerland 


\section{Preface}

The papers contained in the present volume are expanded versions of those presented during the sessions on 'German-Speaking Traditions in Mathematics Education Research' at the 13th International Congress on Mathematics Education (ICME 13) 2016, in Hamburg. Exactly forty years earlier in 1976, ICME 3 took place in the German city of Karlsruhe. It was quite natural then to ask what developments had taken place in German mathematics education research since 1976, what ideas and activities became characteristic, who proved to be influential, how were German-speaking mathematics educators influenced by the international community and how did they interact with it.

'German-speaking traditions' clearly encompass more than those of Germany alone. Austria and Switzerland belong to the family, as does the former German Democratic Republic (GDR), which has its own traditions that are still influential. Nevertheless, in preparing ICME 13, we decided, for the sake of clarity, to adopt an approach in which Germany would be our main focus while we would include cross references, some substantial, to Austria, Switzerland and the former GDR.

Our overview on German-speaking traditions is basically organized in chapters on eight fields of research: Subject-matter Didactics ('Stoffdidaktik'); Design Science and Design Research; Mathematical Modelling; Mathematics and Bildung 1810-1850; Allgemeinbildung, Mathematical Literacy and Competence Orientation; Theories of and in mathematics education; Classroom Studies in a Sociological Perspective; Educational Research on Learning and Teaching of Mathematics and Large-Scale Studies in Mathematics Education Research. In the introductory chapter (Chap. 1), 'Educational Research on Mathematics-A Short Survey of Its Development in German Speaking Countries', we try to provide a historical perspective so that the reader might gain a better understanding of how these different fields of didactical research are interrelated.

Looking at the eight themes above, one realizes the profound changes in German-speaking mathematics education research that have taken place during the last forty years. The only themes that could have appeared in the programme of the Karlsruhe Congress in 1976 are subject-matter didactics, design science (with qualifications) and the two chapters on Allgemeinbildung. All other topics, 
especially modelling, theory traditions, classroom studies and empirical research represent for Germany completely new fields of activity. Today, they define the stage on which German mathematics educators have to act. That said, more traditional fields nearer to mathematics, subject-matter analysis and elementarization, are still alive and we hope they will continue to be areas of intense work so that the common ground of mathematics and education will not be lost.

The development of a scientific discipline in any tradition is a complex and many-sided subject. To give it a fair overview is not possible in a single voice. At ICME 13, therefore, we aimed always to present our themes as far as possible in a dialogical and communicative manner, involving numerous colleagues not only from German-speaking countries but also from other parts of the world. The book of course is organized in unified and polished chapters; however, the attentive reader will find throughout the text hints of the different contributions and views of this diverse group, thus sensing, we hope, the communicative nature of the whole enterprise.

A great number of colleagues worked on and contributed to this book. We would like to express our profound gratitude to them.

Essen, Germany

November 2018
Hans Niels Jahnke Lisa Hefendehl-Hebeker 


\section{Contents}

1 Educational Research on Mathematics-A Short Survey of Its Development in German Speaking Countries . . . . . . . . . 1 Uwe Gellert, Lisa Hefendehl-Hebeker, Hans Niels Jahnke and Timo Leuders

2 Subject-Matter Didactics.

Lisa Hefendehl-Hebeker, Rudolf vom Hofe, Andreas Büchter, Hans Humenberger, Axel Schulz and Sebastian Wartha

3 Design Science and Design Research: The Significance of a Subject-Specific Research Approach

Marcus Nührenbörger, Bettina Rösken-Winter, Michael Link, Susanne Prediger and Anna Susanne Steinweg

4 Mathematical Modelling .

Katrin Vorhölter, Gilbert Greefrath, Rita Borromeo Ferri, Dominik Leiß and Stanislaw Schukajlow

$5 \quad$ Mathematics and Bildung 1810 to 1850

Hans Niels Jahnke with a reaction by Michael N. Fried

6 Allgemeinbildung, Mathematical Literacy, and Competence Orientation

Rolf Biehler with a reaction by Mogens Niss

7 Theories of and in Mathematics Education Angelika Bikner-Ahsbahs and Andreas Vohns

8 Classroom Studies-Sociological Perspectives 201 Uwe Gellert and Götz Krummheuer 
9 Educational Research on Learning and Teaching

Mathematics . . . . . . . . . . . . . . . . . . . . . . . . 223

Timo Leuders and Andreas Schulz

10 Large-Scale Studies in Mathematics Education Research . . . . . . . 249

Kristina Reiss, Andreas Obersteiner, Aiso Heinze,

Ursula Itzlinger-Bruneforth and Fou-Lai Lin 


\title{
Chapter 1 \\ Educational Research \\ on Mathematics-A Short Survey of Its \\ Development in German Speaking \\ Countries
}

\section{Uwe Gellert, Lisa Hefendehl-Hebeker, Hans Niels Jahnke and Timo Leuders}

\begin{abstract}
In German speaking countries, educational thinking and theorizing on mathematics teaching and learning originated with the establishment of compulsory education for all children and the creation of a school system. Though first efforts go back to the 18th century it does make sense to start this survey with the beginning of the 19th century, with the implication that educational research on mathematics has a history of about two hundred years in German speaking countries. During the 19th century a more and more sophisticated system of publication (journals and books) on mathematics education emerged, the education of mathematics teachers had become more professional and teacher training had developed into one of the main obligations of university teaching. However, didactics of mathematics as an academic discipline is a comparably new achievement. Its establishment began approximately fifty years ago, predominately by creating professorships and opportunities of graduation at universities. After a phase of broad discussion on the identity of the discipline (e.g., in a special issue of ZDM edited by Steiner, 1974), the community of didactics of mathematics steadily expanded, diversified and developed fruitful connections to other neighboring disciplines. This overview intends to outline this development with respect to intuitions, key ideas, research strategies and the connection between research and practice. Selected topics are presented in the following chapters in more detail.
\end{abstract}

\section{U. Gellert $(\bowtie)$}

Freie Universität Berlin, Berlin, Germany

e-mail: ugellert@zedat.fu-berlin.de

\section{Hefendehl-Hebeker}

Faculty of mathematics, University of Duisburg-Essen, Essen, Germany

e-mail: lisa.hefendehl@uni-due.de

H. N. Jahnke

Faculty of mathematics, University of Duisburg-Essen, Essen, Germany

e-mail: njahnke@uni-due.de

\section{T. Leuders}

Institute for Mathematics Education, Pädagogische Hochschule Freiburg (Freiburg University of Education), Freiburg, Germany

e-mail: leuders@ph-freiburg.de 
Keywords Humboldtian educational reforms $\cdot$ F. Klein $\cdot$ Didactics of mathematics as academic discipline $\cdot$ New math reform $\cdot$ Interaction in mathematics classrooms $\cdot$ Subject-oriented approaches $\cdot$ Applications and modelling $\cdot$ Empirical research $\cdot$ Theoretical foundation

\section{Preliminary Remark}

A word on terminology is in order. We are aware that the term 'didactics of mathematics' can sound strange to a native speaker of the English language. If it is used at all the term provokes rather narrow connotations (such as 'authoritarian lecturing') that do not meet the broad meaning of 'mathematics education' (in research, development and practice) which the German 'Didaktik der Mathematik' is intended to convey. The latter term is deeply immersed into the German system, and in quite a number of other countries a variation of it is used with a meaning similar to the one which is common in German speaking countries. Thus, we decided to use 'didactics of mathematics' in this chapter.

\subsection{Early Developments}

\subsubsection{The Century of Humboldt}

In 1810 during the course of the Humboldtian educational reforms, mathematics became a full-fledged university discipline and at the same time a school subject (Jahnke 1990, p. 333ff.; Schubring 1987). The teaching of mathematics at schools would no longer be confined to imparting practically useful arithmetic skills as had been the case in the 18th century. Rather, Wilhelm von Humboldt and other reformers of that period considered mathematics as a constitutive part of 'Bildung', which is the formation of a person's personality. The intellectual activity of an educated human being was not supposed to be determined by prescribed rules. Rather, an autonomous person was expected to be able to guide him- or herself by autonomous ideas. Accordingly, the reformers were strongly convinced that pupils should learn to understand things by their own means and from within themselves ('organic thinking'). In this regard, mathematics was considered an especially important subject.

What resulted from this general attitude was a pronounced anti-utilitarianism (Blankertz 1982, p. 95ff.). This becomes clear in some of Humboldt's educational writings where he clearly expressed an attitude against everyday applications and a preference for pure mathematics. According to him, education was to be developed to ensure "that understanding, knowledge and intellectual creativity become fascinating not by external circumstances, but rather by its internal precision, harmony and beauty. It is primarily mathematics that must be used for this purpose, starting with the very first exercises of the faculty of thinking." [“... dass das Verstehen, Wissen und geistige Schaffen nicht durch äussere Umstände, sondern durch seine innere Präcision, Harmonie und Schönheit Reiz gewinnt. Dazu und zur Vorübung des Kopfes zur reinen Wissenschaft muss vorzüglich die Mathematik und zwar von den ersten 
Uebungen des Denkvermögens an gebraucht werden.”] (Humboldt 1810, p. 261). Elsewhere, he opposed the tendency "... of digressing from the possibility of future scientific activity and considering only everyday life. ... Why, for example, should mathematics be taught according to Wirth, and not according to Euclides, Lorenz or another rigorous mathematician? Any suitable mind, and most are suitable, is able to exercise mathematical rigour, even without extensive education; and if, because of a lack of specialized schools, it is considered necessary to integrate more applications into general education, this can be done particularly toward the end of schooling. However, the pure should be left pure. Even in the field of numbers, I do not favor too many applications to Carolins, Ducats, and the like." [“...sich selbst von der Möglichkeit künftiger Wissenschaft zu entfernen, und aufs naheliegende Leben zu denken. Warum soll z. B. Mathematik nach Wirth und nicht nach Euclides, Lorenz oder einem andern strengen Mathematiker gelehrt werden? Mathematischer Strenge ist jeder an sich dazu geeignete Kopf, und die meisten sind es, auch ohne vielseitige Bildung fähig, und will man in Ermangelung von Specialschulen aus Noth mehr Anwendungen in den allgemeinen Unterricht mischen, so kann man es gegen das Ende besonders tun. Nur das Reine lasse man rein. Selbst bei den Zahlverhältnissen liebe ich nicht zu häufige Anwendungen auf Carolinen, Ducaten und so fort.”] (Humboldt 1809, p. 194, our translation).

In the beginning of the 19th century, Prussia established a school system consisting of elementary schools ('Volksschulen') for all children and secondary schools ('Gymnasium') in order to prepare students for university studies, civil service careers, outstanding positions in commerce, or industry. On a level between 'Volksschule' and 'Gymnasium', so-called 'Höhere Bürgerschulen' ('Higher schools of citizens') emerged which provided an education of practical skills in craft and commerce. During the entire 19th century, the (male) students attending Gymnasium comprised only $7 \%$ of the school age cohort (Jahnke 1990, p. 7). Teachers at gymnasium were trained at universities and had to engage in purely scientific studies, without any didactical elements. Teachers at the elementary schools were trained at newly founded seminars of teacher training ('Lehrerbildungsseminare'). In the 1860 s, a separate system of schools with a stronger emphasis on science and mathematics ('Realschulen') in addition and parallel to gymnasium was established. To avoid terminological confusion: These 19th century 'Realschulen' covered like gymnasium grades from 5 to 13, whereas in Germany the modern term 'Realschule' refers to schools covering grades from 5 to 10 . In regard to the social functions of the different types of schools the reader may consult Chap. 5 of this book.

Following the Swiss pedagogue J. H. Pestalozzi (1746-1827), outstanding educators as E. Tillich (1780-1807), F. A. W. Diesterweg (1790-1866) and W. Harnisch (1787-1864) advocated didactical ideas according to which pupils at elementary schools should reach a profound and reflected understanding of arithmetic and geometry, and not only be trained by drill and practice. Harnisch coined the concise phrase that pupils should "calculate by thinking and think by calculating" ["denkend rechnen und rechnend denken"] (Simon 1908, p. 22).

Diesterweg stated as a general principle: "Teach in such a way that the selfdirected activity of the pupil is developed as far as possible." ["Unterrichte so, dass 
überall die Selbsttätigkeit des Schülers möglichst ausgebildet werde."] (Diesterweg 1844, III/IV). He favored mental arithmetic in particular, since it is in this domain that students can develop individual and flexible strategies of calculation. "However, in mental arithmetic is much more freedom which allows individual activity, decision and discretion. For this reason mentally agile children love mental arithmetic so much. They like treating a task in multiple ways and in their own manner.... Therefore, by way of exercises in mental arithmetic [the teacher] should strive for the unleashing and liberation of the young mind by as many different solution methods as possible." ["Beim Kopfrechnen dagegen. herrscht viel mehr Freiheit, welche eigene Bewegung, Auswahl und Belieben zulässt. Darum lieben geistig bewegliche Kinder so sehr das Kopfrechnen. Es gefällt ihnen, eine Aufgabe in mannigfacher Art, auf ihre Weise zu behandeln. ... Darum strebe man ja an den Kopfrechenaufgaben durch möglichst mannigfache Auflösungsweisen die Entfesselung und Befreiung des jugendlichen Geistes an.”] (1.c., IX) For Diesterweg as for Harnisch, mental arithmetic was not a matter of memorizing but of autonomous thinking. Diesterweg coined the artificial word 'Denkrechnen' as a compound of 'thinking' and 'calculating'. Looking at the concrete arithmetic exercises in Diesterweg's handbook the modern reader will easily realize the omnipresence of the 'operative principle'.

Throughout his lifetime, Diesterweg fought against the subordination of elementary schools under the control of the (Protestant) church. In Prussia, this was a completely legal position, but after 1840 conservative forces became dominant and Diesterweg did not hesitate to warn in his handbook against the 'forces of darkness'. "Though, at first, other fields than the teaching of arithmetic will be threatened by the undeniably existing ... reaction; but also it [arithmetic] would be touched upon when the reaction against ... the self-directed activity of the subject ... [i.e.] ... in short the school of Pestalozzi ... would be victorious." ["Zwar werden zuerst andere Gebiete als der Rechenunterricht von der unleugbar eingetretenen ... Reaction bedroht; aber auch er würde an die Reihe kommen, wenn die ... gegen die Selbsttätigkeit im Subjecte ... kurz: gegen die Pestalozzische Schule gerichtete Reaction den Sieg davontragen sollte.”] (1.c., XV)

At the secondary schools (gymnasium and later Realschulen) on the other hand, in accordance with Humboldt's ideas, the teaching of mathematics had a stronger scientific character and teachers considered themselves to be scientists. Standard topics throughout the 19th century were Euclidean elementary geometry, trigonometry, spherical trigonometry and a strand of arithmetic, algebra and elementary analysis. The latter comprised some simple infinite series, but no differential and integral calculus. Within the framework of the general regulations by the state, teachers of mathematics developed multifarious didactical ideas which were published and discussed in textbooks, school programs, journals, and at meetings. Thus, a rich culture of reflection about the teaching of mathematics evolved.

As an important guideline for structuring the arithmetic and algebraic part of the curriculum, the principle of the stepwise extension of number domains from the natural numbers through negative and rational to the real numbers emerged (Jahnke 1990 , p. 405ff.). For the first time, this idea was systematically exposed in the 'Perfectly consequential system of mathematics' by Ohm (1822). Later, the underlying 
principle of adjoining the 'new' numbers to the respective 'old' domain while maintaining the laws of operation was called 'principle of permanence' and received its final formulation in 1867 by mathematician H. Hankel. This principle also served as a guideline for the treatment of the number domains in secondary schools within the new math reform in the 1960s (see Chap. 3).

In the middle of the 19th century, in the wake of the revolutionary events of 1848 , the Prussian government was convinced that too much education of the lower classes was politically dangerous. In 1847, the Prussian government removed Diesterweg from his position as director of the Berlin seminar of teacher training, and in 1854 the government officially cut down the teaching of arithmetic and geometry at elementary schools to a simple training of elementary skills ('Stiehl's regulatives').

At gymnasium, the teaching of mathematics experienced a cultural and mathematical loss of meaning which called for new ideas. Also, the emerging system of 'Realschulen' changed the role of mathematics education. Thus, after 1860 a climate in favor of reforming education developed. Specialized journals on the teaching of mathematics and science were founded:

- Archiv der Mathematik und Physik. This journal appeared from 1841 to 1920 and was dedicated to the special needs of teachers at higher schools.

- Zeitschrift für mathematischen und naturwissenschaftlichen Unterricht: ein Organ für Inhalt, Methode und Organisation des Unterrichtes in den exakten Wissenschaften an allen Schulgattungen, (Journal for teaching of mathematics and exact sciences: organ for content, method and organisation of the teaching of the exact sciences at all types of schools). The journal appeared from 1870 to 1940.

- Unterrichtsblätter für Mathematik und Naturwissenschaften: Organ des Vereins zur Förderung des mathematischen und naturwissenschaftlichen Unterrichts (Paper for the teaching of mathematics and science: organ of the society for the promotion of the teaching of mathematics and science). The journal appeared from 1895 to 1943.

From the 1880s, German books on methods of teaching mathematics at gymnasium began to appear. These included Die Methode des mathematischen Unterrichts: nebst Proben einer schulmäßigen Behandlung der Geometrie by T. Wittstein (1879); Anleitung zum mathematischen Unterricht an höheren Schulen by F. Reidt (1885); and Didaktik und Methodik des Rechnens und der Mathematik. Zweite, umgearbeitete und vermehrte Auflage by M. Simon (1908).

Beyond that, articles on mathematics education appeared in general journals of pedagogy.

In regard to mathematical topics covered in school, two important developments emerged by the end of the 19th century. First of all, Euclidean elementary geometry was questioned from two sides. Some teachers and mathematicians recommended the introduction of elements of transformational and projective geometry (c.f., Krüger 1999, Sects. 3.2 and 5.3). A famous textbook representing this trend was Henrici and Treutlein (1881-1883). P. Treutlein spoke for the introduction of a course on propaedeutic geometry comprising an intuitive study of figures and solid bodies. Only after such an intuitive phase Euclidean geometry was to be systematically studied 
(Treutlein 1911). In 1877, a second development started with a talk by the famous physiologist E. Du Bois-Reymond (1818-1896) who pleaded for the introduction of analytic geometry into gymnasium. And in fact, analytic geometry became a topic in the gymnasium syllabus in 1892.

\subsection{2 'Reformpädagogik' and Its Influence on the Teaching of Mathematics}

'Reformpädagogik' was an educational theory favoring the promotion of the child's creativity. It originated at the beginning of the 20th century and resulted in a new attitude towards the child as well as a new understanding of 'Bildung', which in part continued Humboldtian ideas. From its very beginnings, this reform movement was international (Blankertz 1982, p. 255ff.). The Swedish pedagogue E. Key proclaimed the century of the child, the Italian M. Montessori considered the child as a constructor of its self. Teaching was to be based and focused on the child and its creative powers, thus letting the child evolve its individual personality.

The new attitude towards the child was furthered by the emergence of cognitive psychology. Gestalt psychology (M. Wertheimer) and later, from the 1920s onward, the research of J. Piaget and L. S. Vygotsky considered the thinking of children a quality of its own.

The reform movement influenced the teaching of arithmetic at elementary schools. Mathematics educators like J. Kühnel (1869-1928) (cf. Schmidt 1978) and J. Wittmann (1885-1960) created concepts that replaced the supposedly predominant style of teaching based on passive reception and drill by teaching environments in which pupils could independently work with adequate material and discover number relations by themselves.

In a similar vein new pedagogical ideas emerged for students of the upper grades. Especially prominent was the movement in favor of the so-called 'Arbeitsschulen' ('working schools'). The meaning of this term, however, differed considerably among its proponents. On the one hand, Georg Kerschensteiner (1854-1932) was of the opinion that self-determined manual activity be the most important means for educating self-confident personalities, whereas Hugo Gaudig (1860-1923) based his educational philosophy on the ideal of a 'free intellectual activity' (Führer 1997, pp. 20-45; Oelkers 1996). With their emphasis on the concepts of 'activity' and 'self-confident personalities' both authors pursued ideas similar to those of the earlier Humboldt time. Kerschensteiner and Gaudig had developed their pedagogical ideas in the decade after 1900, but the movement in favor of 'Arbeitsschulen' became important only in the 1920s when their writings influenced also teachers of mathematics and lecturers at teacher training institutions and universities. 


\subsubsection{New Ideas on the Teaching of Mathematics at Gymnasium}

By the end of the 19th century and into the beginning of the 20th, some professors of mathematics began to offer special courses on school mathematics for future teachers at gymnasium. Among them were R. Baltzer (1818-1887), H. Weber (1842-1913) and F. Meyer (1856-1925). Above all, the activities of F. Klein (1849-1925) had a strong influence, which persists until today: He proposed the concept of function as a new guiding principle of school mathematics and engaged himself in the introduction of infinitesimal analysis into school mathematics. In 1911, Klein made possible the habilitation ${ }^{1}$ of the mathematics teacher R. Schimmack, which was the first such qualification in the field of 'Didactics of mathematics' in Germany. A second habilitation in 'Didactics of mathematics' was that of Hugo Dingler at the Technical Institute of Munich in 1912. In general, habilitation in didactics of mathematics at university remained controversial up to the 1980s. Beyond this, Klein was also influential in developing international relations between people who were interested in the teaching of mathematics which, among others, resulted in the foundation of the International Commission on Mathematical Instruction (ICMI). These international initiatives, however, were severely set back by the two world wars and the political development in Germany during the fascist period.

In 1925, the year of Klein's death, infinitesimal analysis was officially introduced into the teaching of mathematics at gymnasium and Realschule, thus finally realizing Klein's reform initiative. During the period between the wars and for a long time after the Second World War, didactical conceptions of mathematics at gymnasium were heavily influenced by W. Lietzmann (1880-1959), a doctoral student of D. Hilbert, then teacher of mathematics and physics, later head of a so-called 'Oberrealschule' in Göttingen (today 'Felix-Klein-Gymnasium'), and since 1910 a close collaborator of Klein.

Above all, Lietzmann's influence on the teaching of mathematics at gymnasium was established by his book, Methodik des mathematischen Unterrichts. 2. Teil: Didaktik der einzelnen Unterrichtsgebiete (Lietzmann 1916), which appeared in several editions until the 1960s (for an analysis see Kaiser-Meßmer 1986a). Another textbook on the teaching of mathematics at gymnasium was Didaktik des mathematischen Unterrichts written by the Austrian philosopher and pedagogue Alois Höfler (1853-1922) (Höfler 1910).

In the 1920s and in the tradition of Klein, mathematicians O. Toeplitz (1881-1940) and H. Behnke (1898-1970) engaged in improving the teaching of mathematics at gymnasium. Toeplitz worked on a concept of genetic teaching (see Toeplitz (1927), translated into English in Fried and Jahnke (2015)); Behnke created a seminar for furthering the cooperation between universities and schools. In 1932, the two of them founded the journal 'Mathematisch-physikalische Semesterberichte'.

\footnotetext{
${ }^{1}$ The term 'habilitation' is used for a formal post-doctoral qualification for university teaching, and is an essential key towards professorship in many European countries.
} 
With regard to elementary education the 1920s brought two important innovations. The new constitution of Germany, proclaimed in 1919, stipulated that all children, independent of their social and religious background, had to attend elementary school ('Grundschule') for the first four years of their school career (Blankertz 1982, p. 232). This was the first type of comprehensive school in Germany and for the teachers at these schools it implied an enormous strengthening of their professional position. Consequently, it was felt that teachers at elementary schools should receive better training. Some of the German states reacted to this requirement, but not all. For example, in 1925, Prussia abandoned the former seminars for training teachers of elementary schools and replaced them by so-called 'Pädagogische Akademien' (pedagogical academies) which required as entrance qualification the 'Abitur'. In 1930 Friedrich Drenckhahn, who for one year had been the personal assistant of Felix Klein, was the first to get a professorship at such an academy with the dedication 'Didaktik der Mathematik' (didactics of mathematics) (Schubring 2016, p. 9). Later, in the 1950s, Drenckhahn was to play a considerable role in further upgrading the Pedagogical Academies to 'Pädagogische Hochschulen' ('Colleges of Education'). In regard to Drenckhahn's ideas on didactics of mathematics see Hefendehl-Hebeker (2016) and Chap. 2 of this book.

\subsection{The Establishment of Didactics of Mathematics as an Academic Discipline}

With the expansion of the university system about 50 years ago, the establishment of didactics of mathematics as an academic discipline began to develop. Different factors were involved, in particular, the 'sputnik-shock' (i.e. the unexpected success of the Soviet Union to launch a satellite) mobilized political efforts directed towards the educational system. They were based on the assumption that a scientific modernization of the subject matter, especially in gymnasium, could contribute to the enhancement of the competitive ability of a nation. This development encouraged tendencies in many of the states of the Federal Republic of Germany to provide training courses in mathematics education, even for teachers at gymnasium, and to establish corresponding chairs at universities.

In general, teacher education began to develop towards academic standards. At around 1980, many teacher-training institutions (Pädagogische Hochschulen) were integrated into the universities. Those teacher-training institutions, which remained autonomous, gradually developed into universities of education with corresponding research and graduation opportunities. At the same time, the development of a community of people in mathematics education was supported by the foundation of a society of German-speaking mathematics educators in 1975 (Gesellschaft für Didaktik der Mathematik, GDM) and a research journal (Journal für MathematikDidaktik), which first appeared in 1980. 
Thus, basic research included different types of schools and linked different institutions. Furthermore, international cooperation of math educators became possible. The works of J. S. Bruner, J. Piaget and L. S. Vygotsky initially defined a common frame of reference for the international discussion. In this context, the Institute for Didactics of Mathematics (IDM) in Bielefeld, which was founded in 1973, gave essential impetus.

The further development of didactics of mathematics in Germany from these origins was determined by an interaction between the efforts of educational policies and internal impulses. Within the scientific community of didactics of mathematics, research approaches that have been developed and used in related academic domains played an important part. They led to a progressive widening of perspective upon all determinants, which influenced the process of teaching and learning, including the individual mental states of the teachers and learners.

In the German Democratic Republic, the development of research on mathematics education was strongly influenced by activity theory developed in the Kharkov School of Developmental Psychology (e.g., Leont'ev 1978; Galperin 1989). Particular important is the work of J. Lompscher in the fields of educational psychology and psychology of learning activities, which emphasizes "the psychic regulation of the learning activity" (Lompscher 1984, p. 40f) conceptualized as the interrelation of learning goals, cognitive and social learning motives, and the process structure of learning actions and learning outcomes. Although activity theory has become canonical in international research on the teaching and learning of mathematics, Lompscher's elaboration of activity theory and learning activities has received only minor attention within German-speaking countries after 1990 (but cf. Bruder and Schmitt 2016).

\subsection{The New Math Reform and Its Consequences}

In the middle of the 1960s, the New Math movement led to a comprehensive conceptual system of school mathematics with a high level of formalization.

The 'modernization of mathematics teaching' was significantly influenced by Bourbaki, a group of French mathematicians who, as is well known, pursued to reorganize the entire field of mathematical knowledge on a structural-logical basis. In Bourbaki's approach the concepts of set, relation and composition became fundamental. Some mathematics educators and influential mathematicians adopted this approach to school teaching, and elements of logic and set theory were implemented in mathematics teaching from the primary level upwards. This process was part of an international phenomenon (Kilpatrick 2012).

An important motive of the reform was the idea that mathematics education should be science-oriented from the very beginning. Thus, at the secondary schools the treatment of the number domains was consequently organized according to the principle of permanence, and enriched by structural aspects and concepts (for example the concept of the 'ordered field of rational numbers'). There was a clear succession, 
which more or less continues to the current day: natural numbers in grade 5, fractions in grade 6, negative numbers in grade 7, and irrational numbers in grade 9 . Algebra and functions were integrated into this setting. The algebra of equations experienced a rigorous extension and reorganization by concepts of logic and set theory, variables were uniquely conceived as placeholders. This reorganization had conflicting effects. On the one hand, it achieved a modernization by considering equations and systems of equations with different cases of solvability (empty, finite or infinite sets of solutions). On the other hand, the logical and set theoretical frame required additional efforts, which were experienced as superfluous complications by the learners (Andelfinger 1985). On the whole, the reform underestimated the epistemological problems entailed by the high level of formalization (Damerow 1977).

Basic elements of logic and set theory were also implemented in the primary schools, which entailed vigorous public discussions. Thus, in the beginning of the 1970s the guidelines for primary schools were revised by the Standing Conference of the Ministers of Education and Cultural Affairs (Kultusministerkonferenz-KMK), and thus the focus of the teaching of mathematics at primary schools shifted. The considerable influence of H. Winter (1975) strengthened the awareness that mathematics teaching should meet requirements from different perspectives, from the science of mathematics, the demands of society, the dispositions of the learners, and from their right of self-realization.

With respect to content, weights were shifted: set theory was no longer considered as an appropriate foundation for the development of number concepts and number operations at school, rather the number concept was considered and taught in its entire complexity (Müller and Wittmann 1984, s. 154). The predominance of arithmetic was restored, however, in a different shape than in traditional teaching, and enriched by further topics (combinatorial counting, algebraic and number theoretical considerations). Geometry as an extended study of spatial phenomena, such as multiple applications (magnitudes, applied arithmetic, stochastic situations), also played an important role. With respect to the learning process, Winter pointed out that mathematics teaching should not only impart content knowledge to the learners in some way or another, but combine contents and general objectives of mathematics teaching by stimulating typical mathematical activities such as exploring, ordering, systematizing, generalizing, formalizing and reasoning. In this context he emphasized the importance of heuristic strategies and discovery learning (Winter 1989). He also introduced the concept of 'productive exercises' related to substantial mathematical problems, which could stimulate exploring, discovering and exercising at once (Winter 1984).

Initially, the newly established concept of mathematics teaching at secondary schools was mainly subject-orientated. 'Didactically oriented content analysis' was developed as a tool for research in didactics of mathematics, resulting from the ambition for solid foundations and conducted with the aim to present the contents in a way that is compatible with the standards of the field and at the same time appropriate to the learners and the requirements of teaching (Griesel 1974).

To begin with, the emphasis was on the lower secondary school level, especially in the domain of algebra and arithmetic, complemented by an analysis of the concept of 
function (Vollrath 1974). A special problem was the attempt to find exact foundations for the relations between numbers and quantities in primary and secondary teaching. The term 'domain of magnitudes' was coined to denote the structural basis of popular reckoning (Kirsch 1970; Griesel 1997).

Kirsch also presented far-reaching analyses of the foundations of proportional reasoning as well as of linear and exponential growth (Kirsch 1969, 1976a). He pointed out that the structural basis of proportional reasoning was a simple mapping between two divisible domains of quantities following an elementary rule: to the $\mathrm{n}$-fold quantity in the one domain is assigned the n-fold quantity in the other domain. From this starting point he developed further basic rules, for example the sum is assigned to the sum', and demonstrated that the mathematical foundations of proportional reasoning can be considered as a small axiomatic theory and its application. In subsequent stages of reasoning and by making use of the isomorphism mentioned above, he finally developed the concept of linear transformation.

The focus in geometry was determined by the ambition to organize geometry by a unifying concept corresponding to the concept of function in arithmetic and algebra (Struve 2015). Thus, didactically oriented content analysis in geometry was mostly centered on transformation geometry (see for example Holland 1974/1977; Schupp 1968; Bender 1982). The supporters of an implementation of transformation geometry in school curricula tried to find convincing arguments for its superiority: a dynamic approach, which was considered to have more clarity and conformity to the disposition of young people than the traditional Euclidean style; the possibility to achieve a clear structure within the geometric school material and to progress stepwise from elementary kinematic considerations to logically strict reasoning, better opportunities to apply heuristic strategies. However, teachers remained reluctant and discrepancies persisted between the official syllabuses and the teaching practice. In a detailed analysis, Bender detected discrepancies between the elementary concept of moving figures based on kinematic experiences, and the abstract concept of mapping (Bender 1982). Towards the end of the 1970s, the general orientation towards logic and set theory was reduced and classical considerations of geometrical figures returned to the center of attention.

After the initial concentration on the primary and lower secondary levels, the didactically oriented content analyses were extended to the domains of upper secondary school teaching. Here the contents already had a solid scientific foundation and the problems were mostly opposite to those with respect to the lower stages. The question was how mathematical theories and concepts could be simplified and made accessible without falsifying the central mathematical content. W. Blum and A. Kirsch suggested more intuitive approaches (at least for basic courses) with the original naïve ideas of function and limit and sequential steps of exactitude, which could be achieved according to the capacity of the learners (Blum and Kirsch 1979; Kirsch 1976b).

A general goal was to develop concepts with which to represent mathematical knowledge in a way that corresponds to the cognitive ability and personal experience of the students, while simultaneously simplifying mathematical material without distorting it from its original form, with the aim of making it accessible for learners 
(Kirsch 1977). The simplifications introduced into mathematical subjects should be 'intellectually honest' and 'upwardly compatible' (Kirsch 1987). That is, concepts and explanations should be taught to students with sufficient mathematical rigor in a manner that connects with and expands their knowledge of the subject.

As these analyses initially were conducted without the accompaniment of systematic empirical research, an increasing critical discussion arose, where the German word 'Stoffdidaktik' (material related didactics) was coined in order to denote the limitations of this approach.

\subsection{Widening the Perspective}

The didactically oriented content analysis as a research method was strongly related to the teaching methods of the 1970s and 1980s, which were primarily based upon instruction and supported by the implicit belief that, in an appropriate ready-made setting, knowledge could be handed over or transmitted from the teacher to the learners - an attitude which was entitled by its critics as 'broadcast metaphor' (Seeger and Steinbring 1992). Among others, this criticism was supported by carefully documented teaching experiences showing that even sophisticated concepts of teaching frequently led to unsatisfactory results with respect to the pupils' learning (Hefendehl-Hebeker 1988, 1991).

Freudenthal (1973) had given an influential impetus through the idea that learning mathematics should become an active process in the construction of knowledge and that substantial mathematics, geared to the preconditions of learners, should be made the foundation of teaching. Following this idea, the development and research project 'mathe 2000' (Müller et al. 1997; Wittmann 2002) was founded, culminating, among other didactic material, in a textbook that is still based on the concepts of 'productive exercise' (Winter 1984) and 'substantial learning environment' (Wittmann 2002). It also promises potential for advanced levels of teaching and learning. Wittmann (2012) characterized this approach to didactics of mathematics as 'design science' with a focus on 'mathematics education emerging from the subject'. In this concept, mathematics curricula are organized around 'substantial learning environments', where children can gain mathematical experience, recognize patterns and solve problems. To construct such environments requires a 'structuregenetic empirical analysis' (ibid.), which comprises content-related analyses of the traditional type and in addition the analysis of the cognitive preconditions of the learners, mathematical practices of exploring patterns and the objectives of teaching.

Empirical studies of interaction in mathematics classrooms contrasted and complemented these developments. The analyses of interpretative research studies (Maier and Voigt 1991) sharpened the awareness that knowledge cannot be transferred in a simple manner, but is developed within the social interaction between a learner, the teacher and other learners in the group (Steinbring 2009). This awareness was accompanied by the conviction that a good structure of an optimal representation of ready-made mathematics does not automatically provide a good structure for teach- 
ing, but that the learning process should be oriented towards natural conditions of knowledge acquirement. It is still a matter of debate how ethnographies of the teaching and learning of mathematics on the one hand and design-based developments of didactic artifacts on the other hand can be related in a productive way (Gellert 2003); productive both for the development of theory in mathematics education and for the improvement of mathematics teaching and learning.

Parallel to this development, the didactics of mathematics in the Federal Republic of Germany experienced an increasing international orientation, which was supported by the foundation of the IDM in Bielefeld (1973). An indication for this internationalization is the Third International Congress on Mathematical Education (ICME-3) in 1976, during which more than 2000 interested educators from all over the world gathered in Karlsruhe. Subsequently, in the 1980s and the early 1990s, several international research groups including German researchers emerged. Among these an influential group dealt, and still deals, with a theoretical foundation of didactics of mathematics, with an outline of a socio-political perspective on mathematics and mathematics education, with learning of mathematics by modeling and application, or with the construction of a micro-sociology of classroom interaction.

\subsubsection{Theoretical Foundation of Didactics of Mathematics}

As any other scientific discipline didactics of mathematics needs a reflection on its theoretical foundations as well as its paradigmatic problems and its basic methods. Increasingly, such meta-theoretical considerations gained recognition. Works stemming from the IDM had a high influence on this process, especially those of $\mathrm{M}$. Otte and H.-G. Steiner. Otte (1993) worked on the philosophy of mathematics by focusing on the teaching of mathematics in regard to its historical, cultural, social, technical, and ecological status — and was influential within an international research group on basic components of mathematics education for teachers (BaCoMET; e.g., Christiansen et al. 1986; Keitel and Ruthven 1993). Steiner's (1985) main interest lay in systematizing fundamental theories and methodologies in mathematics education with respect to research, development, and educational practice. Furthermore, he aimed to identify or draw interdisciplinary connections to other disciplines as well as to analyze its relationship of theory and practical doing. In addition to that, Steiner initiated the foundation of an international research group, Theory of Mathematics Education (TME), which came together five times in the years between 1984 and 1991. This early research on meta-theoretical questions about the didactics of mathematics still has an impact on today's research, and the broad variety of research areas of didactics of mathematics in particular can be traced back to these early beginnings. The works and findings of the TME are regarded as the basic foundation of working groups at meetings such as CERME and ICME. By recognizing the complexities of the field of research in mathematics education, attempts to coordinate and combine theories and methodologies have been systematized and promoted. One characteristic of these attempts is their meta-theoretical depth. In contrast to prag- 
matic strategies, such as a use of theories or a combination of theories in the form of a 'bricolage' (Cobb 2007), the basic principles of theories, the degree of their coherence and contrast and of their commensurability and incommensurability receive systematic attention from working groups at CERME and ICME (Bikner-Ahsbahs et al. 2016; Prediger et al. 2008).

\subsubsection{Socio-Political Perspectives on Mathematics and Mathematics Education}

As one consequence of the internationalization of didactics of mathematics, it became common practice to see it well distinguished from its former tight and traditional link to teaching and learning processes at schools. From this emancipated point of view, parameters such as the cultural relevance, political guidelines of governmental institutions, the socio-historical perspective on the education of mathematics, and the mathematically based technical progressing of society became the focus of attention. Awareness to these parameters became obvious in 1988 at ICME 6 on the topic of Mathematics, Education, and Society. The respective report was published by UNESCO and edited by C. Keitel and P. Damerow, together with A. Bishop and P. Gerdes (1989). Internationally, the focus on this research program was, among others, integrated into the conference set Political Dimensions of Mathematics Education (PDME), which in 1998 was re-founded as Mathematics, Education, and Society (MES); nine MES meetings have taken place so far with MES 6 having hosted 2010 in Berlin (Gellert et al. 2010). Substantial influence on the organization of mathematics education as an international scientific discipline had C. Keitel who, first as Convenor of the International Organisation of Women and Mathematics Education (IOWME), then as Vice-President and subsequently President of the Commission Internationale pour l'Étude et l'Amélioration de l'Enseignement des Mathématiques (CIEAEM; an ICMI-affiliated organization), directed the research community towards a socio-critical understanding of theory and practice in mathematics education (e.g., CIEAEM 2000; Keitel et al. 1993).

\subsubsection{The Teaching and Learning of Applications and Modelling}

The basic idea to understand mathematical modelling not only as a specific scientific research area, but also as a part of the school curriculum and thereby acknowledging its didactical value, originated from Great Britain. Since the beginning of the 1990s, mathematics educators from Germany also contributed substantially to the internationalization, development and spreading of the idea to focus the teaching of mathematics on applications. Under the strong influence of W. Blum and G. Kaiser, 
a new curricular concept was developed. Summarized by the keyword 'modelling', it was later defined as one of the basic mathematical competences and integrated into the educational standards ('Bildungsstandards') and curricula ('Rahmenlehrpläne'). Many of the 17 conferences of the International Community of Teachers of Mathematical Modelling and Applications (ICTMA; an ICMI-affiliated study group), which were organized from 1983 onwards, or the ICMI Study 14: Applications and Modelling in Mathematical Education (Blum et al. 2007), were under the guidance of German colleagues (e.g., conference proceedings Blum et al. 1989; Kaiser et al. 2011). During the last 30 years or so, research on modelling and applications developed empirical research on cognitive aspects of modelling, such as ability (KaiserMeßmer 1986b) and competencies (e.g., Maaß 2006; see Schukajlow et al. 2018 for an overview of empirical research during the early years of modelling and recent developments). Furthermore, in 1991, the study group ISTRON was founded. This study group included members from universities as well as from schools in order to connect theoretical research with practical observations and findings. Its main goal was to discuss and develop suggestions for integrating modelling as well as fitting references to reality into the teaching of mathematics at schools.

\subsubsection{Construction of Meaning Within Classroom Interaction}

While the cooperation of a study group led by H. Bauersfeld in Bielefeld and colleagues with a study group led by P. Cobb at the Purdue University in Indiana did not reach an institutionalized status comparable to one of the above-mentioned study groups with their regularly held conferences, their influence on the development of the research on mathematics education is still of considerable importance. Due to this cooperation, the practical ongoings of the teaching of mathematics were considered a non-negotiable part of the research on teaching-learning processes. Furthermore, it systematically interconnected socio-cultural as well as individual-based psychological perspectives of learning mathematics to their theoretical foundation. Cobb and colleagues began with the description of the learning of mathematics as an individual process of constructing a mental concept. The group of researchers in Bielefeld, on the other hand, focused on the social and interactional processes of learning mathematics within the school environment (Krummheuer 1995; Voigt 1995). As a result of this cooperation, learning mathematics from then onwards was considered a socially situated process of emergence based on an individual's interpretation and construction (Cobb and Bauersfeld 1995). The micro-ethnographic methodology of the work of G. Krummheuer and colleagues has been recognized by educationalists as a promising way to connect classroom research in educational science and in mathematics education.

One effect of the widening of the perspectives on the research object during the last decades is the co-existence of a variety of languages of description in the field. As in many parts of the world, mathematics education in Germany as a field of scientific inquiry is characterized by a horizontal knowledge structure with specialized 
and, to a certain degree, localized languages and research methods. The spread of research on mathematics education in Germany was further augmented when largescale assessment studies entered the field. The upcoming psychometric influence in the field broadened the spectrum of research methods in German mathematics education research substantially.

\subsection{Development of Empirical Research and Recent Stimuli}

\subsubsection{Educational Research on the Learning and Teaching of Mathematics}

During the 1980s and 1990s empirical research in German speaking didactics of mathematics further developed and diversified. Researchers strived to establish research areas that were subject-specific. U. Viet (Viet et al. 1982), for example, criticized that empirical research on mathematics education was dominated by case studies, by pre-post-evaluation of interventions and by achievement testing that regarded mathematical abilities as a rather global construct. Viet and colleagues therefore conducted research on content specific learning processes, drawing flexibly on qualitative and quantitative methods and on diverse theories of cognition. Many groups started similar endeavors, thereby shaping mathematics education as distinct research area. This was acknowledged by the German Research Foundation (Deutsche Forschungsgemeinschaft, DFG) by funding many studies from didactics of mathematics, like e.g. Individual differences in the mental representation of term rewriting (E. Cohors-Fresenborg), Solution strategies of students in primary school during work on picture-text-integrating tasks (M. Franke), Categories of students' mathematical thinking processes (K. Hasemann), Formats of collective argumentation (G. Krummheuer), Problem solving strategies in spatial-geometric tasks (K. Reiss), Understanding of probability of children in kindergarten and primary school (B. Wollring) and many others.

\subsubsection{Large-Scale Research}

In the international comparisons delivered by large-scale studies (particularly TIMSS 1997 and PISA 2000), German students unexpectedly showed only average achievements. This triggered repercussions in society and politics that can be compared to the 'sputnik-shock' (see above). Several activities in education policy and education research ensued that were mutually interconnected. Education research experienced a boost in political awareness and a demand for 'evidence-based policy'. This also led to increased funding in educational research and had an impact especially on those branches of research in mathematics education that used quantitative approaches. 
Roughly beginning in 2000 education in schools was regulated by defining 'outcome standards' rather than 'content standards' (Klieme et al. 2004). For this purpose, a system of continuous, centrally administered assessment procedures and examinations was developed. These developments also resulted in newly accentuated goals in mathematics teaching (although this shift is only gradually recognizable in the classroom): Referring to the concept of 'mathematical literacy' (Neubrand 2003; Niss 2003), the use of mathematics in everyday and professional life received more attention, strengthening competence areas like modelling or using data, while classical topics like plane geometry receded. A debate on the alleged overemphasis of aspects of usefulness of mathematics - incorrectly attributed to Heymann's (1996) analysis of the educational purposes of mathematics - quickly subsided and scholars compromised on Winter's (1995) suggestion of balancing mathematics as a useful tool in describing reality, as deductively structured domain and as an opportunity for intellectual and heuristic activity. Also, after 2003, German education standards throughout the 16 states began to emphasize competences related to mathematical processes (such as modelling, reasoning and problem solving) on the same level as competences for the dimensions of content.

On the part of research, the interest of education policy in a continuous monitoring of the outcome have led to a broad development of assessment measures (predominantly based on the measurement approach used by PISA), coordinated by a centrally founded Institute for Educational Quality Improvement (IQB). Researchers in mathematics education were regularly consulted as domain experts. Furthermore, the video studies conducted within the TIMSS-assessment (Stigler et al. 1997) inspired researchers from Germany and Switzerland to investigate the quality of teaching and its impact on learning by means of video analysis of mathematics lessons as seen in regular classrooms (Rakoczy et al. 2007). The relationship between general and subject specific features of mathematics classroom is still an object of interest and debate.

\subsubsection{Interdisciplinary Research Programs with Collaboration of Mathematics Education}

The stimuli that influenced education policy also had an impact on the research in mathematics education in several areas. It was characteristic for this research that it was conducted cooperatively in interdisciplinary groups connecting their respective research interests and domains of expertise. Some outstanding examples include the following:

- A federal priority research initiative on 'Educational quality in schools' (BiQUA, Prenzel and Schöps 2007) initiated many joint projects between educational psychology and mathematics education. Researchers connected their expertise to investigate questions of mathematics learning and teaching, such as how to learn 
proof by heuristic worked examples (Reiss and Renkl 2002), or how to foster problem solving and self-regulation (Bruder et al. 2007).

- Several research initiatives were launched in order to develop innovative approaches to educational assessment, e.g. in the federally funded priority program 'Competence models for assessing individual learning outcomes and evaluating educational processes' (Koeppen et al. 2008) or the international study of the IEA on teacher competences (Blömeke et al. 2014). Many projects were based on the cooperation between researchers from educational psychology and mathematics education (e.g., Leuders et al. 2017).

A similar development can also be found in education policy and education research with respect to other domains (e.g., Neumann et al. 2010). The impact was especially strong in mathematics, science education and in the domain of reading. Furthermore, the mentioned impulses and cooperations are accompanied by a certain emphasis on quantitative research strategies used in educational psychology. Other research strategies, which are highly relevant in mathematics education, such as the development of local (topic specific) learning theories by means of qualitative analysis of case studies or the cyclical development of learning environments in a design research approach receive considerably less funding within the mentioned programs and initiatives. This may bear the risk of splitting up the research community in opposing factions.

\subsection{Institutional Structure of Mathematics Education in German-Speaking Countries}

The development described above led to the situation of mathematics education in Germany that we encounter today (as of 2018). Pre-service mathematics teacher education in Germany for all school types is located at universities (and universities of education, 'Pädagogische Hochschulen'), each endowed with up to six full professorships and further research and teaching personnel. In most universities mathematics education is located within a faculty of mathematics, sometimes within a faculty of education. Similarly, there are teacher training institutions without university status (also termed 'Pädagogische Hochschulen') in Switzerland and Austria.

Newly appointed professors have usually completed a $\mathrm{PhD}$ thesis in mathematics education, accomplished further research and have a certain amount of practical teaching experience in schools. During the last decade, the group of young researchers has grown considerably since more universities offer funded doctoral programs. Nowadays, fewer researchers have experience in mathematics research and more researchers have experience in educational research than in former times. However, there are concerns that this may be accompanied with a loss of experience in mathematics and a reduction of discipline specificity in research.

German mathematics educators meet on a regular basis on national conferences and special interest groups. A large part of their publications is in the German 
language, some of them can be found in two peer-reviewed journals (Journal für Mathematik-Didaktik, mathematica didactica). The number of international publications is steadily increasing. The 'Zentralblatt der Mathematikdidaktik', founded in 1969, has developed into the international journal 'ZDM-Mathematic education'.

German mathematics educators are also engaged in the organization of international conferences. Forty years after ICME-3 in Karlsruhe, the ICME-13 again took place in Germany at the University of Hamburg. With about 3500 participants from 107 countries it was the greatest congress in the world congress series so far. The proceedings (Kaiser 2017) provided a comprehensive overview on the state-of-artdiscussion in mathematics education.

\section{References}

Andelfinger, B. (1985). Didaktischer Informationsdienst Mathematik. Thema: Arithmetik, Algebra und Funktionen. Soest: Landesinstitut für Schule und Weiterbildung.

Bender, P. (1982). Abbildungsgeometrie in der didaktischen Diskussion. Zentralblatt für Didaktik der Mathematik, 14(1), 9-24.

Bikner-Ahsbahs, A., Vohns, A., Schmitt, O., Bruder, R., \& Dörfler, W. (2016). Theories in and of mathematics education: Theory strands in German speaking countries. Cham: Springer.

Blankertz, H. (1982). Die Geschichte der Pädagogik: von der Aufklärung bis zur Gegenwart. Wetzlar: Büchse der Pandora.

Blömeke, S., Hsieh, F.-J., Kaiser, G., \& Schmidt, W. (Eds.). (2014). International perspectives on teacher knowledge, beliefs and opportunities to learn. Dordrecht: Springer.

Blum, W., \& Kirsch, A. (1979). Zur Konzeption des Analysisunterrichts in Grundkursen. Der Mathematikunterricht, 25(3), 6-24.

Blum, W., Berry, J. S., Biehler, R., Huntley, I. D., Kaiser-Meßmer, G., \& Profke, L. (Eds.). (1989). Applications and modelling in learning and teaching mathematics. Chichester: Ellis Horwood.

Blum, W., Galbraith, P., Henn, H.-W., \& Niss, M. (Eds.). (2007). Applications and modelling in mathematics education: The 14th ICMI study. New York: Springer.

Bruder, R., \& Schmitt, O. (2016). Joachim Lompscher and his activity theory approach focusing on the concept of learning activity and how it influences contemporary research in Germany. In A. Bikner-Ahsbahs et al. (Eds.) Theories in and of mathematics education. ICME-13 topical surveys (pp. 13-20). Cham: Springer.

Bruder, R., Komorek, E., Collet, C., \& Schmitz, B. (2007). Contents and results of an intervention study in mathematics lessons at secondary level with a teaching concept to support mathematical problem-solving and self-regulative competencies. In M. Prenzel (Ed.), Studies on the educational quality of schools (pp. 197-219). Münster: Waxmann.

Christiansen, B., Howson, A. G., \& Otte, M. (Eds.). (1986). Perspectives on mathematics education. Dordrecht: D. Reidel.

CIEAEM. (2000). Manifesto 2000 for the year of mathematics. Available at http://www.cieaem. org/?q=system/files/cieaem-manifest2000-e.pdf.

Cobb, P. (2007). Putting philosophy to work: Coping with multiple theoretical perspectives. In F. K. Lester (Ed.), Second handbook of research on mathematics teaching and learning (pp. 3-38). Greenwich: IAP.

Cobb, P., \& Bauersfeld, H. (Eds.). (1995). The emergence of mathematical meaning: Interaction in classroom culture. Hillsdale: Lawrence Erlbaum.

Damerow, P. (1977). Die Reform des Mathematikunterrichts in der Sekundarstufe I. Band 1: Reformziele, Reform der Lehrpläne. Stuttgart: Klett. 
Diesterweg, F. A. W. (1844). Methodisches Handbuch für den Gesammt-Unterricht im Rechnen. Als Leitfaden beim Rechenunterrichte und zur Selbstbelehrung (1, 4 ed.). Elberfeld: Büschlersche Verlagsbuchhandlung.

Freudenthal, H. (1973). Mathematik als pädagogische Aufgabe. Stuttgart: Klett.

Fried, M. N., \& Jahnke, H. N. (2015). Translation of: Otto Toeplitz, The problem of university courses on infinitesimal calculus and their demarcation from infinitesimal calculus in high schools. Science in Context, 28, 297-310.

Führer, L. (1997). Pädagogik des Mathematikunterrichts. Eine Einführung in die Fachdidaktik für Sekundarstufen. Braunschweig/Wiesbaden: Vieweg.

Galperin, P. Y. (1989). Organization of mental activity and the effectiveness of learning. Soviet Psychology, 27, 65-82.

Gellert, U. (2003). Mathematikunterricht und Innovation. Hildesheim: Franzbecker.

Gellert, U., Jablonka, E., \& Morgan, C. (Eds.) (2010). Proceedings of the Sixth International Mathematics Education and Society Conference. Berlin: Freie Universität Berlin.

Griesel, H. (1974). Überlegungen zur Didaktik der Mathematik als Wissenschaft. Zentralblatt für Didaktik der Mathematik, 6(3), 115-119.

Griesel, H. (1997). Zur didaktisch orientierten Sachanalyse des Begriffs Größe. Journal für Mathematik-Didaktik, 18(4), 259-284.

Hankel, H. (1867). Vorlesungen über die complexen Zahlen und ihre Functionen, Theil 1: Theorie der complexen Zahlensysteme. Leipzig: Leopold Voss.

Hefendehl-Hebeker, L. (1988). „, .. das muß man doch auch noch anders erklären können!“ Protokoll über einen didaktischen Lernprozeß. Der Mathematikunterricht, 34(2), 4-18.

Hefendehl-Hebeker, L. (1991). Negative numbers: Obstacles in their evolution from intuitive to intellectual constructs. For the Learning of Mathematics, 11(1), 26-32.

Hefendehl-Hebeker, L. (2016). Subject matter didactics in German traditions. Early historical developments. Journal für Mathematik-Didaktik, 37(Supplement 1), 11-31.

Henrici, J., \& Treutlein, P. (1881-83). Lehrbuch der Elementar-Geometrie. Teile 1 bis 3. Leipzig: Teubner.

Heymann, H. W. (1996/2003). Why teach mathematics? A focus on general education. Dordrecht: Springer.

Höfler, A. (1910). Didaktik des mathematischen Unterrichts. Leipzig/Berlin: Teubner.

Holland, G. (1974/1977). Geometrie für Lehrer und Studenten. Hannover: Schroedel.

Jahnke, H. N. (1990). Mathematik und Bildung in der Humboldtschen Reform. Göttingen: Vandenhoeck \& Ruprecht.

Kaiser, G. (Ed.). (2017). Proceedings of the 13th International Congress on Mathematical Education. SpringerOpen.

Kaiser-Meßmer, G. (1986a). Anwendungen im Mathematikunterricht. Band 1-Theoretische Konzeptionen. Bad Salzdetfurth: Franzbecker.

Kaiser-Meßmer, G. (1986b). Anwendungen im Mathematikunterricht. Band 2-Empirische Untersuchungen. Bad Salzdetfurth: Franzbecker.

Kaiser, G., Blum, W., Borromeo Ferri, R., \& Stillman, G. (Eds.). (2011). Trends in teaching and learning of mathematical modelling. New York: Springer.

Keitel, C., Damerow, P., Bishop, A., \& Gerdes, P. (Eds.). (1989). Mathematics, education, and society. Paris: UNESCO.

Keitel, C., \& Ruthven, K. (Eds.). (1993). Learning from computers: Mathematics education and technology. Berlin: Springer.

Keitel, C., Kotzmann, E., \& Skovsmose, O. (1993). Beyond the tunnel vision: Analysing the relationship between mathematics, society and technology. In C. Keitel \& K. Ruthven (Eds.), Learning from computers: Mathematics education and technology (pp. 243-279). Berlin: Springer.

Kilpatrick, J. (2012). The new math as an international phenomenon. ZDM Mathematics Education, 44(4), 563-571.

Kirsch, A. (1969). Eine Analyse der sogenannten Schlußrechnung. Mathematisch-Physikalische Semesterberichte, 16(1), 41-55. 
Kirsch, A. (1970). Elementare Zahlen- und Größenbereiche. Göttingen: Vandenhoeck \& Ruprecht. Kirsch, A. (1976a). Vorschläge zur Behandlung von Wachstumsprozessen und Exponentialfunktionen im Mittelstufenunterricht. Didaktik der Mathematik, 4(4), 257-284.

Kirsch, A. (1976b). Eine ,intellektuell ehrliche“ Einführung des Integralbegriffs in Grundkursen. Didaktik der Mathematik, 4(2), 87-105.

Kirsch, A. (1977). Aspects of simplification in mathematics teaching. In H. Athen \& H. Kunle (Eds.), Proceedings of the Third International Congress on Mathematical Education (pp. 98-120). Karlsruhe: Zentrum für Didaktik der Mathematik.

Kirsch, A. (1987). Mathematik wirklich verstehen. Köln: Aulis Deubner.

Klieme, E., Avenarius, H., Blum, W., Döbrich, P., Gruber, H., Prenzel, M., et al. (2004). The development of national educational standards: An expertise. Bonn: Bundesministerium für Bildung und Forschung.

Koeppen, K., Hartig, J., Klieme, E., \& Leutner, D. (2008). Current issues in competence modeling and assessment. Zeitschrift für Psychologie, 216, 61-73.

Krüger, K. (1999). Erziehung zum funktionalen Denken. Zur Begriffsgeschichte eines didaktischen Prinzips. Berlin: Logos.

Krummheuer, G. (1995). The ethnography of argumentation. In P. Cobb \& H. Bauersfeld (Eds.), The emergence of mathematical meaning: Interaction in classroom culture (pp. 229-269). Hillsdale: Lawrence Erlbaum.

Leont'ev, A. N. (1978). Activity, consciousness, and personality. Englewood Cliffs: Prentice Hall.

Leuders, T., Bruder, R., Kroehne, U., Naccarella, D., Nitsch, R., Henning-Kahmann, J., et al. (2017). Development, validation, and application of a competence model for mathematical problem solving by using and translating representations of functions. In D. Leutner, J. Fleischer, J. Grünkorn, \& E. Klieme (Eds.), Competence assessment in education: Research, models and instruments (pp. 389-406). Cham: Springer.

Lietzmann, W. (1916). Methodik des mathematischen Unterrichts. 2. Teil: Didaktik der einzelnen Unterrichtsgebiete. Leipzig: Quelle und Meyer.

Lompscher, J. (1984). Die Lerntätigkeit als dominierende Tätigkeit des jüngeren Schulkindes. In: J. Lompscher u.a. (Eds.) Persönlichkeitsentwicklung in der Lerntätigkeit (pp. 23-52). Berlin: Volk und Wissen.

Maaß, K. (2006). What are modelling competencies? Zentralblatt für Didaktik der Mathematik, $38(2), 113-142$.

Maier, H., \& Voigt, J. (Eds.). (1991). Interpretative Unterrichtsforschung. Köln: Aulis.

Müller, G., \& Wittmann, E. C. (1984). Der Mathematikunterricht in der Primarstufe. Braunschweig: Vieweg.

Müller, G., Steinbring, H., \& Wittmann, E. C. (1997). 10 Jahre „,mathe 2000“. Bilanz und Perspektiven. Düsseldorf: Klett.

Neubrand, M. (2003). „Mathematical literacy“/,Mathematische Grundbildung“: Der Weg in die Leistungstests, die mathematikdidaktische Bedeutung, die Rolle als Interpretationshintergrund für den PISA-Test. Zeitschrift für Erziehungswissenschaft, 6(3), 338-356.

Neumann, K., Fischer, H. E., \& Kauertz, A. (2010). From PISA to educational standards: The impact of large-scale assessments on science education in Germany. International Journal of Science and Mathematics Education, 8(3), 545-563.

Niss, M. (2003). Mathematical competencies and the learning of mathematics: The Danish KOM project. In A. Gagatsis \& S. Papastavridis (Eds.), Mediterranean conference on mathematical education (pp. 115-124). Athens: Hellenic Mathematical Society and Cyprus Mathematical Society.

Oelkers, J. (1996). Reformpädagogik. Eine kritische Dogmengeschichte (3rd ed.). Weinheim/München: Juventa.

Ohm, M. (1822). Versuch eines vollkommen consequenten Systems der Mathematik, erster und zweiter Theil. Auch unter dem Titel: Lehrbuch der Arithmetik, Algebra und Analysis. Nach eigenen Principien. Zunächst für seine Vorlesungen bearbeitet. Nürnberg: Korn.

Otte, M. (1993). Das Formale, das Soziale und das Subjektive. Eine Einführung in die Philosophie und Didaktik der Mathematik. Frankfurt: Suhrkamp. 
Prediger, S., Bikner-Ahsbahs, A., \& Arzarello, F. (2008). Networking strategies and methods for connecting theoretical approaches: First steps towards a conceptual framework. ZDM Mathematics Education, 40(2), 165-178.

Prenzel, M., \& Schöps K. (2007). The educational quality of schools (BiQua): A priority programme of the German Research Foundation (DFG). In M. Prenzel (Ed.): Studies on the educational quality of schools: The final report on the DFG Priority Programme (pp. 7-18). Münster: Waxmann.

Rakoczy, K., Klieme, E., Drollinger-Vetter, B., Lipowsky, F., Pauli, C., \& Reusser, K. (2007). Structure as a quality feature in mathematics instruction: Cognitive and motivational effects of a structured organisation of the learning environment vs. a structured presentation of learning content. In M. Prenzel (Ed.), Studies on the educational quality of schools. The final report on the DFG Priority Programme (pp. 101-120). Münster: Waxmann.

Reidt, F. (1885). Anleitung zum mathematischen Unterricht an höheren Schulen. Berlin: G. Grothe. Reiss, K., \& Renkl, A. (2002). Learning to prove: The idea of heuristic examples. Zentralblatt für Didaktik der Mathematik, 34(1), 29-35.

Schmidt, S. (1978). Die Rechendidaktik von Johnnes Kühnel (1869-1928): Wissenschaftsverständnis, deskriptive und normative Grundlagen sowie deren Bedeutung für die Vorschläge zur Gestaltung de elementaren arithmetischen Unterrichts (Unpublished Ph.D. thesis). PH Rheinland, Cologne.

Schubring, G. (1987). Mathematisch-naturwissenschaftliche Fächer. In K.-E. Jeismann \& P. Lundgreen (Eds.), Handbuch der deutschen Bildungsgeschichte, Bd. III: 1800-1870. Von der Neuordnung Deutschlands bis zur Gründung des deutschen Reiches (pp. 204-221). München: C. H. Beck.

Schubring, G. (2016). Die Entwicklung der Mathematikdidaktik in Deutschland. Mathematische Semesterberichte, 63(1), 3-18.

Schupp, H. (1968). Abbildungsgeometrie. Weinheim: Beltz.

Seeger, F., \& Steinbring, H. (1992). The practical phase in teacher training: Preparing for professional practice under changing conditions. Zentralblatt für Didaktik der Mathematik, 24(7), 280-286.

Schukajlow, S., Kaiser, G., \& Stillman, G. (2018). Empirical research on teaching and learning of mathematical modelling: A survey on the current state-of-the-art. ZDM Mathematics Education, 50(1-2), 5-18.

Simon, M. (1908). Didaktik und Methodik des Rechnens und der Mathematik. Zweite, umgearbeitete und vermehrte Auflage (1st ed.: 1895). München: C. H. Beck.

Steinbring, H. (2009). The construction of new mathematical knowledge in classroom interaction: An epistemological perspective. Berlin: Springer.

Steiner, H.-G. (1985). Theory of mathematics education (TME): An introduction. For the Learning of Mathematics, 5(2), 11-17.

Stigler, J. W., \& Hiebert, J. (1997). Understanding and improving classroom mathematics instruction: An overview of the TIMSS video study. Phi Delta Kappan, 79(1), 14-21.

Struve, H. (2015). Zur geschichtlichen Entwicklung der Mathematikdidaktik als wissenschaftlicher Disziplin. In R. Bruder, L. Hefendehl-Hebeker, B. Schmidt-Thieme, \& H.-G. Weigand (Eds.), Handbuch der Mathematikdidaktik (pp. 539-566). Berlin: Springer.

Toeplitz, O. (1927). Das Problem der Universitätsvorlesungen über Infinitesimalrechnung und ihrer Abgrenzung gegenüber der Infinitesimalrechnung an den höheren Schulen. Jahresbericht der Deutschen Mathematiker-Vereinigung, 36, 88-100.

Treutlein, P. (1911). Der geometrische Anschaunngsunterricht als Unterstufe eines zweistufigen geometrischen Unterrichtes an unseren höheren Schulen. Leipzig: Teubner.

Viet, U., Schmidt, V., Sommer, N., \& Grommelt, U. (1982). Changes in the cognitive level of development of 5th-grade school-children (Orientierungsstufe) in mathematics classes. Zeitschrift für Pädagogik, 28(3), 365-380.

Voigt, J. (1995). Thematic patterns of interaction and sociomathematical norms. In P. Cobb \& H. Bauersfeld (Eds.), The emergence of mathematical meaning: Interaction in classroom culture (pp. 163-202). Hillsdale: Lawrence Erlbaum. 
Vollrath, H.-J. (1974). Didaktik der Algebra. Stuttgart: Klett.

Von Humboldt, W. (1809/1964). Der Königsberger und der Litauische Schulplan. In A. Flitner \& K. Giel (Eds.), W. v. Humboldt, Werke IV (2nd ed., pp. 168-195). Darmstadt: Wissenschaftliche Buchgesellschaft.

Von Humboldt, W. (1810/1964). Über die innere und äußere Organisation der höheren wissenschaftlichen Anstalten in Berlin. In: A. Flitner \& K. Giel (Eds.), W. v. Humboldt, Werke IV (2nd ed., pp. 255-266). Darmstadt: Wissenschaftliche Buchgesellschaft.

Winter, H. (1975). Allgemeine Lernziele für den Mathematikunterricht? Zentralblatt für Didaktik der Mathematik, 7(3), 106-116.

Winter, H. (1984). Begriff und Bedeutung des Übens im Mathematikunterricht. Mathematik lehren, 2, 4-16.

Winter, H. (1989). Entdeckendes Lernen im Mathematikunterricht. Einblick in die Ideengeschichte und ihre Bedeutung für die Pädagogik. Braunschweig: Vieweg.

Winter, H. (1995). Mathematikunterricht und Allgemeinbildung. Mitteilungen der GDM, 61, 37-46.

Wittmann, E. C. (2002). Developing mathematics education in a systemic process. Educational Studies in Mathematics, 48(1), 1-20.

Wittmann, E. C. (2012). Das Projekt "mathe 2000": Wissenschaft für die Praxis - eine Bilanz aus 25 Jahren didaktischer Entwicklungsforschung. In G. N. Müller, C. Selter \& E. C. Wittmann (Eds.), Zahlen, Muster und Strukturen. Spielräume für aktives Lernen und Üben (pp. 265-279). Stuttgart: Klett.

Wittstein, T. (1879). Die Methode des mathematischen Unterrichts: nebst Proben einer schulmäßigen Behandlung der Geometrie. Hannover: Hahn.

Open Access This chapter is licensed under the terms of the Creative Commons Attribution 4.0 International License (http://creativecommons.org/licenses/by/4.0/), which permits use, sharing, adaptation, distribution and reproduction in any medium or format, as long as you give appropriate credit to the original author(s) and the source, provide a link to the Creative Commons licence and indicate if changes were made.

The images or other third party material in this chapter are included in the chapter's Creative Commons licence, unless indicated otherwise in a credit line to the material. If material is not included in the chapter's Creative Commons licence and your intended use is not permitted by statutory regulation or exceeds the permitted use, you will need to obtain permission directly from the copyright holder.

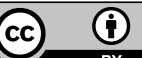




\title{
Chapter 2 \\ Subject-Matter Didactics
}

\author{
Lisa Hefendehl-Hebeker, Rudolf vom Hofe, Andreas Büchter, \\ Hans Humenberger, Axel Schulz and Sebastian Wartha
}

\begin{abstract}
In the development of didactics of mathematics as a professional field in Germany, subject-related approaches play an important role. Their goal was to develop approaches to represent mathematical concepts and knowledge in a way that corresponded to the cognitive abilities of the students without disturbing the mathematical substance. In the 1980s, views upon the nature of learning as well as objects and methods of research in mathematics education changed and the perspective was widened and opened towards new directions. This shift of view issued new challenges to subject-related considerations that are enhanced by the recent discussions about professional mathematical knowledge for teaching.
\end{abstract}

Keywords Subject-oriented didactics - Basic ideas - Mental representations • Didactics of arithmetic $\cdot$ Didactics of calculus

\footnotetext{
L. Hefendehl-Hebeker $(\bowtie)$

Faculty of mathematics, University of Duisburg-Essen, Essen, Germany

e-mail: lisa.hefendehl@uni-due.de

R. vom Hofe · A. Schulz

University of Bielefeld, Bielefeld, Germany

e-mail: vomhofe@math.uni-bielefeld.de
}
A. Schulz
e-mail: axel.schulz@uni-bielefeld.de

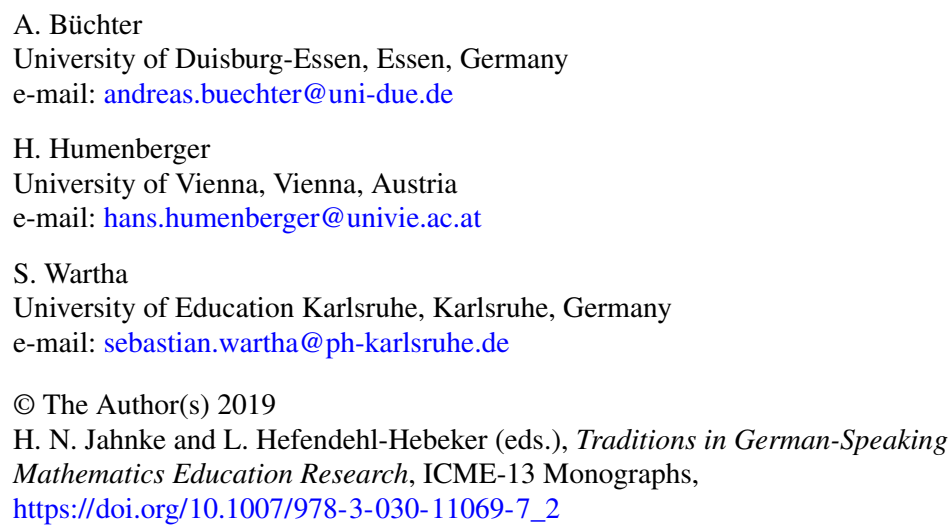




\subsection{Introduction}

In the development of mathematics education as a professional field in Germany, subject-related approaches played an important role from the very beginning (see also Hefendehl-Hebeker 2016). We consider subject-matter didactics as an approach to contents of teaching, which comprises detailed insight into the subject matter such as:

- Essential concepts, procedures and relationships including appropriate formulations, illustrations and arrangements for teaching

- Essential structures and domain-specific ways of thinking

- The inner network of paths by which the components are connected and possible learning paths throughout the domain.

This general approach is open to multifaceted refinements and extensions, and its perspectives and functions can vary under the influence of changing circumstances.

In Sect. 2.2 we outline an overview of origin, main issues, theory and methods of subject-matter didactics (L. Hefendehl-Hebeker). We will also introduce central aspects of the concept of basic ideas (Grundvorstellungen), which is an important theoretical concept of German subject-matter didactics concerning the role of mental representations and procedures (R. vom Hofe). Then we will consider two main fields of application in more detail: In Sect. 2.3 the concept of basic ideas in primary school, which focuses on numbers, fractions, basic operations and their representations (S. Wartha and A. Schulz) is explored, and in Sect. 2.4 the question about clarity and rigor in calculus, which was a main theme of German traditions of subject-matter didactics and which is still an actual problem area (A. Büchter and H. Humenberger).

\subsection{Origins and Main Issues of Subject-Matter Didactics}

\subsubsection{The Origins}

In the course of the Humboldtian educational reform in the beginning of the 19th century, mathematics changed from a marginal to a major teaching subject. Mathematics was considered as a constitutive part of 'Bildung', the development of a person's personality, namely as a key component for developing the capacity of autonomous thinking. Thus, mathematics was no longer confined to imparting practically useful arithmetic skills but was to be taught as a training of cognitive abilities. This general attitude initially resulted in a preference for pure mathematics (see Chap. 1 in this issue and Schubring 2012).

During the second half of the 19th century, both the economy and the industry experienced an enormous upswing, exposing the necessity for an adapted modern education whilst taking into account actual developments of science and technology. At gymnasium (grammar school), a climate of reforming education developed. 
Specialized journals on the teaching of mathematics and science were founded and books on methods of teaching mathematics started to be published. Some professors of mathematics began to offer special courses on school mathematics for future teachers at the gymnasium.

Felix Klein (1849-1925), professor at the University of Erlangen, the Technical College in Munich, the University of Leipzig and finally at the University of Göttingen, had always been engaged in educational aspects of mathematics. He undertook the challenge to instigate a profound reform of mathematics teaching, forging a broad alliance of teachers, scientists and engineers to support his ambitious plans.

The slogan for his Meran reform program was the famous notion of functional reasoning, which should pervade all parts of the mathematics curriculum 'like an enzyme' (Klein 1904). As Krüger (1999) pointed out, this notion should be considered as an overarching curricular guideline and orientation, which refers to a renewal of content and teaching methods of the mathematics curriculum at once.

With respect to content, the aim of the mathematics curriculum in the Meran reform program was to gradually create in the pupil's mind a consciousness for the variability of quantities - in arithmetic as well as geometric contexts and thus to raise a habit of thinking, to prepare an access to analysis and the differential and integral calculus and to bridge the gap between secondary and higher education. With respect to didactic guidelines and concrete pedagogies, the aim was to reject systematicdeductive arrangements and to turn to heuristic and genetic approaches as well as to change from rather static logical conclusions to more flexible ways of thinking. Thus the reform movement determined the course for a profound modernization. However, the teaching practice often failed to fulfill its purpose due to an obvious tendency to deal with rigid subjects of instruction instead of developing habits of flexible thinking (Krüger 1999, p. 304).

The Meran reform movement also entailed extensive publication activities in subject specific journals and monographs, for instance reports of experiences with the new subjects, proposals for the structure of the syllabus and for the design of teaching with regard to content and methods, and finally complete textbooks and task collections (Krüger 1999, p. 149). Klein himself created an example of continued relevance by his lessons on Elementary Mathematics from a Higher Standpoint, which later appeared in a series of books in several editions (Klein 1968). He intended to give an overview over the academic discipline of mathematics as a whole including the historical development and so to convey a general education (Allgemeinbildung) to the teachers.

W. Lietzmann (1880-1959), who was directly involved in the Merano reform, created a classic with his 'teaching methods for mathematics teaching' (Lietzmann 1923). Working in the tradition of Felix Klein, his purpose was to provide practicing teachers with a detailed insight into the subject matter, to propose appropriate formulations and illustrations such as possible learning paths, and to indicate obvious difficulties.

In the beginning of the 20th century, new educational methods (like the so-called Reformpädagogik) gained increasing influence especially on primary teaching. They aspired to replace the old 'learn and drill school' by an education towards self-acting 
and consequently self-reliance. On this basis, J. Kühnel (1869-1928) developed his didactics of arithmetic (Kühnel 1916), which claimed that education and teaching should be oriented towards the natural development of mind ('start from the child'). In the 1920s and 1930s, psychologist J. Wittmann (1885-1960) established his 'holistic didactics of reckoning', which was considered as an application of Gestalt psychology (Wittmann 1939). His concept of arithmetic started with doodle patterns, which children had to arrange, rearrange, compose, decompose and compare. Thus they were trained to discover relationships, which served as an illustrative base for the subsequent systematic consideration of numbers. Many of his figurative patterns are in use today. These approaches marked a rejection of formalist teaching methods, which mainly consisted of training procedures and memorizing rules. Mathematics was seen as offering an opportunity for developing cognitive abilities and forming the mind even at an early age, with a new challenge to create appropriate subject-based teaching material.

Thus, in the 19th and the beginning of the 20th centuries the development of didactics of mathematics as a professional field originated in different traditions which partially started from opposite ends of the field. The secondary education tradition was clearly orientated towards the subject as a scientific domain with a more or less pronounced awareness of psychological needs. The new developments in primary education were mainly oriented towards the contemporary psychology, and hardly any connections to mathematics as a field of science and research were established (Müller and Wittmann 1984, p. 147). Some decades later, the development should lead to syntheses of the approaches, which also resulted in a more differentiated view of the subject matter.

\subsubsection{New Developments After 1945}

The development of new structures within the educational system, the introduction of new curricular contents, and a refined consciousness of facets of subjective representations of knowledge created the need for appropriate literature on subject-oriented didactics as well as discussions about the nature and place of such contributions. F. Drenckhahn (1894-1977) wrote a clarifying contribution, wherein he defined didactics of mathematics to be "the presentation of the subject matter with respect to teaching" (Drenckhahn 1952/1953, p. 205). As he pointed out, the difference between mathematics as a scientific discipline and didactics of mathematics primarily exists in the aspects guiding the presentation, which are linked to different aims:

- Mathematics as a scientific discipline strives for a tight systematization and logical compression. The presentations reproduce the final stage of mathematical insight (according to the latest scientific findings), where the tracks of the thought process are covered up.

- In didactics of mathematics, not only formal logic but also the inner logic of the subject plays an important part. First of all, didactics of mathematics has 
the task to reveal (uncover) the images, notions, ideas, concepts, judgements and conclusions, but also the impulses and working methods, which originally result from the subject matter with logical necessity. This results in a new subject-related architecture of different layers of mathematics with distinct subject-related logics. For example, in this sense the rules for the multiplication of fractions or negative numbers follow another subject-related logic than the empirically based rules for calculation with natural numbers.

With these clarifications, Drenckhahn took up the secondary school tradition and influenced the main orientation up to the 1970s. Mathematics remained the primary academic discipline for referral by didactics of mathematics (Burscheid 2003).

W. Oehl (1904-1991) accentuated the importance of the essential structures of the subject and claimed that subject-related considerations and domain-specific ways of thinking should play a central role in mathematics education from the very beginning (Oehl 1962, 1965).

On this basis 'didactically oriented content analysis' was developed as a tool for research in didactics of mathematics, resulting from the ambition for solid foundations and conducted with the aim to present the contents in a way that is compatible with the standards of the field, and at the same time appropriate to the learners and the requirements of teaching (Griesel 1974).

In a first period, the emphasis of the 'didactically oriented content analyses' was on the lower secondary school level, especially in the domain of arithmetic and algebra, complemented by an analysis of the concept of function (Vollrath 1974). Kirsch presented far-reaching analyses of the foundations of proportional reasoning as well as of linear and exponential growth (Kirsch 1969, 1976a).

After an initial concentration on the primary and lower secondary levels, the didactically oriented content analyses were extended to the domains of upper secondary school teaching. Here the contents already had a solid scientific foundation and the problems were mostly opposite to those with respect to the lower stages. The question was how mathematical theories and concepts could be simplified and made accessible without falsifying the essential mathematical content. W. Blum and A. Kirsch suggested more intuitive approaches (at least for basic courses) with the original naive ideas of function and limit and sequential levels of exactitude, which could be achieved according to the capacity of the learners (Blum and Kirsch 1979; Kirsch 1976b).

A general goal was to develop concepts with which to represent mathematical knowledge in a way that corresponds to the cognitive ability and personal experience of the students, while simultaneously simplifying mathematical material without distorting it from its original form, with the aim of making it accessible for learners (Kirsch 1977). The simplifications introduced into mathematical subjects should be 'intellectually honest' and 'upwardly compatible' (Kirsch 1987). That is, concepts and explanations should be taught to students with sufficient mathematical rigour in a manner that connects with and expands their knowledge of the subject. Such goals also caused a search for guiding orientations in a local and global sense and produced paramount constructs of subject matter didactics, among these the concept 
of Grundvorstellungen and the tension between clarity and rigour, which will be discussed in more detail below.

Special challenges had resulted from the New Math movement in the mid-1960s, which pursued the idea that mathematics education should be science-oriented from the very beginning, and which led to a comprehensive conceptual system of school mathematics adopting the structure-oriented view of the Bourbaki group together with a high level of formalization. A new national curriculum framework (KMK 1968) chose sets, structures, mappings, functions and logical concepts as content of teaching. Numerous contributions in journals and textbooks unfolded these concepts with respect to teaching (for a partial overview, see for example Vollrath 2007). However, teachers and educators were widely unprepared for the reform and it finally failed. The advocates of the reform concentrated overly on the contents of the curriculum, neglected accompanying experimental approaches (Schubring 2014) and underestimated the epistemological obstacles of the new arrangements (Damerow 1977).

Within a changed view of the nature of learning, the focus of teaching had to be shifted from the conveyance of knowledge to the organization and inspiration of learning processes. Thus, wider programs of 'mathematics education emerging from the subject' (Wittmann 2012) were developed (for more details, see HefendehlHebeker 2016; Hußmann and Prediger 2016, as well as Nührenbörger et al. in Chap. 3 of this issue).

\subsubsection{The Concept of Grundvorstellungen}

An important theoretical concept of German subject-matter didactics is the concept of Grundvorstellungen, abbreviated GVs (Oehl 1962; vom Hofe 1998). The German word 'Grundvorstellungen' consists of two sub words: The prefix 'Grund' means 'ground' or 'basis', the second word 'Vorstellung' roughly means 'idea' or in the context of GVs 'conception' or 'notion'. So Grundvorstellung can be roughly translated as 'basic notion' or 'basic idea'. Below we use the abbreviation GV, this is meant to more adequately articulate the specificity of this concept.

The idea of the GV concept was developed during the heyday of the 'New Math', where 'set theory' was forced into elementary schools, and particularly rigorous academic curricula were commonly present in lesson plans, textbooks and in the classrooms of secondary school education. It was during this time that early subjectmatter didactics was developed (cf. Griesel 1968, for fractions; Kirsch 1969, for everyday arithmetic; or Blum and Kirsch 1979, for calculus). The goal of this new approach was not to simply continue importing more precise academic mathematics into schools. Rather, the goal was to develop concepts with which to represent mathematical knowledge in a way that corresponds to the cognitive ability and personal experience of the students, while at the same time simplifying mathematical material without distorting it from its original form (see above). 
Subject matter didactics, in other words, resisted the tendency of formalizing concepts and procedures exhibited by the New Math, and instead placed more value on constructing viable and robust mental representations-i.e. Grundvorstellungen-with which to capture mathematical concepts and procedures. On the one hand, GVs should be able to accurately fit to the cognitive qualifications of students, and on the other hand, capture the substance of the mathematical content. The concept of Grundvorstellungen describes the relationships between mathematical content and the individual concept formation, referring especially to three main characteristics:

- The constitution of meaning of a mathematical concept by linking it back to familiar knowledge or experiences, or to (mentally) represented actions.

- The generation of a corresponding mental representation of that concept; that is, an 'internalization', which (following Piaget) enables operative action at the level of thought.

- The ability to apply a concept to real-life situations by recognizing a corresponding structure in subject-related contexts or by modelling a subject-related problem with the aid of mathematical structures.

\subsubsection{Examples of Grundvorstellungen}

First, we consider an example of GVs and take the concept of subtraction. Figure 2.1 shows GVs and areas of application, symbolized as a tree. The GVs are pictured as roots, which give each student the capability of dealing with the applications pictured in the greenery of the tree. The different GV aspects correspond to different areas of application:

The aspect 'taking away' has the structure state-change-state (S-C-S). It corresponds to situations like this: Tim has $€ 12.30$. He spends $€ 4$.30. How many $€$ does he have left?

The next situation is structurally different: Lily has $€ 12.30$, Luce $€ 4$.30. How many more $€$ does Lily have compared to Luce? In this situation nothing happens, nothing is taken away, everybody keeps what he has. It's a static situation, the structure is state-state-state (s-s-s) and the corresponding GV aspect is comparing states. The third application area refers to comparing of changes. And the fourth example refers to the GV aspect of complementing: Jacob has $€ 12.30$, Mary has $€ 4$.30. How many more $€$ does Mary need to have the same as Jacob? This aspect is difficult for several students, who for example try to solve tasks like How much is 42 minus 39 by counting backward. This usually results in miscounts and errors because they can't activate the GV of complementing.

Over time the learning individual develops a growing system of networked GVs and GV aspects, which builds an important basis of mathematical understanding. Of course the development of GVs doesn't stop with the basic operations. Further examples will be specified in the following sections. 


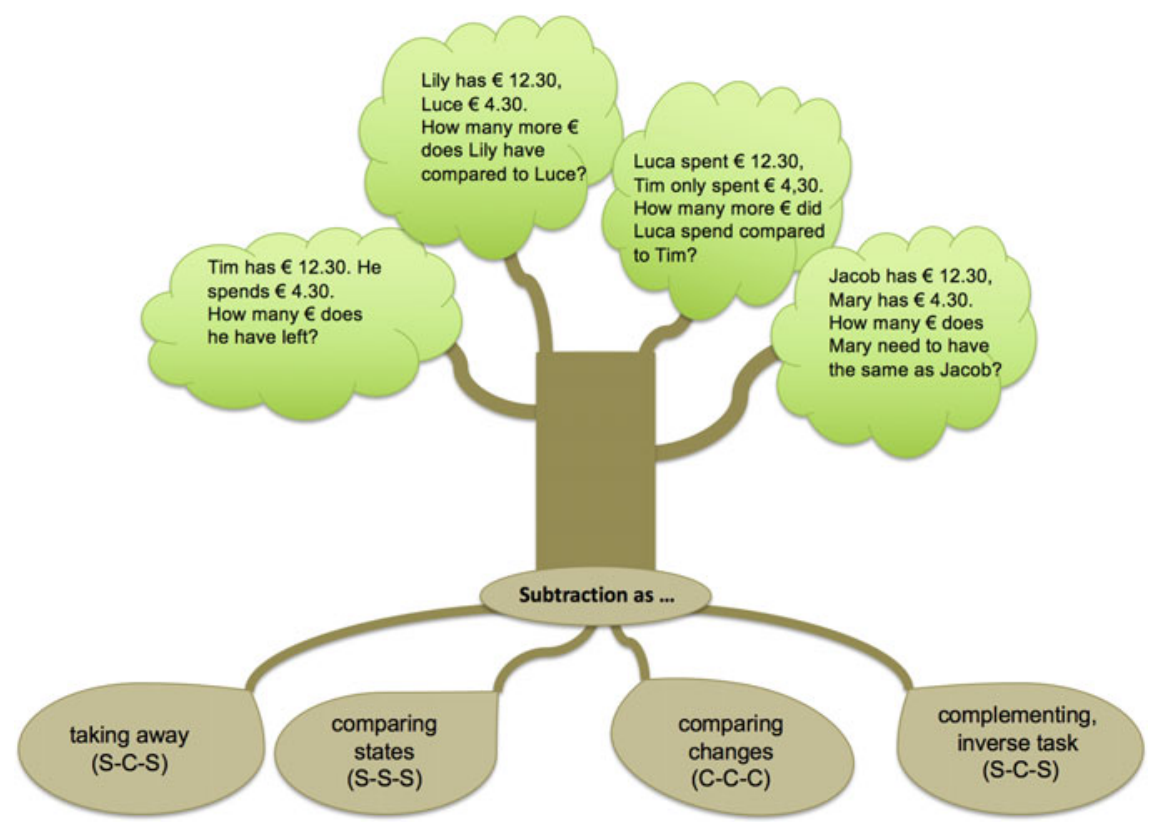

Fig. 2.1 GVs of subtraction

\subsubsection{Central Aspects of the Concept of Grundvorstellungen}

Normative, descriptive, and constructive aspects

An important quality of the GV concept is the combination of normative and descriptive working methods. In this context we can distinguish between two aspects:

- Normative working methods are used to deduce GVs as normative notions. They work as educational guidelines, following a particular educational goal and describing adequate interpretations of the use of mathematical concepts. An example is the normative description of GVs of subtraction and their attribution to appropriate areas of application above (see Fig. 2.1).

- Descriptive working methods are used to get insight into the mental representations, individual images and explanatory models that students have in fact. These individual representations usually deviate more or less from the GVs that are intended as normative guidelines.

Comparing and detecting potential conflicts between normative and descriptive aspects, which is between normative GVs intended by the teacher and observable actual images and explanatory models of the student, can provide constructive insight in learning problems of the student and give hints for removing misconceptions. 


\section{Primary and secondary GVs}

Another important quality of the GV concept is the distinction between primary and secondary GVs (vom Hofe and Blum 2016):

- Primary GVs are based upon concrete actions with real objects. The corresponding concepts can be represented by real objects and actions for instance by joining or dividing real sets of things. Primary GVs for this reason possess a concrete character.

- Secondary GVs are based on mathematical operations with symbolic objects. Constituent of the corresponding mathematical structures is dealing with mathematical objects, such as number lines, terms, and function graphs. Secondary GVs for this reason are said to have a symbolic character.

The distinction between primary and secondary GVs largely corresponds to the distinction given by Fischbein between 'primary' and 'secondary intuitions' (cp. Fischbein 1987).

\section{Grundvorstellungen and modelling}

Primary and secondary GVs play a key role in the process of modelling, that is, in the translation between mathematics and the 'rest of the world'. The important steps of modelling can be considered as: (1) constructing a situation model, (2) simplifying it to a real problem, (3) mathematizing, (4) working mathematically, (5) interpreting, (6) validating, and (7) exposing (cp. Blum and Leiss 2007). Central mental activities work here at step 3, when a real world problem situation is given and a corresponding mathematization has to be found. Or at step 5, when a mathematical result has to be interpreted in relation to the problem situation.

For this process, one needs GVs to decide which mathematical content or method can fit a particular problem situation, or, vice versa, which problem situations can be modelled with specific mathematical content.

Furthermore, modelling processes often require translation between different levels of representation within mathematics, for example between algebra and geometry (step 4 of the modelling process). Again, GVs are required here to assign, for example, geometric representations of concepts such as slope or monotonicity to their corresponding algebraic representations. These processes of translation are typically accomplished with secondary GVs.

All in all, GVs can be considered as means of translation between mathematics and reality or between different representation levels of mathematics - more generally_as objects of transition between different mathematical representation systems. These relationships demonstrate the important role of GVs for the development of mathematical competencies. This development would ideally be accompanied by the formation of both primary GVs and, with progressive learning also secondary GVs, into a growing and networked system. In particular, the ability to apply mathematical skills is based, according to this view, on the quality of development and the degree of the cross-linking of GVs, as well as on the ability to activate and coordinate GVs. 


\section{Relations between $G V s$ and other concepts of mental representations}

The formation of the GV concept as well as its interrelated basic assumptions can be considered in the context of other concepts dealing with mental mathematical representations. We shortly focus on three important approaches: the research on intuition in mathematical thinking, the work on concept image and concept definition, and the theory of conceptual change.

According to Fischbein et al. (1990), even at higher levels the process of mathematical problem solving is always combined with intuitive images and assumptions that can affect the way of problem solving more or less unconsciously (see Fischbein 1987, 1989). Fischbein's research focuses on the contrast between the intuitive level and the formal level, and the finding that many errors in students' mathematical thinking and acting are based on intuitive tendencies which interfere with correct reasoning. Fischbein's insight, where serious problems of understanding and communication found in mathematics lessons are based on conflicts concerning the intuitive level, corresponds clearly to the findings of the early advocators of subject-matter didactics. His work has significantly influenced the generation of the GV concept (see vom Hofe 1995). However, a major difference between Fischbein's approach and the GV concept concepts is that, in the work of Fischbein, intuitions are used exclusively as a descriptive notion while the GV concept uses Grundvorstellungen primarily as a normative notion.

Another important idea in this area is the theory of concept image and concept definition by Tall and Vinner (1981). The term concept image describes "the total cognitive structure that is associated with the concept, including mental pictures and associated properties and processes. It is built up over the years through experience of all kinds, changing as the individual meets new stimuli and matures" (Tall and Vinner 1981, p. 2). It can be more or less in accordance with, or in contrast to, the concept definition. These ideas developed similarly to the GV approach during the area of New Math and provide the insight that teaching mathematics on a formal level does not lead to appropriate understanding of the students. The contrast of concept image and concept definition may seem parallel to the distinction between the descriptive and the normative aspect of the GV concept, but this would be a misunderstanding: both the descriptive and the normative aspect of the GV concept refer to the field of concept image and describe actual detectable individual images (descriptive aspect) and didactically intended GVs (normative aspect).

Finally, we take a look at the theory of conceptual change. A key assumption of this theory is that individuals generate robust and early concepts by interpreting their daily lives, which then could become inadequate in the course of time when facing new information. Therefore, processes of conceptual change are needed in order to extend the existing mental structures and adapt them to the new requirements. This concept has roots in Piaget's theory of assimilation and accommodation and was developed especially in science education (Posner et al. 1982). Furthermore, this concept has also been applied to the learning of mathematics, particularly concerning the advancement from natural to rational numbers (Vosniadou and Verschaffel 2004; Kleine et al. 2005; Prediger 2008). Considering that the generation of Grund- 
vorstellungen in the long run is supposed to be a dynamic process with changes, reinterpretations and substantial modifications (vom Hofe 1998), affinities between the idea of conceptual change and the generation of GVs are obvious.

In summary, we can state that certain aspects of the GV concept can also be interpreted from the perspective of the above-mentioned theories. However, a substantial difference exists concerning the main foci of these concepts: While research concerning the above mentioned concepts has mainly or exclusively a descriptive emphasis, the approach of the GV concept combines normative and descriptive methods with a constructive aim. In this sense, analyses of students' work based on the GV concept typically do not remain at the descriptive level but lead to indications of a constructive 'repairing' of the analyzed problems.

\subsection{Numbers, Fractions, Operations and Representations-Grundvorstellungen in Primary School}

In the following sub-chapter, we would like to show that through the comparison of normative and descriptive interpretations of Grundvorstellungen it is possible to gain constructive insights for research and teaching (Sect. 2.2). To this end, we will use examples of Grundvorstellungen of natural numbers, fractions, subtraction and multiplication.

\subsubsection{Grundvorstellungen and Levels of Representation}

Grundvorstellungen are models that build a bridge between various levels of representation. They allow translations from one level to another (see Fig. 2.2; see also vom Hofe 1995; Wartha and Schulz 2012; Sect. 2.2).

Translations can be performed both between and within different levels of representation. Typical levels of representation are images, actions (e.g. manipulatives), word problems (of realistic situations) and spoken or written mathematical symbols. 'Understanding' means that mathematical ideas are not linked to one isolated level, but they can be used and translated in various levels of representation. The idea that the 'mathematical understanding' can be diagnosed and developed through the translation between and within levels of representation has been described by many authors with similar models (e. g. Kuhnke 2013; Duval 1999; Janvier 1987; Söbbeke and Steinbring 2007). Furthermore, these levels of representation can be more concrete or more abstract (see Fig. 2.2). 


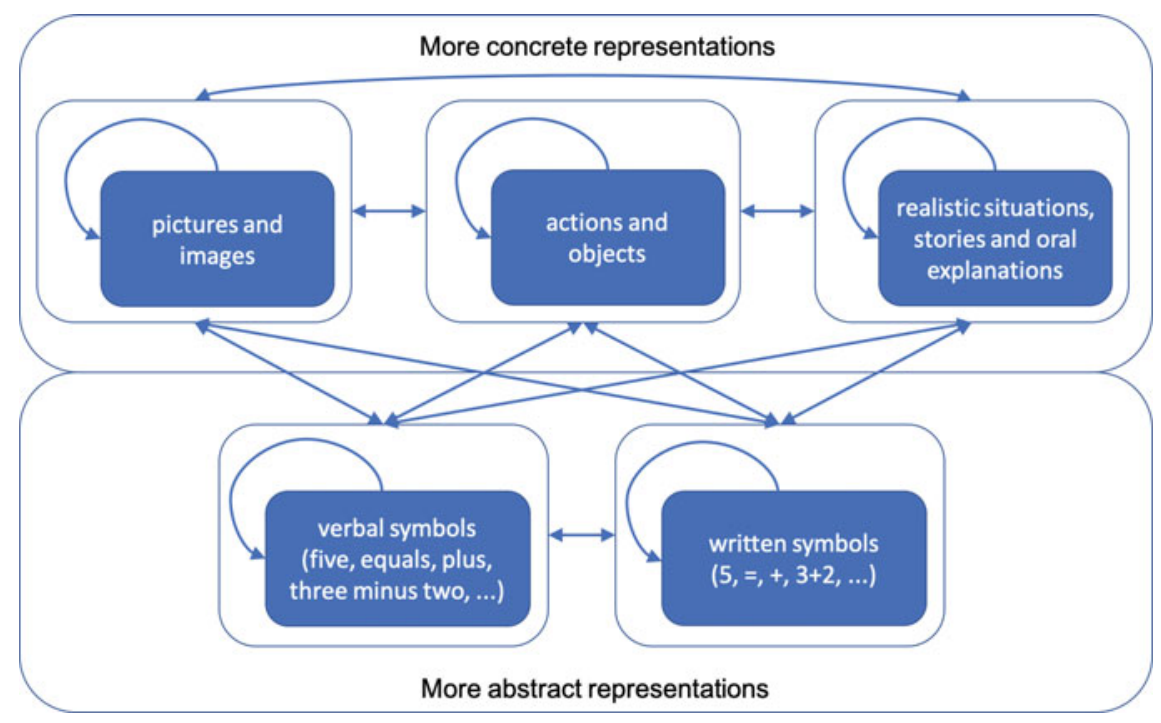

Fig. 2.2 $G V$ and levels of representation (Schulz 2018, p. 6)

\subsubsection{GV of Natural Numbers}

Natural numbers can be interpreted in many different ways. On the normative level we can distinguish, for example, between two aspects of the understanding of natural numbers: one is the cardinal aspect, which is based on the comparison of quantity of numbers (described through equivalence classes), the other one is the ordinal aspect of numbers, which refers to the position of a given number in an order of numbers (Klein 1968; Padberg and Benz 2011; Padberg et al. 2001). In the following excerpt of an interview (Table 2.1) we can identify these two aspects from a descriptive perspective:

Matteo's case is an illustrative example for the empirical finding that children can have two different Grundvorstellungen of numbers:

- a sequenced scheme, which means an ordinal understanding of number or a mental number line (he has problems with determining the number 'just before', if this number is a multiple of ten)

- a quantitative scheme, which means a cardinal understanding of numbers (he is able to name the correct multiple of ten when asked: take one away from 61)

Ever since Resnick's publications on the development of number understanding, we have assumed that robust number sense means integration of these two aspects (e. g. Resnick 1989). Early research shows that number sense develops by integrating the cardinal and ordinal interpretation of numbers. Fuson (1988) has already pointed out that the development of concepts of ordinal and cardinal numbers is closely linked, and that more cardinal prompts (more than/fewer than) are interpreted differently 
Table 2.1 Matteo transcript (a 9-year-old pupil at the end of the second year of primary school)

\begin{tabular}{|c|c|c|c|}
\hline I & Count backwards from 78 & \multirow[t]{3}{*}{ I } & \multirow{3}{*}{$\begin{array}{l}\text { Imagine I'm showing the number } 61 \\
\text { now } \\
\text { What does it look like? } \\
\text { Can you show me this up in the air? } \\
{[\ldots]}\end{array}$} \\
\hline M & Backwards? & & \\
\hline I & Backwards & & \\
\hline M & $78,77,76,75,74,73,72,71,60$ & \multirow[t]{2}{*}{$\mathrm{M}$} & \multirow{2}{*}{$\begin{array}{l}10,20,30,40,50,60,1 \\
\text { (shows with fingers) }\end{array}$} \\
\hline I & Go on & & \\
\hline M & $59,58,57,56,55,54,53,52,51, \mathbf{4 0}, 39$ & \multirow[t]{2}{*}{ I } & \multirow{2}{*}{$\begin{array}{l}\text { If I take this one away, what numbe } \\
\text { will I get? }\end{array}$} \\
\hline \multirow[t]{3}{*}{ I } & \multirow{3}{*}{$\begin{array}{l}\text { OK. Thank you } \\
\text { Please count backwards once again } \\
\text { from } 92\end{array}$} & & \\
\hline & & M & Take this one away. 60. \\
\hline & & $\mathrm{I}$ & And another one away? \\
\hline M & $91,80,79,78,77,76$ & M & (60) $\ldots 59$ \\
\hline I & OK. Thank you & I & OK \\
\hline
\end{tabular}

than more ordinal prompts (just before, just after). In Matteo's case, both approaches could be perceived: there is a difference in his behavior depending on whether Matteo is offered an 'ordinal prompt' or a 'cardinal prompt'. Sayers et al. (2016) have recently presented a somewhat new approach to number sense. By intensive investigations they have elaborated an 'eight component framework' in order to be able to characterize a so called 'foundational number sense' (FoNS). This approach also stresses the correlation between cardinal and ordinal number aspect (see also Gerlach 2007).

Possible implications for teaching and the education of teachers are that instruction can only be appropriate to students' learning processes if the individual underlying concepts and misconceptions are well known and can be taken into account (Schulz 2014). This requires profound knowledge about how students typically learn a specific content, which conceptions they bring with them, and also knowledge about possible, empirically documented misconceptions and mistakes that commonly arise during this learning processes. For the present content this means that teachers should be informed of the existence of different aspects of numbers and of the difference between them, namely for both: a normative and a descriptive level (Clarke et al. 2011; Lindmeier 2011; Schipper 2009; Schulz 2014; Wartha and Schulz 2012). Only in this way are they able to appropriately support the pupils' processes of learning, especially by fostering a simultaneous development of both aspects of number.

In the next section, we will show that the relations between aspects of numbers and between representations can not only support pupils' learning processes, but that these translations between representations can be interpreted as the core of mathematical learning. 


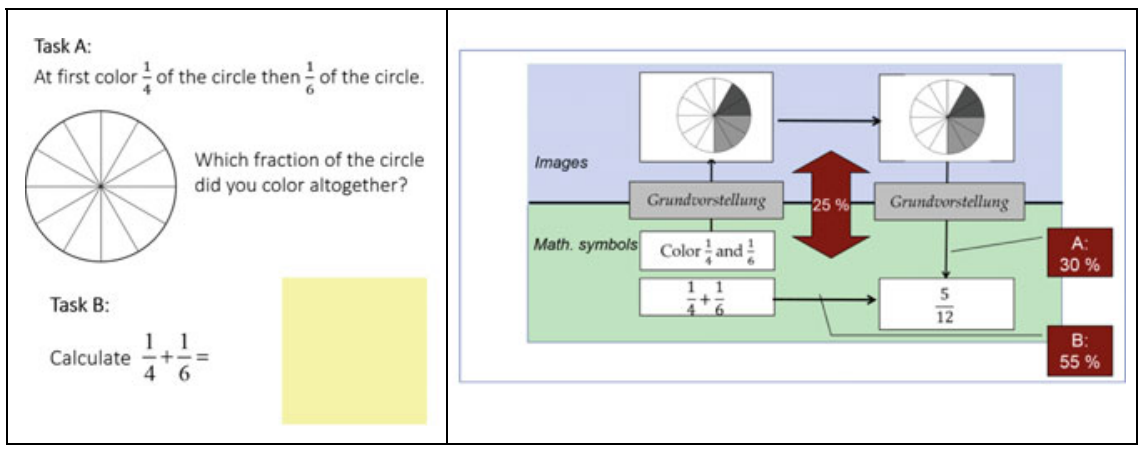

Fig. 2.3 Fraction Tasks A and B, description with Grundvorstellungen, percentage of correct answers

\subsubsection{Grundvorstellungen of Fractions}

There are many different normative descriptions of how fractions can be interpreted. One thing that many interpretations have in common is that a fraction describes a part-whole-relation as the comparison of a quantity to a dividable unit. In this sense, fractions can be interpreted as quotients or measures and represented as areas or countable parts of an object. This interpretation can be seen as continuation of the cardinal aspect of natural numbers. On the other hand, fractions can be interpreted as measure numbers in real life situations. Hope and Owens (1987) state: "Measure numbers are commonly represented as points on a number line partitioned in smaller segments." This interpretation can be seen as a continuation of the ordinal aspect of natural numbers.

From a descriptive perspective, two content-related fraction tasks investigate the part-whole-Grundvorstellung of learners (Fig. 2.3). These two items (Fig. 2.3, left) were developed by Hasemann (1981). In his research, he wanted to assess the role of the level of representation on solving processes (Wartha 2009).

A normative analysis shows that the task A does not require calculation skills with fractions. The fractions $1 / 4$ and $1 / 6$ are given as written symbols and have to be translated into a given image. Two and three parts of the circle should be colored and put together to five parts. In a last step, 5 of 12 parts have to be translated into the symbolic expression 5/12. Grundvorstellungen have to be activated at least twice. In contrast, there is no translation required to solve task B. The sum can be calculated within the symbolic representation by using fraction addition rules. The problems were given to $\mathrm{N}=1010$ 6th grade pupils in Bavaria of all school forms who finished the course on learning fractions.

Less than a third of the pupils are able to activate a Grundvorstellung whereas more than 50\% are capable of solving an arithmetic expression containing the same numbers. Although the tasks followed each other immediately in the tests, only a quarter of all pupils produced the same solution. 
Apparently three out of four pupils do not realize that the mathematics in both problems is the same-just in different levels of representation. They operate with numbers of which they do not have any Grundvorstellung. Numerous other investigations (Hasemann 1997; Mack 1995; Prediger 2008, 2011) also demonstrate that solving processes are influenced significantly by the level of representation and whether translations are required or not.

The comparison of normative analysis and descriptive empirical results shows that translations between representations themselves are the core of mathematical thinking. The request of these translations can be regarded as a didactic principle for both diagnoses and furtherance. On the one hand, the (un-) successful translation can give insight in how well a given content is understood. On the other hand, the constant request to switch between symbols, non-symbolic representations and real or mental models can lead to robust Grundvorstellungen.

The term Grundvorstellung can thus be regarded also as an operationalization of mathematical ideas for planning curricula, preparing lessons and analyzing children's answers, solving processes and supporting improvements (Padberg and Wartha 2017). The fundamental idea relies on the translation between symbols and appropriate models. The adequacy of models is discussed in the next example, Grundvorstellungen of subtraction.

\subsubsection{Grundvorstellungen of Operations: Subtraction}

Hefendehl-Hebeker and vom Hofe (Sect. 2.2) have already provided some examples for different applications and the corresponding GVs of subtraction. These GVs are based on the following two fundamental different models of subtraction (Selter et al. 2012; Usiskin 2008; Wessel 2015)

The mathematical definition of subtraction is linked to addition: $a-b$ is a number $\mathrm{c}$, for which a equals $\mathrm{b}+\mathrm{c}$. For the meaning of subtraction, we can distinguish two fundamental different models or Grundvorstellungen (Wessel 2015)—determining a remaining quantity and determining a difference. Further aspects in order to categorize interpretations of subtraction can be dynamic versus static aspects, given and unknown data. Word problems in additive and subtractive situations are often classified in the categories change, combine, compare and equalizing (Schipper 2009; see also Sect. 2.2).

Determining a remaining quantity by 'taking away' (dynamic) or 'comparison' (static):

In the example 7-4, the first number 7 can be translated as a dot on the number line. ' -4 ' means an arrow back to a position, where the result can be determined (see Fig. 2.4 top left). Word problems such as:

- "I have 7 pets, 4 are taken away, how many are left?"

- "Tim has $€ 12.30$. He spends $€ 4.30$. How many $€$ does he have left?" 


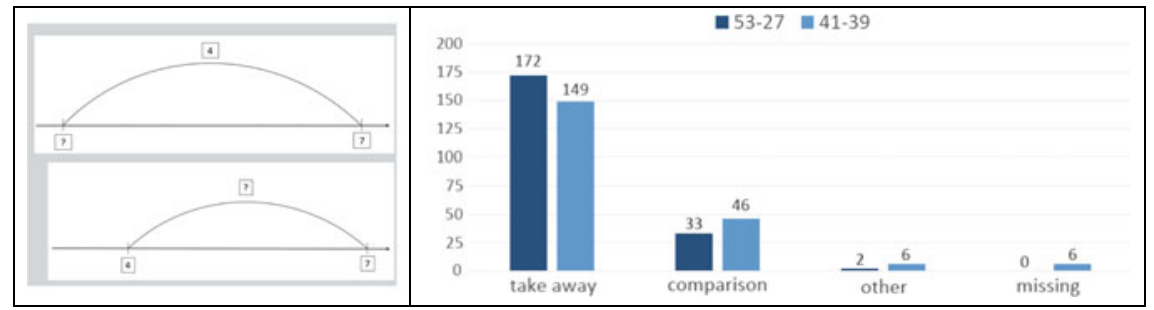

Fig. 2.4 Take away and comparison model normative (left, see Wessel 2015, p. 29) and descriptive (right)

- "Chris has 7 bottles of water, 4 more than I have. How many do I have?"

are associated with this model. The first two are dynamic situations and the third one is a static situation.

Determining a difference by 'complementing' (dynamic) or 'comparison' (static):

In contrast to determining the remaining quantity, both numbers of the term, e.g. 7-4 can be located on the number line and the result is seen in the difference between them (see Fig. 2.4 bottom left). Examples for word problems are:

- "Mat has 7 cars, Tom has 4. How many more cars does Mat have?"

- "Mat has 7 cars, Tom has 4. How many more cars does Tom need in order to also have 7?"

- "Lily has $€ 12.30$, Luce has $€ 4.30$. How many more $€$ does Lily have in comparison to Luce?"

We want to stress that all of these categories come down to these two Grundvorstellungen of subtraction. In other words, every situation that requires a minus sign to be entered into a calculator to solve it contains a Grundvorstellung of subtraction.

In empirical studies, many colleagues showed that solution processes strongly depend on which Grundvorstellung that has to be activated.

- Stern (1998) pointed out that preschool children deal significantly better with dynamic take away situations than with static comparison situations in word problems.

- Schipper et al. (2011) demonstrated that about 80\% of 2000 second-year pupils can solve take away situations correctly, but only $60 \%$ can do so in the case of static comparison word problems-with comparable numbers.

Studies conducted in calculation processes of pupils showed a clear preference of using 'take away' strategies, even if determining the difference would offer more effective solutions:

- Selter (2000) showed that the term 701-698 is very difficult to third graders and only a few of them could use a comparison or complementing GV to interpret subtraction as the difference between 701 and 698 . 
- Wartha and Benz (2015) stressed that only $15 \%$ of fifth graders used a comparison or complementing GV to calculate the term 601-598 - even if more pupils knew that the difference between the numbers was 3 , they could not use this information for the calculation.

- In a further study conducted by Wartha, student teachers were asked to create appropriate word problems by translating the terms 53-27 and 41-39. The vast majority of the (approximately) 200 students created word problems by activating the take away GV. Only a quarter of the students used a word problem based on the comparison or complementing model containing the term 41-39 (see Fig. 2.4, right).

The limited interpretation of subtraction as 'take away' is problematic, as the comparison or complementing model:

- provides efficient calculation strategies for terms like 41-39

- is relevant for the determination of differences in real life situations

- is an important mathematical interpretation of subtraction which is used to construct integers for example.

As a consequence, teachers, textbook authors, and curriculum developers should:

- know both models of subtraction

- emphasize the comparison model

- choose and use appropriate models and representations to construct both Grundvorstellungen.

The previous sections emphasized the interpretation of Grundvorstellungen as the ability to translate between different representations and models concerning a given content. In the next section the important role of choosing appropriate representations will be discussed.

\subsubsection{Representations: The Case of Multiplication}

As mentioned before, the normative and descriptive analysis of Grundvorstellungen can be seen as a useful precondition for planning assessment, promotion and support- especially for analyzing and choosing an appropriate representation for a given content. Using the example of multiplication, it can be clarified that a subject matter didactic analysis can help to choose an appropriate model or type of representation for teaching and learning.

As multiplication of natural numbers is frequently interpreted as repeated addition, school books often show illustrations or models using this kind of idea. For example, the problem $3 \times 6$ is illustrated by placing six apples on three plates each time (see Fig. 2.5a). This representation is appropriate for a first contact with the idea of multiplication.

A closer subject matter analysis reveals the shortcomings of this representation: 
(a)

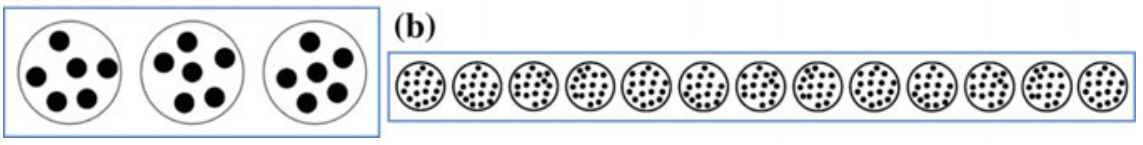

Fig. 2.5 a and b: Illustration for multiplication interpreted as repeated addition $(3 \times 6$ and $13 \times$ 16)

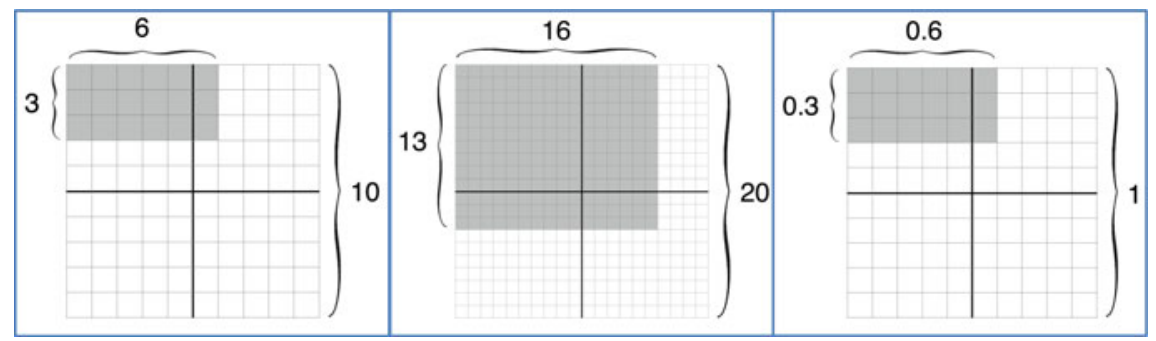

Fig. 2.6 Illustrating multiplication using rectangle representations

(1) This type of representation is hardly suitable for an appropriately extension for larger numbers-reconstructing the model mentally would hardly be possible (see Fig. 2.5b).

(2) Furthermore, it is impossible to illustrate the multiplication of decimal fractions (like $0.3 \times 0.6$ ) using this type of representation.

(3) Also, the illustration of fundamental arithmetic laws (e.g. commutative law) is hardly possible using this type of representation.

(4) For these reasons, this type of representation does not serve for the development of sustainable and long-term calculating strategies (for example using the distributive law).

To overcome these shortcomings, it is worthwhile to provide and use a better type of representation. The interpretation of multiplication using the scheme of a rectangle is a sustainable and extendable model, employing either dots or squares. The factors are represented by the number of columns and rows, the product being equal to the total number of visible objects or to the generated total area. This representation can be used from primary level (multiplication of natural numbers) up to secondary school (e.g. to illustrate the multiplication of decimal fractions) (see Fig. 2.6), and could be developed from the first representation e. g. by restructuring the given dots.

From a subject matter content analysis standpoint, the rectangle model seems to be very appropriate for teaching and learning multiplication. But how do learners interpret the given representation? Is the 'power of the model' sufficient enough to be self-explanatory? The interview reported in Table 2.2 is an illustrative example of the fact that even a suitable and sustainable representation is not necessarily applied without difficulties. 
Table 2.2 Stephanie's interpretation of a rectangle model

\begin{tabular}{|l|l|}
\hline S & I see: There are red dots and blue dots. 5, 10, 15. And the blue ones: Plus 3. \\
\hline I & Would you also see a multiplication task there? \\
\hline S & I could as well, yes. \\
\hline I & Which one would that be? \\
\hline S & Namely 15 times 3. \\
\hline I & And why 15 times 3? \\
\hline S & $\begin{array}{l}\text { Because I've looked at those rows. The red rows amount to 15. And the } \\
\text { blue rows. }\end{array}$ \\
\hline I & OK. \\
\hline
\end{tabular}

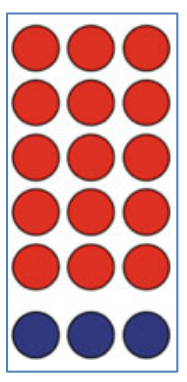

Numerous empirical results show that pupils use didactical beneficial material rather unfavorably or even incorrectly; and faulty interpretations and mainly faulty 'inner images' of materials and representations have also been repeatedly proved empirically (Lorenz 1998; Rottmann and Schipper 2002; Söbbeke 2005). Obviously, a sustainable representation is not self-explanatory. This gap between the normative potential of a given type of representation and the empirically proved interpretation of these representations can lead to a constructive point of view. A possible conclusion might be that representations, their purpose and structure have to be interpreted together with the children. This means amongst other things discussing on mathematical relevant structure and relationships, and discussing different views on the same representation to widen the mathematical perspective of teachers and learners. Concerning this constructive point of view, there still is a gap in empirical research and in design (e. g. in mathematics education as well as in developmental and cognitive psychology). Which representations, models, prompts, discussions are fruitful, sustainable and suitable for the development of mathematical thinking and thus for the development of robust Grundvorstellungen?

\subsubsection{Summary}

To sum up, we would like to deduce some consequences for education, teaching and research.

(1) The goal of mathematics education should be to establish Grundvorstellungen. They should remain sustainable for as long as possible and describe the meaning of numbers and operations comprehensively. At best, Grundvorstellungen of mathematical contents should be operative tools to be used from kindergarten to university.

(2) We underlined the fact that a given content could be described by more than one Grundvorstellung. For this reason, we (teachers, educators, researchers) 
should know which Grundvorstellungen (plural) describe a given content—both normative as well as descriptive.

(3) This is necessary for planning assessment, promotion and support. We should have knowledge on representations, sustainable models, and on how mathematical contents are translated between representation levels.

(4) Beyond that, we have to keep in mind that the results of normative and descriptive consideration are hardly ever congruent and not every learner is able to use the given Grundvorstellungen.

(5) Based on these differences between subject matter didactic analyses and the empirical findings, constructive suggestions can be derived not only for assessment and teaching, but also for further investigations. Mathematics education as 'design research' provides the essential contributions to this task-not only in competition or as a complement to subject matter didactics or to empirical research on instruction, but rather as a necessary conclusion (e. g. Wittmann 1995).

\subsection{Clarity and Rigor in Teaching Calculus}

\subsubsection{Intended Understanding and Students' Concept Images-The Example of Tangents}

'Clarity and rigor in teaching calculus' is a classical topic in subject-matter didactics. In this first part of our paper, we refer to an extended understanding of subject-matter didactics, which focuses explicitly on the learner's perspective. The starting point is the difference between the intended understanding of mathematical concepts und the actual students' concept images. We will show our considerations by referring to an exemplary concept in calculus: the concept of tangent. The goal is to create constructive proposals for the development of curriculum, textbook and lessons. Therefore, we refer to a model of different levels of curriculum, which is suitable for our considerations.

\section{A Model of Curriculum Levels}

The four-level curriculum model has been used in large scale assessments to analyze students' achievement; however it is also suitable for research on students' concept images:

- On the first level of this curriculum model, the intended curriculum includes the targets and objectives defined by the officials at state level (e.g., core syllabus, teaching plan demands, and central examinations).

- The potential curriculum on the second level includes textbooks and other learning materials, which must be often authorized by the ministry of education. This level can be regarded as a superset of learning opportunities. 
- On the third level, the implemented curriculum is about the classroom practice ('Which topics are introduced and how?'). This level can only be examined by classroom observation.

- Lastly, the achieved curriculum on the fourth level concerns the content learned by the students. For our research, we will be focusing on the individual student's concept images.

In the following sections, we begin by outlining the syllabus specifications of the tangent concept ('intended curriculum'). Afterwards, we introduce individual students' concept images of the tangent concept ('achieved curriculum'). Then, we attempt to explain the differences between the intended understanding and the students' concept images by means of excerpts from text books ('potential curriculum') and we propose consequences for the development of learning units in textbooks and in differential calculus ('implemented curriculum'). Finally, we reflect on our analysis regarding the topic of 'clarity and strictness'.

\section{Syllabus Specifications About the Tangent Concept}

The concept of tangent plays an important role in three course units in lower and upper secondary education in most of the German federal states:

- Tangents to circles are introduced in the Euclidean geometry around grade 7.

- Tangents to parabolas are introduced and calculated in analytic geometry in grade 10.

- During differential calculus in upper secondary, the concept of tangent is made an object of discussion again by using curves, which are considered as graphs of functions in order to achieve a higher level of generalization of the same concept.

Thus, students are required to develop an analytic understanding of tangents at upper secondary level. However, a glance at the actual students' concept images about the tangent reveals that the learning opportunities in Euclidean and analytic geometry are more formative, as the next section shows.

\section{Students' Concept Images About the Tangent}

We present two selected examples from the results of a study about students' concept images of tangent. All students who have been interviewed had attended an introductory course and partly an advanced course in differential calculus. The student task consisted of answering the question: 'What is a tangent?', and no examples or hints about use of representations were provided. The following excerpts represent exemplary solutions, which were quite common among the data collected.

In the first example (Fig. 2.7), one can observe that the student activates the definition of tangent to a circle in Euclidean geometry. The striking characteristics in this solution are the global view of the situation as well as the property of having only one point in common, and the perception of touching. The reference to calculus is vague and turned upside down from a content perspective: the derivative is required for an appropriate determination of the tangent line at a curve and not the other way round.

The second typical example (Fig. 2.8) can be positioned more strongly in the world of functions. Even though the starting point is a function, the student refers to 


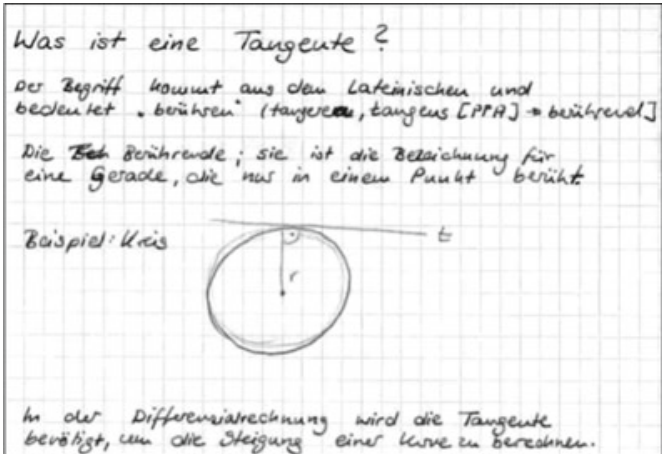

What is a tangent?

The concept name originates from Latin and means to 'touch'

(tangere, [PPA] $\rightarrow$ touching)

The touching one; it is the name for a line, which touches only in one point.

Example: circle

In differential calculus, the tangent is needed to calculate the slope of a curve.

Fig. 2.7 Example for the strong activation of aspects from Euclidean geometry

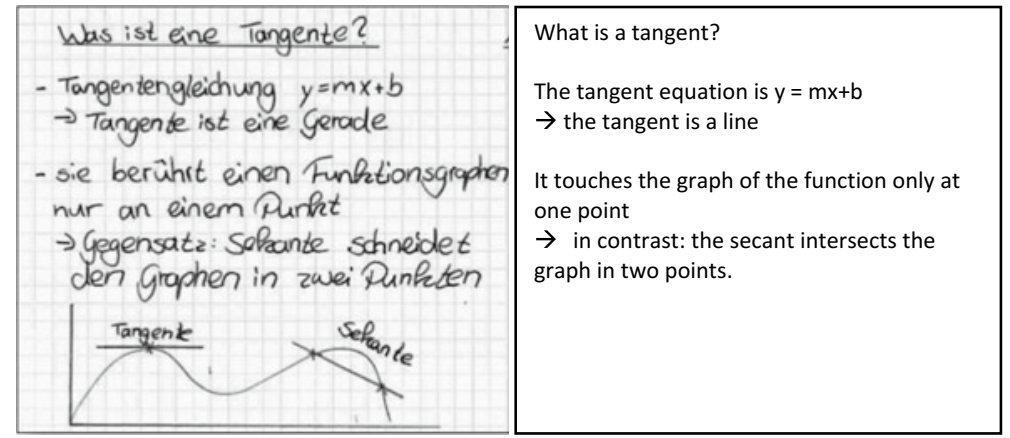

Fig. 2.8 Example for an answer from the world of functions

the characteristic of having only one point in common and the touching phenomenon, hence the perspective is still global. The comparison of the tangent to the secant is generally not sustainable.

Both examples represent several properties of a large number of student solutions obtained:

- A global perception of the situation

- Only one common point between the curve and the tangent line

- 'Touching' to describe the common behavior.

Furthermore, the students did not often establish a relationship between the tangent and derivative. If they had described this relationship in their solutions, then it was mostly false.

Considering the differences between the intended and the achieved understanding of the tangent concept, the next step is to investigate how these differences emerge and where they can be avoided. An appropriate way to analyze these questions is to take a look at textbooks. 

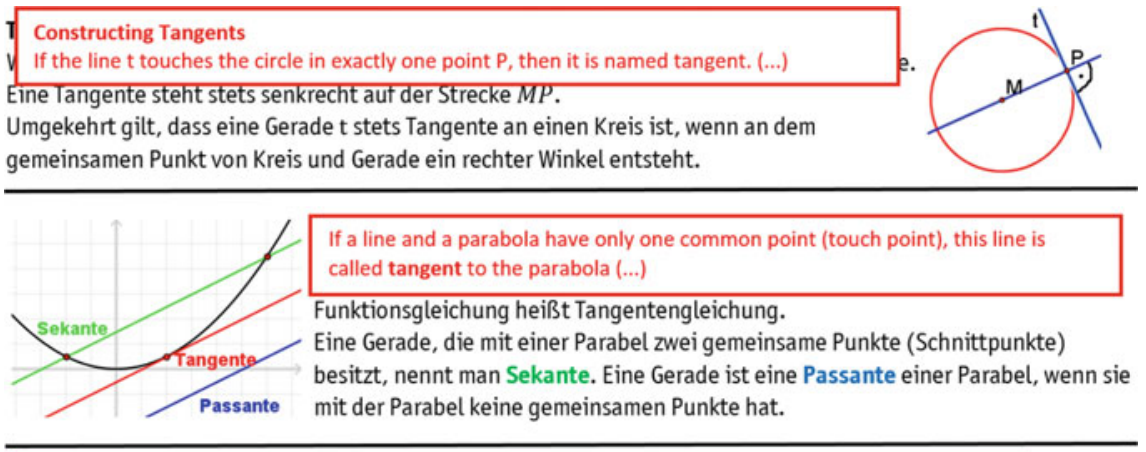

Definition: The line through the point $P(u, f(u))$ which has the slope $f^{\prime}(u)$ is called tangent of the graph of

$f$ in $u$. One can say: "The graph of $f$ has the slope $f^{\prime}(u)$ at u."

Man sagt: „Der Graph von $\mathrm{f}$ hat an der Stelle u die Steigung $\mathrm{f}^{\prime}(\mathrm{u}) .^{\text {" }}$

Fig. 2.9 Excerpts from textbooks

\section{The Concept of Tangent in Textbooks}

The following excerpts are from a typical popular schoolbook series from Grades 7, 10 and 11 respectively (Fig. 2.9).

- In the first excerpt, the concept of tangent is introduced as a tangent line to a circle in the Euclidean geometry. Here, only the properties of a global perception of the situation are mentioned: exactly one point in common and the touching property.

- In the second one, tangents are introduced in analytic geometry. This consideration is still global and the main properties mentioned are the common point between the tangent and the curve and the touching phenomenon. The differences among tangent, secant and passant are explained by referring to the number of common points.

- The third excerpt shows that the concept of tangent is introduced by a formal definition in differential calculus, without referring to previous concept images. The further analytic development of the available tangent concept is not made visible.

In the following sections we would like to make some constructive proposals to support the continuous concept development of tangent in terms of generalization. For instance, in Euclidian geometry one can consider other geometrical objects rather than only circles in order to investigate the tangent concept. For example, consider a triangle and a line through one vertex (Fig. 2.10, left). Students can discuss whether such a line can also be called a 'tangent'. In this case, an adequate argumentation would be that the line and the triangle have exactly one point in common. But if that line is also called a tangent, then different tangents can exist (Fig. 2.10, right)—finally infinitely many. Hence, the uniqueness of the tangent is no longer valid.

These considerations lead to the question: Why are circles appropriate to construct just one tangent to a specific point? This way, one can activate the core aspects of the tangent concept: the local linearity of the figure and the tangent as the line of best 

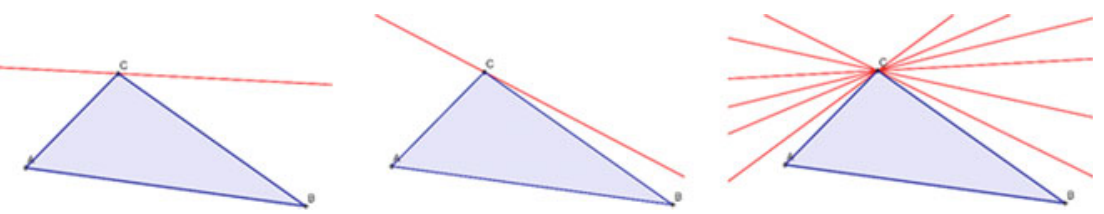

Fig. 2.10 Should these lines also be named 'tangent'?
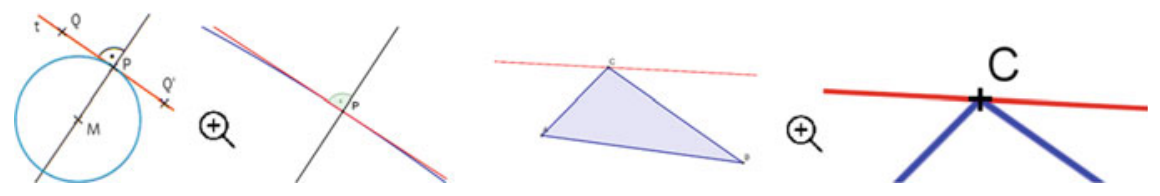

Fig. 2.11 'Figure microscope' and local linearity

approximation. The idea is that of zooming in the figure (Fig. 2.11, left), which was proposed as 'function microscope' by Kirsch in order to examine the local linearity of differentiable functions (cf. Kirsch 1979; Blum and Kirsch 1979). Consider a triangle to highlight the characteristics of the concept of tangent (Fig. 2.11, right). Upon zooming in on the intersection point between the line and the triangle vertex, one can realize that nothing changes. There will still be the possibility of constructing several different lines through the vertex, which has one point in common with the triangle.

The phenomena of local linearity of the curve and the tangent as the line of best approximation are therefore already present in circle geometry. They are suitable as core aspects of the tangent concept on which we can build upon in differential calculus. In the following section, we discuss the question of how previous knowledge or experiences from geometry can be used to develop an analytic concept of tangent as an adequate generalization.

\section{Dealing with the Tangent Concept in Differential Calculus}

Differential calculus builds up on previous experiences and knowledge from circle geometry and analytic geometry. The concept development should be considered as an extension and generalization. At the beginning of the calculus course, the students' actual concept images concerning tangents should be discussed in order to serve as foundations on which the concept development process can be further built upon. For the generalization of the tangent concept, crucial questions for the further concept development should be discussed:

- Which aspects of the tangent concept remain unchanged?

- Which aspects of the tangent concept do change?

- Which new aspects of the tangent concept do emerge?

The concept development should be supported by adequate examples that show the particularity of the analytic concept of tangent (Fig. 2.12). 
(a)

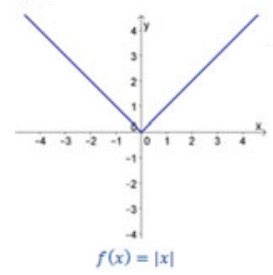

(b)

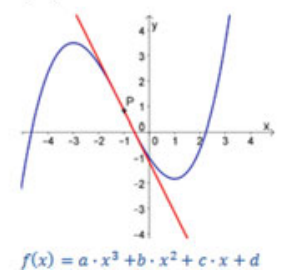

(c)

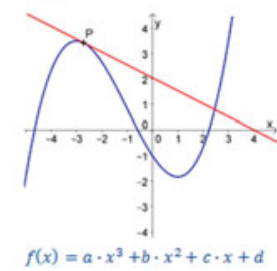

(d)

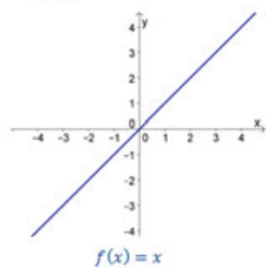

Fig. 2.12 Useful examples for the development of the differential concept of tangent

- The absolute value function (Fig. 2.12a) is a well-known example of a function that is not differentiable at one point. At 0 the situation is similar to the situation of a vertex of a triangle.

- Polynomial functions of order 3 show simple examples of functions with inflection tangents (Fig. 2.12b). In this case it becomes clear that the property of 'touching' cannot be transferred to the analytic definition of a tangent. Graphically it is more 'intersecting' than 'touching'. Even though set theoretically, the 'touching' is also an 'intersection', one can consider a geometrical difference between 'touching' and 'intersecting'. It is important to emphasize that a tangent can 'touch' or 'intersect' the graph.

- By using the same graph (Fig. 2.12c), one can describe the local character of the analytic tangent concept. The tangent could have more common points with the graph.

- A linear function and its tangents are identical (Fig. 2.12d). The consideration of such special cases is also part of a sustainable concept development.

\section{'Clarity and Rigor'}

Finally, we reflect on the tangent concept by referring again to the balance between clarity and rigor:

- Blum and Kirsch stated that clear and pre-formal proofs can also be rigorous: "[A] preformal proof [is] a chain of correct, but not formally represented conclusions which refer to valid, non-formal premises" (Blum and Kirsch 1991; cf. also Wittmann 1989). According to Blum (2000), clarity and vague or superficial are not the same. He emphasizes that strict must not necessarily mean formal.

- Vollrath emphasizes the interplay between 'clarity' and 'strictness'. If both are understood appropriately, then both are dependent on each other: "Strict ideas can only be understood if one has the corresponding clear ideas. Appropriate clear ideas can only develop from strict considerations" (Vollrath 1993).

What does this mean for the development of the tangent concept? The strict aspects-local linearity of the curve and the tangent as the line of best approximation, which are sustainable for calculus - should already be highlighted in the Euclidean geometry. This can happen visually by means of clarity, as we have shown above. Based on these core aspects, special cases and phenomena can be considered, for 
example, the phenomena of touching and of exactly one point in common in the cases of circles and parabolas. ${ }^{1}$ Additionally, the relationship between tangent and derivative should be explicitly focused on in differential calculus. Therefore, it is important to reflect on the way of attaining mathematical knowledge:

- The assumption about the possible existence of the tangent can be used to develop the idea of the tangent as the limit of the family of secants, and of understanding the algebraic transition from the difference quotient to the differential quotient.

- The tangent's uniqueness can be defined by using the derivative.

\subsubsection{Extreme Value Problems and the Monotonicity Theorem for Intervals}

The topic of intuitive accessibility of abstract issues and rigor in calculus is renowned in the German subject-matter didactics during the last decades (e.g. Blum and Törner 1983; Kirsch 1996; Blum and Kirsch 1991; Danckwerts and Vogel 2005; Greefrath et al. 2016, etc.). In particular, we refer to the paper Der Hauptsatz - anschaulich? (Kirsch 1996), in which the author wants to show how to achieve a clear, intuitively accessible understanding of the fundamental theorem of calculus using appropriate Grundvorstellungen (see Sect. 2.2 of this chapter) of the derivative. Anyone teaching calculus at any level has to deal with the problem: What should the balance of clarity and rigor look like? And the answer to this question is surely not the same for courses at university level and at school level. ${ }^{2}$ This problem is not reduced to calculus, it is a problem in principle, as H. Winter stated already (1983, p. 66; translated by the author): "There is a sort of tension between the intuitive accessibility of phenomena and considering them systematically as parts of theories, i.e. between intuition and proof, but this relationship is much more complex than...".

In the following two sections, we would like to focus on two selected aspects of calculus courses at high school or secondary school. The first one deals with the question: Extreme value problems - how and when should these be introduced in the curriculum of differential calculus? The other one deals with the role of the 'criterion for monotonicity in intervals' (why is it important at school? Is there a good way of reasoning for it at school?).

\section{Extreme Value Problems at School}

In German or Austrian mathematics textbooks one can find the following way of dealing with extreme value problems (EVP). At first, one does not only have to understand what a derivative is and how to calculate it for polynomial functions, but also how to know second derivatives, positive and negative curvature, and criterions

\footnotetext{
${ }^{1}$ In the case of parabolas, vertical straight lines (with the equation $x=a, a \in \mathbb{R}$ ) should be examined to see that exactly one point in common is not sufficient for a tangent.

${ }^{2}$ With 'school' we mean the level at which students get to know calculus the first time (high school or secondary school; note this is different in other countries).
} 
that are used in curve sketching etc. EVP are then dealt with as an application of the learned techniques while dealing with curve sketching problems. Therefore, in most cases the second derivative is used when solving EVP.

These steps are quite elaborate and time-consuming for students to learn and achieve before considering EVP, thus we propose a more efficient way of reaching the same goal. Let us consider some typical problems:

- Solving EVP means to calculate global maxima or minima. In curve sketching, one must consider all the local decisions (which of the 'critical points' are local maxima or minima?). We must distinguish between these aspects more precisely (also at school level).

- EVP can only be introduced at a late stage in the curriculum of differential calculus (one requires knowledge concerning curve sketching); however extreme values offer new and motivating perspectives - not only for students (Guinness World Records) - that should be used at a previous stage. Increasing motivation in an early phase of differential calculus is definitely desirable, since it is beneficial for teaching concepts in calculus.

- Nowadays, the 'classical way' of curve sketching (i.e. the graph at the end is the aim) is not a good motivation for differential calculus as computers do a better and quicker job in plotting graphs of functions.

- There is missing rigor in using the second derivative. Students often implicitly/explicitly conclude: "I have found a (local) maximum, therefore this must be the solution of the EVP (meant: global maximum) - I have even checked the situation with the second derivative." But the second derivative can provide only local decisions. At this point, many false conclusions are made and in particular the values on the boundary are ignored. Also when avoiding the second derivative and focusing on does $f^{\prime}$ change its sign at a point? one has the same problem-this leads to only local decisions not global ones.

- There is also missing clarity hidden in this way: involving the second derivative is not very clear to many students, since students have difficulties in understanding its concept.

The 'usual method' at school for solving EVP is: (1) Knowing what the zeros of the first derivative ('critical points') are; (2) one can then decide which of these critical points lead to local maxima or local minima with the help of the second derivative; and (3) the 'conclusion' is made, the minimum/maximum calculated is the solution of the EVP. However, such an argumentation is wrong in the general case, for instance, as it can be observed when dealing with polynomials of degree 3 (quite popular in school mathematics, see Fig. 2.13), because the global maximum or minimum of such polynomials is at the boundary of the interval.

We propose another way for solving EVP (differentiable function $f$, closed interval $[a, b])$ : (1) What are the zeros of $f^{\prime}$ ('critical points'; finitely many ${ }^{3}: x_{1}, \ldots x_{n}$ ?). This first item is the equivalent to the first one described in the 'usual method' above; (2)

\footnotetext{
${ }^{3}$ This is the case with usual problems at school, therefore it is not a major restriction.
} 
Fig. 2.13 EVP solutions at the boundaries of the interval $[a, b]$

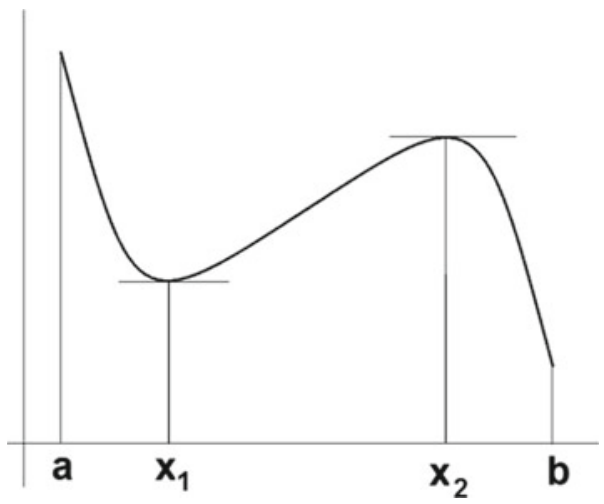

calculate the function values $f(a), f\left(x_{1}\right), \ldots, f\left(x_{n}\right)$; and (3) the smallest of these values is the solution of the minimum problem, the biggest of the maximum problem.

\section{Advantages of this method:}

- The second derivative is not needed

- This method offers better clarity and understanding of EVP among students

- Furthermore, the method is more strict and precise (the consideration of the boundary is deeply integrated in the method; one can hardly skip it)

- This method can be used at an early stage in the curriculum of differential calculus. As soon as students can differentiate polynomials, they can work on several problems (also involving functions like $\sqrt{f}, \frac{1}{f}, \exp (f), \log (f), \ldots$ where $f$ is a polynomial).

EVP and Curve sketching can be seen as different items (local decisions are not relevant in EVP), therefore the corresponding techniques should be different. In case of open intervals, the corresponding limits $\lim _{x \rightarrow a(b, \infty)} f(x)$ must be calculated instead of $f(a)$ and $f(b)$. But in most cases this method is still easier than involving the second derivative.

Only in the specific situation 'there is only one zero $x_{0}$ of $f^{\prime}$ ' the conclusion

$$
\text { 'local minimum at } x_{0} \Rightarrow \text { minimum at } x_{0} \text { ' }
$$

is correct. One would have to think about this 'theorem (1)' more deeply, but this is usually not the case when students apply (2.1), therefore this conclusion is rather critical.

We think the role of EVP should be changed (in the differential calculus curricula at school) with regards to three aspects:

- More emphasis on EVP (as a major important aspect of differential calculus, with high potential for motivation).

- Earlier (in the curriculum of differential calculus) emphasis, without the second derivative. 
Fig. 2.14 Graphical reasoning for the theorems

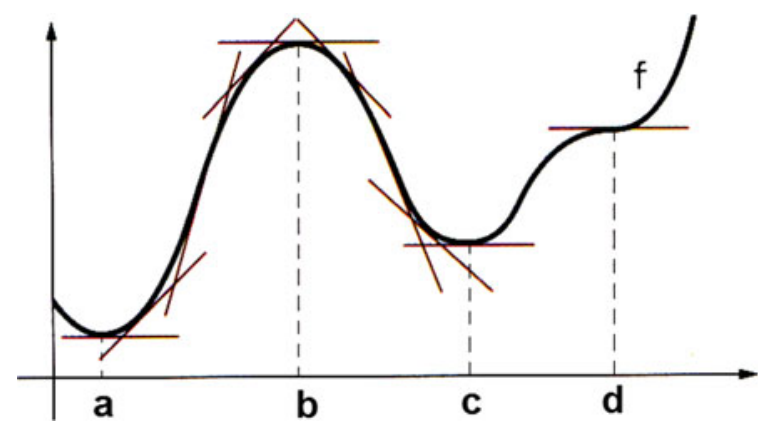

- EVP are not only an application of curve sketching techniques; there should be a further distinction between.

(i) local and global maxima/minima (ii) open and closed intervals.

\section{The Role of the 'Monotonicity Theorem for Intervals'}

Monotonicity theorem for intervals $I$ :

$$
f^{\prime}(x)>0 \forall x I \Rightarrow f \text { is strictly increasing in } I
$$

Why is this theorem important at school?

The core of curve sketching at school can be described using four steps:

1. Find the local minima and maxima

2. Find the points of inflection

3. Find the intervals of monotonicity

4. Find the intervals of positive and negative curvature.

With the information of points 1-4 above, one can sketch the graph of a function. What are the crucial (underlying) theorems?

In points 1 and 2 , the crucial theorem is: If $f$ (differentiable) has an inner local maximum/minimum at $x$, then $f^{\prime}(x)=0$. In points 3 and 4 , the crucial theorem is the monotonicity theorem (above). These two theorems are very often used at school level (although this may happen only implicitly rather than explicitly), particularly in curve sketching problems and EVP. Let us consider possible ways of introducing the content of these theorems at school level. First, one could argue only graphically (see Fig. 2.14), i.e. one can perceive the theorem's statements in the figure. Such reasoning is probably vivid and clear to students but of course lacks precision.

What is the usual way of arguing at university level (for the monotonicity theorem for intervals)? The proof relies mostly on:

(1) Intermediate value theorem for continuous functions

(2) Extreme value theorem for continuous functions

(3) Rolle's theorem

(4) Mean value theorem. 
Fig. 2.15 Non positive slope

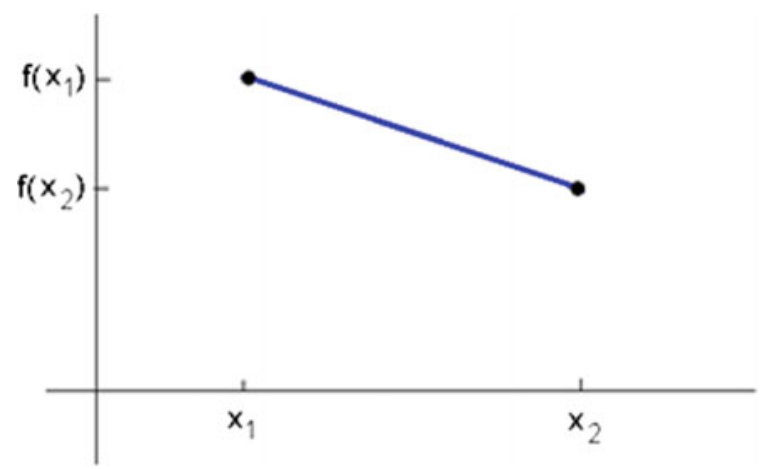

This way of argumentation is highly precise and abstract, hence it is obvious that it cannot be applied at school level (too theoretical; the concept of 'continuity' is not that important at school-often it comes even after dealing with derivatives, making things more precise after having dealt with them on a somehow intuitive level). The question is: Is there something 'in between'? And the answer is: Yes, for the theorem that $f^{\prime}$ vanishes at positions of an inner local maximum/minimum the methods are well known. Regarding the 'monotonicity theorem', there is a good possibility to show the idea of a proof (see Danckwerts and Vogel 2005, 59ff). In this case, the principle of nested intervals is needed and it emphasizes the fact that the whole content of calculus requires the completeness of the reals. This method of finding arguments would be a reasonable compromise between clarity and rigor: The argumentation is not only graphical (also on a somehow theoretical but elementary level); if it is undertaken this way, the monotonicity theorem for intervals is not just a corollary of other theorems (unproven at school), but it serves as a core theorem for argumentation.

\section{Idea of a proof of (2):}

We argue indirectly and assume that $f$ is not strictly increasing in $I$. Then points $\left(x_{1} \mid f\left(x_{1}\right)\right)$ and $\left(x_{2} \mid f\left(x_{2}\right)\right)\left(x_{1,2} \in I ; x_{1}<x_{2}\right)$ exist so that the slope of the connective straight line is not positive (Fig. 2.15).

Then regardless of $f\left(\frac{x_{1}+x_{2}}{2}\right)$, at least one of the corresponding slopes in the lefthand half and in the right-hand half of the interval $\left[x_{1}, x_{2}\right]$ is also not positive (see Fig. 2.16; because if both were positive also the 'total slope' in Fig. 2.3 would also be positive).

Under the consideration of the above aspects, the idea of the proof can be outlined. By using continuous bisection of the intervals, one gets a sequence of connective straight lines with a non-positive slope. The principle of nested intervals yields a point $x_{0} \in I$ (completeness of $\mathbb{R}$ !). At this point, the derivative $f^{\prime}\left(x_{0}\right)$ cannot be positive because a sequence of not positive values cannot come 'arbitrarily near' to a positive one. But this is leads to a contradiction concerning the precondition of 
Fig. 2.16 Bisection of the interval

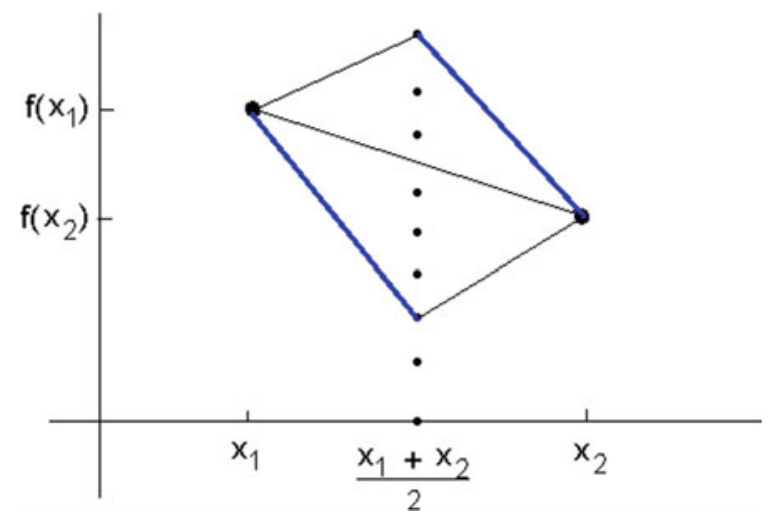

theorem (2): $f^{\prime}\left(x_{0}\right)>0$ for all $x \in I$. A more detailed proof with basically the same idea can be found in Greefrath et al. (2016), p. 196.

\subsection{Conclusion}

In these two chapters, we provided two selected examples about how calculus courses at school can be different from calculus courses at university. Of course, the level of rigor at schools cannot be the same as at universities. In this case, we do not only mean the frequency or depth of formal proofs, but emphasize primarily the way of approaching important items of calculus (theorems, applications, etc.) that are needed at school - for instance the theorems (1) and (2) and solving EVP.

\section{References}

Blum, W. (2000). Perspektiven für den Analysisunterricht. Der Mathematikunterricht, 46(4/5), $5-17$.

Blum, W., \& Kirsch, A. (1979). Zur Konzeption des Analysisunterrichts in Grundkursen. Der Mathematikunterricht, 25(3), 6-24.

Blum, W., \& Kirsch, A. (1991). Preformal proving: Examples and reflections. Educational Studies in Mathematics, 22(2), 183-203.

Blum, W., \& Leiß, D. (2007). How do students and teachers deal with modelling problems? In C. Haines, et al. (Eds.), Mathematical modelling: Education, engineering and economics (pp. 222-231). Chichester: Horwood.

Blum, W., \& Törner, G. (1983). Didaktik der analysis. Göttigen: Vandenhoeck \& Ruprecht.

Burscheid, H. J. (2003). Entwicklung der Disziplin Mathematikdidaktik. Zentralblatt für Didaktik der Mathematik, 35(4), 146-152.

Clarke, D., Clarke, B., \& Roche, A. (2011). Building teachers' expertise in understanding, assessing and developing children's mathematical thinking: The power of task-based, one-to-one assessment interviews. ZDM - The International Journal on Mathematics Education, 43(6-7), 901-913. 
Danckwerts, R., \& Vogel, D. (2005). Elementare analysis. Norderstedt: Books on Demand.

Damerow, P. (1977). Die Reform des Mathematikunterrichts in der Sekundarstufe I. Vol. 1: Reformziele, Reform der Lehrpläne. Stuttgart: Klett.

Drenckhahn, F. (1952/1953). Zur Didaktik der Mathematik und ihrer Wissenschaftsmethodik. Der mathematische und naturwissenschaftliche Unterricht, 5, 205-211. Reprinted in H.-G. Steiner (Ed.) (1978). Didaktik der Mathematik (pp. 3-18). Darmstadt: Wissenschaftliche Buchgesellschaft.

Duval, R. (1999). Representation, vision and visualization: Cognitive functions in mathematical thinking. basic issues for learning. https://pdfs.semanticscholar.org/652a/ 63fa9fb29130ed14b184a1e84a83cf809198.pdf?_ga=2.244464579.751390522.1526548407960559693.1523448248. Accessed May 2018.

Fischbein, E. (1987). Intuition in science and mathematics: An educational approach. Dordrecht: D. Reidel.

Fischbein, E. (1989). Tacit models and mathematic reasoning. For the Learning of Mathematics, 9(1), 9-14.

Fischbein, E., Tirosh, D., Stavy, R., \& Oster, A. (1990). The autonomy of mental models. For the Learning of Mathematics, 10(1), 23-30.

Fuson, K. C. (1988). Children's counting and concepts of number. New York: Springer.

Gerlach, M. (2007). Entwicklungsaspekte des Rechnenlernens: Fördermöglichkeiten bei beeinträchtigtem Erwerb mathematischer Kompetenzen im Grundschulalter. Saarbrücken: Südwestdeutscher Verlag für Hochschulschriften.

Greefrath, G., Oldenburg, R., Siller, H.-St., Ulm, V., \& Weigand, H.-G. (2016): Didaktik der Analysis. Berlin, Heidelberg: Springer.

Griesel, H. (1968). Eine Analyse und Neubegründung der Bruchrechnung. MathematischPhysikalische Semesterberichte, 15(1), 48-68.

Griesel, H. (1974). Überlegungen zur Didaktik der Mathematik als Wissenschaft. Zentralblatt für Didaktik der Mathematik, 6(3), 115-119.

Hasemann, K. (1981). On difficulties with fractions. Educational Studies in Mathematics, 12(1), $71-87$.

Hasemann, K. (1997). Verständnis und Rechenfertigkeit: Ist die Bruchrechnung angesichts von Computeralgebrasystemen noch zeitgemäß? Mathematik in der Schule, 35(1), 7-18.

Hefendehl-Hebeker, L. (2016). Subject-matter-didactics in German traditions. Early historical developments. Journal für Mathematik-Didaktik, 37(Suppl. 1), 11-31.

Hope, J. A., \& Owens, D. T. (1987). An analysis of the difficulty of learning fractions. Focus on Learning Problems in Mathematics, 9(4), 25-40.

Hußmann, S., \& Prediger, S. (2016). Specifying and structuring mathematical topics. A four-levelapproach for combining formal, semantic, concrete and empirical levels exemplified for exponential growth. Journal für Mathematik-Didaktik, 37(Suppl. 1), 33-67.

Janvier, C. (1987). Representation and understanding: The Notion of function as example. In C. Janvier (Ed.), Problems of representation in the teaching and learning of mathematics (pp. 67-71). Hillsdale, N.J. [u.a.]: Erlbaum.

Kirsch, A. (1969). Eine Analyse der sogenannten Schlussrechnung. Mathematisch-Physikalische Semesterberichte, 16(1), 41-55.

Kirsch, A. (1976a). Vorschläge zur Behandlung von Wachstumsprozessen und Exponentialfunktionen im Mittelstufenunterricht. Didaktik der Mathematik, 4(4), 257-284.

Kirsch, A. (1976b). Eine ,intellektuell ehrliche“ Einführung des Integralbegriffs in Grundkursen. Didaktik der Mathematik, 4(2), 87-105.

Kirsch, A. (1977). Aspects of simplification in mathematics teaching. In Athen, H. \& Kunle, H. (Eds), Proceedings of the Third International Congress on Mathematical Education (pp. 98-120). Karlsruhe: Zentralblatt für Didaktik der Mathematik.

Kirsch, A. (1979). Ein Vorschlag zur visuellen Vermittlung einer Grundvorstellung vom Ableitungsbegriff. Der Mathematikunterricht, 25(3), 25-41.

Kirsch, A. (1987). Mathematik wirklich verstehen. Köln: Aulis Deubner. 
Kirsch, A. (1996). Der Hauptsatz - anschaulich? mathematik lehren, Heft 78, 55-59.

Klein, F. (1904). Über eine zeitgemäße Umgestaltung des Mathematikunterrichts an höheren Schulen. In F. Klein \& E. Riecke (Eds.), Neue Beiträge zur Frage des mathematischen und physikalischen Unterrichts an höheren Schulen (pp. 1-32). Leipzig, Berlin: Teubner.

Klein, F. (1968). Elementarmathematik vom höheren Standpunkte aus. 3rd Edition, 1st Volume: Arithmetik, Algebra, Analysis 1933; 2nd Volume: Geometrie 1925; 3rd Volume: Präzisionsund Approximationsmathematik 1928. Berlin: Springer. A complete English translation entitled Elementary Mathematics from a Higher Standpoint appeared by Springer 2016.

Kleine, M., Jordan, A., \& Harvey, E. (2005). With a focus on 'Grundvorstellungen'. Part 1: A theoretical integration into current concepts. Zentralblatt für Didaktik der Mathematik, 37(3), 226-233.

KMK. (1968). Empfehlungen und Richtlinien zur Modernisierung des Mathematikunterrichts an den allgemeinbildenden Schulen. In H. Meschkowski (Ed.), Mathematik-Duden für Lehrer (pp. 483-495). Mannheim: BI.

Krüger, K. (1999). Erziehung zum funktionalen Denken - Zur Begriffsgeschichte eines didaktischen Prinzips. Berlin: Logos.

Kühnel, J. (1916). Neubau des Rechenunterrichts - Ein Handbuch der Pädagogik für ein Sondergebiet. Leipzig: Klinkhardt.

Kuhnke, K. (2013). Vorgehensweisen von Grundschulkindern beim Darstellungswechsel: Eine Untersuchung am Beispiel der Multiplikation im 2. Schuljahr. Wiesbaden: Springer.

Lietzmann, W. (1923). Methodik des mathematischen Unterrichts. 2. Teil: Didaktik der einzelnen Gebiete des mathematischen Unterrichts (2nd ed.). Leipzig: Quelle \& Mayer.

Lindmeier, A. (2011). Modeling and measuring knowledge and competencies of teachers. A threefold domain-specific structure model for mathematics. Münster: Waxmann.

Lorenz, J. H. (1998). Anschauung und Veranschaulichungsmittel im Mathematikunterricht: Mentales visuelles Operieren und Rechenleistung (2nd ed.). Göttingen: Hogrefe.

Mack, N. K. (1995). Confounding whole-number and fraction concepts when building on informal knowledge. Journal for Research in Mathematics Education, 26(5), 422-441.

Müller, G., \& Wittmann, E. C. (1984). Der Mathematikunterricht in der Primarstufe (3rd ed.). Brauschweig, Wiesbaden: Vieweg.

Oehl, W. (1962). Der Rechenunterricht in der Grundschule. Hannover: Schroedel.

Oehl, W. (1965). Der Rechenunterricht in der Hauptschule. Hannover: Schroedel.

Padberg, F., \& Benz, C. (2011). Didaktik der Arithmetik (4th ed.). Heidelberg: Spektrum Akademischer Verlag.

Padberg, F., \& Wartha, S. (2017). Didaktik der Bruchrechnung. Heidelberg: Spektrum.

Padberg, F., Danckwerts, R., \& Stein, M. (2001). Zahlbereiche: Eine elementare Einführung. Heidelberg: Spektrum Akademischer Verlag.

Posner, G. J., Strike, K. A., Hewson, P. W., \& Gertzog, W. A. (1982). Accommodation of a scientific conception: Towards a theory of conceptual change. Science Education, 66, 211-227.

Prediger, S. (2008). The relevance of didactic categories for analysing obstacles in conceptual change: Revisiting the case of multiplication of fractions. Learning and Instruction, 18(1), 3-17.

Prediger, S. (2011). Why Johnny can't apply multiplication? Revisiting the choice of operations with fractions. International Electronic Journal of Mathematics Education, 6(2), 65-88.

Resnick, L. B. (1989). Developing mathematical knowledge. American Psychologist, 44, 162-169.

Rottmann, T., \& Schipper, W. (2002). Das Hunderterfeld: Hilfe oder Hindernis beim Rechnen im Zahlenraum bis 100? Journal für Mathematik-Didaktik, 23(1), 51-74.

Sayers, J., Andrews, P., \& Björklund Boistrup, L. (2016). The role of conceptual subitising in the development of foundational number sense. In T. Meaney, O. Helenius, M. L. Johansson, T. Lange, \& A. Wernberg (Eds.), Mathematics education in the early years (pp. 371-396). Cham: Springer.

Schipper, W. (2009). Handbuch für den Mathematikunterricht an Grundschulen. Braunschweig: Schroedel. 
Schipper, W., Wartha, S., \& Schroeders, N. (2011). BIRTE 2 - Bielefelder Rechentest für das 2. Schuljahr. Braunschweig: Schroedel.

Schubring, G. (2012). Antagonism between German states regarding the status of mathematics teaching during the 19th century: Processes of reconciling them. ZDM-The International Journal on Mathematics Education, 44(4), 525-535.

Schubring, G. (2014). The road not taken-The failure of experimental pedagogy at the Royaumont Seminar 1959. Journal für Mathematik-Didaktik, 35(1), 159-171.

Schulz, A. (2014). Fachdidaktisches Wissen von Grundschullehrkräften: Diagnose und Förderung bei besonderen Problemen beim Rechnenlernen. Heidelberg: Springer.

Schulz, A. (2018). Zur Sache bitte - Einige Gedanken zur Rolle des Sachrechnens in der Grundschule. Fördermagazin Grundschule, 40(4), 5-8.

Selter, C. (2000). Vorgehensweisen von Grundschüler(innen) bei Aufgaben zur Addition und Subtraktion im Zahlenraum bis 1000. Journal für Mathematikdidaktik, 21(2), 227-258.

Selter, C., Prediger, S., Nührenbörger, M., \& Hußmann, S. (2012). Taking away and determining the difference: A longitudinal perspective on two models of subtraction and the inverse relation to addition. Educational Studies in Mathematics, 79, 389-408.

Söbbeke, E. (2005). Zur visuellen Strukturierungsfähigkeit von Grundschulkindern: Epistemologische Grundlagen und empirische Fallstudien zu kindlichen Strukturierungsprozessen mathematischer Anschauungsmittel. Hildesheim: Franzbecker.

Söbbeke, E., \& Steinbring, H. (2007). Anschauung und Sehverstehen: Grundschulkinder lernen im Konkreten das Abstrakte zu sehen und zu verstehen. In J. H. Lorenz \& W. Schipper (Eds.), Hendrik Radatz: Impulse für den Mathematikunterricht. Schroedel: Braunschweig.

Stern, E. (1998). Die Entwicklung des mathematischen Verständnisses im Kindesalter. Lengerich: Pabst Science Publ.

Tall, D., \& Vinner, S. (1981). Concept image and concept definition in mathematics with particular reference to limits and continuity. Educational Studies in Mathematics, 12(2), 151-169.

Tirosh, D., \& Stavy, R. (1999). Intuitive rules: A way to explain and predict student's reasoning. Educational Studies in Mathematics, 38(1), 51-66.

Usiskin, Z. (2008). The arithmetic curriculum and the real world. In D. de Bock, B. D. Sondergaard, B. G. Alfonso, \& C. C. L. Cheng (Eds.), Proceedings of ICME-11-Topic Study Group 10 (pp. 9-16). Monterrey, Mexico.

Vosniadou, S., \& Verschaffel, L. (2004). Extending the conceptual change approach to mathematics learning and teaching. Learning and Instruction, 14, 445-451.

Vollrath, H.-J. (1974). Didaktik der Algebra. Stuttgart: Klett.

Vollrath, H.-J. (1993). Paradoxien des Verstehens von Mathematik. Journal für MathematikDidaktik, 14(1), 35-58.

Vollrath, H.-J. (2007). Towards an authentic teaching of mathematics: Hans-Georg Steiner's contribution to the reform of mathematics teaching. ZDM-The International Journal on Mathematics Education, 39(1), 39-50.

vom Hofe, R. (1995). Grundvorstellungen mathematischer Inhalte. Texte zur Didaktik der Mathematik. Berlin: Spektrum Akademischer Verlag.

vom Hofe, R. (1998). On the generation of basic ideas and individual images: Normative, descriptive and constructive aspects. In: J. Kilpatrick \& A. Sierpinska (Eds.) Mathematics education as a research domain: A search for identity (pp. 317-331). Dordrecht: Kluver Academic Publishers. vom Hofe, R., \& Blum, W. (2016). „Grundvorstellungen“ as a category of subject—matter didactics. Journal für Mathematik - Didaktik, 37(Suppl. 1), 225-254.

Wartha, S. (2009). Zur Entwicklung des Bruchzahlbegriffs - Didaktische Analysen und empirische Befunde. Journal für Mathematikdidaktik, 30(1), 55-79.

Wartha, S., \& Benz, C. (2015). Rechnen mit Übergängen. Mathematik lehren, 192, 8-13.

Wartha, S., \& Schulz, A. (2012). Rechenproblemen vorbeugen: Grundvorstellungen aufbauen: Zahlen und Rechnen bis 100 (1st ed.). Berlin: Cornelsen.

Wessel, J. (2015). Grundvorstellungen und Vorgehensweisen bei der Subtraktion. Wiesbaden: Springer. 
Winter, H. (1983). Zur Problematik des Beweisbedürfnisses. Journal für Mathematik-Didaktik, 4(1), 59-95.

Wittmann, E. C. (1989). The mathematical training of teachers from the point of view of education. Journal für Mathematik-Didaktik, 10, 291-308.

Wittmann, E. C. (1995). Mathematics education as a "design science". Educational Studies in Mathematics, 29(4), 355-379.

Wittmann, E. C. (2012). Das Projekt "mathe 2000": Wissenschaft für die Praxis - eine Bilanz aus 25 Jahren didaktischer Entwicklungsforschung. In G. N. Müller, C. Selter, \& E. Ch. Wittmann (Eds.), Zahlen, Muster und Strukturen. Spielräume für aktives Lernen und Üben (pp. 265-279). Stuttgart: Klett.

Wittmann, J. (1939). Ganzheitliches Rechnen. Dortmund: Crüwell.

Open Access This chapter is licensed under the terms of the Creative Commons Attribution 4.0 International License (http://creativecommons.org/licenses/by/4.0/), which permits use, sharing, adaptation, distribution and reproduction in any medium or format, as long as you give appropriate credit to the original author(s) and the source, provide a link to the Creative Commons licence and indicate if changes were made.

The images or other third party material in this chapter are included in the chapter's Creative Commons licence, unless indicated otherwise in a credit line to the material. If material is not included in the chapter's Creative Commons licence and your intended use is not permitted by statutory regulation or exceeds the permitted use, you will need to obtain permission directly from the copyright holder. 


\title{
Chapter 3 \\ Design Science and Design Research: The Significance of a Subject-Specific Research Approach
}

\author{
Marcus Nührenbörger, Bettina Rösken-Winter, Michael Link, \\ Susanne Prediger and Anna Susanne Steinweg
}

\begin{abstract}
Considering mathematics education as a DESIGN SCIENCE has strong roots in Germany. E. Ch. Wittmann in particular contributed to the establishment of this approach. From a DESIGN SCIENCE perspective, substantial learning environments play a crucial role. They comprise mathematical tasks which are connected in an operative way, indicative of a specific epistemological structure. In such substantial learning environments, students are actively immersed in learning mathematics, and the learning environments allow for the pursuit of individual and differentiated learning processes. In this chapter, we first address the scope of Design Science and pay attention to characteristics of the learning environments and how teaching experiments can be conducted. We then focus on key ideas and their role as a design principle. In the next section, we provide a comprehensive example of designing a learning environment. Lastly, we shift our attention to the Design Research approach, which complements designing substantial learning environments by empirically studying the initiated learning processes to gain evidence for both theoretical considerations and design principles.
\end{abstract}

Keywords Design science $\cdot$ Learning environments $\cdot$ Teaching experiments • Learning processes $\cdot$ Key ideas

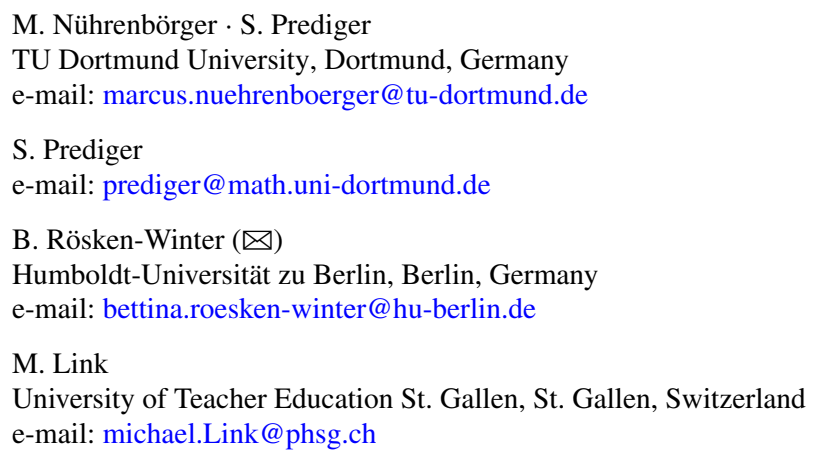

\section{A. S. Steinweg}

University of Bamberg, Bamberg, Germany

e-mail: anna.steinweg@uni-bamberg.de 


\subsection{Introduction}

DESIGN SCIENCE is a research approach with strong roots in Germany. This applies specifically for the research approach advocated in Dortmund by Wittmann and Müller (1990), assigning a central role to so-called substantial learning environments. Particularly, Wittmann (1995) outlined how these can be a starting point to establish mathematics education as a scientific field in its own right. That is, exploring the epistemological structure reflected in such learning environments or reflecting didactical principles while testing the learning environments in practice adds to a deeper understanding of both the mathematics involved and students' learning processes. Of course, there have been similar trends in Germany. Some researchers, for instance, focused on specifying and fostering 'Grundvorstellungen' ('basic ideas', see Chap. 1) and informal proving (Kirsch 1978; Blum and Kirsch 1991) or cognitive aspects of mathematical learning environments (Cohors-Fresenborg 1993). These various approaches share the responsibility for designing learning environments, testing them in practice and drawing consequences for a partial redesign. All kept a strong emphasis on the mathematical learning content rather than on generic pedagogical issues only, and all contributed to elaborating 'design principles', serving as a theoretical background for a research-based design.

In this chapter, we present the traditional 'Dortmund approach' of DESIGN SCIENCE with its focus on substantial learning environments as well as more recent developments towards Design Research.

First, Marcus Nührenbörger and Bettina Rösken-Winter discuss how the theoretical orientations of DESIGN SCIENCE are reflected in Wittmann's work, especially in the DESIGN SCIENCE project, 'mathe 2000'. By doing so, they focus on developments that are close to Wittmann's approach and have led to modifications in terms of research approaches containing collaborative and iterative designs or designing learning environments along with developing theories (Sect. 3.2). In the following contribution (Sect. 3.3), Anna Susanne Steinweg points out key ideas as a framework for designing substantial learning environments in relation to a spiral curriculum. The key ideas serve as design principles as well as guiding principles for classroom interaction. In Sect. 3.4, Michael Link presents an example of designing and examining a substantial learning environment ("number patterns in operative structured sequences of addition in grade 3"). After outlining different stages of developing such substantial learning environments, we discuss the resulting products (learning activities for students). This project already marks a partial shift as it combines elements of DESIGN SCIENCE, the original approach pursued by Wittmann, and design research, having a greater orientation towards empirically substantiating the initiated learning processes. Finally, in the last Sect. 3.5 Susanne Prediger reports on current strands of developing DESIGN SCIENCE into approaches of Design Research, with their stronger emphasis on empirical investigations. Design Research aims explicitly at gaining deep insights into teaching-learning processes, and local theories underpinning the observed learning processes, for classrooms as well as for professionalization and scaling up processes. 


\subsection{Scope of Design Science: Learning Environments and Teaching Experiments}

Advocating 'mathematics education as a DESIGN SCIENCE', E. Ch. Wittmann elaborated on constructing and investigating learning environments. From their very nature, such learning environments contain substantial mathematical contents. These allow, on the one hand, for the exploration of the epistemological structure in depth, and on the other hand, the reflection of didactical principles while testing substantial learning environments in practice, which adds to a deeper understanding of both the mathematics involved and students' learning processes. Thus, for Wittmann "the design of substantial learning environments around long-term curricular strands should be placed at the very center of mathematics education. Research, development and teacher education should be consciously related to them in a systematic way" (Wittmann 2001a, p. 4). Respectively, mathematics education has been conceptualized as a constructive scientific discipline that has contributed teaching concepts, units, examples, and materials. The main objective has been to develop feasible designs for conceptual and practical innovations, involving the teachers actively in any design process. In the following sections, we briefly explore the roots of DESIGN SCIENCE (Sect. 3.2.1), elaborate on the role of substantial learning environments (Sect. 3.2.2), and finally pay attention to the design of teaching experiments (Sect. 3.2.3). For a more detailed discussion of DESIGN SCIENCE and its relation to other European strands in mathematics education, we refer to Akinwunmi et al. (2016).

\subsubsection{Roots of DESIGN SCIENCE}

The fundamental scope of mathematics education has been the initiation and support of the deep mathematical learning processes of students. Therefore, one important research approach is aimed at designing learning environments, exploring the induced learning processes, and deriving fundamental design principles. In the Germanspeaking tradition, the notion of DESIGN SCIENCE is closely connected with Wittmann (1995), who has emphasized and elaborated this research approach over the past decades. The careful analysis of the mathematical substance and the potentials of mathematical structures within the specific designs have played a prominent role. In this regard, the concept of DESIGN SCIENCE is embedded in the German Stoffdidaktik tradition (cf. the respective chapter in this book). Describing "the specific status and the relative autonomy of mathematics education", Wittmann (1995, p. 355) pointed out that mathematics education on the one hand differs essentially from pure mathematics, and on the other hand is not simply a conglomerate discipline of mathematics involving related sciences such as psychology, sociology, or pedagogy. Rather, this 'research approach' is characterized as an applied approach whose core task is to develop practical, constructive products of acknowledged quality for 
teaching mathematics. Thus, this core task encompasses many different components such as analysing mathematical activities and related mathematical thinking, as well as developing local theories on mathematising or problem solving, to name but a few (Wittmann 1995).

DESIGN SCIENCE, according to Wittmann (1995), deals with the artificial objects of mathematics teaching (i.e., with exercises as well as specific mathematics learning and teaching processes) and adapts these constructively with a view to further developing mathematics education. The focus on designing for teaching and learning has already been referred to in former times as, for instance, by Simon (1970) who distinguished between 'artificial sciences' and 'natural sciences' as follows:

\footnotetext{
Historically and traditionally, it has been the task of the science disciplines to teach about natural things; how they are and how they work. It has been the task of engineering schools to teach about artificial things: how to make artefacts that have desired properties and how to design. (Simon 1970, p. 55)
}

In this sense, artificial sciences develop and study artificial objects that are in principle adaptable and can be changed with reference to specific objectives or functions. In 2005, Lesh and Sriraman still called for re-conceptualizing "the field of mathematics education research as that of a design science akin to engineering and other emerging interdisciplinary fields which involve the interaction of 'subjects', conceptual systems, and technology influenced by social constraints and affordances" (p. 490). However, optimising how mathematics is taught in the classroom and developing practical aids for teachers has been pursued by researchers over the past decades, employing design research with different foci (Gravemeijer and Cobb 2006; Lesh and Sriraman 2005; Hußmann and Prediger 2016; Ruthven et al. 2009; van den Akker et al. 2006).

\subsubsection{Characteristics of Substantial Learning Environments}

Wittmann and Müller (1990) concentrated their design efforts on what they called substantial learning environments, as this focus allows different aspects of several disciplines (like psychology, sociology or pedagogy) relevant for teaching and learning mathematics to be integrated (Wittmann 1995). From their perspective, students' learning is an active process, assigning particular relevance to pedagogical theories and methods of social learning.

The term 'substantial learning environment' refers to mathematical tasks which are connected in an operative way. That is, a focus on mathematical structures sets the frame for students to learn mathematics in an active and cooperative way. Therefore, the tasks are adapted to the level of learners' thinking and offer different learning ways for the students. In this sense, learning environments are open for individual and differentiated learning processes. The inherent structures of learning environments induce impulses for students' comprehensive learning processes. By referring to the educational philosophy of Dewey (2008), Wittmann points out that the logically 
ordered mathematical content is the basis used to describe the earlier and later stages of a single developmental learning process. For teaching mathematics, this process has to be viewed from two directions as aptly outlined below:

From the side of the child, it is a question of seeing how his experience already contains within itself elements facts and truths of just the same sort as those entering into the formulated study; and, what is of more importance, of how it contains within itself the attitudes, the motives, and the interests which have operated in developing and organizing the subjectmatter to the plane which it now occupies. From the side of the studies, it is a question of interpreting them as outgrowths of forces operating in the child's life, and of discovering the steps that intervene between the child's present experience and their richer maturity. (Dewey 1966, p. 11)

With respect to mathematics, the following core characteristics of substantial learning environments reflect these thoughts:

- They represent fundamental objectives, contents, and principles of mathematical learning at a particular level.

- They are based on fundamental mathematical content, processes, and procedures beyond this level and contain a wealth of mathematical problems ('exercises').

- They can be flexibly tailored to the specific conditions of a particular class.

- They integrate mathematical, psychological, and educational aspects of mathematics teaching and learning and therefore provide a rich field for empirical research

- (Wittmann 2001a, p. 2).

In order to design substantial learning environments, Wittmann (1995) considers the mathematical substance of the exercise, or in other words the 'epistemological structure of the topic', to be of particular importance. The latter provides the basis of composing mathematical activities for children at very different ages and levels. However, the mathematical substance does not appear as the systematic deductive structure of already 'finished' mathematics. Rather, it recalls Freudenthal's ideas and helps with the understanding of mathematics from a learner's perspective on the subject.

Classical substantial learning environments are, for example, arithmogons or number walls (Fig. 3.1).

The rules for calculating within the number wall or the arithmogon are very simple: Add the numbers of two adjacent fields and write the sum in the field above (number wall) respectively outside of the corresponding side (arithmogon). Based on

Fig. 3.1 An arithmogon (Wittmann 2001b, p. 193) and a number wall
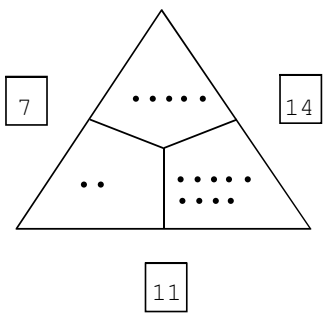

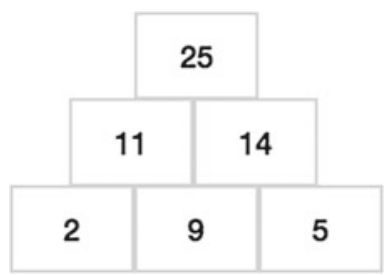


the mathematical substance of these two exercises, substantial learning environments that vary in their focus of initiating deep learning of mathematics can be developed (see Fig. 3.2).

For example, one can find different problems for adding and subtracting numbers within the triangle by offering different numbers inside and/or on the outside of the triangle. The operational structure of the arithmogons can be examined by changing the entries in the fields systematically (see Fig. 3.3). In this sense, the sequence of tasks and problems can arise naturally from the mathematical substance of the context.

While the epistemological structure of the subject offers an essential orientation for evaluating learning environments, the creative act of designing new learning environments ultimately is not explicitly comprehensible and explainable. This depends mainly on the 'constructive imagination' of the designer (Wittmann 1995). Nonetheless, according to Wittmann (2015), the following characteristics provide orientation for developing substantial learning environments: mathematical substance and richness of activities at different levels, assessment of cognitive demands, curricular fit (in terms of content and general learning objectives), curricular coherence and consistency, curricular coverage, exercise potential, and the estimation of the time required. Ultimately, mathematics education considered as a DESIGN SCIENCE is a creative science, based on the solid knowledge of fundamental mathematical structures and processes combined with the profound knowledge of children's learning, professional learning requirements, and objectives of mathematics teaching, also with a reference to curricular frameworks.

For Wittmann (2001b), substantial learning environments are conducted as teaching experiments, which do not encompass complete and detailed lesson units. Instead, to learners substantial learning environments are revealed as a space for error and discovery as well as a path of their own learning.

Fig. 3.2 The algebraic structure of an arithmogon and a number wall
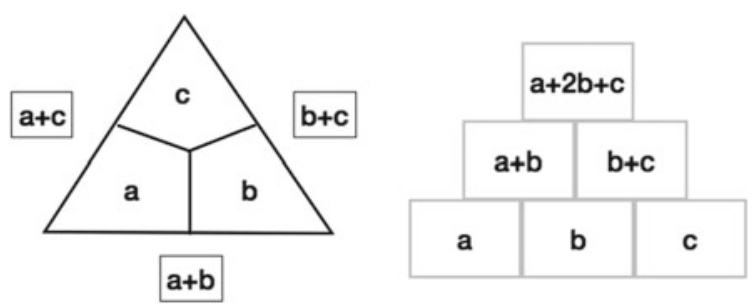

Finde passende Zahlen. Wie viele Möglichkeiten?

(a)

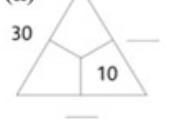

(b)

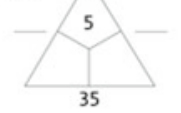

(c)

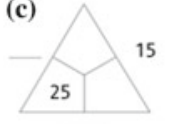

Wie ändern sich die Außenzahlen? Finde die Innenzahlen.

(a)
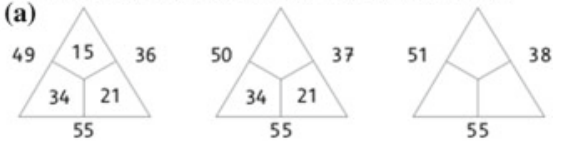

Fig. 3.3 Variations of problems: 'Find the suitable numbers. How many possibilities?' and 'The outside numbers are changing. Find the inside numbers' (Nührenbörger and Schwarzkopf 2017) 


\title{
3.2.3 Conducting Teaching Experiments for Improving the Design
}

The quality of the learning environments developed by Wittmann has been continuously reviewed in collaboration with teachers, and so the processing of learning environments has undergone cyclical revisions. Echoing Piaget's clinical interviews, Wittmann (1995) proposed 'clinical teaching experiments' as a suitable empirical method:

\begin{abstract}
As a result we arrive at 'clinical teaching experiments' in which teaching units can be used not only as research tools, but also as objects of study. The data collected in these experiments have multiple uses: They tell us something about the teaching/learning processes, individual and social outcomes of learning, children's productive thinking, and children's difficulties. They also help us to evaluate the unit and to revise it in order to make teaching and learning more efficient. [...] Clinical teaching experiments can be repeated and thereby varied. By comparing the data we can identify basic patterns of teaching and learning and derive wellfounded specific knowledge on teaching certain units. (Wittmann 1995, p. 367f.)
\end{abstract}

Following the idea of 'lesson studies' (Fernandes and Yoshida 2004), a group of teachers (and researchers) work together by planning, teaching and discussing a concrete teaching unit. In order to finally revise the teaching unit, the teachers not only discuss the documents of the lesson but their impressions and observations as well, with reflection on the initiated processes. Learning environments in particular serve as a basis to closer investigate the teaching experiments with the mathematics teaching and learning processes, especially the mathematical thinking of students.

For example, within the project PEnDEL (practice-oriented development projects in discussion with educators and teachers; Schwarzkopf et al. 2018), different teaching experiments are designed to provide a rich frame for comparing tasks with a view on the mathematical structures. The teaching experiments are based on the assumption that individual learning processes always depend on an active discussion of mathematical issues and, at the same time, are also linked to social interactions where such discussions are realized. Therefore the didactical principles (e.g. operative principle, natural differentiation, spiral principle, genetic principle) for designing the teaching experiment are enriched by 'productive irritations' for fostering mathematical argumentation processes (Nührenbörger and Schwarzkopf 2016). To this end, the pupils should challenge routinely generated expectations in the processing of assignments or in a mathematical observation. Such a productive irritation should create an opportunity for the children to recognise a subject-specific conflict, while on the other hand trying to resolve it argumentatively. In this sense, a productive irritation needs to be ultimately understood as a deviation from received expectations that require resolution.

Next, we provide an example of a short teaching experiment, fostering the mathematical argumentation processes of children in a primary class (4th class) (Nührenbörger and Schwarzkopf 2016). First, the children calculate a sequence of number walls; increasing the number in the bottom box on the right and decreasing the number in the bottom left box by the same amount leaves the number at the top of the wall constant (keeping the same number in the middle of the bottom row) (see Fig. 3.4). 
The children calculate the number at the top and try to find arguments to explain the constancy of the number at the top of the wall. However, having calculated some of these tasks, the students just focus on the changing bottom numbers without reflecting on the structure of the number wall (see Fig. 3.5). For example, the written document refers to the relation of the corner numbers $(+10$ and -10$)$ as argument for explaining the equality of the results.

For rich argumentation, it is important that the children reason not only on a number level, but take into account the terms for calculation. In a complement task, the children are confronted with another number wall that does not exactly fit the previously discovered pattern (see Fig. 3.6). So, the question for the children was: Will the number at the top of the wall change or not? This is considered a productive irritation, helping the children to become aware of the special function of the number in the bottom middle box.

The example shows how substantial learning environments pursue not only the goal to provide mathematical learning opportunities for students, but to enrich teachers' understanding of their learning processes. In view of reaching the ultimate goal of fostering children's argumentation, the first approach of designing the learning environment is only partly successful. Based on the initiated reasoning, the teaching experiment has been modified so that conducting cyclical teaching experiments is an essential methodological prerequisite within the DESIGN SCIENCE approach.
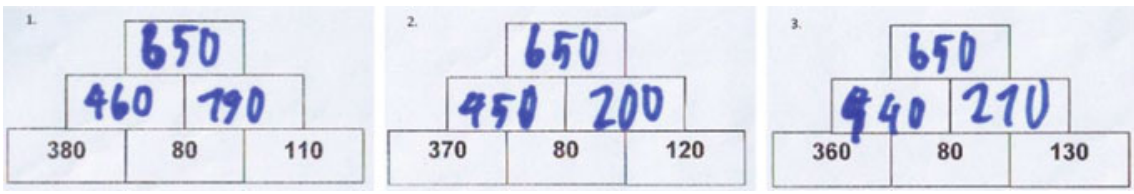

Fig. 3.4 An operative series of number walls with constant number at the top of the wall

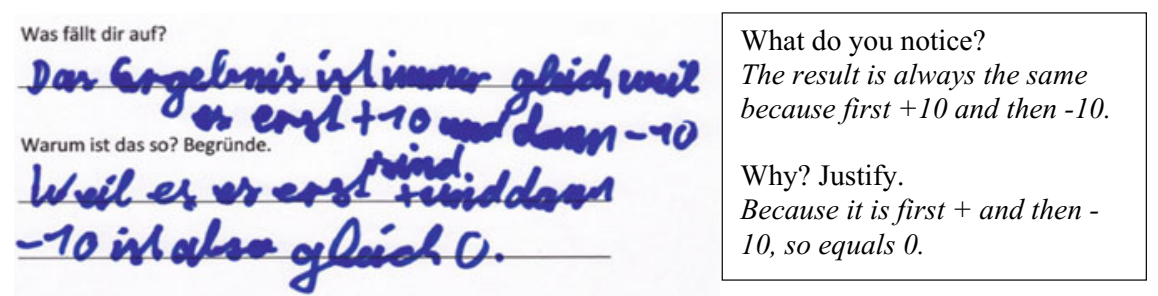

Fig. 3.5 A child's explanation of the constant number at the top of the number walls (see Fig. 3.4)

Fig. 3.6 A new series of number walls with a constant number at the top of the wall
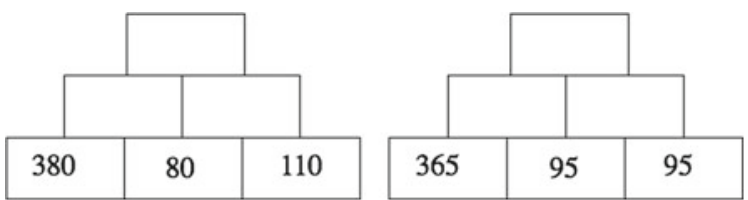
Designing and researching substantial learning environments has substantially permeated research in mathematics education. Chapter 2 and this chapter provide some current examples that centre research on such learning environments, but pursue different emphasis as well. Thus, the concept of DESIGN SCIENCE has undergone some change, both in terminology as well as methodology.

\subsection{Identifiying and Following Key Ideas as a Design Principle}

Research in mathematics education as a DESIGN SCIENCE in line with Wittmann (1995) puts emphasis on a constructive element, i.e. designing substantial learning environments. As outlined in Sect. 3.2, these are based on fundamental mathematical content and represent fundamental objectives (Wittmann 2001a). One pending issue still to be resolved is identifying content, which is fundamental in this sense. This is where key ideas of mathematics come into play.

In this chapter the different meanings of these key ideas are specified. Afterwards, some brief insights into two examples of using key ideas in research projects are given. Furthermore, in the projects' descriptions the interweaving relation between key ideas as normative settings and empirical research is addressed.

\subsubsection{Theoretical Reflections on Key Ideas of Mathematics}

In the early 1970s - around the same time as the founding of the German Society of Didactics of Mathematics (GDM) — different studies on fundamental ideas of mathematics and mathematics education started to appear in Germany. The papers at that time try to assure and reassure the newly established community of its purpose and aims. Some of the studies focus on mathematical behaviour and mathematics as an activity. Others address mathematics education as a recently encountered independent research field. And last not least, studies put an emphasis on the scope of mathematics contents and topics.

The concept of structuring the 'body of knowledge' by fundamental ideas dates back to Bruner (1966a, p. 41). In Bruner's work various terms, such as 'basic idea', 'general idea', or 'fundamental idea', can be already identified (Bruner 1966b). In subsequent studies and literature the various terms are taken up by others or even the scope is broadened by big ideas, core ideas, etc.

The understanding of key ideas in the current studies seems to depend on miscellaneous underlying meanings. It is indeed futile to attempt to nail down each term in its specific meaning, although the respective focus on (key) ideas can be identified. Bruner (1966b) has already used such ideas with the aim of at least two objectives: He merges thoughts on basic subjects and the grasping of general principles or atti- 
tudes of mathematical thinking by the learner whilst working on these basic contents. In a nutshell, the aim of using key ideas is twofold: a focus on specific mathematical thinking processes on the one hand, and a focus on fundamental mathematical content on the other.

\subsubsection{Focus on Key Ideas of Mathematical Thinking}

In different papers, mathematical thinking is attributed to special objectives and behaviour (for more detailed information, see Vohns 2016). For instance, Bender and Schreiber (1985) record inter alia ideation and exhaustion to be fundamental for geometrical thinking. Vollrath (1978) characterizes no specific mathematical thinking types but defines ideas to be fundamental indirectly by the impact of such ideas within an individual thinking process:

\footnotetext{
When I speak of ideas in the following, I mean the crucial thought of a theme, the substantial core of a consideration, a fruitful inspiration while solving a problem, the leading question of a theory, the central statement of a proposition, the underlying relations of an algorithm, and the images linked to conceptualization. (Vollrath 1978, p. 29, translation by the author of this paper)
}

Other studies outline the understanding of mathematical ideas in the context of learning and mathematics education, e.g. Winter (1975) identifies general ideas of learning mathematics in using heuristic strategies, proving, mathematising, formalizing, and using mathematical skills. The attempt to describe certain cognitive activities to be typical of mathematical thinking is still ongoing. Current studies mostly reflect on the register that the Organisation for Economic Co-operation and Development (OECD 2013) identifies as so-called mathematical literacy and the therein described mathematical processes "formulating situations mathematically; employing mathematical concepts, facts, procedures, and reasoning; and interpreting, applying and evaluating mathematical outcomes" (p. 9) and fundamental mathematical capabilities. Moreover, in this view it is common to differentiate mathematical thinking gradually in competence levels which are denominated to be reproductive, connective, or reflective.

In summary, this perspective tries to outline the specific components of thinking which define thinking processes and attitude to be mathematical. This meaning of fundamental or key ideas is taken up in current standards and curricula as so-called process goals or principles. Hence, they define fruitful teaching and learning interactions, attitudes, and beliefs towards favourable terms of learning mathematics.

\subsubsection{Focus on Key Ideas of Mathematical Content Cores}

In a different perspective, it is not the thinking and interaction processes that are focused upon but the core content areas. The approach used here follows a constructive orientation in order to provide practical and concrete designs (Wittmann 1974). 
Learning mathematics is not an event but a lifelong process. Mathematical key ideas are one possible answer to identify strands-aligned to age and level of development-but also to keep in mind the big picture and connectivity. Bruner recommends to present knowledge as a connected set of facts in a sufficient structure to be re-examined throughout both primary and secondary school (Bruner 1966b).

The scope of mathematical contents, which is considered to be crucial and substantial, constitutes key ideas. Of course it is necessary to condense mathematical contents in such ideas which are continuative and expandable. This concentration in key ideas allows one possible orientation for researchers and teachers.

In order to provide teachers with an orientation beyond substantial learning environments, it is useful to summarize basic knowledge about mathematics, learning, and teaching mathematics in didactical principles. One principle, for example, is "orientation on fundamental mathematical ideas". (Wittmann 2016, p. 26)

In accordance with Whitehead's (1929) view on mathematical education, Wittmann follows the idea to restrict the teaching contents (Table 3.1) and not to choose any subject but the mathematical important ones in line with Freudenthal (1983). Ideally, key ideas are never out of fashion because mathematics and its structural important subjects do not change.

Key ideas make it possible to get an overview of important topics from kindergarten up to grade 12. They allow for the understanding of content areas at a glance. This possibility should not be underestimated especially by both teachers and researchers. Focusing on the relations and connections of topics in mathematics education stops the whole picture from being put on the line and from creating isolated or disconnected (Whitehead 1929) teaching-learning-environments, which would be useless for mathematical literacy or the development of fundamental mathematical thinking. At best, key ideas, metaphorically spoken, function as the backbone of the living body of the lifelong mathematical education process.

For research, key ideas function as a framework for designing substantial learning environments. Lifelong learning in terms of a spiral curriculum allows individuals

Table 3.1 Key ideas (Wittmann and Müller 2012, pp. 160-161)

\begin{tabular}{l|l|l}
\hline Ideas of arithmetics & Ideas of geometry & Ideas of stochastics \\
\hline Number line & $\begin{array}{l}\text { Shapes and their } \\
\text { constructions }\end{array}$ & $\begin{array}{l}\text { Quantitative description of } \\
\text { random events }\end{array}$ \\
\hline $\begin{array}{l}\text { Calculating, properties, } \\
\text { calculating strategies }\end{array}$ & Operating with shapes & Probability \\
\hline Number system & Co-ordinates & Random experiments \\
\hline Algorithms & Measurements and formulas & Formulas \\
\hline $\begin{array}{l}\text { Arithmetical patterns and } \\
\text { structures }\end{array}$ & $\begin{array}{l}\text { Geometrical patterns and } \\
\text { structures }\end{array}$ & $\begin{array}{l}\text { Stochastic patterns and } \\
\text { structures }\end{array}$ \\
\hline Numbers in daily life & Shapes in daily life & Random events in daily life \\
\hline \multicolumn{2}{l}{ Translation in number- and shape-language } & Stochastic modelling \\
\hline
\end{tabular}


to deepen their understanding while working on these designed tasks in continuous strands of key ideas.

\subsubsection{Two Examples of Using Key Ideas}

Key ideas can be seen as normative settings determined by mathematics itself, even though empirical research is consistent with these ideas. On the one hand, mathematics education as a DESIGN SCIENCE (Wittmann 1995) needs researchers and expert practitioners to translate the ideas into suitable learning environments and tasks. In doing so, the design naturally takes into account empirical findings according to learning conditions which are psychologically and educational sound. On the other hand, mathematics education research is requested to evaluate the effects and impacts of the implementation of the environments on students' abilities and mathematical development.

The key ideas serve as designing principles for substantial learning environments. The research responsibility is to identify crucial key ideas and learning trajectories and to implement these ideas into tasks and SLEs. Consequently, these activities provide access to the key ideas and allow sensibility for the main subjects:

The language in which substantial learning environments are communicated is understandable to teachers, so reflective practitioners have good starting points to transform what is offered to them into their context and to adapt, extend, cut, and improve it accordingly. (Wittmann 2016, p. 25)

The projects briefly presented in this chapter are assigned to the essential phases of transition concerning primary school, i.e. the transition from kindergarten to school and the transition from primary to secondary school. Both approaches aim to support the smooth transition phases by pinpointing mathematical key ideas.

\subsubsection{Mathematical Key Ideas in Kindergarten}

Early mathematics in kindergarten is commonly regarded as being an important lifelong learning process. Nevertheless, the scope of core areas has not yet been entirely agreed upon. The role of key ideas here is to suggest one possible approach of an overview of important subjects.

In our design and research project MAIKE (Mathematics in Kindergarten), we take into account the wide range of competencies which are considered to promote a successful school beginning, different content areas such as number and operations, geometry and spatial sense, measurement, pattern, etc. as described in the learning paths or the big ideas (e.g. NAEYC \& NCTM 2010; Wittmann 2009).

In this project, the design of a little application for tablet use is the specific vehicle for allowing children, parents, and kindergarten educators to gain access to the normative set of important key ideas. The design idea is to provide awareness 
of the wide range of suitable mathematical contents (for both children and adults). The purpose of the digital feature is to tempt children and adults to explore real life mathematical objects and analogous situations.

Of course the design of tasks and learning situations has to be accompanied by empirical research on the use, accessibility, and impact of the substantial learning environments: "The big ideas or vital understandings in early childhood mathematics are those that are mathematically central, accessible to children at their present level of understanding, and generative of future learning" (NAEYC \& NCTM 2010, p. 6). For instance, first case studies indicate substantial differences between the abilities and competencies shown in an interview versus the digital play environment (Birklein and Steinweg 2018).

Key ideas in this research end up in designing digital learning environments. They thereby offer adults the chance to become aware of the mathematical contents and activities suitable for kindergarten children, and are helpful to overcome the widespread uncertainty of kindergarten educators, which subjects should be provided in early maths education. Furthermore, they may hopefully serve as an implicit inservice education to kindergarten teachers (and parents).

\subsubsection{Key Ideas of Algebraic Thinking}

In the field of algebraic thinking, the particular situation in Germany asks for key ideas for some other reason. Algebraic thinking is not mentioned in primary curricula and therefore the fundamental rule in the interplay of contents and topics is neglected (Steinweg et al. 2018). Hence, key ideas in this branch of mathematics pave the way to become aware of algebraic ideas as a possible subject in primary mathematics education.

International research indicates major ideas and core areas of algebraic thinking (e.g. Kaput 2008), even though these registers are not suitable for German teachers and thus have no influence on teaching-learning-situations in schools. Key ideas have to be made accessible in the specific cultural context. Furthermore, they have to take into account the existing ideas of mathematics and work out the interplay between the common and the supposedly new ideas. Only the connectivity of key ideas ensures dissemination and implementation in classrooms. Moreover, the sensible emphasis on the interweaving of contents protects classroom interaction against disconnected and isolated teaching.

The major branch of patterns and structures, which is given in the national standards (KMK 2004), is taken up as a possible link to algebraic thinking. This content area is controversially discussed and difficult to grasp for teachers. The offer of algebraic key ideas thereby gives one possible answer to the open question of which topics might be condensed in this twosome concept. Consequently, the key ideas of algebraic thinking are formulated in the spirit and wording of patterns and structures: patterns (and structures), property structures, equivalence structures, and functional structures (Steinweg 2017). 
Exemplarily, one SLE in the idea of property structures is sketched here. Numbers have certain properties, which can be discovered and described. For instance, the divisibility relation between natural numbers is essential in mathematics. The abstract relation can be made accessible if the product is regarded as a rectangle area with a given length and width, k and a (see Fig. 3.7).

The rectangle has the area $b$ which is - for given a and $k$ - equal to the number of squares in the field on a piece of grid paper. Many mathematically sound activities arise from this idea of rectangles as a representation of factors as edge length. Special numbers that only have two dividers can be identified as numbers with only one possible representation (prime numbers). Numbers that can be divided by $3,4,5$, etc. can be found and compared.

If the divisibility by two is investigated, odd and even numbers can be displayed. Moreover, not only the properties of numbers but the properties of additive operations on these numbers can be investigated by children. The introduced representation of rectangle areas allows the discovery of the remarkable behaviour of the sums of odd addends to be even (see Fig. 3.8).

This example illustrates the impact of key ideas put into concrete terms of learning environments and tasks. Key ideas allow teachers to become aware of main topics and fruitful tasks in order to initiate and enhance the chances of children's learning processes.

$$
\begin{gathered}
\forall a, b \in \mathbb{N}: a \mid b \\
: \Leftrightarrow \exists k \in \mathbb{N}, \\
\text { such that } b=k \cdot a
\end{gathered}
$$

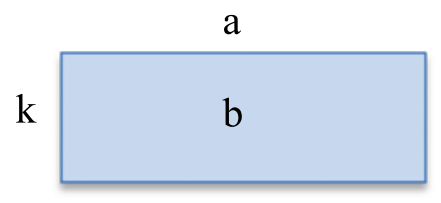

Fig. 3.7 The definition of the divisibility relation represented as a rectangle

Fig. 3.8 Properties of sums of odd and even numbers

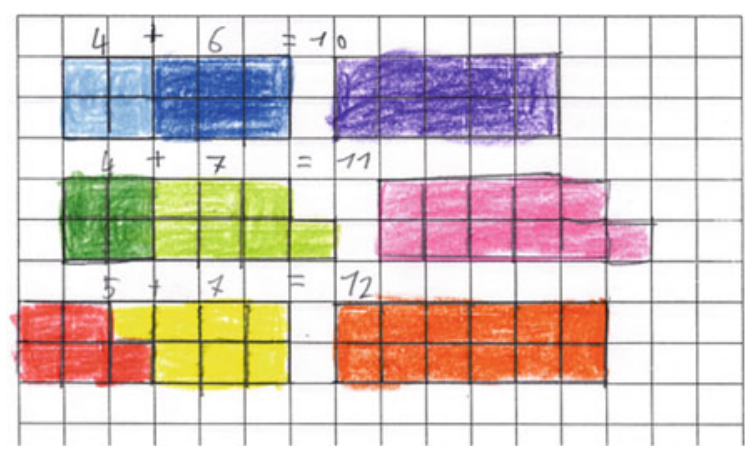




\subsubsection{Closing Remarks}

The two illustrations given above indicate the possibilities of key ideas. First of all they serve as the designing principles for researchers in a constructive understanding of mathematics education. They function as a framework for designing substantial learning environments and adequate material. In addition to the area of research therein (identifying key ideas and design), research thereafter is essential. This research evaluates and eventually adjusts the designed environments on the one hand, and monitors and supports children's learning processes and developments on the other.

For teachers, key ideas serve as guiding principles for classroom interaction. They allow for the awareness of core contents and to differentiate between important tasks and questions and less fruitful ones.

Teachers need to work with learners on the fundamental ideas behind topics. The Chinese teachers seem to me to be paying explicit attention and taking time over what I would call core awareness, or threshold concepts. Everybody can work at those, everybody can take that in, anybody who can get to school can comprehend them. (Mason 2016, p. 45)

Key ideas enhance the chances of children's learning processes. At the same time they put emphasis on the core objectives of children's developments. The important steps and milestones can be seen as being structured along the key ideas for both teachers and children.

\subsection{Describing Number Patterns. an Example for Designing a Learning Environment}

Within his concept of mathematics education as a DESIGN SCIENCE, Wittmann points out different options to combine design with empirical research (Wittmann 1995). One is the ongoing design, evaluation and revision of learning environments in cyclic teaching experiments. This iterative approach is a common characteristic of comparable accounts to intertwine design and research known as design research or design-based research. Combining design and empirical research is a suitable methodological account when an educational problem is recognised and there are not yet sufficient solutions available to 'solve' this problem in educational practice (Plomp 2013; Kelly 2013; Gravemeijer 1994). Sketching the problem should form the starting point of every design research project, and therefore, I will briefly outline the background and the problem of the project presented here: Why is it necessary to design learning activities on describing number patterns?

Communication competences, which are specific for the discipline, are part of revised mathematical curricula and standard listings all over the world. Following the NCTM standards in the US, for example, students should learn to "organize and consolidate their mathematical thinking through communication", to "communicate their mathematical thinking coherently and clearly to peers, teachers and others", 
and to "use the language of mathematics to express mathematical ideas precisely" (NCTM 2000). These competences do not only contribute to the communication between individuals, but through communicating about mathematics, students should deepen their individual understandings of mathematical concepts and procedures. Writing about mathematics in particular has this effect because, in contrast to oral communication, a much more precise language and complete explanation and thus a deeper analysis is required (Morgan 2001; Elliott 1996). Morgan (1998, p. 25) speaks in this context of 'writing-to-learn' mathematics. But she also points out that these writing competences of students do not evolve naturally and spontaneously; teachers should plan focused opportunities for students to practice 'learning-to-write' mathematics.

A simple and not too complex example for 'writing-to learn' and 'learning-towrite' mathematics in the first years of primary school are the so-called Entdeckerpäckchen (Discovering Pacs) (see Fig. 3.9). These are series of calculations that emerge through operative variations of the given numbers. Besides practising computational competences, students can also discover a pattern and continue it (What comes next?), they can investigate the connections between the variations of the given numbers and the results (What happens with the result?), and they can describe the discovered patterns (What do you notice?).

The patterns in Discovering Pacs are based on general operation-specific properties (e.g. the sum remains constant if the summands are varied in the opposite direction by the same amount, or the difference remains constant if minuend and subtrahend are varied in the same direction by the same amount). By recognising the patterns and connections and particularly by formulating precisely and writing down their discoveries, students can extend their understanding of the arithmetic operations by exploring these properties (in the sense of Morgan: 'writing-to-learn' mathematics). By focusing on general properties of operations and by stimulating typical mathematical processes like generalization and abstraction, describing patterns in Discovering Pacs can be seen as a valuable pre-algebraic activity (Steinweg 2013). But in order to fully initiate these learning processes, it is not sufficient just to ask students to write down what they notice; students' first attempts to describe number patterns show often potential to improvement (Frobisher and Threlfall 1999; Steinweg 2004). These first attempts can be used as a starting point for further discussions, reflections and revision for formulating descriptions of number patterns in the classroom, so that the students have the opportunity to 'learning-to-write'

Fig. 3.9 Examples for discovering pacs

$$
\begin{array}{ll}
65+11= & 65-11= \\
55+21= & 75-21= \\
45+31= & 85-31= \\
35+41= & 95-41=
\end{array}
$$


mathematics. It was the aim of the project presented here to design such learning opportunities.

\subsubsection{Stages of the Design Research Project}

Characteristic for a design research project, a cyclic approach of designing, testing in teaching experiments, and revising and redesign was employed (van den Akker et al. 2006), similar to the concept of lesson studies (Lewis et al. 2006). With the project progressing, the teaching experiments took place under increasingly realistic conditions in classroom situations.

\subsubsection{Stage 1: Clarifying the Starting Points}

In an initial stage of the project, data was collected on how students in grade 3 describe number patterns in Discovering Pacs, if they were not accustomed to them through previous teaching. The aim of this stage was to document the instructional starting points on which the following learning activities could be built upon (Cobb and Gravemeijer 2008).

The analysis resulted in criteria to evaluate students' descriptions and provided examples that could be used as materials in classroom activities initiating discussions with students about the quality and quality criteria of number pattern descriptions. Besides the criteria- such as the extent of the description and accuracy and precision-it was interesting that some students described both variations and the positions on which these variations took place and others did not (see examples in Fig. 3.10).

\subsubsection{Stage 2: Interviews with Students}

After the initial stage, a first draft of learning activities was designed. Two of them, Beschreibungen vergleichen (Comparing Descriptions) and Beschreibungen verbessern (Improving Descriptions), required students to evaluate one or several given descriptions to a Discovering Pac, to think about what the author could have meant by writing this, and to suggest how the descriptions could be improved. The aim of these activities was to stimulate discussions and reflections with students upon the quality criteria of number pattern descriptions and applying them in order to find a better description. These two activities were tried out in teaching experiments (Wittmann 1995), in interviews with students from grade 3.

All participating students were able to criticize the given descriptions by implicitly referring to the quality criteria of number pattern descriptions. For example, as a reaction to the Discovering Pac at the left in Fig. 3.11, one student argues why he 


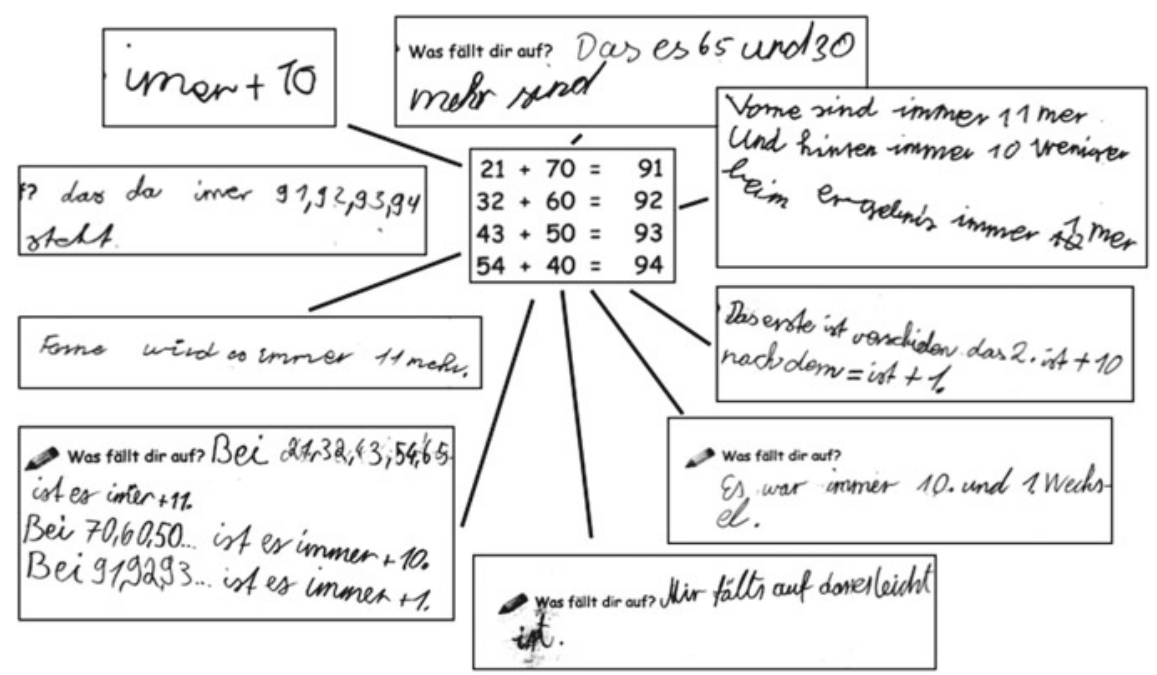

Fig. 3.10 Examples for descriptions (Translations, starting with the description at the top: "It's 65 and 30 more"; "In front, there are always 11 more, behind, there are always 10 less, the result is always 1 more"; "The first is different, the second is +10 , after the $=$ it is +1 "; "There are always 10 and 1 Changes"; "I notice that it is easy"; "At 21, 32, 43, 54, 65 it is always +11 . At 70, 60, 50... it is always +10 . At $91,92,93, \ldots$ it is always +1 "; "In front, there are always 11 more."; "There is always 91, 92, 93, 94."; "Always +10")

$$
\begin{aligned}
& 35+5=40 \\
& 36+4=40 \\
& 37+3=40 \\
& 38+2=40
\end{aligned}
$$

Leon writes:

The numbers at the front are different.

$$
\begin{aligned}
& 15+10=25 \\
& 15+20=35 \\
& 15+30=45 \\
& 15+40=55
\end{aligned}
$$

Mary writes:

It's always one more.

Fig. 3.11 Two examples for the learning activity Improving Descriptions that were used in interviews (translated by the author of this paper, see Link (2012) for the originals)

doesn't like the description: "Because it depends not only on the numbers here at the front. You have to look also at the numbers behind (points to the column with the second summands) and here at the back (points to the column with the sums)." (Translated by the author.) In reaction to the Discovering Pac and the description to the right, another student says: "Because what is always one more, the tens or the ones [...] It could also be that he means the ones, but this isn't correct." (Translated by the author.) While the first student criticizes the extent of the given description, the second refers to the accuracy of the description as it is not clearly stated which object or position is varied 'always one more'. 


\subsubsection{Stage 3: Teaching Experiment in Two Classrooms}

The interviews have shown that it is possible to reflect with third graders on quality criteria of pattern descriptions. The two learning activities were then used with three additional activities in a teaching experiment in two classes consisting of seven lessons, including a test at the beginning and at the end of the experiment. Teaching materials were provided for all five learning activities (work sheets for students, posters, teacher instructions at the beginning and the end of the lessons) and discussed with the math teachers of both classes. The math teachers conducted the teaching experiment in their own classes, the researcher was present during the lessons as co-teacher.

One of these five learning activities had the name Markieren und Schreiben (Colouring/Highlighting and Writing). In this learning activity, the students are asked to use colour to highlight all the places in the Discovering Pacs where they noticed a pattern or something else that they found noteworthy. In a second step, they should write a sentence for every colour used. The intention was for the students to first document their discoveries in a nonverbal way and then use the colours as a scaffolding to write down everything they discovered. The colours could also be used with finalising the writings as reference to the positions in the Discovering Pac (where something is remarkable), as a help if suitable words or expressions to verbalize this aspect of the pattern are missing. The students used this help in very different and creative ways. Some used coloured dots to express what position their sentence is referring to (see Fig. 3.12, on the left), others used the colours in a verbalized way: "At green ..." or "The blue numbers..." (see Fig. 3.12, on the right).

The expression of positions by colours can work as a 'bridge' between informal, everyday language and mathematical language, particularly as the students will then proceed to find and collect words and expressions to verbalize the positions in the Discovering Pacs without the use of colours. This way, technical terms like 'summand' or 'sum' can be introduced by the teacher, too.

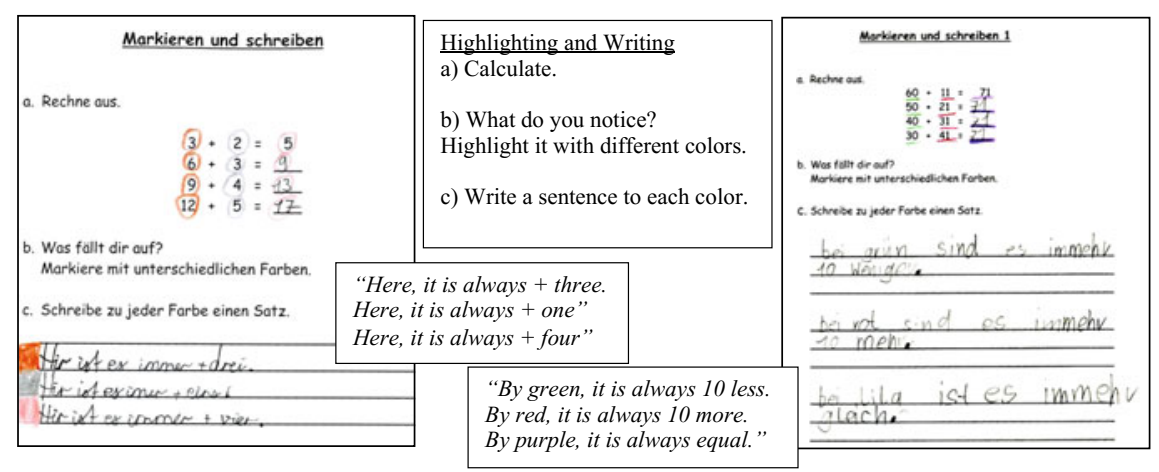

Fig. 3.12 Student documents from the learning activity Colouring/Highlighting and Writing 
In contrast to the test at the beginning of the teaching experiment, the extent of the number pattern descriptions increased noticeably among most of the students who had participated in this learning activity. Almost all students were able to verbalize the positions in the Discovering Pacs or make a reference to the coloured markings they applied themselves.

\subsubsection{Stage 4: Evaluation of the Materials in Seven Classrooms}

Based on the results of the teaching experiments in stages three and four, all materials were revised and modified. In a final stage of the project, these materials were used in seven classrooms. This time, the teachers received a short introduction, but they worked alone and independently with the materials in their classrooms. At the end, feedback from the participating teachers was collected, and all documents of students' work, including tests at the beginning and at the end of the teaching unit, were provided for further analysis. Evaluations of the tests show that the students' descriptions of number patterns after the unit became more extensive and more accurate, and the students verbalized positions in the Discovering Pacs much more frequently than before (Link 2012).

\subsection{From Design Science to Design Research: Trends and Developments in Germany}

Throughout the last two decade(s), the strong German tradition on DESIGN SCIENCE, a heritage of Erich Wittmann and others, has evolved into the research program of DESIGN RESEARCH in which Wittmann's focus on designing learning environments for developing mathematical structures is complemented by empirical studies, investigating the learning processes initiated by the design, and aiming at contributions to theory as well as to practical designs. This brief overview illustrates how the German tradition gives a slightly different emphasis to topic-specificity than in other well established approaches to DESIGN RESEARCH.

\subsubsection{From DESIGN SCIENCE to DESIGN RESEARCH-Lines of Development in Dortmund}

In Dortmund, the pathway from DESIGN SCIENCE to DESIGN RESEARCH started quite early, as already Wittmann emphasized. "In order to develop didactics as design science, it is important to find ways of connecting design and empirical 
research" (Wittmann 1995, p. 337). An important motor for this enhancement of DESIGN SCIENCE by empirical investigations was Heinz Steinbring, who joined the Dortmund group from 1995 to 2004 . He contributed substantially by empirical investigations of learning processes on the micro-level, as evidenced for example in his seminal book (Steinbring 2005) in which he explored the processes of knowledge construction by an epistemological perspective on the micro level, emphasizing the need to mentally construct structures and meanings.

Other substantial influences for this enhancement by empirical investigations were given by the tight connection to the Freudenthal Institute (Treffers, van den HeuvelPanhuizen, and others) and its program of developmental research (Gravemeijer 1998) which was later called DESIGN RESEARCH (especially Gravemeijer and Cobb 2006).

From 2004 to 2009, a new generation of professors started working in Dortmund. They jointly decided to continue the work of Wittmann and Müller by consequently intertwining both the strong mathematical focus in topic-specific research and development (following Wittmann 1995) and the deep empirical focus on processes of knowledge construction on the micro level (following Steinbring 2005; Gravemeijer and Cobb 2006).

\subsubsection{Topic-Specific Didactical DESIGN RESEARCH with a Focus on Learning Processes-A Model for DESIGN RESEARCH}

For elaborating the Dortmund research model of Topic-specific Didactical DESIGN RESEARCH with a focus on learning processes, four main working areas have been specified as printed in Fig. 3.13. Meanwhile, several Ph.D. projects and other projects have been conducted in this model.

Developing designs, conducting and analysing design experiments and developing local theories on teaching and learning processes are typical working areas appearing in many models of DESIGN RESEARCH (e.g. Plomp and Nieveen 2013). The specific strong emphasis on processes on the micro level have been justified and theoretically embedded by other researchers (e.g. Gravemeijer and Cobb 2006). The strong topic-specific content focus, in contrast, appears less often in DESIGN RESEARCH projects internationally, but reflects the German tradition of Stoffdidaktik (Hußmann et al. 2016). In the Dortmund model, the strong content focus is realized by establishing a separate working area "specifying and Structuring learning contents" for which typical leading questions, methods and connections to the empirical work have been made explicit by Hußmann and Prediger (2016), see Table 3.2. 
Table 3.2 Typical questions on four levels for specifying and structuring the content (Hußmann and Prediger 2016, p. 36)

\begin{tabular}{|c|c|c|}
\hline & $\begin{array}{l}\text { Specifying the content (selecting } \\
\text { aspects and their backgrounds) }\end{array}$ & $\begin{array}{l}\text { Structuring the content (relating and } \\
\text { sequencing aspects, including } \\
\text { connecting points for long-term } \\
\text { processes) }\end{array}$ \\
\hline $\begin{array}{l}\text { Formal } \\
\text { level }\end{array}$ & $\begin{array}{l}\text { Which concepts and theorems have to } \\
\text { be acquired? } \\
\text { Which procedures have to be acquired, } \\
\text { and how are they justified formally? }\end{array}$ & $\begin{array}{l}\text { How can the concepts, theorems, } \\
\text { justifications and procedures be } \\
\text { structured in logical trajectories? } \\
\text { Which connections are crucial, which } \\
\text { are contingent? } \\
\text { How can the network between } \\
\text { concepts, theorems, justifications and } \\
\text { procedures be elaborated? }\end{array}$ \\
\hline $\begin{array}{l}\text { Semantic } \\
\text { level }\end{array}$ & $\begin{array}{l}\text { What are the underlying big ideas } \\
\text { behind the concepts, theorems and } \\
\text { procedures? } \\
\text { Which basic mental models and } \\
\text { (graphical, verbal, numerical and } \\
\text { algebraic) representations are crucial } \\
\text { for constructing meaning? }\end{array}$ & $\begin{array}{l}\text { How do the underlying ideas and } \\
\text { meanings relate to each other and to } \\
\text { earlier and later learning contents? } \\
\text { How can the meanings be successively } \\
\text { constructed by horizontal } \\
\text { mathematization in the intended } \\
\text { learning trajectories? } \\
\text { Which trajectories of vertical } \\
\text { mathematization have to be elicited in } \\
\text { order to initiate the } \\
\text { invention/discovery of core ideas, } \\
\text { concepts, theorems and procedures? } \\
\text { How can the intended learning } \\
\text { trajectories be sequenced with respect } \\
\text { to the logical structure? }\end{array}$ \\
\hline $\begin{array}{l}\text { Concrete } \\
\text { level }\end{array}$ & $\begin{array}{l}\text { Which core questions and core ideas } \\
\text { can guide the development of the } \\
\text { concepts, theorems, and procedures? } \\
\text { In which context situations and by } \\
\text { which problems can the core questions } \\
\text { and ideas be treated exemplarily for } \\
\text { re-inventing the content? }\end{array}$ & $\begin{array}{l}\text { How can the meanings be successively } \\
\text { constructed in situations in the } \\
\text { intended learning trajectories? } \\
\text { How can the intended learning } \\
\text { trajectories be sequenced with respect } \\
\text { to the problem structure? } \\
\text { Which trajectories of horizontal } \\
\text { mathematization have to be elicited in } \\
\text { order to initiate the invention/ } \\
\text { discovery of core ideas, concepts, } \\
\text { theorems and procedures? }\end{array}$ \\
\hline $\begin{array}{l}\text { Empirical } \\
\text { level }\end{array}$ & $\begin{array}{l}\text { Which typical individual perspectives } \\
\text { of students (conceptions, ideas, } \\
\text { knowledge, ...) can be expected? } \\
\text { How do they relate to the intended } \\
\text { perspectives (resources vs. obstacles)? } \\
\text { What are origins of typical obstacles } \\
\text { or idiosyncratic conceptions? }\end{array}$ & $\begin{array}{l}\text { Which critical points in students' } \\
\text { learning path-ways are most crucial } \\
\text { (obstacles, turning points, ...)? } \\
\text { Which typical preconceptions or } \\
\text { previous knowledge can serve as } \\
\text { fruitful starting points? } \\
\text { How can the intended learning } \\
\text { trajectory be re- } \\
\text { sequenced with respect to students' } \\
\text { starting points and obstacles? }\end{array}$ \\
\hline
\end{tabular}




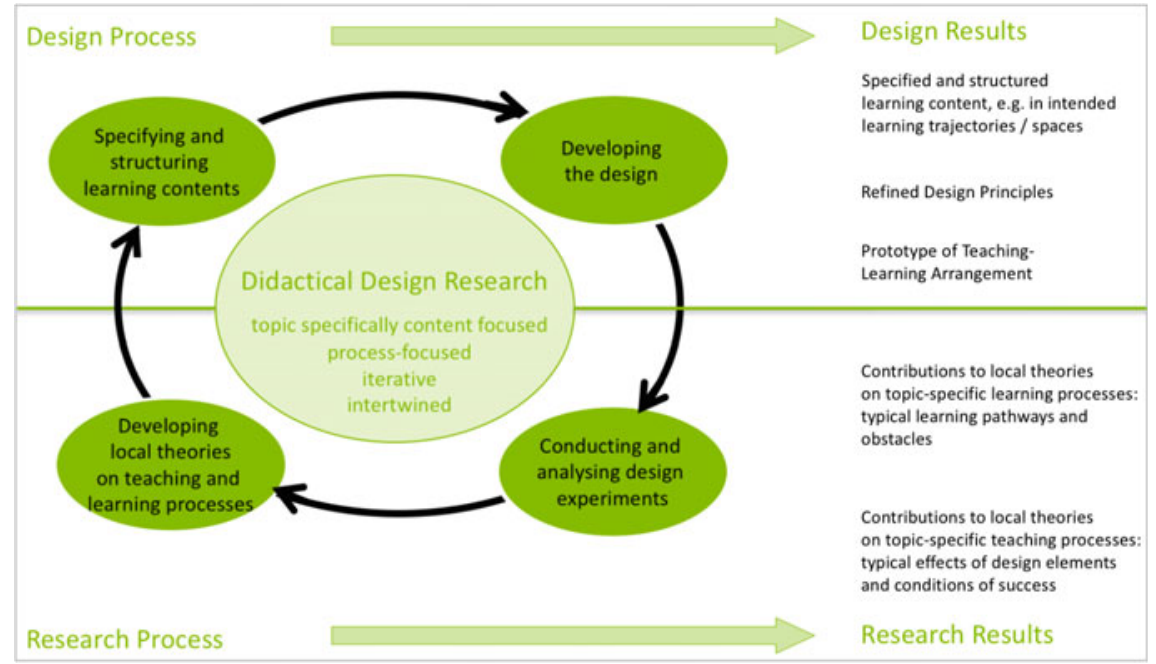

Fig. 3.13 Working areas in the model of Topic-specific DESIGN RESEARCH, applied across nine subject didactic disciplines (Hußmann et al. 2013; in English Prediger and Zwetzschler 2013)

\subsubsection{Illustration of Research Outcomes for a Typical Project: Exploring Individual Schematization Pathways}

One typical DESIGN RESEARCH project is described here in detail in order to illustrate typical outcomes. The exemplary project explores a well-known design principle: progressive schematization (Treffers 1987), according to which learning trajectories towards procedural rules can be organized as independent discoveries when the learning environment invites the students first to develop models for mathematical concepts and model-based informal strategies; then to explore the strategies and to discover pattern for progressively developing procedural rules.

The project (Glade and Prediger 2017) contributed to the theoretical and empirical foundation of the design principle of progressive schematization by empirically investigating students' individual schematization pathways on the micro-level for the specific case of part-of-part determination of fractions (see Fig. 3.14).

Structuring the learning content part-of-part in this case meant developing a schematization trajectory in several steps:

- starting with context problems

- establishing graphical models for the part-of-part

- developing informal strategies for determining part-of-part

- successively economizing the informal strategies in graphical procedures

- internalizing the informal strategies and underlying structures

- discovering formal procedure multiplication of fraction. 
In a series of laboratory set design experiments, nine pairs of sixth graders explored the part-of-part determination and progressively schematized their graphical strategies before discovering the procedural rule. A qualitative in-depth analysis of $760 \mathrm{~min}$ of video was conducted.

The analysis showed that progressive schematization is a multi-facetted process. The individual schematization pathways are much more diverse than the developed schematization trajectory, and cannot be described by internalization of graphical procedures alone. Instead, also finding inherent structures in the visualization and developing concepts is required before economizing is possible for students (Fig. 3.15).

A major contribution to the theory of schematization is that the schematization must be described by a dual progression in which the reduction of external actions are tightly intertwined with the compaction of concepts- and theorems-in-action. The project explores the students' pathways through successively compacting concepts on part-of-part, and hereby contributes to the topic-specific learning theory on fractions with typical pathways and obstacles. The reconstructed challenge to develop a justifiable procedural rule by connecting the informal and formal thinking also yields orientation for necessary design-elements, its effects and conditions of success. These empirical findings inform the theory as well as the redesign of the learning environment.

However, these kinds of Design Research studies have methodological limitations, so the results are restricted with respect to (1) the mathematical topic in view (only determining the part-of-part which is a simpler case than others, e.g., addition

Fig. 3.14 Part of part schematization: informal graphical solutions schematized into a rule
Fig. 3.15 Theoretical contribution: dual progression on external and internal side
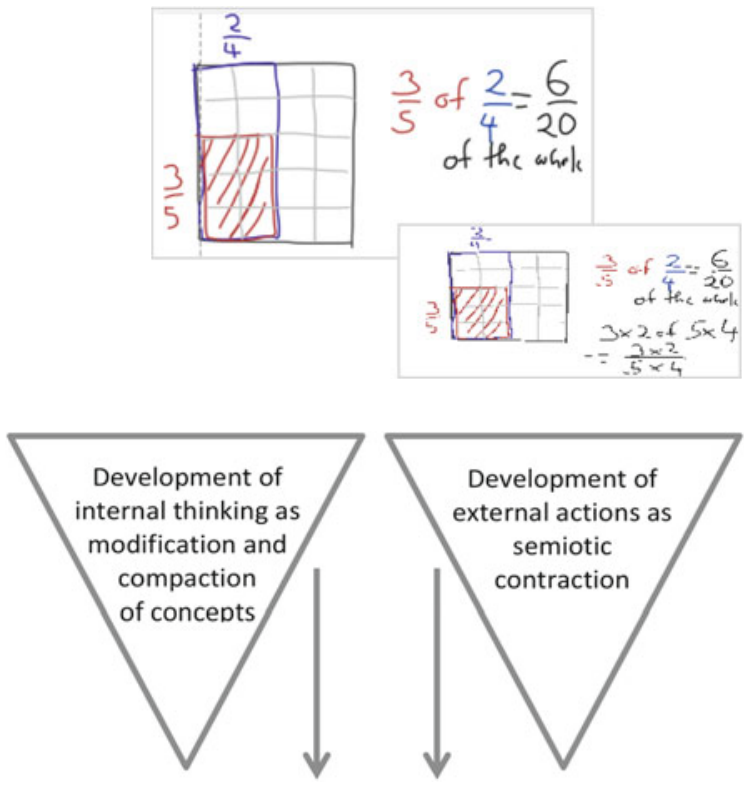
of fractions or long division), (2) the number of participants involved ( $\mathrm{n}=18)$, (3) the specific learning environments, and (4) the specific teacher in the design experiments. Hence the results are only local contributions to theory (Cobb et al. 2003), which are worth extending in future studies to a larger group of students and other learning environments and topics. By accumulating over several studies, a successive generalization to different topics and conditions will then be reached.

\subsubsection{Extensions of DESIGN RESEARCH to Other Subjects, Places, and to Teacher Education}

One milestone for the consolidation of DESIGN RESEARCH as a research program is its transfer from mathematics education to other disciplines. This was realized by the establishment of interdisciplinary graduate schools in Dortmund and other universities such as Bremen. In Dortmund, for example, the graduate school FUNKEN gathered nine subject matter education disciplines (including e.g. mathematics education, science education, language education and music) to collaborate within a joint research program (Hußmann et al. 2013). The establishment of interdisciplinary graduate schools reflects a growing interest not only in general education and mathematics education, but also to many other subject didactics.

Another extension concerns the shift from school classrooms to teacher education. For pre-service or in-service teacher education and professional development, DESIGN RESEARCH also proves to be a suitable research model to combine two aims, the development of suitable designs of learning environments for professional development and empirically investigating teachers' learning processes with typical pathways and obstacles for specific PD topics.

In the German Center for Mathematics Teacher Education (DZLM), especially, design experiments are put into a broader frame to substantiate professional development courses for teachers (Rösken-Winter and Sceszny 2016; Prediger et al. 2017). That is, research studies on the classroom level are needed to inform teachers' learning on the professional development level systematically. A deep understanding of students' learning of particular mathematics content and how this learning can be supported are both the basis for spreading professional development courses on a large scale. Within the scope of such courses additional teaching experiments, following the idea of DESIGN SCIENCE as outlined earlier in the chapter, complete the picture. However, the whole complexity of how teachers develop professionally demands a comprehensive DESIGN RESEARCH approach.

\section{References}

Akinwunmi, K., Lensing, F., Nührenbörger, M., Rösken-Winter, B., \& Schacht, F. (2016). Survey on the state of the art. In M. Nührenbörger, B. Rösken-Winter, Ch. Ip Fung, R. Schwarzkopf, \& 
E.Ch. Wittmann (Eds.), Design science and its importance in the german mathematics educational discussion (pp. 1-10). Rotterdam: Springer.

Bender, P., \& Schreiber, A. (1985). Operative Genese der Geometrie [Operative genesis of geometry]. Wien: Hölder-Pichler-Tempsky.

Birklein, L., \& Steinweg, A. S. (2018). Early maths via app use-Some insights in the EfEKt project. In Ch. Benz, H. Gasteiger, \& A. Steinweg et al. (Eds.), Mathematics education in the early years-Results from the POEM3 conference. Heidelberg: Springer.

Blum, W., \& Kirsch, A. (1991). Preformal proving: Examples and reflections. Educational Studies in Mathematics, 22(2), 183-203.

Bruner, J. (1966a). Towards a theory of instruction. Cambridge, MA: Harvard University Press.

Bruner, J. (1966b). The process of education. Cambridge, MA: Harvard University Press.

Cobb, P., \& Gravemeijer, K. (2008). Experimenting to support and understand learning processes. In A. Kelly, R. Lesh, \& J. Baek (Eds.), Handbook of design research methods in education (pp. 68-95). New York: Routledge.

Cobb, P., Confrey, J., diSessa, A., Lehrer, R. \& Schauble, L. (2003). Design Experiments in Educational Research. Educational Researcher, 32(1), 9-13.

Cohors-Fresenborg, E. (1993). Registermachine-As a mental model for understanding computer programming. In E. Lemut, D. Du Boulay, \& D. Dettori (Eds.), Cognitive models and intelligent environments for learning programming (pp. 235-248). Berlin: Springer.

Dewey, J. (1966). The child and the curriculum. Toronto, London: The University of Chicago Press (28th impression).

Dewey, J. (2008). Individuality and Experience. In J. A. Boydston (Ed.), The later works (1925-1927) (pp. 55-62). Carbondale: Southern Illinois University Press.

Elliott, W. (1996). Writing: a necessary tool for learning. The Mathematics Teacher, 89(2), 92-94.

Fernandez, C., \& Yoshida, M. (2004). Lesson study: A Japanese approach to improving mathematics teaching and learning. Mahwah, NJ: Lawrence Erlbaum.

Freudenthal, H. (1983). Didactical phenomenology of mathematical structures. Dordrecht: Reidel.

Frobisher, L., \& Threlfall, J. (1999). Teaching and assessing patterns in number in the primary years. In A. Orton (Ed.), Pattern in the teaching and learning of mathematics (pp. 84-103). London: Cassell.

Glade, M., \& Prediger, S. (2017). Students' individual schematization pathways-Empirical reconstructions for the case of part-of-part determination for fractions. Educational Studies in Mathematics, 94(2), 185-203.

Gravemeijer, K. (1994). Developing realistic mathematics education. Utrecht: CD- $\beta$ Press.

Gravemeijer, K. (1998). Developmental Research as a Research Method. In J. Kilpatrick \& A. Sierpinska (Eds.), What is research in mathematics education and what are its results? (pp. 277-295). Dordrecht: Kluwer.

Gravemeijer, K., \& Cobb, P. (2006). Design research from a learning design perspective. In J. V. D. Akker, K. Gravemeijer, S. McKenney, \& N. Nieveen (Eds.), Educational design research: The design, development and evaluation of programs, processes and products (pp. 17-51). London: Routledge.

Hußmann, S., \& Prediger, S. (2016). Specifying and structuring mathematical topics-A fourlevel approach for combining formal, semantic, concrete, and empirical levels exemplified for exponential growth. Journal für Mathematik-Didaktik, 37(Suppl. 1), 33-67.

Hußmann, S., Rezat, S., \& Sträßer, R. (2016). Subject matter didactics in mathematics education. Journal für Mathematik-Didaktik, 37(1), 1-9.

Hußmann, S., Thiele, J., Hinz, R., Prediger, S., \& Ralle, B. (2013). Gegenstandsorientierte Unterrichtsdesigns entwickeln und erforschen - Fachdidaktische Entwicklungsforschung im Dortmunder Modell [Developing and investigating topic specific instrucitonal designs]. In M. Komorek \& S. Prediger (Eds.), Der lange Weg zum Unterrichtsdesign [The long pathway to instrucitonal designs] (pp. 19-36). Münster al: Waxmann.

Kaput, J. (2008). What is algebra? What is algebraic reasoning? In J. Kaput, D. W. Carraher, \& M. L. Blanton (Eds.), Algebra in the early grades (pp. 5-17). New York: Routledge. 
Kelly, A. E. (2013). When is Design Research Appropriate? In T. Plomp \& N. Nieveen (Eds.), Educational design research-Part A: An introduction (pp. 135-147). Enschede: Netherlands Institute for Curriculum Development.

Kirsch, A. (1978). Aspects of simplification in mathematics teaching. In H. Athen \& H. Kunle (Eds.), Proceedings of the 3rd International Congress on Mathematical Education (pp. 98-120). Karlsruhe: FIZ.

KMK [Kultusministerkonferenz]. (2004). Bildungsstandards im Fach Mathematik für den Primarbereich [Standards in primary school mathematics]. Retrieved from http://www.kmk. org/fileadmin/Dateien/veroeffentlichungen_beschluesse/2004/2004_10_15-BildungsstandardsMathe-Primar.pdf.

Lesh, R., \& Sriraman, B. (2005). Mathematics education as a design science. ZDM Mathematics Education, 37(6), 490-505.

Lewis, C., Perry, R., \& Murata, A. (2006). How should research contribute to instructional improvement? The case of lesson study. Educational Researcher, 35(39), 3-14.

Link, M. (2012). Grundschulkinder beschreiben operative Zahlenmuster [Children in primary school describe operative patterns of numbers]. Wiesbaden: Springer.

Mason, J. (2016). In conversation with John Mason-Laurinda Brown interviews John Mason, who directed the Centre for Mathematics Education at Open University. Mathematics Teaching, 254, $42-45$.

Morgan, C. (1998). Writing mathematically. The discourse of investigation. London: Falmer Press.

Morgan, C. (2001). The place of pupil writing in learning, teaching and assessing mathematics. In P. Gates (Ed.), Issues in mathematics teaching (pp. 232-244). London: Routledge.

Wittmann, E. Ch., \& Müller, G. N. (1990). Handbuch produktiver Rechenübungen [The handbook of productive exercises of calculating]. Stuttgart: Klett.

Wittmann, E. Ch., \& Müller, G. N. (2009). Das Zahlenbuch - Handbuch zur Frühförderung [The number book-Handbook of early support]. Stuttgart: Klett.

Wittmann, E. Ch., \& Müller, G. N. (2012). Das Zahlenbuch 1 - Begleitband [The number book 1 -Companion volume]. Stuttgart: Klett.

NAEYC \& NCTM. (2002/updated 2010). Early childhood mathematics: Promoting good beginnings. Retrieved from https://www.naeyc.org/files/naeyc/file/positions/psmath.pdf.

National Council of Teachers of Mathematics (NCTM). (2000). Principles and Standards for School Mathematics. Reston, VA: NCTM.

Nührenbörger, M., \& Schwarzkopf, R. (2016). Processes of mathematical reasoning of equations in primary mathematics lessons. In N. Vondrová (Ed.), Proceedings of the 9th Congress of the European Society for Research in Mathematics Education (CERME 9) (pp. 316-323). Prag: ERME.

Nührenbörger, M., \& Schwarzkopf, R. (2017) (Eds.). Das Zahlenbuch 2 [The numberbook 2]. Leipzig: Klett.

OECD. (2013). PISA 2015-Draft mathematics framework. Retrieved from https://www.oecd.org/ pisa/pisaproducts/Draft\%20PISA\%202015\%20Mathematics\%20Framework\%20.pdf.

Plomp, T. (2013). Educational design research: An introduction. In T. Plomp \& N. Nieveen (Eds.), Educational design research-Part A: An introduction (pp. 10-51). Enschede: Netherlands Institute for Curriculum Development.

Plomp, T., \& Nieveen, N. (2013). Educational design research. Enschede: SLO, Netherlands Institute for Curriculum Development.

Prediger, S., Leuders, T., \& Rösken-Winter, B. (2017). Drei-Tetraeder-Modell der gegenstandsbezogenen Professionalisierungsforschung: Fachspezifische Verknüpfung von Design und Forschung [The model of three tetrahedrons in the topic specific research of proressionalisation. The subject specific alliance of Design and Research]. Jahrbuch für Allgemeine Didaktik, 2017, 159-177.

Prediger, S., \& Zwetzschler, L. (2013). Topic-specific design research with a focus on learning processes: The case of understanding algebraic equivalence in grade 8. In T. Plomp \& N. Nieveen (Eds.), Educational design research: Illustrative cases (pp. 407-424). Enschede: SLO, Netherlands Institute for Curriculum Development. 
Rösken-Winter, B., \& Szczesny, M. (2016). Continuous professional development (CPD): Paying attention to requirements and conditions of innovations. In S. Doff \& R. Komoss (Eds.), Making change happen: Wandel im Fachunterricht analysieren und gestalten (pp. 129-140). Wiesbaden: Springer Fachbuch.

Ruthven, K., Laborde, C., Leach, J., \& Tiberghien, A. (2009). Design tools in didactical research: Instrumenting the epistemological and cognitive aspects of the design of teaching sequences. Educational Researcher, 38(5), 329-342.

Schwarzkopf, R., Nührenbörger, M., \& Mayer, C. (2018). Algebraic understanding of equalities in primary classes. In C. Kieran (Ed.), Early Algebra (pp. 195-212). Rotterdam: Springer.

Simon, H. A. (1970). The sciences of the artificial. Cambridge, MA: MIT Press.

Steinbring, H. (2005). The construction of new mathematical knowledge in classroom interaction. An epistemological perspective. Berlin: Springer.

Steinweg, A. S. (2004). Zahlen in Beziehungen - Muster erkennen, nutzen, erklären und erfinden [Numbers in relations-recognising, explaining and inventing patterns]. In P. Scherer \& D. Bönig (Eds.), Mathematik für Kinder-Mathematik von Kindern [Mathematics for children-mathematics of children] (pp. 232-242). Frankfurt a. M.: Grundschulverband - Arbeitskreis Grundschule e. V.

Steinweg, A. S. (2013). Algebra in der Grundschule [Algebra in primary schools]. Heidelberg: Springer Spektrum.

Steinweg, A. S. (2017). Key ideas as guiding principles to support algebraic thinking in German primary schools. In T. Dooley \& G. Gueudet (Eds.), Proceedings of the Tenth Congress of the European Society for Research in Mathematics Education (CERME10), February 1-5, 2017 (pp. 512-519). Dublin, Ireland: DCU Institute of Education and ERME.

Steinweg, A., Akinwunmi, K., \& Lenz, D. (2018). Making implicit algebraic thinking explicit: Exploiting national characteristics of German approaches. In C. Kieran (Ed.), Teaching and learning algebraic thinking with 5- to 12-year olds: The global evolution of an emerging field of research and practice (pp. 283-307). Cham: Springer International Publishing.

Treffers, A. (1987). Three dimensions. A model of goal and theory description in mathematics instruction. Dordrecht: Reidel.

Van den Akker, J., Gravemeijer, K., McKenney, S., \& Nieveen, N. (2006). Introducing educational design research. In J. van den Akker, K. Gravemeijer, S. McKenney, \& N. Nieveen (Eds.), educational design research (pp. 3-7). London: Routledge.

Vohns, A. (2016). Fundamental ideas as a guiding category in mathematics education: Early understandings, developments in german-speaking countries and relations to subject matter didactics. Journal für Mathematikdidaktik (JMD), (Suppl. 1), 193-223.

Vollrath, H.-J. (1978). Rettet die Ideen! [Save the ideas!]. MNU, 31(8), 449-455.

Whitehead, A. N. (1929). The aims of education and other essays. New York: Macmillan.

Winter, H. (1975). Allgemeine Lernziele für den Mathematikunterricht? [General educational objectives in teaching mathematics?]. ZDM, 3, 106-116.

Wittmann, E. Ch. (1974). Didaktik der Mathematik als Ingenieurwissenschaft [Mathematics education as engineering]. Zentralblatt für Didaktik der Mathematik, 6, 119-122.

Wittmann, E. Ch. (1995). Mathematics education as a "design science". Educational Studies in Mathematics 29, 355-374 [repr. In A. Sierpinská \& J. Kilpatrick (Eds.) (1998), Mathematics Education as a Research Domain. A Search for Identity (pp. 87-103). Dordrecht: Kluwer].

Wittmann, E. Ch. (2001a). Developing mathematics education in a systemic process. Educational Studies in Mathematics, 48(1), 1-20.

Wittmann, E. Ch. (2001b). Drawing on the richness of elementary mathematics in designing substantial learning environments. In M. van den Heuvel-Panhuizen (Ed.), Proceedings of the 25th Conference of PME (Vol. 1, pp. 193-197), Utrecht, The Netherlands.

Wittmann, E. Ch. (2015). Structure-genetic didactical analyses-Empirical research "of the first kind". In P. Błaszczyk, B. Pieronkiewicz, \& M. Samborska (Eds.), Mathematical transgressions (pp. 5-19). Kraków: PWN. 
Wittmann, E. Ch. (2016). Collective teaching experiments: Organizing a systemic cooperation between reflective researchers and reflective teachers in mathematics education. In M. Nührenbörger, B. Rösken-Winter, C. I. Fung, R. Schwarzkopf, E. Wittmann, K. Akinwunmi, et al. (Eds.), Design science and its importance in the German mathematics educational discussion (pp. 22-29). Rotterdam: Springer.

Open Access This chapter is licensed under the terms of the Creative Commons Attribution 4.0 International License (http://creativecommons.org/licenses/by/4.0/), which permits use, sharing, adaptation, distribution and reproduction in any medium or format, as long as you give appropriate credit to the original author(s) and the source, provide a link to the Creative Commons licence and indicate if changes were made.

The images or other third party material in this chapter are included in the chapter's Creative Commons licence, unless indicated otherwise in a credit line to the material. If material is not included in the chapter's Creative Commons licence and your intended use is not permitted by statutory regulation or exceeds the permitted use, you will need to obtain permission directly from the copyright holder. 


\title{
Chapter 4 \\ Mathematical Modelling
}

\author{
Katrin Vorhölter, Gilbert Greefrath, Rita Borromeo Ferri, Dominik Leiß \\ and Stanislaw Schukajlow
}

\begin{abstract}
Mathematical modelling plays a prominent role in German mathematics education. The significance of modelling problems in school and in teacher education has increased over the last decades, accompanied by various research projects. In addition, there has been a vivid discussion on the implementation of modelling in schools. This chapter gives on overview on the current state of mathematical modelling in German speaking countries. After a short summary of the development of the past years, a widespread conceptualisation of modelling competence as well as its description within the German Educational standards is presented. Ways of implementing mathematical modelling in classrooms as well as in everyday lessons but also via modelling projects are described and an example of one of these problems worked on by students of grade 9 over two years is given. Furthermore, different modelling cycles are shown and their aims and usage in different circumstances are outlined. In addition, research questions currently being discussed are addressed and an example for a quantitative research project is given.
\end{abstract}

Keywords Mathematical modelling $\cdot$ Modelling competencies $\cdot$ Modelling cycle $\cdot$ Implementing modelling $\cdot$ Research on modelling $\cdot$ German modelling debate

\footnotetext{
K. Vorhölter $(\bowtie)$

University of Hamburg, Hamburg, Germany

e-mail: katrin.vorhoelter@uni-hamburg.de

G. Greefrath · S. Schukajlow

University of Münster, Münster, Germany

e-mail: greefrath@uni-muenster.de

S. Schukajlow

e-mail: schukajlow@uni-muenster.de

R. Borromeo Ferri

University of Kassel, Kassel, Germany

e-mail: borromeo@mathematik.uni-kassel.de

D. Leiß

University of Lüneburg, Lüneburg, Germany

e-mail: leiss@leuphana.de 


\subsection{Introduction}

Mathematical modelling plays a prominent role in German mathematics education. The significance of modelling problems in school and teacher education has increased over the last decades, accompanied by various research projects. In addition, there has been a vivid discussion on the implementation of modelling in schools.

Thus, this chapter is subdivided into three parts as follows: In the first part, we outline the German discussion of mathematical modelling by presenting definitions, educational standards and modelling competencies. This chapter is based on the topical survey on approaches and developments from German-speaking countries on teaching and learning mathematical modelling (Greefrath and Vorhölter 2016). We also provide an overview on "Implementing mathematical modelling in schools" by presenting several projects of the last two decades aiming at the implementation of modelling in Germany.

In the second part, we provide a classification of modelling cycles that focuses on how these yield greater insights into the cognitive processes of learners when solving modelling problems. We also discuss the role of technology in mathematical modelling in the context of modelling cycles. In the third part, we provide an overview of some important research questions which have arisen in the German-speaking debate on mathematical modelling. In addition, we report an example of findings from a research project conducted in Germany, searching for the "best" learning environment for teaching modelling in a regular classroom.

\subsection{Developments in Mathematics Modelling for Teaching in Germany}

In Germany, the focus on mathematical modelling has intensified considerably since the 1980s. Earlier, in 1976, Pollak gave a talk at the ICME 3 in Karlsruhe, where he contributed to defining the term "modelling" (Pollak 1977). Different modelling cycles (for example Schupp 1989) were developed and discussed, in order to describe modelling processes and goals, as well as arguments for using applications and modelling in mathematics teaching. After subject-matter didactics (Stoffdidaktik) had affected mathematics education with pragmatic and specific approaches in Germany, there was a shift in the last quarter of the 20th century towards a competence orientation, focusing on empirical studies and international cooperation.

\subsubsection{Background of the German Modelling Debate}

In fact, the discussion of applications and modelling in education has played an important role in Germany for more than 100 years. The background to the German 
modelling debate at the beginning of the 20th century can be divided into a practical arithmetic approach (Sachrechnen) at the public schools (Volksschule, primary school and lower secondary school) and an approach of applications supported by Klein and Lietzmann in the higher secondary school (Gymnasium).

At the beginning of the 20th century, mathematics education was influenced by the reform pedagogy movement. Johannes Kühnel (1869-1928) was one of the key figures in this movement. Kühnel criticised teaching problems that were basically irrelevant and called for problems that were truly interesting and relevant for students. During this period, applications were considered to be more important for the learning process. They were used to help visualise issues and motivate the students, rather than prepare them for real life (Winter 1981).

In contrast to the practical arithmetic approach at the Volksschule, the formal character of mathematics was the centre of attention at the Gymnasium. Mathematical applications were mostly neglected. Whereas Kühnel and other educators (representing the reform pedagogy movement) had a greater influence on the Volksschule, Klein started a reform process in the Gymnasium. At the beginning of the 20th century, a more appropriate balance between formal and material education was requested, due to the impact of the so-called "reform of Merano". The main focus was on "functional thinking". In the context of Merano's reform, a utilitarian principle was propagated "which was supposed to enhance our capability for dealing with real life through a mathematical way of thinking" (Klein 1907, p. 209, translated). Because of the industrial revolution, more scientists and engineers were needed in the economy and society. This is why applied mathematics gained in importance and real-life problems were used more often. Lietzmann (1924) made some important proposals for the implementation of Merano curricula and constituted an implementation of applications in the classroom. Finally, the contents of the Merano reform in 1925 were included in the curricula of Prussian secondary schools.

This trend continued until the 1950s. In the late 1950s, Lietzmann stressed the need for stronger inner-mathematical objectives (Kaiser-Messmer 1986). After World War II, some ideas that had evolved from the progressive education movement and the reform of Merano were picked up again, but with applications losing importance. More emphasis was again placed on subject classification rather than on applications (Kaiser-Messmer 1986).

In 1976, Pollak gave a talk at ICME 3 in Karlsruhe, where he defined the term modelling. He pointed out that at that time, people were less familiar with how applications were used in mathematics teaching. To clarify the term, he distinguished between four definitions of applied mathematics (Pollak 1977, s. Fig. 4.1):

- Classical applied mathematics (classical branches of analysis, parts of analysis that apply to physics)

- Mathematics with significant practical applications (statistics, linear algebra, computer science, analysis)

- Single modelling (the modelling cycle is only conducted once)

- Ongoing modelling (the modelling cycle is repeated several times). 


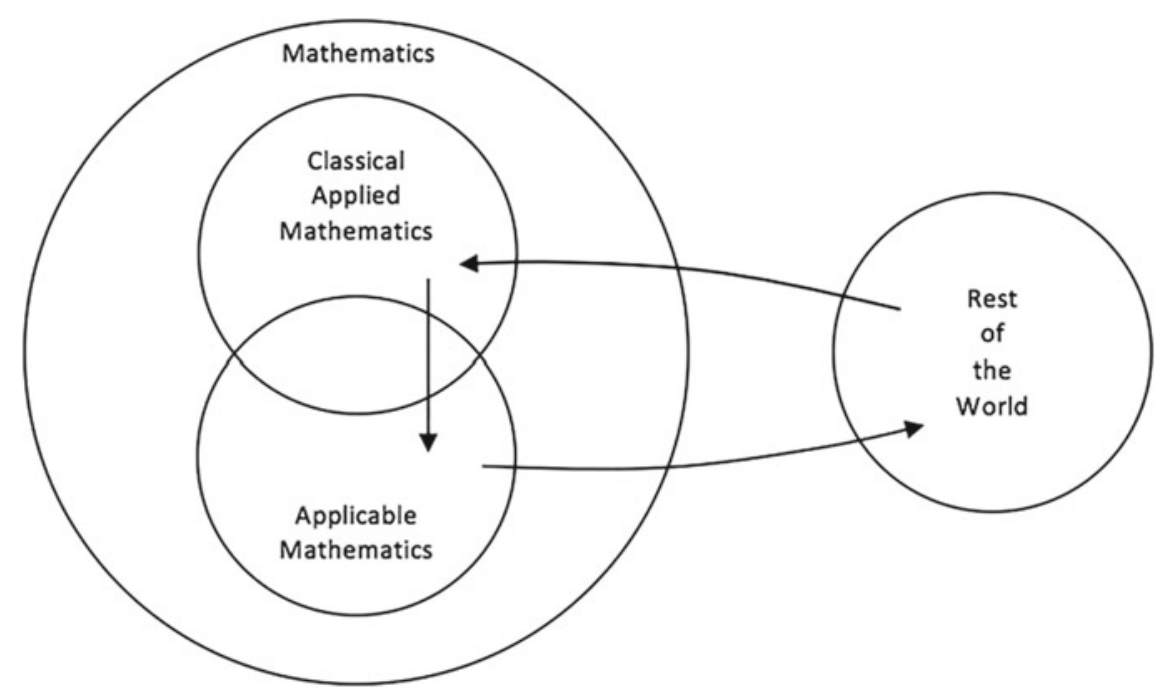

Fig. 4.1 Perspectives on applied mathematics by Pollak (1977, p. 256)

In the 1980s, the so-called New Practical Arithmetic (Neues Sachrechnen) evolved at all types of schools in Germany (Franke and Ruwisch 2010). The principles of the reform pedagogy movement were emphasized again and schools started to use applications in mathematics education more frequently. The New Practical Arithmetic aimed at finding authentic topics for students and to conduct long-term projects that were separated from the current mathematical topic and offered a variety of solutions. New types of question, such as Fermi problems, which are formulated as one question only and can be solved by estimating different physical quantities, were used accordingly (Herget and Scholz 1998). At the same time as the development of the New Practical Arithmetic, the term modelling became better known in mathematics education, and the two have partially complemented each one another. However, the main focus of New Practical Arithmetic and modelling was on different types of schools (Greefrath 2018).

The development in German-speaking countries was diverse. For example, in the field of stochastics, there were modelling approaches emphazising stochastic aspects (e.g. Eichler and Vogel 2016).

In 1991, the German ISTRON Group was founded by Werner Blum and Gabriele Kaiser. This caused an intensified debate on modelling in Germany. The idea behind ISTRON was that - for various reasons - mathematics education should focus more on practical applications. Students should learn to understand environmental and real-life situations by means of mathematics and develop general mathematical skills (e.g., transfer between reality and mathematics) and become open-minded regarding new situations. They should thereby establish an appropriate comprehension of mathematics including the actual use of the concepts. Learning mathematics should be supported relating it to real life (Blum 1993). A new series established in 
1993 and published by Springer since 2014 has enabled the ISTRON Group, having already produced 20 volumes, to be present and visible in mathematics teaching, as well as in the academic community. Their contributions are intended to support teachers in dealing with real-life problems in school. Teachers are considered to be experts in teaching, so that teaching proposals should be modifiable, enabling teachers to adapt them to a specific situation. They should suggest innovative ways of teaching mathematics and support lesson preparation (e.g., Bardy et al. 1996).

\subsubsection{Modelling as a Competency and German Educational Standards}

Based on results from the Danish KOM project (Niss 2003) and accompanied by international comparative studies, mandatory educational standards for mathematics were introduced in Germany in 2003 (first at the non-university entrance level). Mathematical modelling is now one of the six general mathematical competencies that the education standards for mathematics regard as obligatory for intermediate school graduation. This approach can also be found in the educational standards for primary school, as well as for upper secondary school.

By means of varied mathematical content, students are to acquire the ability to translate between reality and mathematics in both directions. In the work of Blum (Blum et al. 2007), modelling skills are described in a more detailed way as the ability to adequately perform the necessary steps in the process of changing back and forth between reality and mathematics, as well as comparatively analysing and evaluating models.

It is possible to consciously divide modelling into partial processes for reducing complexity for teachers and students, and for creating suitable exercises (see Table 4.1). This view of modelling especially enables training individual partial competencies and establishing a comprehensive modelling competency in the long term. For more information on modelling competencies, we refer to the comprehensive overview by Kaiser and Brand (2015).

The German educational standards for mathematics at the secondary level for 2003 - as well as those at the primary level for 2004 and for the higher education entrance qualification of 2012 - describe mathematical modelling as a competency. The educational standards for the general higher education entrance qualification, for example, specify the requirements regarding the modelling competency in the three following areas:

Requirement areas of study I: Students can:

- Apply familiar and directly immediately recognisable models

- Translate real situations directly into mathematical models

- Interpret mathematical results in the context to the real situation. 
Table 4.1 Sub-competencies involved in modelling (Greefrath et al. 2013, p. 19)

\begin{tabular}{l|l}
\hline Sub-competency & Indicator \\
\hline Constructing & $\begin{array}{l}\text { Students construct their own mental model from a given problem and thus } \\
\text { formulate an understanding of their problem }\end{array}$ \\
\hline Simplifying & Students identify relevant and irrelevant information from a real problem \\
\hline Mathematising & $\begin{array}{l}\text { Students translate specific, simplified real situations into mathematical } \\
\text { models (e.g., terms, equations, figures, diagrams, and functions) }\end{array}$ \\
\hline Interpreting & $\begin{array}{l}\text { Students relate results obtained from manipulation within the model to the } \\
\text { real situation and thus obtain real results }\end{array}$ \\
\hline Validating & Students judge the real results obtained in terms of plausibility \\
\hline Exposing & $\begin{array}{l}\text { Students relate the results obtained in the situational model to the real } \\
\text { situation, and thus obtain an answer to the problem }\end{array}$ \\
\hline
\end{tabular}

Requirement areas of study II: Students can:

- Conduct modelling processes consisting of several steps and with a few and clearly formulated limitations

- Interpret the results of such modelling processes

- Adopt mathematical models to changing situations.

Requirement areas of study III: Students can:

- Model complex real situations for which variables and conditions need to be specified

- Check, compare, and evaluate mathematical models considering the real situation (KMK 2012, p. 17, translated).

Since 2006, an overall strategy for educational monitoring in Germany has been pursued by the Standing Conference of the Ministers of Education and Cultural Affairs. The aim is to strengthen the competence orientation within the educational system. The general modelling competency plays an important role in mathematics. In addition to international school achievement studies (PISA, TIMSS), there are national achievement studies as well as comparative studies (VERA). These tests are carried out in class in Grades 3 and 8 in all general education schools, in order to investigate which competencies students have achieved at a particular point in time. The comparative studies aim to give teachers individual feedback on the educational standards requirements that students can handle.

Beginning in 2017, a pool with audit tasks for the Abitur examination has been be provided for Germany, from which all states can obtain audit tasks for the Abitur. This was an important step in improving the quality of audit tasks and gradually adjusting the level of requirements in all states. Tasks are developed based on the educational standards. Thus, by default, some of the tasks for the Abitur include modelling as a competency. The use of modelling in examination problems, however, is not unreservedly viewed positively. The fact that in many cases, the relevance of the factual context used is not the focus of examination problems, has given rise 
to criticism on the part of some expert representatives with regard to modelling in examinations: On the one hand, there is criticism of the fact that "modelling competence" is not examined at all through the used audit tasks. On the other hand, other authors point to the categorical refusal of modelling problems also in examinations. Strong criticism is also directed against the fact that examination problems tend to contain to much text (s. Greefrath et al. 2018).

\subsubsection{Implementation of Modelling in Everyday Lessons}

Fostering students' modelling competence is compulsory for all mathematics teachers in all grades. But classroom observations regularly reveal only a low proportion of modelling of working on a holistic modelling task in everyday-lessons and class exams in Germany (Blum 2011). Several reasons may apply:

Modelling has been part of the national standards for only about fifteen years. Therefore, many teachers are not trained to teach modelling. Although there are many in-service teacher trainings in modelling, German teachers are not obliged to attend them. Accordingly many simply do not know how to implement modelling in everyday-lessons, how to behave during students' work on modelling problems, and generally how to support their students best. Modelling is a competence that is difficult not only for students, but for teachers as well. Because students are encouraged to develop their own models, teachers can only anticipate what students will do. They therefore have to be able to diagnose and intervene spontaneously, but often, do not feel confident in doing so (Tropper et al. 2015).

In addition, concurrently to the implementation of modelling in the national standards, state-wide comparison tests have been established in Germany. As modelling is one of the six competencies of the national standards, it is included in these tests. Thus, teachers who want to prepare their students for these tests must implement modelling in their classes to a certain extent. But, as Henn and Müller (2013) stated, most of the so-called modelling problems at school and particular in exams, are not modelling at all, according to the description of modelling problems given above. Mostly, not a complete complex modelling task is tested, but only sub-competencies of modelling. Therefore, teachers do not have to tackle entire modelling problems in their mathematics classes to prepare for the central exams.

Furthermore, teachers claim that there is insufficient knowledge about how to foster students' modelling competence best and most effectively. At first glance, this is surprising, as many studies have researched single aspects (for an overview of research results, see Greefrath and Vorhölter 2016). But clearly, until now, these findings have not been integrated in such a manner as to be useful for teachers. However, Böhm (2013) developed a theoretical approach for improving students' modelling competencies systematically and permanently. Furthermore, Blum (2015) presented-based on empirical findings - ten important aspects of a teaching methodology for modelling. In addition, there are various task collections (for example, the 
ISTRON series and the collection of tasks by MUED, see Greefrath and Vorhölter 2016) that can be used as a teaching resource for modelling problems.

Summing up, there has been much research on different aspects of fostering students modelling competencies. But until now, this knowledge has not been applied in practice (at least not as much as one would wish). One indication that teachers want to implement modelling, but do not know how to do so is the fact that at least in Hamburg, it is not difficult for researchers to convince teachers to take part in research projects on modelling. Furthermore, teachers in Hamburg often wish to participate in modelling days or even weeks. These projects are introduced in the next section.

\subsubsection{Implementation of Modelling via Modelling Projects}

Modelling cannot only be conducted during regular mathematics instruction. In Germany, there is quite a tradition of modelling projects, carried out by different universities all over Germany and Austria. They were originally developed at the University of Kaiserslautern by the working group of Helmut Neunzert, an applied mathematician, more than twenty years ago, and their structure has been adopted by different universities. Although the aims and the target group of these projects differ, all modelling projects follow a similar structure. During modelling weeks or days, as these projects are termed, students have to work on one complex problem over a longer period, more or less on their own. The modelling problems often come from research or industry and have been simplified only slightly. Normally, these are introduced in a short presentation. Problems that have been tackled so far include:

- Pricing for Internet booking of flights

- Optimal automated irrigation of a garden

- Chlorination of a swimming pool

- Optimal distribution of bus stops

- Optimal distribution of rescue helicopters in skiing areas.

Often, the students are able to choose between modelling problems, as several problems are offered. Afterwards, according to their particular interests, they are divided into different groups.

The students are supervised either by university teachers or by university students trained as tutors. The supervisors are required to use the principal of minimal help. At the end, the students have to present their solution to an audience. Modelling projects that last roughly one week are referred to as modelling weeks and often take place outside school (usually at a university or a youth hostel), while modelling projects lasting only two or three days are called modelling days and normally take place in a school.

The aim and target group of the modelling days and weeks differ, depending on the host in question. In some cases, as in Kaiserslautern and Aachen, applied mathematicians (originally) carry out those projects. They focus mostly on introducing students to the role of mathematics in other sciences. Often, they offer their 
In 2015, ca. 1,5 Mio refugees came to Germany. They are distributed in accordance to the Königsteiner Schlüssel, a distribution key, developed in 1949 for distributing money to the federal states of Germany. It regards $2 / 3$ taxes and $1 / 3$ population and is measured every year. These days, it is often claimed that the Köngisteiner Schlüssel is inappropriate for distributing refugees, but till now, no other distribution key has been developed.

Is there a better key for distributing refugees?

Develop an alternative procedure and discuss the pro's and con 's.

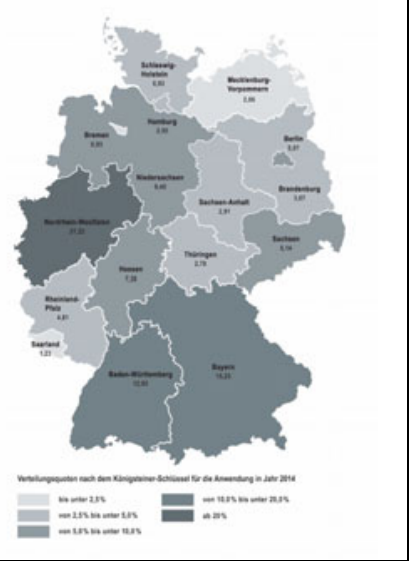

Fig. 4.2 Modelling problem "Distribution of refugees"

modelling projects to highly gifted or at least interested students. In other cases, as in Hamburg, Kassel and Koblenz, carrying out modelling days is only part of a whole programme. Didactical considerations, such as fostering students modelling competencies or increasing their motivation, form the focus. Normally, whole classes, regardless of their mathematical competencies, take part in those modelling days or weeks. Furthermore, in these cases, not only the students working on the modelling problems, but also those supervising them (in- and pre-service teachers) can be considered the target group. Preparation for supervising students during modelling days or weeks not only includes telling them how to behave so as to help students as little as possible, but as much as necessary concerning the special problem, but in general. This includes general knowledge about modelling and diagnosing problems, as well as intervening in such a way that the learning outcome for the students is as high as possible. To convey the general idea, in the following discussion, the procedure of modelling days, as well as student reactions and outcomes concerning a particular task, will be presented.

Since 2001, modelling days are conducted by the working group on Didactics of Mathematics of the Educational Department of the University of Hamburg. Upon consultation with participating schools, they last 2 or 3 days, directly after winter term in February. Every year, whole grade 9 classes from different schools participate, that is over 200 students and about 10 teachers. Teachers meet beforehand, are informed about the modelling problems and trained. Furthermore, student teachers were trained within a didactic seminar that focuses on teaching modelling in general; part of the seminar entails supervising the students during the modelling days. Every year, three different modelling problems are presented to the students who can choose what work they wish to do. In 2016, the problem in Fig. 4.2 was posed. 
As there is a shortage of living space in Hamburg, students firstly claim the distribution key is unfair, because some larger counties (which one would assume have more living space) like Mecklenburg-Western Pomerania only had to receive the same number of refugees. They soon decided to consult further aspects for the new distribution key such as area, empty houses and vacancy. They investigated relevant data and considered how to develop a new distribution key. They measured proportions and compared the outcome for the different federal states of "their" distribution key to those of the "Königsteiner Schlüssel". Summarizing, they developed a solution for a highly relevant topic, use proportions in a real context (and not to forget how to calculate a proportion in the future) and form one's own opinion.

In contrast to the implementation of modelling in everyday lessons, there has not been much research on the impact of modelling days or weeks on students, pre-service or in-service teachers. One exception is the study by Stender (2016), that focused on the acting of teachers tutoring students while working on a complex modelling problem. He videotaped the working process (lasting 2.5 days) of 10 groups of students working on the modelling task "Roundabout versus traffic light: Which intersection allows more cars to pass through?". The tutors had been trained before on how to supervise students. The results clearly indicate the trained strategic interventions were used to a considerable extent and were mostly successful. However, tutors had different preferences; some seldom intervened, but their interventions last longer; some intervene more frequently, but gave only very short interventions. Furthermore, the intervention "Explain your work" proved to be very effective and was often used. The results indicate in addition the importance of an accurate diagnosis of the students' situation and their current motivation, as interventions were rather unsuccessful if diagnoses were not accurate. Furthermore, an inadequate understanding of the modelling situation and the mathematical situation by the tutors led to rather misleading interventions.

Although there had not been much research on this issue, modelling weeks and days were evaluated regularly, revealing great approval and good learning outcomes in various types of competencies (for more details, see Kaiser and Schwarz 2010; Kaiser et al. 2013; Vorhölter et al. 2014).

\subsection{Modelling Cycles}

\subsubsection{Mathematical Models}

The debate over the term mathematical model plays an important role in the research on mathematical modelling in Germany.

As the development of a mathematical model as such is crucial, the term is discussed below. A starting point for the definition of this term can be found in the publications of Heinrich Hertz. 
Hertz mentions (logical) admissibility, accuracy, and expediency as criteria. A mathematical model is admissible if it does not contradict the principles of logical thinking. In this context, it is accurate if the relevant relations of a real-world problem are shown in the model. Finally, a model is expedient if it describes the matter with appropriate as well as relevant information. Whether a model proves to be expedient, it can only be judged in comparison with the real-life problem. It can be expressed by means of an economical model or in a different situation by the richness of relations (Neunzert and Rosenberger 1991). A new problem might require a new model, even if the object is the same. Furthermore, Hertz emphasises as a conditio sine qua non, that the mathematical model has to correspond to the real-life items (Hertz 1894).

The term mathematical model has been described in the German literature in many ways. Models are simplified representations of reality, that is, only reflecting aspects to some extent objectively (Henn and Maaß 2003). For this purpose, the observed part of reality is isolated and its relations are controlled. The subsystems of these selected parts are substituted by known structures without destroying the overall structure (Ebenhöh 1990). Mathematical models are a special representation of the real world enabling the application of mathematical methods. If mathematical methods are used, mathematical models that only represent the real world can even deliver a mathematical result (Zais and Grund 1991). Thus, a mathematical model is a representation of the real world, which-although simplified-corresponds to the original and allows an application of mathematics. However, the processing of a real problem with mathematical methods is limited, as the complexity of reality cannot be translated completely into a mathematical model. This is usually not even desired. Another reason for generating models is the possibility of processing real data in a manageable way. Thus, only a selected part of reality will be transferred into mathematics through modelling (Henn 2002).

\subsubsection{Different Modelling Cycles}

When looking at the literature on modelling and applications, one can find many different modelling cycles. These cycles are different from one another, as they were developed with different intentions and for different aims. When looking at different cycles, the purposes for which they were developed should always be kept in mind. The following classification shows the different aims and purposes of these cycles for research and practice (Borromeo Ferri 2006, 2018):

- Modelling cycle from applied mathematics

- Didactical or pedagogical modeling cycle

- Psychological modeling cycle

- Diagnostic modeling cycle/modeling cycle from a cognitive perspective. 


\subsubsection{Modelling Cycle from Applied Mathematics}

In almost all books on mathematical modelling from applied mathematics, one can find modelling cycles which have one thing in common: there is a direct transition from a real problem to a mathematical one, which implies that there is no distinction between the real situation and real model, or real model and mathematical model. This has to do partly with the kind of modelling problems which are used in this context. These are mostly "realistic and complex" problems, such as from industry or economics. The complexity of real problems influences the number of phases within the modelling cycle to some extent, because there is no need to make more distinctions.

A well-known researcher in the field of modelling in general, but especially in terms of considering modelling as a way to understand the real world better, is certainly Pollak (1979), whose perspectives on applied mathematics are presented in Fig. 4.1. Pollak's ideas have influenced considerably the development of modeling cycles in research on modelling in mathematics education.

\subsubsection{Didactical or Pedagogical Modeling Cycle}

Mathematics lessons constitute a different situation in which modelling cycles are used. Here, cycles are used to help students to get to an understanding of the modelling process and to give them a metacognitive tool for overcoming problems. Furthermore, the implementation of a cycle within modelling lessons offers students the opportunity to reflect on what they have done while solving real problems. Furthermore, the students learn the notions of "real models" or "mathematical models" and thus reach a metacognitive level, thus promoting modelling competencies. There are various kinds of so-called didactical or pedagogical modelling cycles. However, what they have in common is that reality and mathematics are seen as two "separated worlds", also in Pollak's model. At first glance, they differ only marginally from the four steps of Ortlieb (Fig. 4.3). However, some of them additionally differentiate between real problems and real models. Furthermore, most of them differ like Ortlieb, between mathematical results and real results, which means that the interpretation of the mathematical result(s) are mentioned as a crucial part of working on a modelling problem (s. Fig. 4.4).

\subsubsection{Diagnostic Modeling Cycle: Modeling Cycle from a Cognitive Perspective}

During the last few decades, some researchers focused on cognitive processes of individuals during modelling processes (Borromeo Ferri 2007; Blum and Leiß 


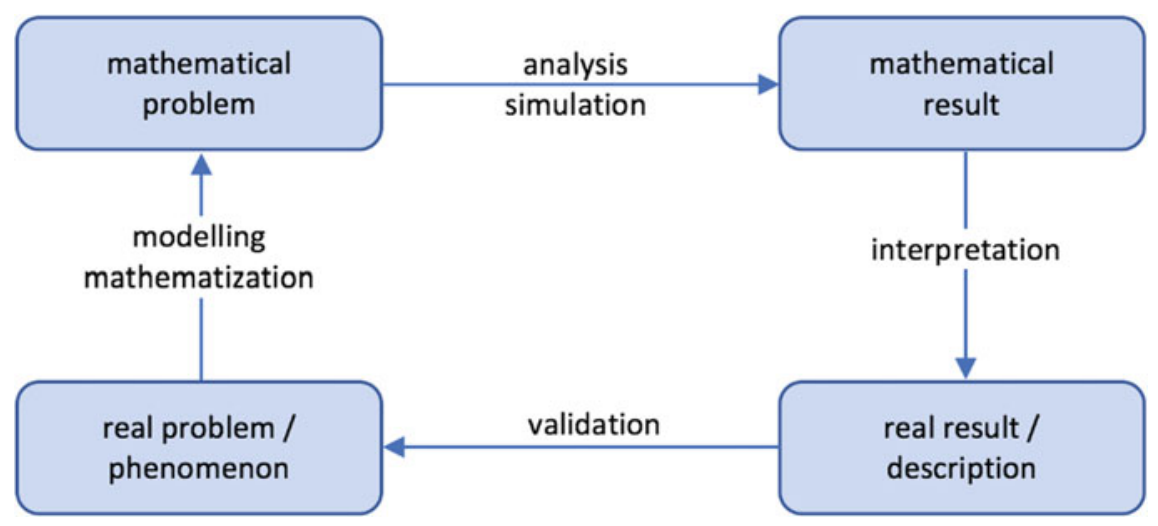

Fig. 4.3 Prototype for modelling cycles from applied mathematics (Ortlieb 2004, p. 23)

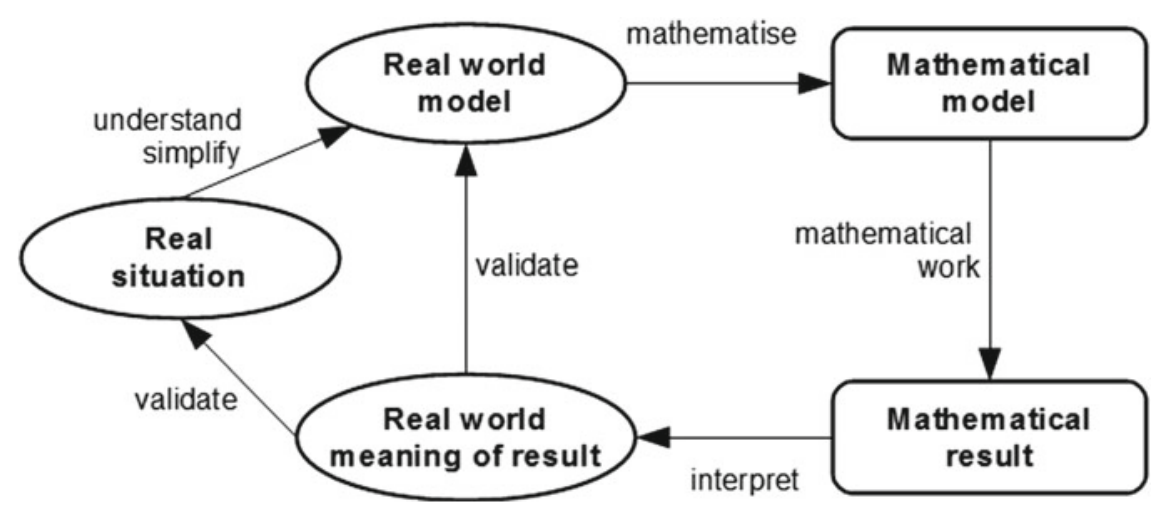

Fig. 4.4 Modelling cycle of Kaiser and Stender (2013, p. 279)

2007). Thus, a situation model was included in the modelling cycle, because researchers assumed that all individuals more or less proceed through this phase during modelling.

Blum and Leiß (2007; s. Fig. 4.5) understand the situation model in their cycle as an important phase during the modelling process. That is because they describe the transition between real situation and situation model as a phase of understanding the task. A similar approach was pursued in the $\mathrm{COM}^{2}$-project (Borromeo Ferri 2007; see Fig. 4.6). Here, an additional phase was integrated, similar to the situation model of the modelling cycle by Blum and Leiß.

However, Borromeo Ferri used the name "mental representation of the situation" (MRS) instead of situation model, because this term focusses on internal processes through which an individual goes to obtain a corresponding mental picture while/after reading the (complex) modelling task. 


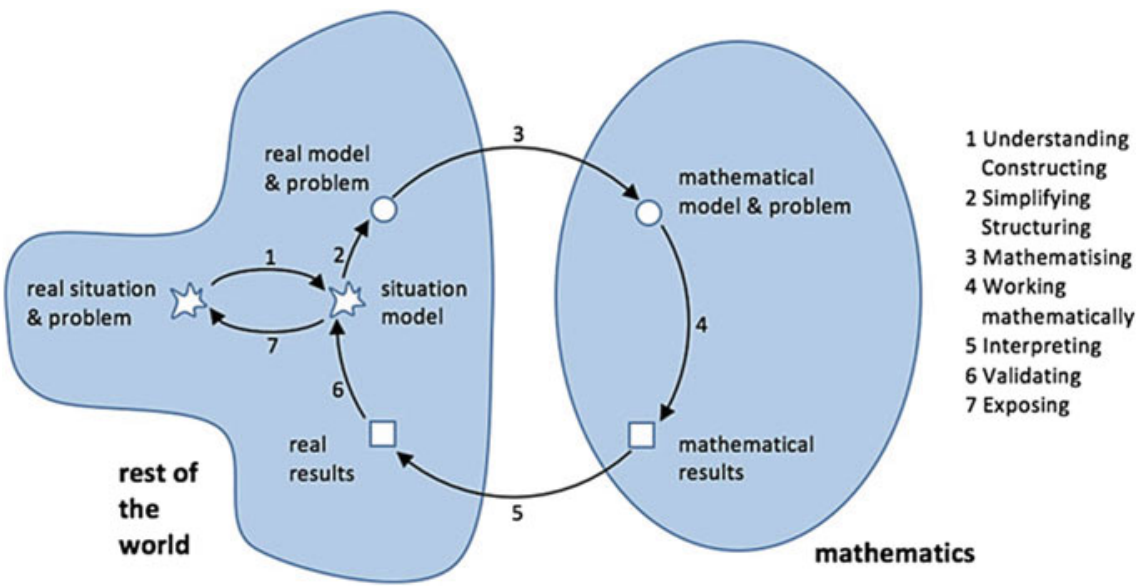

Fig. 4.5 Modelling cycle of Blum and Leiß (2007, p. 225)

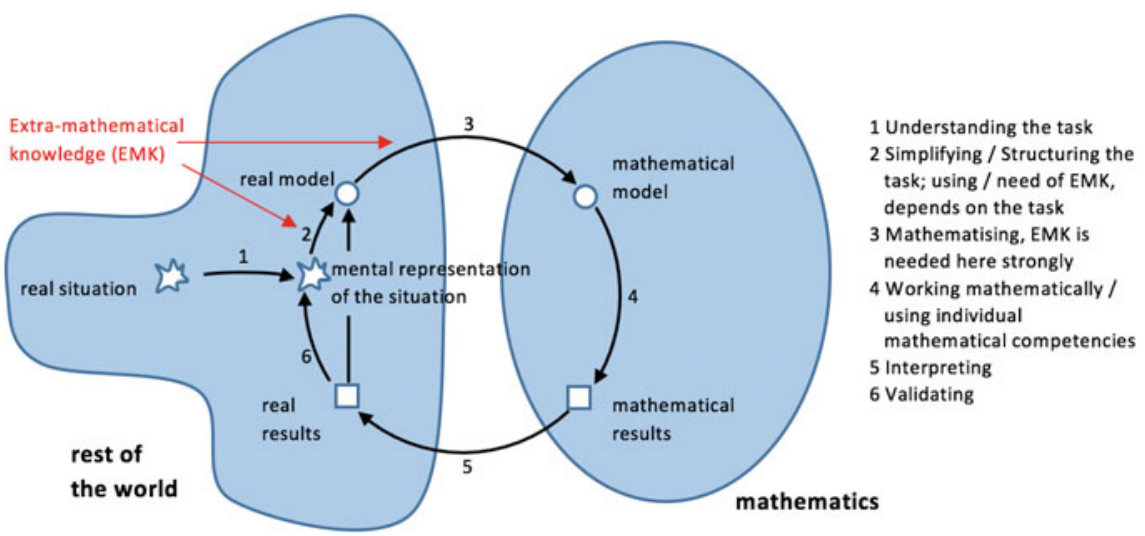

Fig. 4.6 Mathematical modeling cycle from a cognitive perspective (Borromeo Ferri 2007, p. 266)

Through the situation model and the mental representation of the situation, a cognitive view of modeling processes is provided. Thus, for diagnostic purposes, this cycle is a good instrument. If teachers are able to name and to distinguish between steps within the modeling cycle, they can diagnose possible cognitive barriers students encounter while modeling.

The theoretical construct of a situation model comes from text linguistic works and is mainly related to non-complex word problems (see Kintsch and Greeno 1985; Verschaffel et al. 2000).

The situation model includes inferences that are made using knowledge about the domain of the text information. It is a representation of the content of a text, independent of how the text was formulated and integrated with other relevant experiences. Its structure is adapted 
to the demands of whatever tasks the reader expects to perform. (Kintsch and Greeno 1985, p. 110)

These cycles are not used in school and it was not the developers' intention to do so. However, the relevance of including the situation model in the diagnostic modelling cycle offered new paths for research and practice, and particularly for teacher education and training on mathematical modelling.

\subsubsection{Modelling and Digital Tools}

Possible modelling activities in mathematics teaching have changed over the last few years, mainly due to the existence of digital tools. Especially when dealing with realistic problems, a computer or an adequately equipped graphical calculator can be a useful tool for supporting teachers and students. Henn (1998), for example, suggested this early on and proposed implementing digital tools, e.g., notebooks with algebra software, because this would enable the introduction of complex applications and modelling into daily teaching (see also Henn 2007).

Currently, digital tools are often used to work on such problems, such as to process models with complex function terms or to reduce calculation effort. Digital tools can perform a range of tasks in teaching applications and modelling. One possibility for using these tools is experimenting and exploring (Hischer 2002). Simulating is very similar to experimenting. Simulations, which are experiments that use models, are intended to provide insights into the real system presented in the model or into the model itself (Greefrath and Weigand 2012).

A common use of digital tools, especially computer algebra systems, is that of calculating or estimating numerical or algebraic solutions (Hischer 2002). Without such tools, students would not be able to make these estimations, at least not within a reasonable time frame. A computer can also be used to find algebraic representations from the information given. In addition, digital tools can perform a visualisation of a subject taught at school (Barzel et al. 2005; Hischer 2002; Weigand and Weth 2002), and also play a useful role in controlling and verifying (Barzel et al. 2005). Therefore, digital tools can, for example, help with control processes for discrete functional models. If computers with an internet connection are provided for mathematics teaching, they can be used to conduct investigations (Barzel et al. 2005), e.g., in context with applications. In this way, real problems can be understood initially and simplified afterwards.

A computer's various functions can be used in mathematics education for a range of steps in the modelling cycle. Control processes, for example, are usually the last step of a modelling process. Calculations are by means of the generated mathematical model, which in analysis, for example, is often represented by a function. Digital tools can be usefully in every step of the modelling cycle (s. Greefrath 2011).

If the steps of calculating with digital tools are considered more precisely, working on modelling problems with digital tools requires two translation processes. First, the 


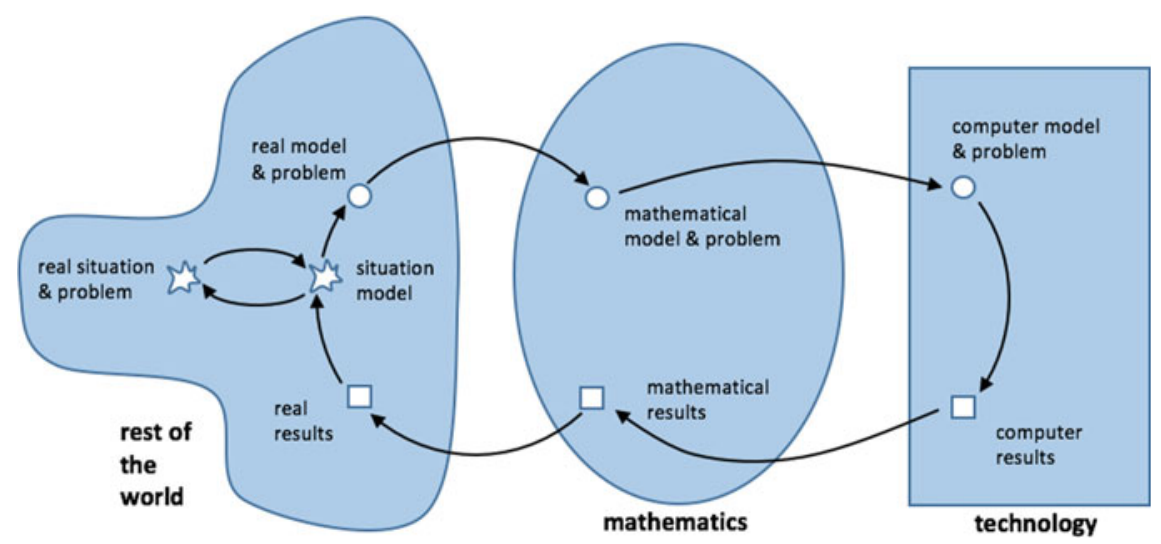

Fig. 4.7 Extended modelling cycle (Greefrath 2011, p. 302; Blum and Leiß 2007, p. 22)

modelling question has to be understood, simplified, and translated into mathematics. The digital tool, however, can only be used after the mathematical terms have been translated into the computer's language. The results calculated by the computer then have to be transformed back again into mathematical language. Finally, the original problem can be solved when the mathematical results are applied to the real situation. These translation processes can be represented in an extended modelling cycle (see Fig. 4.7), which in addition to the rest of the world and mathematics, also includes technology (Savelsbergh et al. 2008; Greefrath 2011). Current studies, however, show that actual modelling activity which includes a computer can be better described by integrating the computer in every step of the modelling cycle.

Currently, there is little empirically established knowledge about the possibilities of teaching modelling with digital tools. Open research questions can be found in the works of Niss et al. (2007). These include the following questions: How should digital tools be used in different grades to support modelling processes? What is the effect of digital tools on the spectrum of modelling problems to be worked on? How is teaching culture influenced by the existence of digital tools? When do digital tools enhance or hinder learning opportunities in the modelling process?

Additional empirical research is required to clarify the above questions, especially considering the extended modelling cycle and the necessary translation processes. Case studies (e.g. Geiger 2011) indicate though, that digital tools could be useful for each and every step of the modelling process. This is particularly true for interpreting and validating. 


\subsection{Research on Modelling}

\subsubsection{The Development of Research on Mathematical Modelling in German-Speaking Countries}

With regard to Niss et al. (2007), the research activities on mathematical modelling have been characterized by three phases over the last 50 years. The so-called advocacy phase (1965-1975), in which there was little research, because there was no consensus the importance of applied mathematics in school. In the second development phase (1975-1990), there was considerable historical and theoretical research, as well as curricula and material development. The third maturation phase (1990-2005) contains the first (qualitative) empirical studies. At least in Germany-and possibly worldwide - it seems that a new phase has begun, that of consolidation (2005-today). Mathematical modelling is now (or should be) part of everyday school mathematics; research on this issue is respected by other research disciplines, so that it takes place with regard to a variety of methodological approaches. Accordingly, beside theoretical content analysis and qualitative case studies, there is a growing number of projects which use state of the art quantitative methods to obtain answers to research questions.

\subsubsection{Research Questions in the Field of Mathematical Modelling}

Fifteen years ago, Blum et al. (2002), on the occasion of preparing the 14th ICMI study, pointed out that there are at least nine important topics or research questions on mathematical modelling which yet waiting to be answered:

1. Epistemology: e.g. What is the nature of mathematical modelling?

2. Tasks: e.g. What kind of tasks are needed to teach/learn mathematical modelling?

3. Competencies: e.g. Which subcompetencies can be identified in the process of mathematical modelling?

4. Attitudes: e.g. What is the influence of mathematical modelling on beliefs about mathematics?

5. Curriculum: e.g. What are the main goals of lessons or units with applied problems?

6. Pedagogy: e.g. Does the learning of mathematical modelling require special teaching methods?

7. Implementation: e.g. How can mathematical modelling be implemented in everyday math classrooms?

8. Assessment: e.g. How can the performance of a modelling process be supported by adaptive feedback? 
9. Technology: e.g. What implications does the use of technology have for modelling process?

Researchers in Germany followed the call of Blum et al. "Readers are invited to come up with additional relevant issues." (2002, p. 159) and discovered several new research areas in Germany's research landscape, for example:

10. Metacognition: e.g. How can metacognitive activities support students' modelling processes?

11. Strategies: e.g. What is the influence of specific learning tools on mathematical modelling?

12. Language: e.g. What role do language competencies play in the modelling process?

13. ...

For example, ten years ago, there were only a handful of projects in Germanspeaking countries which examined the process of text comprehension during the modelling process. Along with an awareness of the important role of language for mathematical solution processes (Paetsch et al. 2016) there is now a growing community of researchers in this field of interest. Topics range from the role of the mental model of a given task, to the teaching language, language disadvantages or linguistic modifications of tasks (e.g. Leiß et al. 2010; Prediger et al. 2013; Haag et al. 2015). In addition to this thematic extension, there has also been a considerable methodological development. This might be one reason (beside others like national educational standards) for changes in the kind of research projects on mathematical modelling in the last few decades. Research projects in modelling more often used experimentalcontrol-group designs and sophisticated statistical methods for analysing the various research questions.

\subsubsection{Multiple Solutions: An Example of Quantitative Research on Modelling}

One example of quantitative research on modelling is research project MultiMa (Multiple Solutions for Mathematics Teaching Oriented Toward Students' SelfRegulation). One starting point of MultiMa project entails expectations about the importance of constructing multiple solutions for learning mathematics. However, there is a lack of empirical evidence on positive effects of this teaching element on student learning in general and on modelling competency in particular. Thus, the aim of the above project was to investigate the effects of encouraging students to find multiple solutions while solving modelling problems and the impact on performance, motivation, emotions and strategies.

The theoretical analysis of student solution processes has enabled distinguishing between three types of multiple solutions for modelling problems: (1) multiple solutions that occur due to different assumptions about missing information and lead 


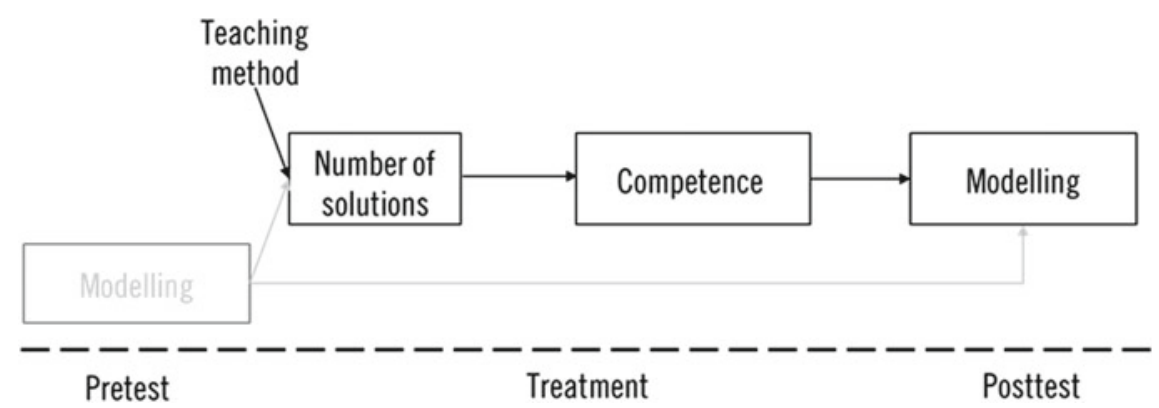

Fig. 4.8 Hypothesised path analytic model (Schukajlow et al. 2015)

to different mathematical results, (2) multiple solutions through applying different mathematical procedures that lead to the same mathematical results and (3) a combination of the first and second type of multiple solutions (Schukajlow et al. 2015). The main part of the first stage of the project was a randomized interventional study aimed at comprising the effects of two teaching methods: encouraging students to find multiple solutions for modelling problems versus encouraging students to find just one solution for modelling problems. On the basis of motivational, emotional and cognitive theories, we assumed that the positive effects of intervention on students affect performance and strategies, and we hypothesised how encouraging multiple solutions affects dependent variables, using path analytic models. We hypothesised, for example, that prompting students to construct multiple solutions will affect the number of solutions they develop and the number of solutions will in turn affect student experiences of competence during teaching units, and their experiences of competence will affect performance (see Fig. 4.8).

In order to examine our hypothesis, we assigned students from 6 classes to two treatment conditions according to a specific procedure. Students in both conditions worked for five lessons long on modelling problems. Before, after and during their lessons, they completed questionnaires. Moreover, before and after this teaching unit, they solved tests on modelling and intra-mathematical performance. In both conditions, we used similar problems and the same type of cooperation script (socalled "individual work in groups"), which was evaluated positively in the DISUMproject. One sample problem is Parachuting (Fig. 4.9).

In the multiple-solution condition, each student was required to find two solutions to the Parachuting problem: "Find two possible solutions. Write down both solution methods." In the one-solution condition, the problem was modified by providing all important data for solving the problem and by changing the question to "What distance does the parachutist cover during the entire fall, if a wind of medium power blows? Write down your solution method." In the multiple-solutions condition, all students used the Pythagorean Theorem as a mathematical procedure. Solutions differed, for example, in assumptions about the wind speed in each falling stage.

Contrary to our expectations, we did not find (total) positive effects of encouraging students to construct multiple solutions on student performance. However, we find 


\begin{tabular}{|c|c|c|}
\hline \multicolumn{3}{|c|}{$\begin{array}{l}\text { Parachuting } \\
\text { When "parachuting," a plane takes jumpers to an altitude of about } 4,000 \text { meters. From } \\
\text { there, they jump off the plane. Before a jumper opens his parachute, he free falls about } \\
3,000 \text { meters. At an altitude of about } 1,000 \text { meters, the parachute opens, and the } \\
\text { sportsman glides to the landing place. While falling, the jumper is carried off target by the } \\
\text { wind. Deviations at different stages are shown in the table below. }\end{array}$} \\
\hline Wind speed & $\begin{array}{l}\text { Side deviation per thousand meters } \\
\text { during free-fall }\end{array}$ & $\begin{array}{l}\text { Side deviation per thousand } \\
\text { meters while gliding }\end{array}$ \\
\hline Light & 60 meters & 540 meters \\
\hline Medium & 160 meters & 1,440 meters \\
\hline Strong & 340 meters & 3,060 meters \\
\hline
\end{tabular}

Fig. 4.9 Modelling problem parachuting

indirect effects of the teaching method on performance, and confirmed the hypotheses that were formulated in hypothesised path analytic model. This result indicated that students who developed multiple solutions and feel competent, benefit from this teaching method.

\subsection{Conclusion and Summary}

Teacher requests for modelling projects, teacher training on the implementation of modelling as well as a willingness to participate in modelling research projects, all clearly indicate that teachers do attempt to implement modelling in their classrooms. So, the efforts of the last few years do seem to have had a positive effect. Yet, research on how to foster students' modelling competencies best, teacher training on how to support students solving modelling problems, as well as research on the effects of modelling days and weeks, should be intensified. Furthermore, in order to disseminate modelling to a wider audience and a greater extend, modelling tasks should be part of the task pool for the German School leaving examination (Abitur). An initial analysis of the available pool of items shows a rather low proportion of modelling (Greefrath et al. 2018). Thus, developing tasks that are appropriate for testing modelling competences within exams is one of the important open issues for the near future.

As presented above, modelling and applications were and remain an important part of German debate on mathematics education. In the last century, the German debate on modelling focused on conceptual aspects and exemplarily modelling problems. This was an important step in clarifying the content of the concept mathematical model. During this time, a discussion on different types of models and modelling examples in the light of a long German tradition of applications in school mathematics took place. An important step in bringing research and school practice closer together, 
and integrating modelling examples into the classroom, was the establishment of the German-speaking ISTRON group 25 years ago. A new development in integrating applications and modelling in all types of schools started at the end of the 20th century. A much-debated issue is the adaptation of a particular modelling cycle for a particular research question. This development led to a greater internationalisation of German research on modelling, and the integration of modelling as a competency into the curriculum at the beginning of the millennium. Currently, modelling is part of the German educational standards. However, as in most countries, applications and modelling play only a small role in everyday teaching. The presented empirical results reveal the main foci of research on modelling applications over the few last years. At presents, the effective promotion of student modelling competencies is the core of research. Concurrently, instruments for helping students to work on modelling problems independently (and relieving teachers in various ways) are being developed and analysed.

\section{References}

Bardy, P., Danckwerts, R., \& Schornstein, J. (Eds.). (1996). Materialien für einen realitätsbezogenen Mathematikunterricht, Band 3. Hildesheim: Franzbecker.

Barzel, B., Hußmann, S., \& Leuders, T. (2005). Computer, Internet \& Co im Mathematikunterricht. Berlin: Cornelsen Scriptor.

Blum, W., Galbraith, P., Henn, H.-W., \& Niss, M. (2002). ICMI study 14: applications and modelling in mathematics education-Discussion document. Educational Studies in Mathematics, 5(1-2), 149-171.

Blum, W. (Ed.). (1993). Anwendungen und Modellbildung im Mathematikunterricht. Hildesheim: Franzbecker.

Blum, W. (2007). Mathematisches Modellieren - zu schwer für Schüler und Lehrer? In Beiträge zum Mathematikunterricht 2007 (pp. 3-12). Hildesheim [u.a.]: Franzbecker.

Blum, W. (2011). Can Modelling Be Taught and Learnt? Some Answers from Empirical Research. In G. Kaiser, W. Blum, R. Borromeo Ferri, \& G. A. Stillman (Eds.), International Perspectives on the Teaching and Learning of Mathematical Modelling: rends in teaching and learning of mathematical modelling (pp. 15-30). Dordrecht: Springer Science+Business Media. https://doi. org/10.1007/978-94-007-0910-2_3.

Blum, W. (2015). Quality teaching of mathematical modelling: What do we know, what can we do? In S. J. Cho (Ed.), The Proceedings of the 12th International Congress on Mathematical Education (pp. 73-96). Cham: Springer International Publishing.

Blum, W., \& Leiß, D. (2007). How do students and teachers deal with modelling problems? In C. Haines, W. Blum, P. Galbraith, \& S. Khan (Eds.), Mathematical modelling (ICTMA 12): Education, engineering and economics (pp. 222-231). Chichester: Horwood.

Blum, W., Galbraith, P. L., Henn, H.-W., \& Niss, M. (Eds.). (2007). Modelling and applications in mathematics education. The 14th ICMI study. New York: Springer.

Böhm, U. (2013). Modellierungskompetenzen langfristig und kumulativ fördern: Tätigkeitstheoretische Analyse des mathematischen Modellierens in der Sekundarstufe I. Wiesbaden: Springer Spektrum.

Borromeo Ferri, R. (2006). Theoretical and empirical differentiations of phases in the modelling process. ZDM-The International Journal on Mathematics Education, 38(2), 86-95. 
Borromeo Ferri, R. (2007). Modelling from a cognitive perspective: Individual modelling routes of pupils. In: C. Haines, P. Galbraith, W. Blum, \& S. Khan (Eds.), Mathematical modelling. Education, engineering and economics (pp. 260-270). Chichester: Horwood Publishing.

Borromeo Ferri, R. (2018). Learning how to teach mathematical modeling in school and teacher education. New York: Springer.

Ebenhöh, W. (1990). Mathematische Modellierung Grundgedanken und Beispiele. Der Mathematikunterricht, 36(4), 5-15.

Eichler, A., \& Vogel, M. (2016). Young students' mental modelling of statistical situations. In D. Ben-Zvi \& K. Makar (Eds.), The teaching and learning of statistics. Cham: Springer.

Franke, M., \& Ruwisch, S. (2010). Didaktik des Sachrechnens in der Grundschule. Heidelberg: Spektrum.

Geiger, V. (2011). Factors affecting teachers' adoption of innovative practices with technology and mathematical modelling. In G. Kaiser, W. Blum, R. Borromeo Ferri, \& G. Stillman (Eds.), Trends in teaching and learning of mathematical modelling (pp. 305-314). Dordrecht: Springer.

Greefrath, G. (2011). Using technologies: New possibilities of teaching and learning modelling-Overview. In G. Kaiser, W. Blum, R. Borromeo Ferri, \& G. Stillman (Eds.), Trends in teaching and learning of mathematical modelling, ICTMA 14 (pp. 301-304). Dordrecht: Springer.

Greefrath, G. (2018). Anwendungen und Modellieren im Mathematikunterricht. Didaktische Perspektiven des Sachrechnens in der Sekundarstufe. Berlin: Springer Spektrum.

Greefrath, G., Kaiser, G., Blum, W., \& Borromeo Ferri, R. (2013). Mathematisches Modellieren - Eine Einführung in theoretische und didaktische Hintergründe. In R. Borromeo Ferri, G. Greefrath, \& G. Kaiser (Eds.), Mathematisches Modellieren für Schule und Hochschule. Theoretische und didaktische Hintergründe. Wiesbaden: Springer Spektrum.

Greefrath, G. Siller, H.-S., \& Ludwig, M. (2018). Modelling problems in German grammar school leaving examinations (Abitur)-Theory and practice. In Proceedings of the Tenth Congress of the European Society for Research in Mathematics Education (CERME 10) (pp. 829-836), Dublin, Ireland.

Greefrath, G., \& Vorhölter, K. (2016). Teaching and learning mathematical modelling: Approaches and developments from German speaking countries. ICME-13 topical surveys. Cham: Springer International Publishing.

Greefrath, G., \& Weigand, H.-G. (2012). Simulieren - mit Modellen experimentieren. mathematik lehren, 174, 2-6.

Haag, N., Heppt, B., Roppelt, A., \& Stanat, P. (2015). Linguistic simplification of mathematics items: Effects for language minority students in Germany. European Journal of Psychology and Education, 30(2), 145-167.

Henn, H.-W. (1998). The impact of computer algebra systems on modelling activities. In P. Galbraith, W. Blum, G. Book, \& I. D. Huntley (Eds.), Mathematical modelling. Teaching and assessment in a technology-rich world (pp. 115-124). Chichester: Horwood.

Henn, H.-W. (2002). Mathematik und der Rest der Welt. mathematik lehren, 113, 4-7.

Henn, H.-W., \& Maaß, K. (2003). Standardthemen im realitätsbezogenen Mathematikunterricht. In W. Henn \& K. Maaß (Eds.), Materialien für einen realitätsbezogenen Mathematikunterricht. Bd. 8 (ISTRON) (pp. 1-5). Hildesheim: Franzbecker.

Henn, H.-W. (2007). Modelling pedagogy-Overview. In W. Blum, P. L. Galbraith, H.-W. Henn, $\&$ M. Niss (Eds.), Modelling and applications in mathematics education. The 14th ICMI study (pp. 321-324). New York: Springer.

Henn, H.-W., \& Müller, J. H. (2013). Von der Welt ins Modell und zurück. In R. Borromeo Ferri, G. Greefrath, \& G. Kaiser (Eds.), Mathematisches Modellieren für Schule und Hochschule (pp. 202-220). Wiesbaden: Springer Fachmedien.

Herget, W., \& Scholz, D. (1998). Die etwas andere Aufgabe aus der Zeitung. Seelze: Kallmeyer.

Hertz, H. (1894). Die Prinzipien der Mechanik in neuem Zusammenhange dargestellt. Leipzig: Barth.

Hischer, H. (2002). Mathematikunterricht und Neue Medien. Hintergründe und Begründungen in fachdidaktischer und fachübergreifender Sicht. Hildesheim: Franzbecker. 
Kaiser-Messmer, G. (1986). Anwendungen im Mathematikunterricht. 1. Theoretische Konzeptionen. Texte zur mathematisch-naturwissenschaftlich-technischen Forschung und Lehre Bd. 20. Bad Salzdetfurth: Franzbecker.

Kaiser, G., Bracke, M., Göttlich, S., \& Kaland, C. (2013). Authentic complex modelling problems in mathematics education. In A. Damlamian, J. F. Rodrigues, \& R. Sträßer (Eds.), New ICMI study series. Educational interfaces between mathematics and industry (Vol. 16, pp. 287-297). Cham: Springer.

Kaiser, G., \& Brand, S. (2015). Modelling competencies: Past development and further perspectives. In G. A. Stillman, W. Blum, \& M. Salett Biembengut (Eds.), Mathematical modelling in education research and practice (pp. 129-149). Cham: Springer International Publishing.

Kaiser, G., \& Schwarz, B. (2010). Authentic Modelling Problems in Mathematics Education-Examples and Experiences. Journal für Mathematik-Didaktik, 31(1), 51-76.

Kaiser, G., \& Stender, P. (2013). Complex modelling problems in co-operative, self-directed learning environments. In G. Stillman, G. Kaiser, W. Blum, \& J. Brown (Eds.), Teaching mathematical modelling: Connecting to research and practice (pp. 277-293). Dordrecht: Springer.

Kintsch, W., \& Greeno, J. (1985). Understanding word arithmetic problems. Psychological Review, 92(1), 109-129.

Klein, F. (1907). Vorträge über den mathematischen Unterricht an den höheren Schulen. Teil 1. Leipzig: Teubner.

KMK. (2012). Bildungsstandards im Fach Mathematik für die Allgemeine Hochschulreife. Beschluss der Kultusministerkonferenz vom 18.10.2012.

Leiß, D., Schukajlow, S., Blum, W., Messner, R., \& Pekrun, R. (2010). The role of the situation model in mathematical modelling-Task analyses, student competencies, and teacher interventions. Journal für Mathematik-Didaktik, 31(1), 119-141.

Lietzmann, W. (1924). Methodik des mathematischen Unterrichts (Vol. III). Leipzig: Quelle \& Meyer.

Neunzert, H., \& Rosenberger, B. (1991). Schlüssel zu Mathematik. Econ.

Niss, M. (2003). Mathematical competencies and the learning of mathematics: The Danish KOM project. In A. Gagatsis \& S. Papastavridis (Eds.), Mediterranean Conference on Mathematical Education (pp. 115-124). Athen: 3rd Hellenic Mathematical Society and Cyprus Mathematical Society.

Niss, M., Blum, W., \& Galbraith, P. (2007). Introduction. In W. Blum, P. L. Galbraith, H.-W. Henn, \& M. Niss (Eds.), Modelling and applications in mathematics education. The 14th ICMI study (pp. 3-32). New York: Springer.

Ortlieb, C.-P. (2004). Mathematische Modelle und Naturerkenntnis. mathematica didactica, 27(1), 23-40.

Paetsch, J., Radmann, S., Felbrich, A., Lehrmann, R., \& Stanat, P. (2016). Sprachkompetenz als Prädikator mathematischer Kompetenzentwicklung von Kindern deutscher und nicht- deutscher Familiensprache. Zeitschrift für Entwicklungspsychologie und Pädagogische Psychologie, 48(1), 27-41.

Prediger, S., Renk, N., Büchter, A., Gürsoy, E., \& Benholz, C. (2013). Family background or language disadvantages? Factors for underachievement in high stakes tests. In A. Lindmeier \& A. Heinze (Eds.), Proceedings of the 37th Conference of the International Group for the Psychology of Mathematics Education (Vol. 4, pp. 4.49-4.56).

Pollak, H. O. (1977). The interaction between mathematics and other school subjects (Including integrated courses). In H. Athen \& H. Kunle (Eds.), Proceedings of the Third International Congress on Mathematical Education (pp. 255-264). Karlsruhe: Zentralblatt für Didaktik der Mathematik.

Pollak, H. O. (1979). The interaction between mathematics and other school subjects. In UNESCO (Eds.), New trends in mathematics teaching IV, (pp. 232-148). Paris: OECD. 
Savelsbergh, E. R., Drijvers, P. H. M., van de Giessen, C., Heck, A., Hooyman, K., Kruger, J., et al. (2008). Modelleren en computer-modellen in de $\beta$-vakken: advies op verzoek van de gezamenli$j k e$-vernieuwingscommissies. Utrecht: Freudenthal Instituut voor Didactiek van Wiskunde en Natuurwetenschappen.

Schukajlow, S., Krug, A., \& Rakoczy, K. (2015). Effects of prompting multiple solutions for modelling problems on students' performance. Educational Studies in Mathematics, 89(3), 393-417.

Schupp, H. (1989). Applied mathematics instruction in the lower secondary level-Between traditional and new approaches. In W. Blum, et al. (Eds.), Applications and modelling in learning and teaching mathematics (pp. 37-46). Chichester: Ellis Horwood.

Stender, P. (2016). Wirkungsvolle Lehrerinterventionsformen bei komplexen Modellierungsaufgaben. Wiesbaden: Springer Fachmedien.

Tropper, N., Leiß, D., \& Hänze, M. (2015). Teachers’ temporary support and worked-out examples as elements of scaffolding in mathematical modelling. ZDM Mathematics Education, 47(7), $1225-1240$.

Verschaffel, L., Greer B., \& De Corte, E. (2000). Making sense of word problems. Swets \& Zeitlinger: The Netherlands.

Vorhölter, K., Kaiser, G., \& Borromeo Ferri, R. (2014). Modelling in mathematics classroom instruction: An innovative approach for transforming mathematics education. In Y. Li, E. A. Silver, \& S. Li (Eds.), Advances in mathematics education. Transforming mathematics instruction. Multiple approaches and practices (pp. 21-36). Cham: Springer.

Weigand, H.-G., \& Weth, T. (2002). Computer im Mathematikunterricht. Neue Wege zu alten Zielen. Heidelberg: Spektrum.

Winter, H. (1981). Der didaktische Stellenwert des Sachrechnens im Mathematikunterricht der Grund- und Hauptschule. Pädagogische Welt, 666-674.

Zais, T., \& Grund, K.-H. (1991). Grundpositionen zum anwendungsorientierten Mathematikunterricht bei besonderer Berücksichtigung des Modellierungsprozesses. Der Mathematikunterricht, $37(5), 4-17$.

Open Access This chapter is licensed under the terms of the Creative Commons Attribution 4.0 International License (http://creativecommons.org/licenses/by/4.0/), which permits use, sharing, adaptation, distribution and reproduction in any medium or format, as long as you give appropriate credit to the original author(s) and the source, provide a link to the Creative Commons licence and indicate if changes were made.

The images or other third party material in this chapter are included in the chapter's Creative Commons licence, unless indicated otherwise in a credit line to the material. If material is not included in the chapter's Creative Commons licence and your intended use is not permitted by statutory regulation or exceeds the permitted use, you will need to obtain permission directly from the copyright holder.

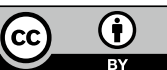




\title{
Chapter 5 \\ Mathematics and Bildung 1810 to 1850
}

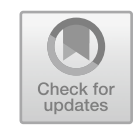

\author{
Hans Niels Jahnke with a reaction by Michael N. Fried
}

\begin{abstract}
Section 5.1 of this chapter is written by Hans Niels Jahnke on the basis of his presentation at ICME 13. Michael Fried was invited to react to this presentation at ICME 13 and elaborated his reaction as Sect. 5.2 of this chapter. Although the authors are only responsible for their respective parts, the parts belong together and are therefore published here as a joint chapter. The first part analyzes the role of mathematics within the ideas on education of the neo-humanist movement. It refers to the period of around 1800-1850 and concentrates on the thinking of W. von Humboldt and the two catchwords of "anti-utilitarianism" and "self-directed activity'. From this general educational attitude resulted a certain preference for pure mathematics which had to be balanced against the daily needs of shopkeepers and workmen. A compromise on this issue was developed and implemented in the 1820s. Nevertheless, a strong emphasis on theoretical thinking, understanding and pure science remained for a long time the main stream of educational thinking In the eyes of the neo-humanists this was not a denial of the demands of practical life, but the best way to meet them. In his reaction entitled "Bildung, Paideia, and some undergraduate programs manifesting them," Michael N. Fried discusses how notions similar to that of Bildung are enshrined in the idea of paideia and the classical concept of the liberal arts. He shows that such ideas also work in modern times in the English speaking world by hinting at examples of prominent colleges in North America.
\end{abstract}

Keywords Anti-utilitarianism • Bildung • Everyday applications • Liberal arts • Paideia $\cdot$ Pure mathematics $\cdot$ Self-directed activity 


\section{Preliminary Remark}

In this and the following Chap. 6 the authors use the two German terms Bildung and Allgemeinbildung since there is no adequate translation into English which reflects all the connotations they have taken on in German. The English words 'education' and 'general education' are only first approximations of their German counterparts. However, as Mogens Niss (Chap. 6) rightly remarks, there exist also in other countries and other cultures ideas similar to the ones enshrined in those German words.

A second difficulty concerns the distinction between the two terms of 'Bildung' and 'Allgemeinbildung'. One can observe that as a rule authors of the 19th century used the term Bildung whereas in more recent times Allgemeinbildung became more common. In the background there are subtle differences of meaning. Whereas Bildung emphasizes the comprehensive intellectual, ethic and aesthetic cultivation of personalities, Allgemeinbildung refers more explicitly to the idea that such a cultivation should be made accessible to all human beings. With these different nuances the terms are used in for example (Klafki 2000) as well as in this chapter. But the reader should be careful. Already W. von Humboldt and other neo-humanist thinkers considered Bildung as a right to which all human beings should have access (see below), and, of course, also modern conceptions of Allgemeinbildung aim at the cultivation of personalities in all their dimensions.

This chapter and Chap. 6 discuss the relation of Bildung and mathematics in Germany at two periods of time separated by a time span of nearly two hundred years. The reader who is interested in the development of educational thinking and the teaching of mathematics in Germany during the period between Humboldt and PISA is referred to Chap. 1 of this book "Educational Research on Mathematics-a Short Survey of its Development in German Speaking Countries". On the evolution of educational thinking in general she/he might also consult Blankertz (1982) and Klafki (2000).

\subsection{Mathematics and Bildung at the Time of Humboldt ${ }^{1}$}

\section{Systematizing Public Education}

The educational reforms in Prussia of the early 19th century which influenced the development in the other German states and which bear the name of W. von Humboldt (see below) were part of a longer process beginning in the second half of the 18th century to reorganize and systematize the proliferation of schools which had been created by local communities for different needs. In cities existed learned schools ("gelehrte Schulen") teaching mainly Latin as the language of the educated people giving access to the knowledge of the time. The process of how these learned schools were transformed into the system of Prussian gymnasia has been analysed in detail by Jeismann (1974). Besides the learned schools there were also "Bürgerschu-

\footnotetext{
${ }^{1}$ Many thanks go to Michael Fried for his linguistic advice and thoughtful remarks.
} 
len" ["schools for citizens"] with a more practical orientation to which children of workmen and shopkeepers were sent. However, the great majority of the population lived in the country and children there attended, if at all, elementary schools which provided, frequently under very bad conditions, some basic reading, writing and reckoning. By means of several laws from 1717, 1763 and 1794 school education had become compulsory in Prussia. But data from 1816 say that only $60 \%$ of the children attended a school, and one must infer that this figure was not higher than $50 \%$ during the second half of the 18th century (Lundgreen 1980, Chap. 2; Leschinsky and Roeder 1976, 137; Jahnke 1990a, 6). Only during the 19th century the Prussian state succeeded in getting school education really compulsory, by educating teachers and creating new elementary schools. But the social situation of the lower classes was so bad that frequently the police had to be sent to poor people who preferred to have their children earning some money instead of attending school. Of course, child labour of up to twelve hours a day is not compatible with school attendance.

In the following we confine ourselves to the role of neo-humanism in this process of systematizing public education under the perspective of the teaching of mathematics. Neo-humanism favoured a revival of ancient Greek at learned schools (gymnasia) and also pleaded for a strong position of mathematics (Jahnke 1990a, 333 pp; Schubring 1987, 207). It was not a closed system of propositions, but a more or less vague collection of ideas and convictions which were developed and refined by different persons in different directions. Nevertheless, there was a common core which was condensed in the concept of 'Bildung' and proved heavily influential during the entire 19th century.

After 1810, as reaction of its military defeat against Napoleonic France, Prussia launched a number of social and political reforms whose core lay in restructuring and, in part, establishing a new educational system. To some people in Prussia it appeared reasonable to imitate the earlier educational reforms of revolutionary France which had proved so successful, as the military events had shown, and to give up the seemingly outmoded universities. However, the final decisions were just the other way round. Instead of closing universities and learned schools, Prussia made at first sight a conservative turn: it maintained universities and schools, but endowed them with a new understanding of education and research. This development was deeply rooted in a cultural and intellectual milieu to which we now turn.

\section{The Cultural and Intellectual Milieu Influencing the Emergence of the Neo- Humanist Movement}

We begin with considering the biographies of two men who during some years of their lives had been in close contact yet, nevertheless, were representatives of opposite currents of educational thinking, Johann Heinrich Campe (1746-1818) and Wilhelm von Humboldt (1767-1835), the latter being the most important representative of the neo-humanist movement.

Johann Heinrich Campe (Fig. 5.1), born in a small village in the kingdom of Hannover, studied theology and linguistics in Helmstedt and Halle and worked for a time as a Pastor in Potsdam (cf. Blankertz 1982, $79 \mathrm{ff}$ ). In 1776, he became head of a reform school (a so-called Philanthropin) in Dessau and later founded another such school 
in Hamburg. He was a leading figure of the German enlightenment pedagogy. Following the ideas of Rousseau these people wanted to inaugurate new schools and new teaching. Their basic motive was a fight against the antiquated customs of scholastic teaching. Schools should impart to their students useful knowledge for their future life. The method of teaching should no longer emphasize the written word, but show to students real phenomena. After 1783 Campe gave up practical pedagogical work and dedicated himself exclusively to literary activities. He wrote, on the one hand, theoretical works on pedagogy and linguistics and, on the other hand, as a sort of practical pedagogy, books addressed especially to children and young persons. From 1785 to 1792 he edited a huge work of 16 volumes describing education in Germany, the Examination of the entire system of schools and education: by a society of practical educators ("Allgemeine Revision des gesamten Schul-und Erziehungswesens: von einer Gesellschaft praktischer Erzieher") (Campe 1785-1792). For a time Campe was one of the private tutors of Wilhelm von Humboldt with whom, in 1789, he travelled to Paris where they witnessed the early phases of the French revolution. Campe was one of the most progressive educational thinkers of late 18th century Germany: he carried out educational experiments and fought for freeing education from seemingly outmoded traditions and for introducing new useful subjects into teaching. As we have mentioned he was also an early and influential writer of young adult literature.

The most important figure of the neo-humanist movement was Wilhelm von Humboldt (Fig. 5.2), the elder brother of Alexander von Humboldt (cf. Scurla 1976). Humboldt's father was a military man and had been elevated to nobility by the Prussian king Frederick II. The family was well-off so that Humboldt was financially independent. He received a careful private education and then studied in Göttingen philosophy, history and ancient languages. In 1801 he entered the service of the Prussian state as ambassador at the Vatican. In 1809 he was put in charge of the educational reforms in Prussia. He served in this position only for sixteen months, and then resigned because the Prussian king refused to establish a separate government department for education as Humboldt had claimed for. After 1819 he finally resigned from Prussian services altogether finding the spirit of the ongoing restoration at variance with his own perspective. From then on he worked exclusively as a private scholar on political philosophy and comparative studies on language and art and was very productive in these domains. Humboldt cultivated contacts with numerous intellectuals all over Europe.

Campe and Humboldt represented different generations, and Humboldt's thinking on matters of education was to develop in a direction quite different from Campe's. Nevertheless, they maintained friendly relations and shared a number of opinions, for example a more or less positive view of the revolutionary events in France. The reader should keep this in mind, since neo-humanist views on education as they emerged in the first decades of the 19th century were frequently exposed as a sharp and sometimes unfair and insulting critique of enlightenment pedagogy (see Niethammer 1808). In a way, the personal connection between Campe and Humboldt symbolizes the overarching relation between enlightenment and neo-humanism, the 
Fig. 5.1 J. H. Campe (1746-1818) (source Wikipedia Public Domain, (C)

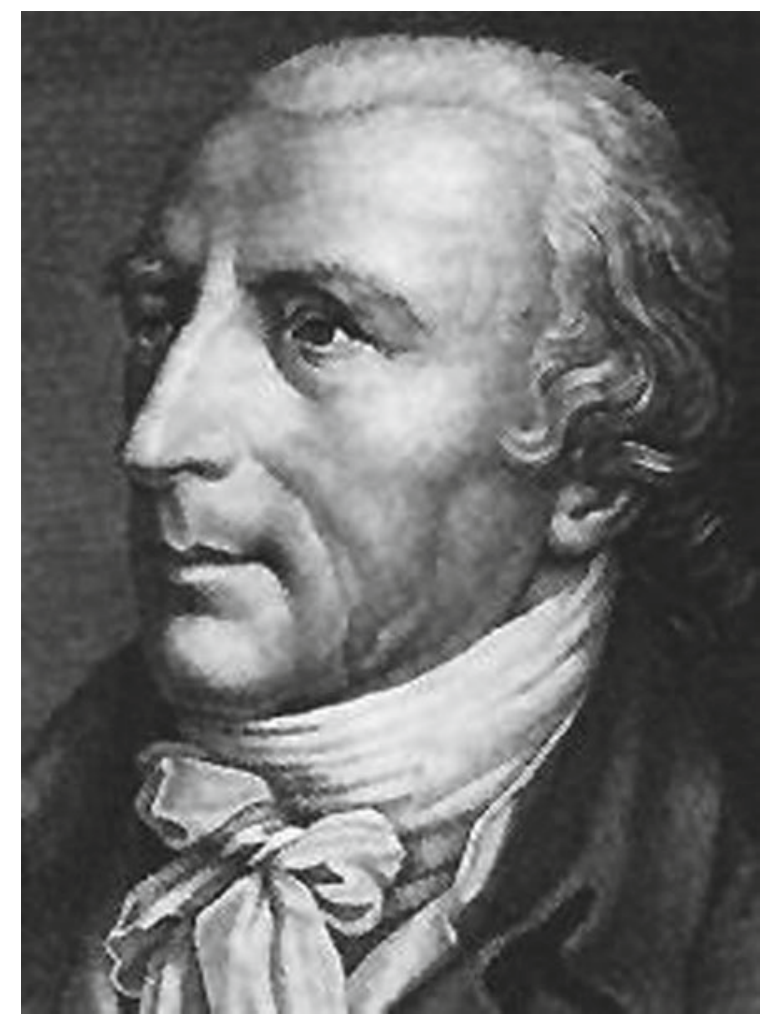

latter being so-to-speak a child of the former. And, as is frequently the case, children come to criticize their parents.

For understanding the general intellectual climate in Germany which was to become the breeding ground of educational philosophy after 1810 it is very illuminating to take a look at the small city of Jena in the 1790s. Between 1794 and 1800 quite a number of German intellectuals attended the university of Jena and listened to the lectures of philosopher J. G. Fichte (1762-1814). Fichte had publicly defended the French revolution in 1793. As a philosopher he started with an elaboration of Kant's philosophy and then conceived of a philosophical system of his own based on the idea of the self-development of the individual. He became the philosopher of the romantic movement in Germany. Later in 1808, after Prussia's military defeat at the hands of Napoleon, Fichte delivered a series of lectures in Berlin under the title Speeches to the German Nation in which he recommended a reshaping of education as a necessary requirement for a revival of Germany. He pointed explicitly to the Swiss pedagogue Johann Heinrich Pestalozzi (1746-1827) as a thinker who had developed decisive ideas for elementary education. This caused sort of a Pestalozzi hype in Germany, and the Prussian administration decided to send a number of teachers to Switzerland in order to learn about Pestalozzi's teaching methods. 
Fig. 5.2 W. von Humboldt (1767-1835) (source Wikipedia Public Domain, (C))

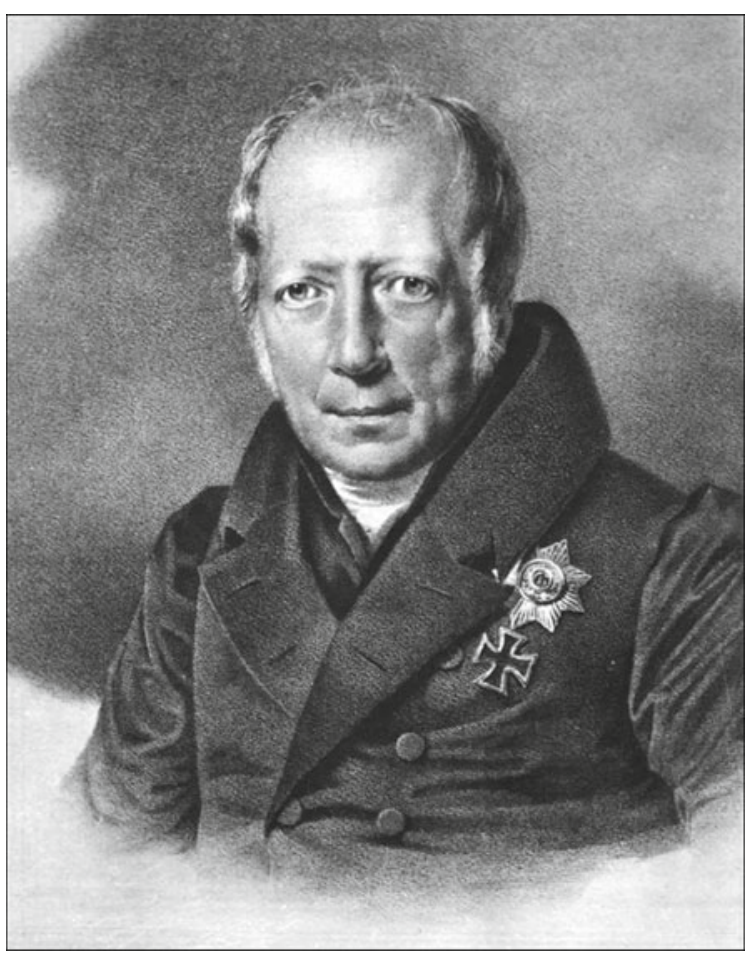

Back to the 1790s we name some thinkers who had come to the university of Jena in order to listen to Fichte. Among others there were

J. F. Herbart (1776-1841),

K. Chr. Fr. Krause (1781-1832),

J. F. Fries (1783-1843),

F. W. J. Schelling (1775-1854),

G. W. F. Hegel (1770-1831),

A. W. and F. Schlegel (1767-1845; 1772-1829)

Friedrich von Hardenberg (Novalis) (1772-1801).

In 1809 Herbart took over Kant's chair of philosophy at the university of Königsberg, and, by the middle of the 19th century, he was considered the most influential pedagogue of Germany. Krause, Fries and Schelling were widely known philosophers though representing quite different directions of philosophical thinking. Hegel took over the prestigious chair of philosophy at the university of Berlin in 1818 and remained there until his death. A. W. and F. Schlegel who were brothers were to become the most influential propagators of the romantic movement in Germany, and Novalis became the romantic writer. Intellectually, these people developed in quite different directions. Nevertheless, there was a common core of interest. They all observed the French revolution and they all wrote about mathematics. A detailed 
exposition of the views of Herbart and Novalis on mathematics can be found in Jahnke (1990b, 1991).

From 1794 to 1796 also W. von Humboldt spent his time in Jena where he became close to Friedrich Schiller, who, like Fichte, was professor of philosophy (and history) at the university. Humboldt also entered personal relations with J. W. Goethe who lived in Weimar twenty kilometers distant from Jena and who functioned at that time as ministry of the grand duchy Sachsen-Weimar-Eisenach responsible for the university (Fig. 5.3).

Much earlier Goethe had brought Johann Gottfried Herder (1744-1803) to Weimar and Jena. Herder was a theologian and in 1776 he took over the position of a 'Generalsuperintendent' (superintendent general) in the grand duchy SachsenWeimar-Eisenach. In this function he presided the highest administrative body of the protestant church in the grand duchy (the 'Oberkonsistorium') and was among others responsible for the schools. He functioned in this position until his death in 1803. Herder was an important philosopher of history and language and a central figure in what later on became to be called 'Deutsche Klassik'. In the German historiography of pedagogy, he is considered to be the "founder" of the German theory of Bildung (Horlacher 2004, 420). According to Herder "Bildung is a non-political concept that focuses on the individual's process of inner self-development, unfolding, self-cultivation -in accordance with an organic concept of nature and natural development." (1.c., 421) In forming and elaborating the concept of Bildung Herder relied among others on his reception of Shaftesbury and Rousseau, and thus the very concept of Bildung is rooted in the European enlightenment and in its origin was not an exclusively German idea (see Oelkers 1999).

Fig. 5.3 Meeting in Jena. Schiller, W. and A. von Humboldt, Goethe (left to right) (source Wikipedia Public Domain, ()

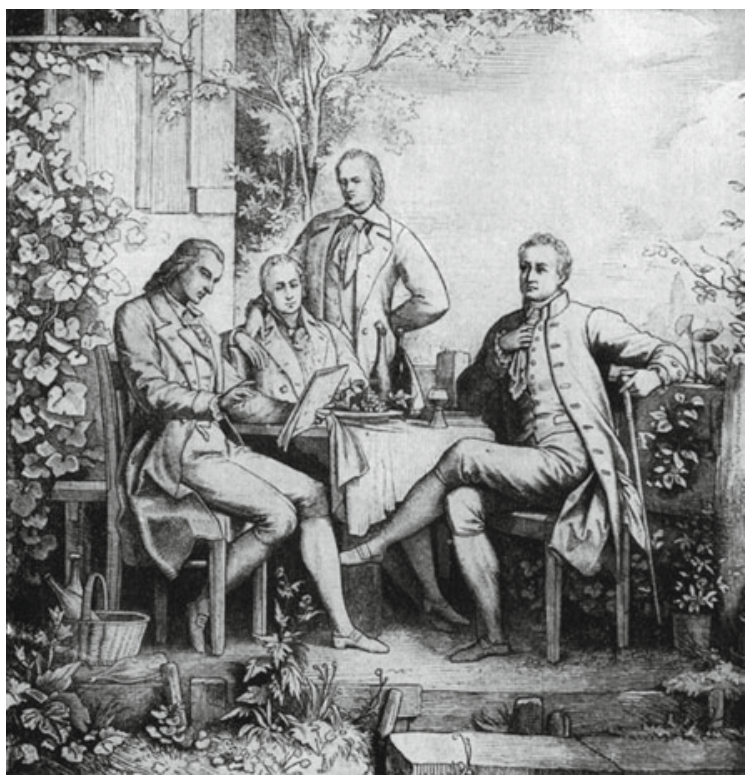


It was at this time and in these circles that a general outlook on science emerged which can be called "cultural foundation of science" (Jahnke 1993a, 266 pp) and which was influential in Germany all over the 19th century. The term is intended to convey the idea that science is pursued not so much for the sake of technical or commercial applications but as a human effort to foster a comprehensive understanding of nature and of culture. By way of this, science contributed to the development of a certain awareness of life and of notions by which a human being may gain a better understanding of himself and his aims, and to the cultivation (Bildung) of the individual. Wilhelm Dilthey has described the spirit of these times by the apt phrase that the interpretation of the world out of itself became the watchword of all free minds (Dilthey 1905, 211). Just as philosophy and art generate interpretations of reality, science was seen as part of an interpretive effort as well, and mathematics was an important component of this undertaking.

Beyond the special views the persons mentioned above held on philosophy and the world in general it was an important fact that they lived in a permanent intellectual discourse, often quite controversial. They were not just a collection of students, poets and philosophers, but people joined together by intense intellectual and emotional relations. The romanticists Novalis and brothers Schlegel created the artificial word "symphilosophieren" (joint philosophizing) as a designation of this mixture of personal company and intellectual exchange. Many people know from their own experience that this can be a great, even decisive influence in the course of their lives.

\section{Essentials of the Neo-Humanist Educational Reforms}

As mentioned above, with W. von Humboldt as the person responsible for the educational system in Prussia, far-reaching reforms were launched. Before entering into details of this reform we sketch Humboldt's ideas on Bildung, school teaching and education following the succinct account by Blankertz (1982; see also part 2 of this chapter).

Humboldt's theory of Bildung was not at all confined to schools (Blankertz 1982, $101 \mathrm{pp}$ ). Rather, he saw Bildung as the way of a human being to himself and, therefore, as an infinite task which will never end. This amounted to a consequent siding with the individual and against any subordination of the individual to the needs of society. According to Humboldt individuality is the capacity of a human to transform the outer world into his own inner being. This constitutes a dialectical relationship between the individual and the world. On the one hand any human being considers the world by way of her/his specific, individual perspective (in analogy to Kant's concept of 'a priori'). On the other hand, this individual perspective emerges from being active in the world. In German at that time this capacity or perspective was frequently called 'Form' from which derived the concept of 'formale Bildung'. According to Humboldt the key component in this dialectical relationship between an individual and the world is language, any language constitutes a certain world-view. Thus Humboldt did not conceive of individuals as isolated beings living in their own world, but as social beings not subordinated to the 'needs of society' but contributing to society.

Blankertz (1982, 119 pp) condenses Humboldt's views on education into four principles. First of all, general education takes precedence over professional educa- 
tion. Since 'Bildung' should be thought of in terms of the individual and its selfdevelopment, public schools under the governance of the state should provide the best opportunities such that the individual can develop and strengthen her/his intellectual, aesthetic and emotional capabilities.

\begin{abstract}
"General teaching at schools aims at the human being on the whole, namely ... at the main functions of his personality." ["Der allgemeine Schulunterricht geht auf den Menschen überhaupt, und zwar ... auf die Hauptfunktionen seines Wesens.”] (1.c., 188/9, transl. by $\mathrm{HNJ})$
\end{abstract}

From this principle Humboldt derived that public schools should provide historical, linguistic and mathematical subjects.

What students needed for a profession should be acquired separately after general education had been completed. Training for special professions should take place in special schools.

The second principle follows from the first. According to Humboldt there can be only one general education. Thus, there should be a system of 'comprehensive schools'. As Humboldt wrote:

"Thus, this entire instruction has to rest on only one and the same foundation. For originally, the lowest day labourer and the most delicately educated [person] have to be equally tuned in their mind so that the former should not be brutish and below human dignity and the latter should not be sentimental, airy-fairy, crank and below human strength. ... in this way having learnt Greek could be as little useless to the carpenter as making tables to the scholars." ["Dieser gesamte Unterricht kennt daher auch nur Ein und dasselbe Fundament. Denn der gemeinste Tagelöhner, und der am feinsten Ausgebildete muss in seinem Gemüth ursprünglich gleich gestimmt werden, wenn jener nicht unter der Menschenwürde roh, und dieser nicht unter der Menschenkraft sentimental, chimärisch und verschroben werden soll. ... Auch Griechisch gelernt zu haben, könnte auf diese Weise dem Tischler ebenso wenig unnütz sein, als Tisch zu machen dem Gelehrten"] (1.c., 189, transl. by HNJ)

Of course, it was not Humboldt's idea that every child should learn ancient Greek nor did he think that everybody should learn to make tables. But he had the vision that there should be a common foundation in education for everybody. This was an extraordinarily political and at the same time theoretical statement: the right and the aims of Bildung and education are a matter of human dignity and not of serving the needs of society. Stated in modern words: Bildung and education are a human right!

Third, the state has to take care of schools, but at the same time the influence of the state on schools has to be restricted-a somewhat paradoxical idea. Fourth, Humboldt, according to Blankertz, believed that by way of Bildung students will become (also politically) self-determined persons.

Essentials of the educational reforms inaugurated by Humboldt can be seen in three crucial junctures.

(1) In 1810 Prussia founded a new university in its capital Berlin which was to inaugurate a new understanding of the spirit and the way of functioning of a university in entire Germany. The slogan of a "unity of research and teaching" implied the idea that students and professors should closely cooperate. Instead of outsourcing research into academies as had been frequently done in earlier 
times seminars and laboratories were founded as university institutions in which such cooperation could take place. It is easy to see behind this the romantic idea of continual open discussion and exchange of ideas which Humboldt and so many others had experienced in their youthful days at the university of Jena. Humboldt's 'definition' of a university expressed this idea in a perfect way:

"In fact, attending courses is only secondary, the essential thing is that between school and the entrance to life the young man dedicates a number of years exclusively to scientific reflection at a place which brings together many persons, teachers and learners." ["Das Collegienhören selbst ist eigentlich nur zufällig; das wesentlich Nothwendige ist, dass der junge Mann zwischen der Schule und dem Eintritt ins Leben eine Anzahl von Jahren ausschließend dem wissenschaftlichen Nachdenken an einem Orte widme, der Viele, Lehrer und Lernende in sich vereinigt."] (von Humboldt 1809, p. 171, transl. by $\mathrm{HNJ}$ )

Of course, it was not by chance that philosopher Fichte was elected as first rector of the university of Berlin, though he never actually served in this position owing to his sudden death in 1814.

(2) In 1810 an 'Edict Concerning the Introduction of a General (university) Examination of Future Teachers' was issued. The edict concerned future teachers at gymnasium, and among others defined the subjects which should/could be studied in order to become teacher. Among these subjects mathematics had a prominent place, and universities had to offer courses in mathematics and to create the necessary professorships. Thus, for the first time, mathematics became a full-fledged university discipline rather than a mere component of the elementary studium generale, as had been the practice until then.

(3) In 1812 the Prussian government issued the 'Edict Concerning the Students Entering the Universities'. According to this edict entrance to a university was no longer a matter of feudal privileges but required passing the 'Abitur'. The edict regulated which subjects a student had to study successfully at gymnasium in order to be admitted to university. Without going into details it can be said that compared with 18th century Latin Schools two disciplines were given new emphasis. As mentioned above, these were ancient Greek and mathematics. Ancient Greek was part of the special ideology of neo-humanisn, but how can we explain the strengthening of mathematics?

\section{Cultural Meaning of Mathematics}

The new strong position of mathematics in school teaching and at universities was partially due to the model of the educational reforms in France. The Prussian government was impressed by the success of French military and economy, and viewed them in terms of the new French education. Nevertheless, the German view on mathematics was markedly different from the French and stressed the cultural meaning of mathematics in agreement with what we have called the cultural foundation of science. A sense of this view can be gained from a sample from Humboldt's writings. It should be said that these quotations come from opinions which Humboldt had written for the Prussian administration in an official capacity. Thus, in his time 
they were not known to a broader public. Nevertheless, they express the spirit of the time in a perfect way.

According to Humboldt, education was to ensure

"that understanding, knowledge and intellectual creativity become appealing not because of external circumstances, but because of their internal precision, harmony and beauty. It is primarily mathematics that must be used for this purpose, starting with the very first exercises of the faculty of thinking." ["...dass das Verstehen, Wissen und geistige Schaffen nicht durch äussere Umstände, sondern durch seine innere Präcision, Harmonie und Schönheit Reiz gewinnt. Dazu und zur Vorübung des Kopfes zur reinen Wissenschaft muss vorzüglich die Mathematik und zwar von den ersten Uebungen des Denkvermögens an gebraucht werden."] (von Humboldt 1810, p. 261, transl. by HNJ)

Mathematics is seen as the most important subject "from the first exercises of the faculty of thinking" to provide to pupils a feeling for the fascination of intellectual creativity, and this is possible because of its "internal precision, harmony and beauty". In Humboldt's thinking precision and beauty, rigour and aesthetics entered a close relationship.

At another place, Humboldt expressed himself against the tendency

“... of digressing from the possibility of future scientific activity and considering only everyday life .... Why, for example, should mathematics be taught according to Wirth, and not according to Euclides, Lorenz or another rigorous mathematician? Any suitable mind, and most are suitable, is able to exercise mathematical rigour, even without extensive education; and if, because of a lack of specialized schools, it is considered necessary to integrate more applications into general education, this can be done particularly toward the end of schooling. However, the pure should be left pure. Even in the field of numbers, I do not favour too many applications to Carolins, Ducats, and the like.” [“... sich selbst von der Möglichkeit künftiger Wissenschaft zu entfernen, und aufs naheliegende Leben zu denken. Warum soll z. B. Mathematik nach Wirth und nicht nach Euclides, Lorenz oder einem andern strengen Mathematiker gelehrt werden? Mathematischer Strenge ist jeder an sich dazu geeignete Kopf, und die meisten sind es, auch ohne vielseitige Bildung fähig, und will man in Ermangelung von Specialschulen aus Noth mehr Anwendungen in den allgemeinen Unterricht mischen, so kann man es gegen das Ende besonders tun. Nur das Reine lasse man rein. Selbst bei den Zahlverhältnissen liebe ich nicht zu häufige Anwendungen auf Carolinen, Ducaten und so fort."] (von Humboldt 1809/1964, p. 194, transl. by HNJ)

This is a core quotation for the whole bundle of ideas we are talking about. Firstly, there is a strong anti-utilitarian sentiment. Humboldt is against "considering only everyday life" as a benchmark for determining the subjects of education. At the end of the quotation, he repeats again that he does not favour "too many applications to Carolins, Ducats and the like". [Carolins and Ducats were common monetary units of the time.] He also emphasizes two times the importance of mathematical rigour - a remarkable statement. We remark that Humboldt did not plead for cancelling "Carolins, Ducats and the like" from teaching, but that he did not want too many applications to them. Thus, the role of "Carolins, Ducats and the like" in teaching elementary arithmetic is a question of the right measure and has to be balanced with the requirement of developing rigorous thinking.

No wonder then that 
„... any knowledge, any skill which does not elevate the faculty of thinking and imagination by a complete insight into the rigorously enumerated reasons or by elevation to a universal intuition (like the mathematical or aesthetical) [is] dead and sterile." ["ist ... jede Kenntnis, jede Fertigkeit, die nicht durch vollständige Einsicht der streng aufgezählten Gründe, oder durch Erhebung zu einer allgemeingültigen Anschauung (wie die mathematische und ästhetische) die Denk- und Einbildungskraft, und durch beide das Gemüth erhöht, todt und unfruchtbar.'] (1.c., 188, transl. by HNJ)

In what follows we shall enlarge upon two points of view expressed in Humboldt's texts, namely his "anti-utilitarianism" and his "preference for pure mathematics".

The latter term needs some qualification. As we have seen, Humboldt did not use the term "pure mathematics", but spoke of "rigour" and "rigorous mathematician". Nevertheless, it seems rather clear what he had in mind. Treating "Carolins, Ducats and the like" in teaching, should not obscure the conceptual and logical relations within mathematics. On the contrary, clarifying these relations should be the central concern of teaching. Since the term "reine Wissenschaft" ("pure science") was frequently used at the time and for lack of a better word for expressing this idea we shall use the phrase "preference for pure mathematics" knowing the difficulties of the distinction between "pure" and "applied" mathematics.

\section{Anti-utilitarianism and Self-directed Activity}

To enlarge on this preference for pure mathematics we consider elementary education. Looking upon arithmetic under the perspective of the needs of society it might seem to be most important to future workmen and shopkeepers that they be able to calculate fluently with money and the elementary magnitudes of length, area, volume and weight. This was even more so in a politically fragmented country like Germany with numerous different systems of money and different units of measurement. To carpenters and shopkeepers it was a matter of survival to know these different units and magnitudes and to master the resulting calculations. Thus, it seemed to be most important to children becoming acquainted with "Carolins, Ducats, and the like", and in fact training faculties in the domains of measurement and money had been the core of arithmetic teaching at traditional 18th century elementary and higher schools.

Now the neo-humanist ideas were radically the other way round. These people thought that it is most important to young children to become first and foremost acquainted with the very concept of number and with number relations independent of magnitudes. Children should become fluent and flexible in calculating with abstract numbers. The handling of money and magnitudes was considered secondary and an easy exercise once children had learnt to operate with abstract numbers. These ideas were completely in line with Pestalozzi's approach to elementary education, and this explains why Pestalozzi became such a prominent person in German elementary education. And of course, this is also the modern view on the teaching of arithmetic. Surely, money and simple magnitudes are part of the teaching of elementary arithmetic but also to us it seems more important that children understand the concept of number and number relations in themselves.

Humboldt's disdain of "Carolins, Ducats, and the like" echoes the prominent pedagogue F. A. W. Diesterweg (1790-1866) who wrote: 
„Arithmetic lessons are no stores and no fairs, no stock market and no courtroom.” [Die Rechenstunde ist kein Materialladen und kein Jahrmarkt, keine Börse und keine Gerichtsstube.] (Diesterweg 1859, quoted according to: von Sallwürk 1899, 479, transl. by $\mathrm{HNJ}$ )

Diesterweg also made it clear that the refusal of the utilitarian point of view is closely connected with another important idea. As we have seen neo-humanist pedagogues considered as the foremost aim of school teaching the raising of autonomous personalities, and, therefore, another central catchword of the neo-humanist reforms was "Selbsttätigkeit" ("self-directed activity"). As Diesterweg put it:

"Teach in such a way that the self-directed activity of the pupil is developed as far as possible." ("Unterrichte so, dass überall die Selbsttätigkeit des Schülers möglichst ausgebildet werde." (Diesterweg 1844, III/IV, transl. by HNJ)

Diesterweg favoured especially mental arithmetic, since it is in this domain that children can develop individual and flexible strategies of calculation.

"However, in mental arithmetic there is much more freedom for individual activity, decision and discretion. For this reason mentally agile children love mental arithmetic so much. They like treating a task in multiple ways and in their own manner .... Therefore, by way of exercises in mental arithmetic [the teacher] should strive for the unleashing and liberation of the young mind by as many different solution methods as possible.” [(,Beim Kopfrechnen dagegen. herrscht viel mehr Freiheit, welche eigene Bewegung, Auswahl und Belieben zulässt. Darum lieben geistig bewegliche Kinder so sehr das Kopfrechnen. Es gefällt ihnen, eine Aufgabe in mannigfacher Art, auf ihre Weise zu behandeln .... Darum strebe man ja an den Kopfrechenaufgaben durch möglichst mannigfache Auflösungsweisen die Entfesselung und Befreiung des jugendlichen Geistes an."] (1.c., IX, transl. by HNJ)

Thus, mental arithmetic should not be a matter of mere memorizing, but a matter of thinking. Pupils were expected to develop their own clever strategies of calculation. This in fact is again a completely modern idea.

For his approach to calculating and mental arithmetic Diesterweg coined the artificial word "Denkrechnen" as a compound of "thinking" and "calculating". The idea that mental arithmetic should be a matter of thinking and further the development of self-directed activity was supported by many educators and teacher trainers for elementary schools and was a hallmark of the Pestalozzi school in Germany. We name Wilhelm Harnisch (1787-1864), Ernst Tillich (1780-1807), W. von Türk (1774-1846), Peter Kawerau (1789-1844), Ernst Hentschel (1804-1875), Carl Gotthilf Ehrlich (1776-1857) (see Jänicke 1877; Radatz and Schipper 1983, 31 pp; Biermann 2010, 95 pp).

Diesterweg was a teacher trainer for elementary schools and the quotations above refer to elementary education, but a similar and even stronger rejection of a utilitarian point of view was also true for gymnasium and higher education in general. It is plausible that this entire approach to education was very much in line with the general scientific culture of the time which stressed the notion of understanding. Educators considered it more important that students understand something than to merely train them in seemingly useful skills. 
The "imperative of understanding" provides also another reason why neohumanists wanted to exclude preparation for special professions from the state-driven public schools. Humboldt explained:

\begin{abstract}
In regard to skills in application "it is very often necessary to confine oneself to results which are not understoood from their reasons, since the skill must be there, and time or talent for insight are missing. Such is the case with unscientific surgeons, many factory owners etc." [Im Hinblick auf Fertigkeiten zur Anwendung "muss man sich sehr oft auf in ihren Gründen unverstandene Resultate beschränken, weil die Fertigkeit da seyn muss, und Zeit oder Talent zur Einsicht fehlt. So bei unwissenschaftlichen Chirurgen, vielen Fabrikanten u.s.f." (1.c., 188, transl. by HNJ)
\end{abstract}

The knowledge necessary for special professions implied too many elements which cannot be understood from their reasons and are only recipes contrary to the principle of understanding as the core of teaching and learning.

\title{
Pure Mathematics and Every Day Applications: A Compromise
}

As we have seen, in Humboldt's and his followers' eyes emphasis should be put on pure mathematics. However, to understand this adequately, one has to distinguish between two different types of applications. One type consisted of those elementary calculations mentioned above which are needed in everyday life and in the daily affairs of shopkeepers and workmen. We call these the everyday applications. A completely different matter was the application of mathematics in astronomy, physics and other mathematized sciences. There is no common term for these applications; we will call them theoretical applications. Whereas the neo-humanist-idealist pedagogues intended to reduce the amount of everyday applications in teaching, they favoured theoretical applications. In fact, taken as a mathematical theory mechanics is simply mathematics. In the first syllabus for gymnasium of 1816 which never became obligatory mechanics (kinematics, statics) was included in the mathematics lessons of the upper grades of gymnasium. However, when trying to implement this syllabus at some schools this proved to be unfeasible, and very soon the mechanics lessons were cancelled from the mathematics plan.

The discussion on whether the everyday applications should at all be included in the mathematics lessons at gymnasium lasted until the end of the 1820s. The intention to break with 18th century traditions and to introduce exclusively "scientific" mathematics that is mathematics beyond these practical needs into gymnasium met severe problems with parents and students. As a rule, a gymnasium was attended by a student population with quite mixed interests. It served for pupils who were intending to take the university entry qualification and to continue with university studies as well as for children who were going to become shopkeepers and workmen. The latter left school after grade seven or eight and were called "Frühabgänger" (they were "early leaving"). Their parents expected their children to be trained in elementary arithmetic and the everyday applications and, thus, resisted against a radical change of mathematics teaching. In the 1820 s it became clear that a compromise was necessary, and finally, the government decided that elementary calculations with numbers including the everyday applications became subjects in the first two grades of gymnasium whereas the course on "scientific mathematics" started only in the 
third grade (see Jahnke 1990a, 377, 388 pp). The distinction between "Calculating" ("Rechnen") and ("scientific") Mathematics" remained common for a long time, in fact well into the 1960s until it finally was overcome by the New Math Movement.

Since the 1830s, the mathematical syllabus at gymnasium comprised in the two lowest grades a course on elementary calculating after which, in the higher grades, the course in scientific mathematics followed. Standard topics of the latter were until the 1870s Euclidean elementary geometry, trigonometry, spherical trigonometry and a strand of arithmetic, algebra and sort of elementary analysis. The latter comprised some simple infinite series, but no differential and integral calculus.

The compromise in regard to everyday applications made it possible that gymnasia in Prussia until the 1850s functioned as sort of comprehensive schools (see Müller 1977). With its mixed population Gymnasium took care for $7 \%$ of the respective male age groups at the beginning as well as at the end of the period. Beyond that, local circumstances made many modifications necessary, and the administration was flexible in doing this. When a city was too small and not enough children wanted to finish gymnasium schools were created covering only the first seven or eight grades. They were called "Höhere Bürgerschulen" ("Higher schools of citizens"). All in all Prussia established a school system consisting of elementary schools (,,Volksschulen”) for all children, and of secondary schools ("Gymnasium") in order to prepare students for university studies, civil service careers, outstanding positions in commerce, or industry. On a level between "Volksschule" and "Gymnasium" so-called "Höhere Bürgerschulen" ("Higher schools of citizens") emerged which educated for practical skills in craft and commerce. In the 1860 s a separate system of schools with a stronger emphasis on science and mathematics ("Realschulen") in addition and parallel to gymnasium was established. To avoid terminological confusion: These 19th century "Realschulen," like the gymnasia, extended from grade 5-13, whereas in today's Germany the term "Realschule" refers to schools extending only from grade 5-10.

\section{An Engineer's Expert Opinion: Pure Mathematics Is the Best One Can Do for Applied Mathematics}

That pure mathematics rather than everyday applications should be the chief focus of mathematics teaching, was not only Humboldt's opinion, but it was also that of most teachers and educators, including professional mathematicians. A good example was August Leopold Crelle (1780-1855). Crelle is well-known as the founder of the prestigious Journal für die reine und angewandte Mathematik. He worked for 20 years as an engineer in the Prussian administration, was engaged in the building of railways and advisor of the ministry of education for the teaching of mathematics. In a remarkable preface to a textbook on number theory (1845) he gave a justification why he thought pure mathematics so important in education and also the best one could do for applied mathematics. According to Crelle, the use of mathematics could be divided into two categories, one being its use in immediate applications, and the other, its use for training one's ability to think. Upon weighing these two purposes against one another, Crelle argued that with most practical problems it is difficult to apply mathematics because they are too complicated. Frequently, the application of mathematics would even lead to serious mistakes and errors, because people rely on 
mathematical rigour and certainty without considering the complexity of the conditions. Quite indubitable, however, was according to Crelle the use of mathematics to exercise the ability of thinking, and this in turn was then the indispensable condition for the direct application of mathematics (Fig. 5.4).

Only after a mathematical spirit has been awakened by assiduously exercising judgment by means of mathematics (without regard for applications), and only then, one may quite boldly count on the uses of mathematics in applications. Mere knowledge in mathematics, intended for applications ... is not sufficient for appropriate applications, but the guiding principle must be the mathematical spirit, the mathematical way of thinking. Only he who tackles applications on this basis will err less easily, for he will first of all examine what mathematics can properly achieve, and where and how the tool can be usefully applied .... Hence it is quite right that mathematics be exercised as much as possible in schools ... at first without any consideration of applications in common life. (Crelle 1845, pp. IX-X, transl. by HNJ).

With the notion of judgment, Crelle referred to Kant who in the Critique of Pure Reason had explained that a rule does not say by itself to which cases it can be applied, and that, therefore, the application of a rule requires faculty of judgment. Later, Kant elaborated this in his Critique of Judgement.

Considering Crelle's argument from a modern perspective we understand his point very well. To use 20th century terminology, we can say that modelling is an interplay of forming hypotheses, drawing consequences from them and evaluating the hypotheses in light of their consequences. It is exactly the latter process of evaluation which is aptly described by the concept of 'judgement'. A core component of judgement in applying mathematics is, of course, understanding the deductive interplay between hypotheses and its consequences, and by this we are back to pure mathematics. To say it shortly: proof and modelling are inseparably connected. It is no wonder, then, that in most documents on the aims of mathematics education all over the 19th century the term 'faculty of judgement' played a prominent role.

Fig. 5.4 Commemorative plaque for A. L. Crelle (source Wikipedia Public Domain, ())

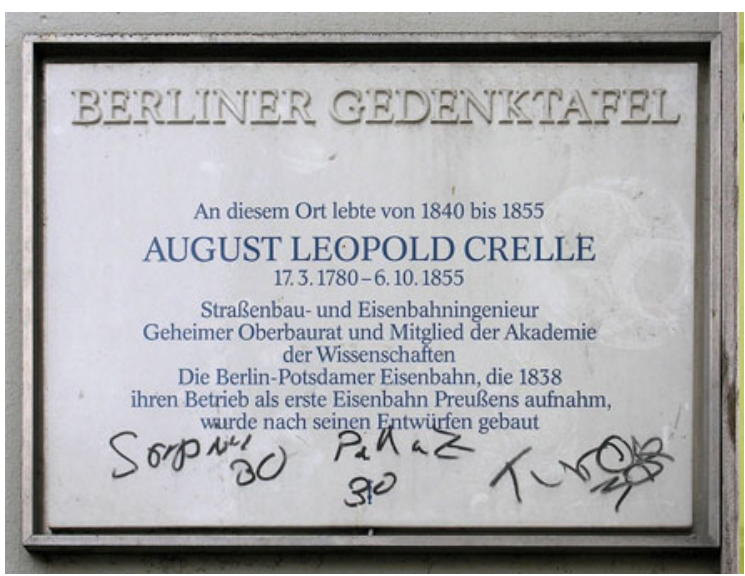


Crelle and other mathematicians of the time were convinced that for the sake of applications we have to cultivate pure mathematics. This was in line with the general conviction of scientists and philosophers of the time that the cultivation of pure science would not lead to a contemplative stance. Philosopher Johann Gottlieb Fichte favoured an approach to education involving pure thinking because the ability to think abstractly was, in his opinion, the decisive precondition for imagining alternatives, and of being able to develop a new design for the future, thereby creating an ethically acceptable world. According to Fichte: "That ability to independently design images which are by no means copies of reality but suitable to become ideals for it would be the first principle from which the cultivation of the species by means of the new education would have to proceed." (Fichte 1808, 31/2). This same idea is echoed by famous philologist August Böckh who in a speech as Rector of the University of Berlin said that not those people are suitable for the "higher service" who can adapt themselves to the given circumstances, but those who are ready to change them. These people have to be educated by pure science (Boeckh 1853, 97). Thus, the ability to think in terms of hypothetical alternatives was seen as a decisive condition of "aptness for the future" ("Zukunftsfähigkeit"). Changing to modern times, the motto of the university of Duisburg-Essen reads in German: "In Möglichkeiten statt in Grenzen denken." ["Think in terms of possibilities, instead of limits."] This exactly was the core of all these opinions.

\section{Final Remarks}

a. Neo-humanist pedagogy defined Bildung as the comprehensive intellectual and emotional self-development of the individual and refused subordinating education at public schools by recourse to requirements of professional life and of needs of society. In this radical anti-utilitarianism neo-humanist pedagogy was unique, and this justifies continuing to use the German word 'Bildung' instead of the English 'General education'.

b. There was no noticeable difference between the number of weekly hours devoted to the teaching of mathematics at learned schools and "Bürgerschulen" of the 18th century and the respective number at a Prussian gymnasium in, say, the year 1837 (Jahnke 1990a, 335 pp). But the character of mathematics which was provided by school teaching in the 18th and 19th centuries had deeply changed. At elementary schools there were more and more teachers who followed the ideas of what was called the Pestalozzi school with its conception of "Denkrechnen" ("calculating by thinking"). At gymnasium only in the 19th century mathematics in a scientific sense was introduced. This was the great historical achievement of the neo-humanist pedagogy in regard to the teaching of mathematics in Germany.

c. The strong emphasis of the neo-humanists on theoretical thinking, understanding and pure science was in their eyes not a denial of the demands of practical life, but the best way to meet them. In their eyes theoretical thinking is a necessary condition for change. Thus, to educate young people in theoretical thinking is the best way to make them "apt for the future". Considering the dynamic technological development of Germany in the second half of the 19th century one might be inclined to agree. 
d. Even today, it is a critical question as to whether utility and the relatedness of a subject to everyday life is a sufficient argument for including it into the school curriculum. Among experts, it is clear that deeper conceptions than utility must play a part in our deliberations about what mathematics should be taught and how it should be taught. Nevertheless, pressure from the public (policy, economy, media) to reduce school teaching to everyday life is persistent and strong. It is the duty of pedagogical experts to clarify 'Bildung' in its proper sense and persuade the public of its cogency. The conviction that the creation and development of intellectual worlds by the individual is a fundamental qualification for becoming "apt for the future" was a strong motive for neo-humanist pedagogical thinking as well as it should be a guideline for modern approaches.

\subsection{Bildung and Paideia and Their Presence in Some Undergraduate Programs (Reaction by Michael N. Fried)}

On first sight, it may seem strange at the very least and, perhaps, even inappropriate that an English speaker, born in America and teaching at a university in Israel's Negev Desert, a person far removed from the community of German mathematics educators, should presume to say anything about the concept of Bildung. Yet, in a way, a non-German speaking about Bildung is completely in line with Humboldt's own ideas about the concept, which were directed towards an object at once individual and international. So, though a German word, the idea of Bildung should not be restricted to Germans, just as mathematics, a Greek word, should not be restricted to Greeks, but rather to human beings as far as they are human beings. Bildung, in this sense, is akin to the idea of liberal education, which was the subject of my own ICME invited lecture, for these "liberal arts" are directed towards human beings possessing libertas, the freedom to live as fully a human life as possible, as opposed to slaves prevented from fulfilling their human potential. Indeed, Bildung and liberal education are closely, even profoundly, related.

In the brief remarks below, with no claim of originality, I would like simply bring out the connection between Bildung and the classical liberal arts. Moreover, I would like to give a few examples of liberal arts colleges which, while they do not necessarily manifest that other Humboldtian ideal of research and teaching, nevertheless capture something of the deeper sense of Bildung as the formation of full human beings: thus they are also liberal arts colleges in the deeper sense of the liberal arts themselves. Significantly too, these college see mathematics as part of liberal education, and two, in particular, see mathematics as an essential part.

\section{Humboldt's Theory of Human Bildung}

Wilhelm von Humboldt's (1767-1835) early fragment "Theorie der Bildung des Menschen" (1793) gives some idea of what Humboldt had in mind when he spoke 
of Bildung, and therefore, how he conceived what education could achieve and what good it could do. In this early piece one can discern his pointed attention to wholeness-both in what we study and, more importantly, in our own being. In this connection, he says that in the narrowness and fragmentation standing opposed to that kind of integrity which he has his eye on,

...lies one of the preeminent reasons for the frequent, not, unjustified, complaint that knowledge remains idle and the cultivation of the mind unfruitful, that a great deal is achieved around us, but only little unimproved within us... (Humboldt 1960, pp. 234-235, Trans. Horton-Krüger, p. 58).

This sounds familiar. We are often asked to be more connected to the world, in the sense of being more interested in material progress, but we are also often reminded that material progress fails to match what we might call spiritual progress. We hear both the call to be practical and the call to be more spiritual or more moral. Then, as now, this incompatibility was expressed as a "complaint," a sense of genuine dissatisfaction. However, the source of the problem, our lack of wholeness or fullness, it seems to me, is still not seen clearly today, even after Humboldt.

It is that picture of a human being engaged in a whole world, that is to say, not every detail in the world, not our love of information, but the world as something whole and our own wholeness within it, it is that which Humboldt wants us to understand. Although he leaned towards pure studies, specifically in mathematics (see Jahnke 1993b, p. 418), he would not have us completely retreat into a sort of vita contemplativa and ignore an active life in the world-and therefore, in the case of mathematical studies, he would not have us ignore the mathematics which is of use in daily life. He wants us, in fact, very much to look towards the external world around us, but he also wants to press the point that the ground for this should be, in a slightly paradoxical way, our own inner integrity. Thus he writes:

What man needs most, therefore, is simply an object that makes possible the interplay
between his receptivity and his self-activity. But if this object is to suffice to occupy his
whole being in its full strength and unity, it must be the ultimate object, the world, or at
least (for only this is in fact correct) be regarded as such. Man seeks unity only to escape
from dissipating and confusing diversity. In order not to become lost in infinity, empty and
unfruitful, he creates a single circle, visible at a glance from any point. In order to attach the
image of the ultimate goal to every step forward he takes, he seeks to transform scattered
knowledge and action into a closed system, mere scholarship into scholarly Bildung, merely
restless endeavor into judicious activity (Humboldt 1960, p. 238, translation by Horton-
Krüger 2000, p. 60)

The word "picture" seems to me the right one, for it too is something grasped as a unity. For this reason, I do not take it as accidental that the word Bildung has a relation to Bild or picture. Indeed, I confess, as I read this fragment by Humboldt, a youthful piece to be sure, I begin to see in my mind - and begin to understand better - that iconic image of romanticism, the well-known painting by Caspar David Friedrich, Wanderer above the Sea of Fog (Der Wanderer über dem Nebelmeer) (1818), the original can be seen in the Kunsthalle Museum in Hamburg, where ICME-13 was held). It is not the pejorative view of the romantic lost in the clouds, for, note, the wanderer's feet are firmly placed on the solid rock of a mountain. Moreover, we too 
Fig. 5.5 C. D. Friedrich, Wanderer above the sea of fog (source Wikipedia Public Domain, ())

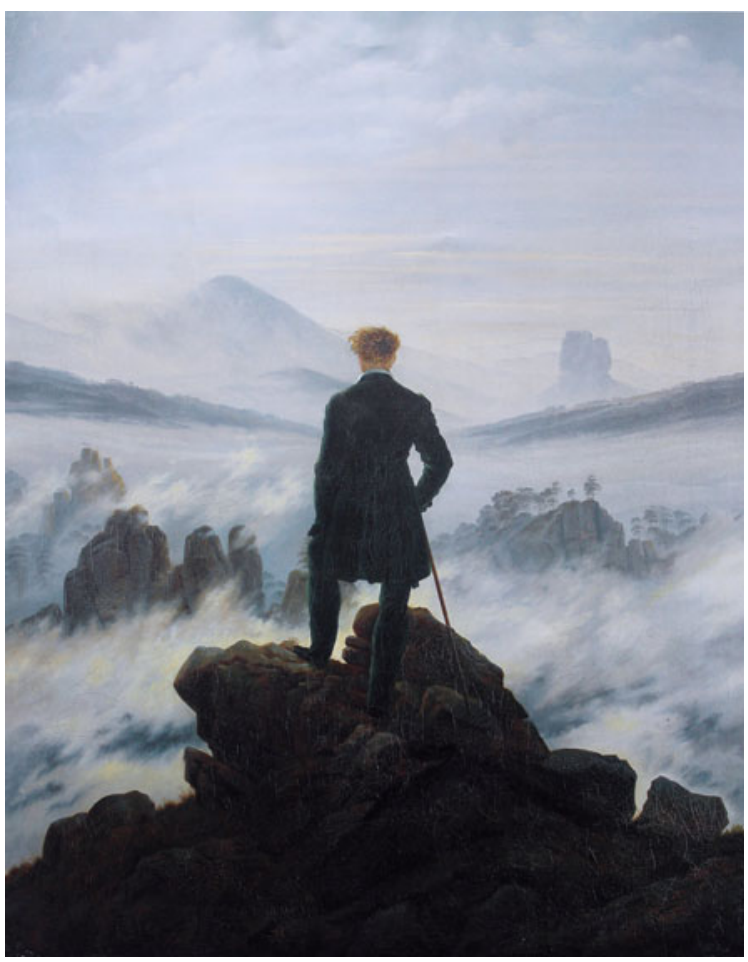

are standing on that mountain. Yet the landscape is open and undefined-that is to say, the solidness of the rocks do not crush or confine us, but free us. And "us" and "we" are the right words, for we are standing on the same rock, looking in the same direction - that of course is one reason why we only see the back of the man: the picture is not about him, but about us (Fig. 5.5).

\section{Humanistic Education}

Now, a somewhat different picture is one by Botticelli, showing a young man introduced to the liberal arts - seven sisters - the core of his education. You will notice in the painting that there are eight, not seven, women. The eighth is seen holding a snake - she is Prudentia, or, to use the well-known Greek term, Phronesis: she is not one of the liberal arts, but she is the spirit of the full life the young man will live, reflecting, making decisions, and growing in wisdom (on the matter of animals, the one with the scorpion is logic, who possesses the power of stinging arguments) (Fig. 5.6).

The liberal arts formed a complete system - and included both arts of communication, i.e., constructions with words-grammar, logic, and rhetoric - and arts of things or of the world - the mathematical arts of arithmetic, music, geometry, and astronomy (in the Botticelli painting, three of the latter can be clearly seen: to the right of Prudentia, we have first geometry holding a right angle, then astronomy with 
Fig. 5.6 Botticelli, liberal arts-seven sisters (source Wikipedia Public Domain, (C)

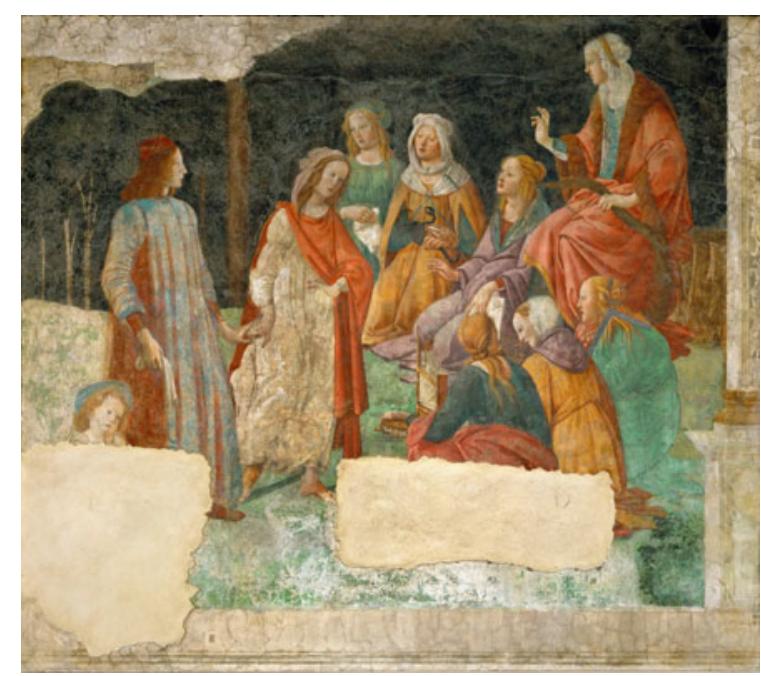

an armillary sphere, and then music with her "positive organ"; arithmetic is likely the woman ushering in the young man). In late antiquity, these seven liberal arts were often completely identified with a Greek word, Paideia, a kind of general education, the word one hears in the word Encyclopaedia, literally, a "course of general education." The truth of the matter though is that Paideia, like Bildung, is tremendously difficult to translate, for, like Bildung, it takes in education, culture, upbringing, to name a few. The great classical scholar Werner Jaeger (1945) required three thick volumes to explain the word Paideia, which is also the name of that three volume work.

But one can say this about it:

(1) paideia was rooted in the literature and thought of one's tradition-here the translation, "culture," is apt

(2) It was meant to be carried throughout life, so that...

(3) It was very much an expression of being a human in the fullest sense of the word, thus the Latin translation of paideia as humanitas.

I might mention as an aside that Werner Jaeger dreamed of a "third humanism," where the second humanism happened to be that implicit in the aspirations of Humboldt's Bildung (see, for example, Östling 2015, p. 209) But this is a complicated story....2

In any case, the three central characteristics of Paideia listed above seem truly very close to what Humboldt himself may have had in mind when he referred to Bildung.

\footnotetext{
${ }^{2}$ Marrou (1982) saw that Jaeger's particular admiration of Spartan education gave voice to fascist and Nazi ideologies (see p. 23). Whether this is a fair assessment can be debated. Jaeger, it might be noted, fled Germany in 1936 and came to the United States, where he spent the rest of his life.
} 
Indeed the difficulty of translating both words-Bildung and Paideia-may have much to do with their mutual attempts to grasp an almost unlimited whole.

\section{Some Undergraduate Colleges}

My original task in this note was to reflect on these Humboldtian and classical ideas in the context of Israeli school mathematics or the Israeli educational system generally. But I could find, in fact, very little of that desire for a whole human being and a whole experience of human life-at least not explicitly, even though I could see that pieces were there. Nor, however, could I find this in other places I am familiar with. In almost every instance, I found far more pronounced that very tendency towards material progress without true inner human progress that Humboldt had hoped to steer us away from.

Where I do see something like an active embracing of Bildung or the liberal arts in the sense of Paideia is in two or three undergraduate colleges in North America (I am certain there must be similar islands of the liberal arts in other places as well). These include:

Quest University in British Columbia, Canada

St. Mary's College in Morage, California, USA

St. John's College in Annapolis, Maryland and Santa Fe, New Mexico, USA.

All three have one degree-Quest a degree in the Arts and Science; and St. Mary's and St. John's a Liberal Arts degree. Quest has some choice in courses, while St. John's and St. Mary's (which is to a large degree modeled after St. John's, though St. Mary's has a religious orientation whereas St. John's is completely non-sectarian) have a set curriculum. Since time is short, I will only say a few words about St. John's. ${ }^{3}$

St. John's is based on a set of books studied in common by all students and very much at the center of the western tradition (there is a graduate program at the college which looks closely at the great books of Eastern traditions as well). The books thus form the foundation of a community in which both the students and faculty (called tutors rather than professors since they are not supposed to be professing something) share a common set of ideas-sometimes conflicting ideas, sometimes radically so-which forms, in turn, a foundation for continuous conversation. It is

\footnotetext{
${ }^{3}$ Just for the record though, here is how Quest describes its own program on its website (http:// www.questu.ca/arts-and-sciences-degree.html):
}

As the world further transitions from the industrial era into the information age, our education needs to keep pace. Technical, job-oriented training is no longer sufficient to handle the complex and shifting challenges of the 21 st century.

Enter the liberal arts and sciences.

Consisting of arts, humanities, mathematics, and social, life and natural sciences, the liberal arts and sciences form the basis of a well-rounded education. They allow one to develop critical thinking, intellectual breadth, and an informed, worldly perspective - they allow one to really think. 
telling in this regard that in all the classes students are seated around a large single table with their tutor sitting among them.

The books studied come from poetry and philosophy as well as from science, history, and mathematics. All students study mathematics. The questions and ideas in these books are considered complementary parts of a whole, which means not so much a single message as a single intellectual endeavor. The singleness of the endeavor - the continual reflection, reasoning, and discussion about the world and one's place in it-implies that although mathematical studies may have a technical side (and students do learn some mathematical techniques) they can never be viewed as simply technical, only means to some other narrow end: they must always be viewed in terms of the greater endeavor. Therefore, it is typical - and expected - that a discussion of one set of books will come into play with another, possibly because the rock their own authors stand upon is common: a lively discussion, for example, of Plato's Meno might well erupt as students try to make sense of Book X of Euclid's Elements.

The list of mathematical books that students read in the "mathematics tutorial" has changed over the years, but certain works are quite stable in the program. These include Euclid's Elements (all thirteen books) and Nichomachus's Arithmetic in the first year; the first three books of Apollonius's Conics and Descartes's La Géométrie in the second year; Newton's Principia and Dedekind's Continuity and Irrational Numbers in the third year; and Lobachevski's Theory of Parallels in the fourth year. In all cases, the theorems proven in the books or the problems solved are presented at the board by the students, and fully discussed.

Newton's Principia of course could also be considered a reading in physics (and study read other works from physics in their laboratory tutorials), but in the mathematics tutorial a distinction between mathematics and physics or astronomy is not always made. Thus, in the second year the mathematics tutorial also includes Ptolemy's Almagest; the third year includes readings from Galileo, and the fourth year Einstein's two 1905 papers on special relativity and Minkowski's 1908 lecture, "Space and Time." The fact that the distinction between physics, astronomy, and mathematics is not always made itself a question for the students to consider, leading them to frequent discussions about the nature of mathematics.

From the emphasis on "great books," one might get the false impression that St. John's is based on western dogmas, partly because of the word "great." Yet, nothing could be further from the truth. The goal of the program, in mathematics no less than in literature or philosophy, is to try to uncover and get behind the basic assumptions in the books being read. In this way, however, it is in line with one modern philosophical position, though one meant to keep questions alive, namely, Husserl's idea that philosophy has the role of breaking through layers of conceptual "sedimentation" (see Husserl 1989, pp. 168 ff). Thus, Jacob Klein, who had a decisive role in shaping the St. John's program and who was student of Husserl, writes:

The passing on of sciences, arts, and skills, especially of intellectual ones, cannot quite avoid the danger of blurring the original understanding on which those disciplines are based. The terms which embody that understanding, the indispensable terms of the art, of the techne in question, the "technical" terms, acquire gradually a life of their own, severed from the 
original insights. In the process of perpetuating the art those insights tend to approach the status of sediments, that is, of something understood derivatively and in a matter-of-course fashion.... Liberal education has to counteract this process of sedimentation... (Klein 1985, p. 263)

And specifically about mathematics, he emphasizes:

It is necessary...to study mathematics, always bearing in mind that this studying has to be reflective and cannot be satisfied with a sedimented understanding of mathematical relationships. (p. 266)

Whether St. John's, or any of these schools, actually achieve the Bildung Humboldt aimed for or the Paideia the classical thinkers aimed for, I am not sure. It is clear, however, that they are turned towards these directions. And that may be the best we can hope for.

\section{References}

Biermann, H. R. (2010). Praxis des Mathematikunterrichts 1750-1930. Längsschnittstudie zur Implementation und geschichtlichen Entwicklung des Mathematikunterrichts am Ratsgymnasium Bielefeld. Berlin: Logos.

Blankertz, H. (1982). Die Geschichte der Pädagogik: Von der Aufklärung bis zur Gegenwart. Wetzlar: Büchse der Pandora.

Boeckh, A. (1853). Über die Wissenschaft, insbesondere ihr Verhältnis zum Practischen und Positiven. Festrede gehalten auf der Universität zu Berlin am. In A. Boeckh (Ed.), Gesammelte kleine Schriften (Vol. 2, pp. 81-98), October 15, 1853.

Campe, J. H. (Ed.). (1785-1792). Allgemeine Revision des gesamten Schul- und Erziehungswesens: Von einer Gesellschaft praktischer Erzieher. Theil 1-16. Hamburg, Wolfenbüttel, Wien, Braunschweig.

Crelle, A. L. (1845). Encyklopädische Darstellung der Theorie der Zahlen und einiger anderer damit in Verbindung stehender analytischer Gegenstände; zur Beförderung und allgemeineren Verbreitung des Studiums der Zahlenlehre durch den öffentlichen und Selbst-Unterricht. Erster Band. Berlin.

Diesterweg, A. (1859). Sachlicher und formaler Rechenunterricht. In Rheinische Blätter. Neuste Folge (Vol. 3, $50 \mathrm{ff}$ ).

Diesterweg, F. A. W. (1844). Methodisches Handbuch für den Gesammt-Unterricht im Rechnen. Als Leitfaden beim Rechenunterrichte und zur Selbstbelehrung. Bd. 1 (4th ed.). Elberfeld: Büschlersche Verlagsbuchhandlung.

Dilthey, W. (1905). Die Jugendgeschichte Hegels. In W. Dilthey (Ed.), Gesammelte Schriften IV (4th ed., pp. 1-282). Stuttgart, Göttingen (1968).

Fichte, J. G. (1808). Reden an die deutsche Nation. In I. H. Fichte (Ed.), J. G. Fichtes Sämmtliche Werke (Vol. 7, pp. 260-490). Berlin (1845-1846).

Horlacher, R. (2004). Bildung-A construction of a history of philosophy of education. Studies in Philosophy and Education, 23(5), 409-426. https://doi.org/10.1007/s11217-004-4452-1.

Husserl, E. (1989). The origin of geometry. Introduction by Jacques Derrida. Lincoln, NB: University of Nebraska Press.

Jaeger, W. (1945). Paidea: The ideals of greek culture (Vol. 3) (Gilbert Highet, Trans.). New York: Oxford University Press.

Jahnke, H. N. (1990a). Mathematik und Bildung in der Humboldtschen Reform. Göttingen: Vandenhoeck \& Ruprecht. 
Jahnke, H. N. (1990b). J. F. Herbart (1776-1841): Nach-Kantische Philosophie und Theoretisierung der Mathematik. In G. König (Ed.), Konzepte des mathematisch Unendlichen im 19. Jahrhundert (pp. 165-188). Göttingen: Vandenhoeck \& Ruprecht.

Jahnke, H. N. (1991). Mathematics and culture: The case of Novalis. Science in Context, 4(3), 279-295.

Jahnke, H. N. (1993a). Algebraic analysis in Germany, 1780-1840: Some mathematical and philosophical issues. Historia Mathematica, 20, 265-284.

Jahnke, H. N. (1993b). Cultural influences on mathematics teaching: The ambiguous role of applications in nineteenth-century Germany. In R. Biehler, R. W. Scholz, R. Strässer, \& B. Winkelmann (Eds.), Didactics of mathematics as a scientific discipline (pp. 415-429). New York: Kluwer.

Jänicke, E. (1877). Geschichte des Rechenunterrichtes. In C. Kehr (Ed.), Geschichte der Methodik des deutschen Volksschulunterrichtes (Vol. 1, pp. 280-460). Gotha: Thienemanns Hofbuchhandlung.

Jeismann, K.-E. (1974). Das preußische Gymnasium in Staat und Gesellschaft. Die Entstehung des Gymnasiums als Schule des Staates und der Gebildeten 1787-1817. Stuttgart: Klett.

Klafki, W. (2000). The significance of classical theories of bildung for a contemporary concept of Allgemeinbildung. In I. Westbury, S. Hopmann \& K. Riquarts (Eds.), Teaching as a reflective practice. The German didaktik tradition. Studies in curriculum theory (pp. 85-108). Mahwah, NJ: Lawrence Erlbaum Associates, Publishers.

Klein, J. (1985). On Liberal Education. In R. B. Williamson \& E. Zuckerman (Eds.), Jacob Klein: Lectures and essays (pp. 261-268). Annapolis, MD: St. John's College Press.

Leschinsky, A., \& Roeder, P. M. (1976). Schule im historischen Prozeß. Stuttgart: Klett.

Lundgreen, P. (1980). Sozialgeschichte der deutschen Schule im Überblick, Teil I: 1770-1918. Göttingen: Vandenhoeck \& Ruprecht.

Marrou, H. I. (1982). A history of education in antiquity (G. Lamb, Trans.). Madison, Wisconsin: University of Wisconsin Press.

Müller, D. K. (1977). Sozialstruktur und Schulsystem. Aspekte zum Strukturwandel des Schulwesens im 19. Jahrhundert. Göttingen: Vandenhoeck \& Ruprecht.

Niethammer, F. J. (1808). Der Streit des Philanthropismus und Humanismus in der Theorie des Erziehungsunterrichtes unserer Zeit. Jena: Frommann.

Oelkers, J. (1999). The origin of the concept of "Allgemeinbildung" in 18th century Germany. Studies in Philosophy and Education, 18(1), 25-41. https://doi.org/10.1023/a:1005131203479.

Östling, J. (2015). The Humboldtian tradition: The german university transformed, 1800-1945. In P. Dhondt (Ed.), University Jubilees and University history writing: A challenging relationship (pp. 183-216). Leiden: Brill.

Radatz, H., \& Schipper, W. (1983). Handbuch für den Mathematikunterricht an Grundschulen. Hannover: Schroedel.

Schubring, G. (1987). Mathematisch-naturwissenschaftliche Fächer. In K.-E. Jeismann \& P. Lundgreen (Eds.), Handbuch der deutschen Bildungsgeschichte, Bd. III: 1800-1870. Von der Neuordnung Deutschlands bis zur Gründung des deutschen Reiches (pp. 204-221). München.

Scurla, H. (1976). Wilhelm von Humboldt. Werden und Wirken (Nachdruck der Ausgabe Berlin 1970). Düsseldorf: Claassen.

von Humboldt, W. (1809). Der Königsberger und der Litauische Schulplan. In A. Flitner \& K. Giel (Eds.), W. von Humboldt, Werke IV (2nd ed., pp. 168-195). Darmstadt: Wissenschaftliche Buchgesellschaft 1964. Written in 1809.

von Humboldt, W. (1810). Über die innere und äußere Organisation der höheren wissenschaftlichen Anstalten in Berlin. In A. Flitner \& K. Giel (Eds.), W. von Humboldt, Werke IV (2nd ed., pp. 255-266). Darmstadt: Wissenschaftliche Buchgesellschaft 1964. Written in 1810.

von Sallwürk, E. (1899). Adolf Diesterweg. Darstellung seines Lebens und seiner Lehre und Auswahl aus seinen Schriften (Vol. 1). Langensalza: H. Beyer \& Söhne. 
Open Access This chapter is licensed under the terms of the Creative Commons Attribution 4.0 International License (http://creativecommons.org/licenses/by/4.0/), which permits use, sharing, adaptation, distribution and reproduction in any medium or format, as long as you give appropriate credit to the original author(s) and the source, provide a link to the Creative Commons licence and indicate if changes were made.

The images or other third party material in this chapter are included in the chapter's Creative Commons licence, unless indicated otherwise in a credit line to the material. If material is not included in the chapter's Creative Commons licence and your intended use is not permitted by statutory regulation or exceeds the permitted use, you will need to obtain permission directly from the copyright holder.

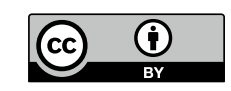




\title{
Chapter 6 \\ Allgemeinbildung, Mathematical \\ Literacy, and Competence Orientation
}

\author{
Rolf Biehler with a reaction by Mogens Niss
}

\begin{abstract}
The first part of this chapter has been written by Rolf Biehler on the basis of his presentation at ICME 13. Mogens Niss was invited to react to this presentation at ICME 13 and elaborated his reaction as the second part of this chapter. Although the authors are only responsible for their respective sections, they both belong together and are therefore published here as a joint chapter. The first part gives a sketch of the discussion on 'Allgemeinbildung' (general education for all) and mathematical literacy in Germany from the late 1960s to today. In the 1970s, educational goals for Allgemeinbildung were condensed in different visions, for example, a 'scientifically educated human being', a 'reflected citizen', an 'emancipated individual being able to critique society', and a person 'well educated for the needs of the economic system'. In the early 1990s, a book by H. W. Heymann on Allgemeinbildung and mathematics education initiated a controversial discussion, which will be critically examined and related to other conceptions. Due to bad results in TIMSS (Third International Mathematics and Science Study) and PISA (Programme for International Student Assessment) starting in the late 1990s, a new discussion on educational goals in mathematics arose and made PISA's conception of mathematical literacy popular in Germany. However, the idea of mathematical literacy was modified and extended by the German debate, some traits of which can be traced back to Humboldt and the 19th century. In his reaction "Allgemeinbildung, mathematical competencies and mathematical literacy: Conflict or compatibility?" Mogens Niss relates the German discussions to the international development on competence orientation, featuring the KOM project (Competencies and Mathematical Learning), including the various conceptualisations in the PISA frameworks.
\end{abstract}

Keywords Bildung $\cdot$ Allgemeinbildung $\cdot$ General education $\cdot$ Mathematical literacy $\cdot$ Mathematical competencies $\cdot$ Mathematical literacy

R. Biehler with a reaction by Mogens Niss ( $\bowtie)$

Universität Paderborn, Paderborn, Germany

e-mail: biehler@math.upb.de 


\title{
6.1 Allgemeinbildung, Mathematical Literacy, and Competence Orientation in Mathematics Education in Germany (Rolf Biehler)
}

\subsubsection{Introduction: Bildung and Allgemeinbildung in Germany}

\begin{abstract}
Since the 19th century in German history, Bildung and Allgemeinbildung have repeatedly been reinterpreted depending on changes in society and the school system, and on changes of views about the function of the school system. Niels Jahnke discusses the approaches to Bildung in the times of Humboldt in Chap. 5 of this book. Horlacher (2016) provides an informative overview reaching from the origins to modern contemporary conceptions, including the relation of Bildung to PISA's conceptions of mathematical literacy.

\footnotetext{
In a comprehensive study of Bildung und Schule, Dohmen concludes in 1964 that the concept of "Bildung" is one of the most ambiguous and vague fundamental concepts of German pedagogy (Dohmen 1964, p. 15). Indeed, it is typical of the lack of clarity of the concept that in the discussion on school reform, it is used by conservatives and reformers alike. Alternatives, like Erziehung (education) or Unterricht (instruction, teaching), do not really catch on, as they cannot rival the grandness and splendor that lies in concept of Bildung. When related to the concept of Bildung, says Dohmen, the school becomes elevated into the high winds of the spiritual, so to speak (ibid., p. 16), whereby this ideal concept generally refers to perfecting the person's "true nature," or "higher self". (Horlacher 2004, pp. 410-411)
}

'Allgemeinbildung', which can also be characterised as 'general Bildung' is more related to the school system, meaning goals of general education (grades 1-9(10)) for all students with the connotation of holistic self-enculturation. It is contrasted to vocational 'Bildung' (vocational education) that prepares for specific vocations.

In German-speaking countries, after grade 9 or 10, students can either go to a Gymnasium or a vocational school. Vocational schools usually mean part-time courses, as students are being educated in craft businesses or companies in parallel (this system is called 'dual system'). This description is a simplified model, and the actual system is much more complicated. Grades 11-13 (or 10-12, depending on the Land and the type of school) which are meant to prepare for university and finish with the Abitur (school-leaving certificate allowing access to academic education) are also said to provide Allgemeinbildung. As a distinction, the specific Allgemeinbildung at this level is referred to with attributes such as 'higher' (Fischer 2001), 'academic' (Huber 2009) or 'deepened' (KMK 2012) as it does concern only those students who have chosen to attend these grades. In 2017, nearly half of each student cohort in Germany was enrolled in a Gymnasium. In the 1960s this was 10\% and in the 19th century even less.

Several years ago, German-speaking countries introduced national standards. In Germany, they were published for grades 5-10 in 2004 (KMK 2004) and for the final level of grade 12(13) in 2012 (KMK 2012). Although Allgemeinbildung or deepened Allgemeinbildung are mentioned, the main focus of the standards-which 
are called 'Bildungsstandards' is on (mathematical) competencies, a notion that was influenced by its use in PISA and international discussions on competence orientation (Niss and Højgaard 2011). This development has raised concerns that the national standards do not take the more general understanding of Bildung into sufficient consideration. This concern was not only raised in mathematics education but also in educational theory on education until grade 12/13. The title of the book "Bildung at the Gymnasium between competence orientation and cultural work" edited by Bosse (2009) is symptomatic. The debates in educational philosophy are reflected in the discussions on the goals of mathematics education at school level in the community of mathematics educators too (Neubrand 2015).

Despite the variability in the meaning of Allgemeinbildung, there are some common elements in these debates. Conceptions of Allgemeinbildung emphasise the relative autonomy of students and schools and are critical against too direct transpositions of societal and economic needs into the school system and against the direct transposition of mathematical content into schools. The selection of mathematical content for school education has to be justified from a theory of goals of general education respectively from a conception of Allgemeinbildung. Conceptions of Allgemeinbildung in principle have to take a specific view of the relationships depicted in Fig. 6.1.

Conceptions of Allgemeinbildung always deal with the 'justification problem' in the sense of Niss (1994), they provide an argumentation basis from which the selec-

Fig. 6.1 Conceptions of Allgemeinbildung

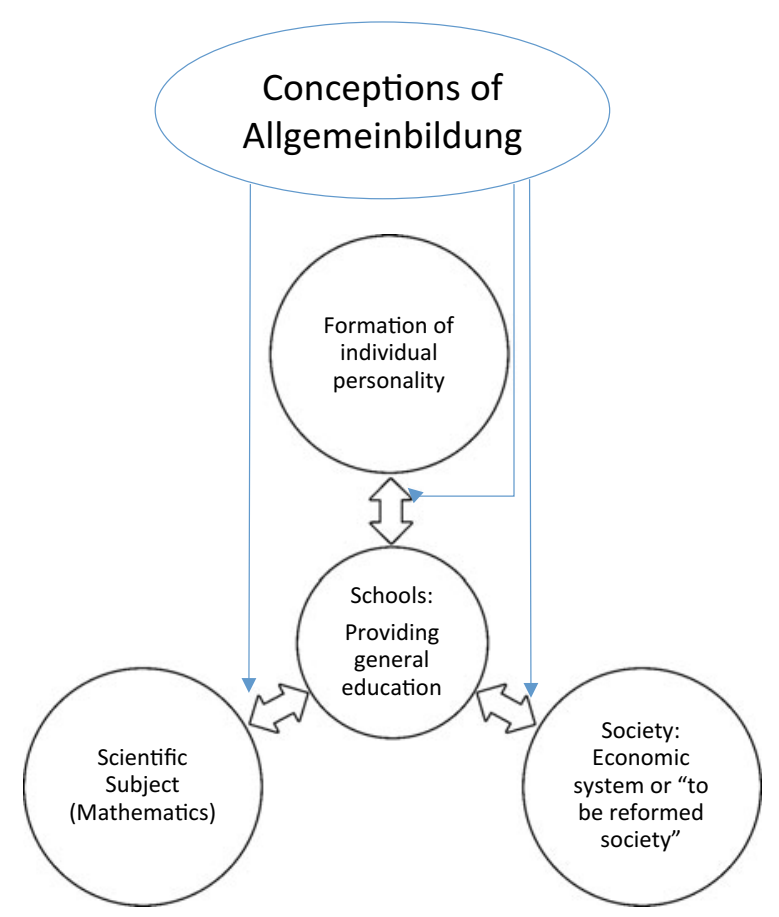


tion of content and goals of teaching can be justified. However, they do not always deal sufficiently with what Niss (1994, p. 373) calls the 'possibility problem' and the 'implementation problem'. Is it possible to teach the selected and justified curricular content to the concrete students in a specific society at a specific point in time, and is it possible to achieve a large implementation of such curricular goals? Actually, there is a dialectic interrelation and tension between the justification, the possibility, and the implementation problem. As Horlacher's (2004) quote mentions, discussions on Bildung sometimes taste of idealistic debates and are somewhat removed from the social reality of societies and real classrooms.

Allgemeinbildung comes with the additional connotation of general in the sense of 'for all students'. In this respect, there is a relation to international discussions (Gates and Vistro-Yu 2003). Beyond gender, ethnicity, language etc., the specific meaning of Allgemeinbildung in German-speaking countries has to be put into context, namely the streaming in the school system, which is less common in other countries. In general, at least since the beginning of the 20th century, students are streamed after grade 4 already into three different types of schools representing three levels of education: Hauptschule (formerly Volksschule. low), Realschule (medium) and Gymnasium (high). The Hauptschule und Realschule prepare for different types of vocations (blue- or white-collar workers or business employees, whereas Gymnasium lasts three years longer than the other schools and is preparing for university studies. This streaming in Germany before World War II was resumed in West Germany after the war. Comprehensive schools entered the scene only in the late 1960s in West Germany. They never became the regular standard in West Germany, but about $16 \%$ of the students in grades 5-10 went to a comprehensive school in 2014/15 (Malecki 2016, p. 12). In contrast, the German Democratic Republic (East Germany) implemented a comprehensive school system during its existence, from 1949 to 1989. After the reunification, the new federal states from East Germany adopted the West German system to a large extent, some of them implementing two streams instead of three. This streaming into three school types goes back to the 19th century (see Sect. 6.1 of this chapter), and the Humboldtian spirit of Bildung influenced mostly the Gymnasium with its pronounced function of preparing for university, whereas the other school types provided education in a much more utilitarian way.

Thus, Allgemeinbildung is not just a term of educational philosophy but a concept that is used and filled with different meanings in the spheres of general politics, educational politics and school administration, in the educational sciences and philosophy of education, and in didactics of mathematics itself. This adds a level of complexity to this notion.

In this paper, we will deal with this complexity by focusing on three periods, which provide interesting insights into the development in (West) Germany.

- The late-1960s to the 1980s, where significant reforms of the whole educational system in West Germany were partially undertaken in parallel to considering 'new math' in schools.

- The mid-1990s with a specific sudden public concern of 'Allgemeinbildung and mathematics education'. 
- The late-1990s where Germany showed unsatisfactory results in TIMSS and PISA, which among other aspects gave rise to the first national standards in mathematics education since World War II and lead to the introduction of competence orientation.

The paper focuses on West Germany from the 1960s and will integrate the developments in other German-speaking countries (German Democratic Republic, Austria, Switzerland).

\subsubsection{Looking Back into the Late 1960s and 1970s: New Math and Educational Reforms}

We will focus on the situation in West Germany, where, as mentioned above, the school system consisted of three streams in grade 5-10. All of these schools were supposed to provide Allgemeinbildung but had very different goals, and mathematics education in these three school types differed considerably. In a first approximation, Haupt- and Realschule provided more utilitarian types of mathematics education, whereas the Gymnasium started its preparation for university studies from grade 5 onwards with a view towards mathematics as a scientific discipline. Grades 5 and 6 still had elements of utilitarian mathematical content, stemming from the curricular reforms in the 19th century, as was analysed by Jahnke (in this volume).

Moreover, the type of mathematics taught in these schools was largely influenced by teacher education: mathematics teachers for the Gymnasium were educated at universities practically along the same curriculum as mathematics majors, whereas teachers of Haupt- and Realschule were educated at special institutions of higher education for teachers (Pädagogische Hochschulen), learning different types of mathematics more remote from the 'real academic mathematics'.

Beginning in the 1960s, the West German school system came under pressure because it was considered to be dysfunctional for the economic system. Strengthening the role of the sciences and mathematics was seen as an essential contribution to the economic development of the country. Processes to revise syllabi were initiated on a large scale. However, fundamental changes also affected the school system and the university system itself. Many new universities were created, and the Gymnasium was opened up for a broader range of students, both measures aiming at increasing the number of university students. The Gymnasium was and still is the primary course of education for future university students. The proportion of students attending a Gymnasium has risen from about $10 \%$ in the 1960 s to more than $50 \%$ today. Moreover, new ways were then opened for students of vocational schools to pass the Abitur and enter Universities of Applied Science (Fachhochschulen). At the same time-as in other western countries - a broad political movement began, including the 1968 students' movements, aiming at more equity, political participation, individual emancipation, and democratisation in western societies. This progressive movement obviously had different views on the needs of society and what it meant to cultivate and develop a 
holistic personality within the school system. The view ranged from being an emancipated personality able to criticise society over a 'reflected citizen' to a 'scientifically educated human being'.

From this perspective, the educational system was supposed to contribute to the social change and not primarily to the economic transformation. The three streams school system was attacked in favour of establishing comprehensive schools for compulsory education until grade 9 or 10 . The three different educational goal systems of the three school types were put into question in favour of one conception of Allgemeinbildung stating that three-for each school type different-conceptions of Allgemeinbildung are a contradiction in terms. However, comprehensive schools were implemented in only some of the federal states, and only some states developed a common syllabus for all school types in the first place, making some differentiation according to the three levels, but still based on common ground. Education was the responsibility of the federal states in West Germany, which largely explains this variability.

During this period, we observe contradictory factors influencing mathematics education (Fig. 6.2). On the one hand, societal pressure was put on the school system to revise the curricula, to break with traditions, and to question all curricular content with regard to its contribution to the education of students. In its extreme end, curricular content has to come from analysing how students have to act competently in societal or vocational situations (Robinsohn 1969a, b). On the other hand, and this thinking was more influential in mathematics education worldwide, the orientation towards the fundamental ideas of a scientific discipline (Bruner 1960) was seen as the principle from which mathematics education had to be revised from primary education up to the Abitur, concerning all types of schools. This approach is based

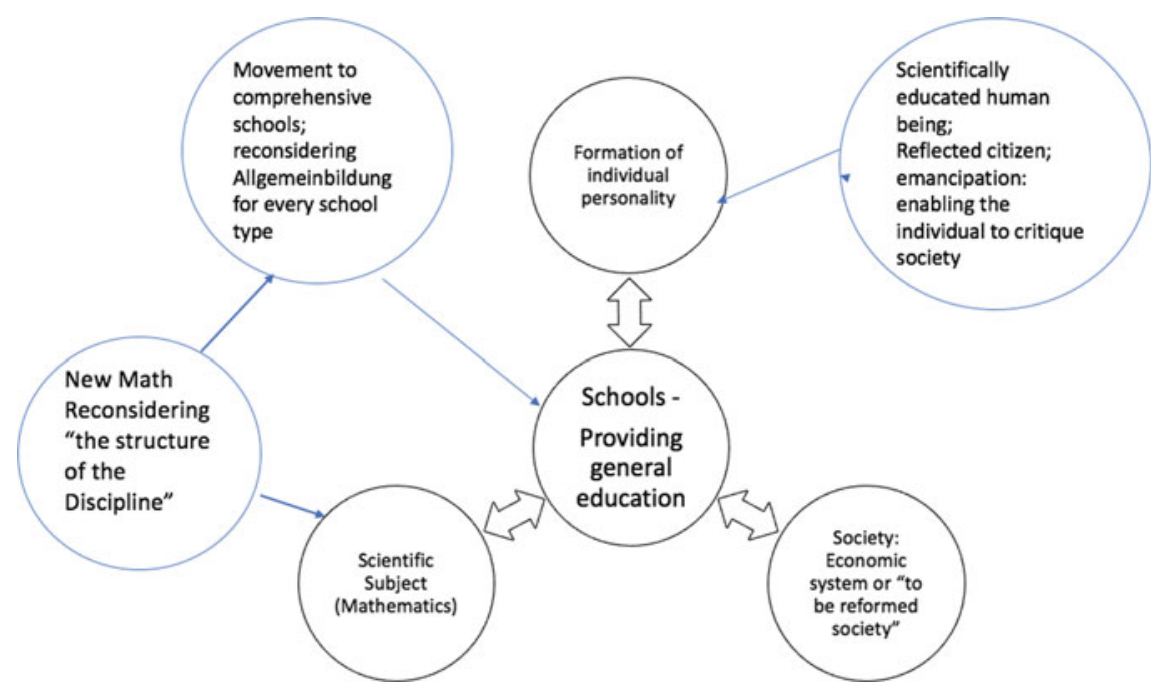

Fig. 6.2 Factors influencing the role of mathematics in the educational system 
on the conviction that orientation towards the sciences and scientific thinking is the way to achieve economic and societal growth.

A common ground for these curriculum revisions in mathematics, therefore, was, for a while, the orientation towards mathematics as a scientific discipline, interpreted in the Bourbakian view of mathematics as a science of structures in accordance with international developments. The Gymnasium curricula were criticised as being oriented towards an old-fashioned view of mathematics, which was to be replaced by new and modern mathematics closer to the current state of the discipline. The curricula of the secondary schools Haupt-and Realschule, as well as those of primary schools, were criticised as being insufficiently rooted in mathematics as a discipline at all but pursuing much more practical utilitarian goals. Introducing the principle of orientation towards mathematics as a scientific discipline into these schools was also seen as an act of emancipation for the pupils there, allowing them access to scientific knowledge instead of treating them as second- or third-class pupils, thereby contributing to increased social mobility.

As in other countries, these reforms were not very successful in either school type for many reasons. One reason for this failure was assigned to a rather naïve transposition didactics. Although this was the established approach in the emerging field of mathematics education, there were some different approaches as well.

The call for curriculum revision also created the need to identify better ways to express learning goals for students. Conceptions from the educational sciences ('learning goal orientation') entered German mathematics education and were deployed regularly (Bloom 1956; Gagné 1970; Gagné and Briggs 1974), but approaches rooted in a conception of 'Bildung' were also put forward. One of the leading and influential educational scientists, who aimed at re-defining Bildung and Allgemeinbildung based on the German tradition and the new challenges from society and science, was Wolfgang Klafki, who also inspired real reform projects in various school subjects (Klafki 1963, 1974). The 1963 book received many new editions in the 1970s and 1980s [see Klafki $(1995,2000)$ for basic ideas in the English language]. He attempted to integrate the conceptions of material and formal Bildung (see the section by Jahnke) and established an analytical framework with which teachers and educators can analyse the educational value (Bildungswert) of a certain topic, reflecting on the current and future meaning of this topic for students and on the 'exemplary character' of a topic to be taught. However, he did not relate his framework to the analyses of a scientific discipline.

The debate on curriculum revision included a critique of educational practices in the Gymnasium from the perspective of Bildung. This perspective was also taken up in mathematics education and is best represented by Wittenberg (1963) and Wagenschein (1965)—with relations to Klafki's approach. Compared to different early versions of New Math in German-speaking countries, these approaches were profoundly critically analysed by Lenné (1969). A more recent account of these historical developments in the English language, focusing on the contribution of Hans-Georg Steiner, is the paper by Vollrath (2007). Among other things, it was to Lenné's merit that he had already pointed out the large discrepancy between the ideals of general education formulated within mathematics education (including neohumanistic 
aspects) in the preambles of syllabi and the reality of its catalogues of topics, and not to speak of the realities in the classroom.

In the 1970s, the debate about the goals of mathematics education continued, and the approaches of 'new math' were regarded more critically from both practical and theoretical perspectives. In this context, Winter (1975) tried to specify how mathematics education could and should contribute to "general educational goals" (Allgemeine Lernziele) in schools. Heinrich Winter strongly influenced the debate on Allgemeinbildung in mathematics education in the 1990s (Winter 1990, 1995), which we will refer to in the next section.

First, we will look at his influential 1975 paper. Winter asks the question of how mathematics education can contribute to Allgemeinbildung, using the then modern terminology of general educational goals to express his view of Allgemeinbildung for mathematics education. He relates general goals for schools to general goals for mathematics education, which in turn correspond to features of mathematics as a scientific discipline and to general characteristics of human beings. This approach is more anthropological than sociological or political.

Winter's Table 6.1 provides an overview and summary; the article itself gives examples for mathematics education that illustrate and further interpret the different facets, and that would help realise these general goals in everyday mathematics teaching. Two aspects are remarkable. First, his view of mathematics is different from a perspective focusing on ready-made mathematics without applications, whereas this view was partly underlying the new math approach. Second, general goals of mathematics education are not 'deduced' from general goals of schooling, but rather from a broad philosophy of mathematics interacting with requirements from education and anthropological aspects.

A different contemporary contribution was the book by Damerow et al. (1974) on "Elementary mathematics: Learning for the practice", which today we consider as a contribution to critical mathematics education (Skovsmose 1994). Christine Keitel made important contributions to this field later on. The authors' project had the aim

Table 6.1 General learning goals for mathematics education (Winter 1975, p. 116; transl., R.B.)

\begin{tabular}{l|l|l|l}
\hline Human being & Mathematics & $\begin{array}{l}\text { General goals: } \\
\text { school }\end{array}$ & $\begin{array}{l}\text { General goals: } \\
\text { mathematics } \\
\text { education }\end{array}$ \\
\hline Creative, playful & $\begin{array}{l}\text { As a creative } \\
\text { science }\end{array}$ & $\begin{array}{l}\text { Unfolding the } \\
\text { creative potential }\end{array}$ & $\begin{array}{l}\text { Learning heuristic } \\
\text { strategies }\end{array}$ \\
\hline $\begin{array}{l}\text { Thinking, searching for } \\
\text { reasons and insight }\end{array}$ & $\begin{array}{l}\text { As a proving, } \\
\text { deducting science }\end{array}$ & $\begin{array}{l}\text { Supporting rational } \\
\text { thinking }\end{array}$ & Learning to prove \\
\hline $\begin{array}{l}\text { Designing, economising, } \\
\text { using technology }\end{array}$ & $\begin{array}{l}\text { As an applicable } \\
\text { science }\end{array}$ & $\begin{array}{l}\text { Supporting } \\
\text { understanding } \\
\text { reality and its usage }\end{array}$ & $\begin{array}{l}\text { Learning to } \\
\text { mathematise }\end{array}$ \\
\hline Speaking & As a formal science & $\begin{array}{l}\text { Supporting the use } \\
\text { of language faculty }\end{array}$ & $\begin{array}{l}\text { Learning to } \\
\text { formalise, learning } \\
\text { technical skills }\end{array}$ \\
\hline
\end{tabular}


to determine interdisciplinary goals for mathematics education that qualify students for competent and autonomous actions in future situations of practice determined by heteronomy. For accountants that means not only doing the necessary calculations but understanding the whole mathematical system (the real abstraction) behind the limited calculations they are supposed to focus on. The analysis is rooted in the approach by Robinsohn (1969a, b), who worked at the same institution in Berlin (Max Planck Institute for Educational Research in Berlin) as Damerow et al. (1974). However, their emphasis is on autonomous action, besides competent action, providing the specific character of this approach.

In Winter's 1990 paper on citizens and mathematics (Winter 1990), he took elements from this politically critical tradition and combined them with aspects in the Humboldtian tradition. We will discuss it as an intermediate step in this section before we enter into the debate of the mid-1990s.

In this paper, Winter indicated 'enlightenment in the Kantian sense' as an essential goal of education at public schools. Accordingly, we have to think about the question of how to educate our children to become free and responsible citizens of society, be it in local communities, the state, or the world in general.

Can the teaching of mathematics - and how could this be afforded - help to develop the faculty of judgement in matters of public life? In short: can it contribute to enlightenment? (Winter 1990, 131)

According to Winter, the idea that all human beings are equal, have equal votes in elections, and should have equal chances in life does make sense only under the assumption of responsible citizens. Democracy can only be imagined as a society of responsible persons.

Winter considers the participation of citizens in public affairs under the perspective of the tension between experts and non-specialists. Most political decisions require highly specialised knowledge which is provided by experts, whereas in principle all members of society are supposed to decide upon political and social matters and at the same time are laymen regarding most questions. Consequently, in a democratic society, non-specialists should be qualified to understand how experts arrive at their specialised knowledge, how safe this knowledge is and to ask critical questions, in short: citizens should develop a faculty of judgement.

Taking these principles and notions as a starting point, in his (1990) paper Winter concentrated on those parts of mathematics that might contribute to furthering an understanding of society, politics and economy. Only in the last part of the paper examples from science are discussed under the heading of 'Public mathematics'.

It is no wonder that talking about society and economy leads among others to those subjects that, in the first part of our paper, we called everyday applications. We shall keep to this term though Winter uses the German word 'Bürgerliches Rechnen' ('Civil calculations'). Concerning these everyday applications, he sees a tension between 'mathematical systematics' and the 'reality of life' $(1990,134)$ that implies a twofold danger of trivialisation. There is, first, the danger of trivialising reality to apply predefined mathematical procedures; then there is the danger of trivialising mathematics, abandoning the elaboration of sophisticated mathematical algorithms 
and concepts to increase concreteness. According to Winter, a way out consists of examples of 'authentic and reflective modelling' (1.c.).

Winter warned against trivialising 'everyday applications' not only from a mathematical point of view but hinted at the danger of reducing applications to innocent and harmless subjects without providing insights of a more general nature (1.c., 135). In doing so, the aim of enlightenment would be missed. Thus, we see here an anti-utilitarian argument in a similar vein to early 19 th century thinkers. 'Bildung' should open the way to critically thinking in alternatives and not to stick to existing conditions. No wonder, exactly at this point of his argument, Winter quoted F. Diesterweg whom we discussed above in connection to Humboldt's disregard for learning, "Carolins, Ducats, and the like".

The essence of Winter (1990) consists of carefully elaborated examples of how he understood 'authentic and reflective modelling'. As noted above, most of these examples are chosen from economy and social sciences-seemingly a consequence of his approach to view Allgemeinbildung as education for free and responsible citizens. In fact, this is a restriction of the very idea of Bildung in a twofold sense. First, we do not know whether the participation of citizens in social life will be organised in the same way in the future as it is done today, nor do we know whether economic conditions will remain the same as they are at present. Second, a human being is more than a citizen of a society, and reducing human beings to this role would deprive them of many potentialities (see for a similar remark Vohns 2017b).

\subsubsection{Allgemeinbildung and Mathematics Education in the Mid-1990s-A Snapshot}

Starting in the 1970 s, there was a growing concern among some mathematics educators that a too narrow orientation towards mathematics as a scientific discipline was insufficient or even misleading if interpreted as in the new math reform movement. The need for foundational research in this domain was one reason to create the Institute for Didactics of Mathematics (IDM) in 1973, with the aim of conducting research in the didactics of mathematics, thus providing foundations for more well-grounded and successful educational reforms in the future. One of its research programs was involved with studies on the history and epistemology of mathematics to develop a broader and more in-depth view of what constitutes mathematics as a scientific discipline as part of the broader culture and society (Biehler 1994). Another program was concerned with analysing the relation of mathematics education to conceptions of Bildung and Allgemeinbildung (Biehler et al. 1995; Heymann 1996, 2003; Jahnke 1990). Niels Jahnke, Hans-Werner Heymann and I were colleagues at the IDM from the late 1970 s to the mid-1990s.

Starting in the early 1990s, a working group at the IDM in Bielefeld was founded to bring together several perspectives on the topic 'Allgemeinbildung and mathematics education' (Biehler et al. 1995). A specific view on this topic was developed in the 
habilitation theses of Heymann (1996), which initiated a large public controversy. A symposium in Bielefeld in 1996 again tried to bring together different views (Biehler and Jahnke 1997). Heymann' s book was later published in English, unfortunately without the chapter on the theory of Bildung (Heymann 2003). The paper by Winter (1995) is a reaction to the 'Heymann controversy' and is still today a standard reference, whenever general goals of mathematics education are being discussed in German-speaking countries.

The public controversy was initiated by some newspaper articles that interpreted Heymann's work in an extremely reduced way distorting the original meaning. For example, the Süddeutsche Zeitung wrote on 8 October 1995: "Seven years of mathematics is enough. What adults need in mathematics, they can learn in the first seven school years. Everything taught to pupils in mathematics beyond this, plays practically no role in their future lives." (my translation R.B.) Accompanying texts claim that this 'was shown' in the habilitation thesis of the Bielefeld 'mathematician' HansWerner Heymann. Heymann received massive criticism from mathematicians who pointed out that he was not a mathematician but a mathematics educator, and that his habilitation thesis was submitted at the faculty of education and not at the faculty of mathematics. However, Heymann received many letters from readers expressing opinions such as: "It was time that somebody told the truth"; "I always suffered from my mathematics lessons: senseless calculation with no meaning to me - and much pressure from the teachers"; "Again and again I am dreaming of my horrible matriculation examination (Abitur)". He also received support from educationalists and politicians who had been critical about the amount and type of mathematics education within general education, sometimes suspecting that the hidden aim of mathematics education simply was the selection of students.

The reaction of the wider public indicates that many did not consider mathematics as a valuable enrichment of their Allgemeinbildung and their development as fullyeducated human beings. Many wish for a reduction of mathematical content in school (or maybe a different type of mathematics education). The reaction of mathematicians indicated that they did not consider (parts of) didactics of mathematics as a partner in fostering mathematics education at school.

However, summarising Heymann's thesis as "seven years of mathematics education are enough" was a gross misunderstanding of his work. The main reason for this public misunderstanding was, among others, the following passage in his book:

Concluding Remarks. In their private and professional everyday lives, adults who are not involved in mathematics-intensive careers make use of relatively little mathematics. Everything beyond the content of what is normally taught up to the 7th grade (computing percentages, computing interest rates, rule of three) is practically insignificant in later life. (Heymann 2003, p. 104)

However, this was just a summary of one chapter of his book with the heading "Mathematics Instruction and Preparation for Later Life (in a strict sense)". The rest of the book puts forward arguments from a multitude of perspectives for justifying a much larger role for mathematics education within general education, based on Heymann's elaborated theory of Bildung, that specifies a framework for goals for general 
education that he then interprets for mathematics education. Heymann's argument was essentially a hypothetical one "if only we justified mathematics education from the perspective of everyday applications then this would imply ..."

The complete framework has further dimensions that are formulated as chapter headings (Heymann 2003, p. v):

- Preparation for Later Life

- Promoting Cultural Competence

- Developing an Understanding of the World

- Development of Critical Thinking

- Developing a Willingness to Assume Responsibility

- Practice in Communication and Cooperation

- Enhancing Students' Self-Esteem.

All dimensions are concerned with preparing students for their future lives (in a broader sense). The first chapter only covers the narrow range of everyday skills, but it features a title that supports misinterpretations. Positively speaking, Heymann distinguishes narrow utilitarian arguments (in his first chapter) from other justifications and contributions to the education of students. For instance, 'developing critical thinking' is akin to requirements in the era of Humboldt to develop thinking skills, and 'developing an understanding of the world' contains what Niels Jahnke termed 'theoretical applications' in his contributions to this volume.

These seven dimensions were constructed and elaborated upon the basis the German history of the theory of Bildung and structured the goals of general education for all subjects. In this sense, Heymann understands his contribution as a contribution to general educational science critically synthesising the theories of Bildung.

The second half of Heymann's book is devoted to how these dimensions can be used for a critical reflection and new determination of the goals, as well as the teaching and learning methods of school mathematics education that are adequate to realise the general goals.

Before we go into the details of his specification, we should understand that scientific disciplines as such are not explicitly mentioned in the framework. This observation is in contrast to other approaches to a theory of Bildung and in particular the theories of Bildung in mathematics education mentioned above, for example by Winter (1975), which are based on an at least rudimentary philosophy of mathematics in bidirectional interaction with philosophies of education.

If we are convinced that Thom's famous dictum, "In fact, whether one wishes it or not, all mathematical pedagogy even if scarcely coherent, rests on a philosophy of mathematics" (Thom 1973, p. 204) is right, we will regard it as a deficiency that we do not find an elaborated view on a philosophy of mathematics in his book.

Another critical point in the debate hit on Heymann's distinction of mathematicsintensive careers and careers that are not mathematics-intensive (see quote above) that was not well founded in an analysis of the needs of various vocations and future careers in tertiary education, the latter presents a relevant point for a growing proportion of students. 
These deficiencies, the partly irrational debate in public spheres, and discussions between mathematicians and mathematics educators all initiated a reaction by Winter that was simultaneously published in the newsletter of the German Mathematics Education Society (GDM) and the newsletter of the German Mathematics Union (DMV).

Here, he defined 'Allgemeinbildung' as competencies and knowledge that are essential to every human being as an individual and as a member of society independent of his/her gender, religion, (future) profession, etc. This definition could have been stated in similar terms by Humboldt and neohumanist authors two centuries ago.

Supposing this definition, the teaching of mathematics can and should provide 'three basic experiences'. The term 'experience' is important since it says that something is offered to the students, but it is up to the student what she or he makes of it. According to Winter, the learning of mathematics is more than simply storing knowledge. Thus, Allgemeinbildung has to be seen in terms of the self-development of the individual.

The three basic experiences are (all quotes from Winter are translated by the author of this chapter):

(1) to perceive and understand the phenomena of the world around us in nature, society and culture in a specific way,

(2) to get to know and to apprehend mathematical objects and facts represented using language, symbols, images or formulae as intellectual creations and as a deductively organised world of its own

(3) to acquire by working on tasks capabilities of problem-solving which go beyond mathematics (heuristic competencies). (Winter 1995, p. 37)

The term 'problem solving (experience 3) refers to activities that in the 19th century were discussed under the heading of 'formale Bildung'; the contribution of a discipline to developing the very capability of thinking. However, while at the beginning of the 19th century the core of productive thinking was seen in the faculty of judgement with all the connotations that Kant's fundamental book Critique of Judgement provided, the later understanding of 'formale Bildung' degenerated to simply meaning 'logical thinking'.

Experience (2) refers to mathematics as an autonomous subject and in a world of its own. Students should become aware that human beings are capable of both creating concepts and building whole architectures with them. Thus, experience (2) aims at pure mathematics as a deductive science, and we take explicit notice of the fact that Winter thinks this an indispensable dimension of mathematics in relation to Allgemeinbildung. Experience (2) is a significant point of departure from Heymann's approach.

Experience (1) refers to mathematics as a useful discipline, and this immediately leads to the question of an utilitarian or anti-utilitarian view of education. According to Winter, mathematics shows an almost infinite wealth of applications. However, he was quick to state that the utility of an application does not per se qualify it as a subject of Allgemeinbildung. 
Applications of mathematics are interesting and really indispensable for education only when a student can experience by them how mathematical modelling works. (Winter 1995, 38)

Thus, he returns to the concept of modelling as the core for qualifying applications as belonging to Allgemeinbildung. As expected, he adds the remark,

Even the everyday applications, in spite of their realism, fail to contribute to Allgemeinbildung when their status of being a model is concealed and their context remains vague. (1.c., p. 38)

He exemplifies this latter statement by discussing that and how the topic "calculation of interest' should be treated as a case of modelling.

A desirable and actually necessary conception of "Civil Arithmetic" should also contain fundamental questions of population growth, pensions, insurance, and taxation, as a component of politically enlightening arithmetic (and not the arithmetic of an insurance salesman or a taxman). (Winter 1995, p. 38)

He then continues,

Allgemeinbildung also comprises descriptive models of phenomena of the physical world insofar they are relevant to life and let experience in an exemplary way how mathematisations in technology and physics work and have been significant in the history of humankind. Above all, one should think of simple physical movements (throw, free fall, rotation, oscillation) including their causes and consequences. For example, the discovery of the law of falling bodies by Galileo in its historical context allows to experience paradigmatically: from a plausible hypothesis (velocity grows proportional to time) can be derived purely mathematical consequences whose interpretation illuminates phenomena which one would not observe with the naked eye and without mathematics. In general, successful mathematisations of a real phenomenon allows to look beyond the surface and substantially extends the everyday experience. (1.c., pp. 38/39)

Thus, it is mathematics that allows human beings to see beneath the surface of phenomena and detect deep structures which could not be uncovered otherwise. But to do so researchers must be able to play the game of hypotheses and deductions and to handle mathematics as a deductive science. The latter, however, is basic experience (2). Thus, both experiences (1) and (2) are inseparably intertwined.

In Winter's conception of Allgemeinbildung an application is not interesting, per se. Instead, the interactive and creative process of inventing hypotheses and drawing mathematical conclusions from them is the essential value for the intellectual development of young people. This, however, is only possible when students experience mathematics as an argumentative and deductive science. In Winter's word, students should experience that "rigorous science is possible". This is the essence of basic experience (2). Without a basic competence in pure mathematics, modelling cannot be understood and, of course, vice versa.

This general approach is different from Heymann, although we find similarities to Heymann's dimension that mathematics education has to contribute to the understanding of the world (and not 'just prepare for future life'). The relevance paradox (Niss 1994) is a major obstacle to overcome: mathematics contributes to many aspects of modern technology and society but remains hidden from the user who does not 
need any advanced mathematical knowledge to operate cars, computers and smartphones, for instance. So the relevance argument of mathematical content has to be much more sophisticated.

The examples that Winter and Heymann put forward include 'theoretical applications' (see Jahnke's contribution) from the sciences (modelling motions in physics, particularly planetary motions), and also 'hot societal topics' such as an understanding of environmental problems, quantitative aspects in equity issues, etc.

There is a consensus that widespread textbook problems that are solely made up for teaching mathematics and not for understanding the world outside mathematics, do not adequately contribute to this general goal. Mathematical modelling is considered a central notion in making the contribution of mathematics for the real world understandable, however, neither Winter nor Heymann advocates mathematical modelling only as a formal competence that can be developed at any example whatsoever. Authentic examples of 'the world' and reflection on the achievements and limitations of mathematical modelling are part of their approach. The theories of Allgemeinbildung, however, remain incomplete in that we cannot deduce which part of the world we should make more accessible to students by using mathematics.

The above judgment that Heymann's approach is not based on a philosophy of mathematics has to be relativised. We find analyses of mathematics under the heading of 'promoting cultural competence' (a verbatim translation from German would be 'maintaining cultural coherence'). Heymann discusses the 'cultural meaning of mathematics', the meaning of mathematics in wider culture and elaborates:

Yet, in which way can mathematics teaching actually contribute at all to promoting cultural competence? My reply to this question is to be substantiated and explicated in this and the following sections: The decisive contribution of mathematics instruction to the promotion of cultural competence is to allow for the specific universal features of mathematics and their significance for culture as a whole to be vividly experienced in an exemplary fashion on the basis of main ideas. (Heymann 2003, p. 108, emphasis as original)

Heymann relates to the discussion on "fundamental ideas of a discipline" (Bruner 1960). The critical reception of New Math, which interpreted fundamental ideas in the sense of the Bourbakian view of mathematics as the science of structures, lead to various new attempts, especially in Germany, to identify and base fundamental ideas on a broader view of mathematics. This is an ongoing program. A most recent account and critical analysis of the development in German-speaking countries is the paper by Vohns (2016), who also puts Heymann's approach into perspective. We will now concentrate on Heymann's specific focus.

After a broad review of approaches to fundamental, central, or main ideas, Heymann develops the following criteria for selecting what he calls 'main ideas'. He wants to point out a difference to the 'fundamental ideas of a discipline', because he postulates that the main ideas cannot be determined exclusively by the discipline itself. He develops the following selection criteria for main ideas:

- with the main ideas for instruction oriented to general education, the universal features of mathematics should be expressed in a way comprehensible to students;

- they should be meaningful for various individual mathematical topics; 
- they should be something other than simply basic mathematical concepts, i.e. they should not exclusively have a significance internal to mathematics;

- above all, they should demonstrate how mathematics is interrelated to other aspects of the culture of our society. (Heymann 2003, p. 109)

Applying these criteria to list of such ideas developed by others, he filtered out the following main ideas:

- the idea of number

- the idea of measuring

- the idea of structuring space

- the idea of functional relationship

- the idea of an algorithm

- the idea of mathematical modeling. (Heymann 2003, p. 124)

Heymann sketches what he regards as the meaning of these ideas in the broader culture. The approach stresses that a main idea cannot just be considered as a concept inside mathematics. The concept of function, for example, can be defined as a mapping between sets (especially sets of numbers). However, in the real world, we deal with and model functional relations of magnitudes. Magnitudes are no longer concepts of modern mathematics (which abandoned magnitudes in the 19th century). It indeed poses a challenge for mathematics education to deal with this difference, which is still a prevailing problem in mathematics education. Which concept of function and functional relationships should be developed in school? How can consistency with mathematics as a discipline be developed on one hand and the use of functions for modelling functional relationships (of magnitudes) on the other? An elaboration is necessary, albeit this is not the focus of Heymann's book.

Such an elaboration would have to take into account other approaches to this fundamental or main idea. For example, 'functional thinking' has been a main or fundamental idea in the history of mathematics education in German-speaking countries, associated with the Meran reform of mathematics education in 1905 and the name of Felix Klein (Krüger 2000), and it is not clear how this is taken into account. Klein stressed that functional thinking could relate mathematics to the broader culture and bridge between secondary and tertiary mathematics education. The following introduction of calculus into the Gymnasium curriculum was a lasting achievement.

The identified need for further elaboration applies to other main ideas as well, as, for example, 'structuring space' can be done on various levels, and the specific role of Euclidean deductive theory in this context remains unclear.

An obvious deficiency of Heymann's list is that probability and statistics, or data and chance, are not mentioned at all, although many other authors assign a most prominent role to these domains in any conception of mathematics education that intends to contribute to general education (but see Burrill and Biehler 2011 for an approach to fundamental ideas in statistics).

The list can also be criticised from a different perspective, namely with regard to the symbol systems that are characteristic of mathematics. When Winter (1975) analysed the role of mathematics in general education he pointed to mathematics as 
a formal science. This is repeated by the second point in his 1995 paper, emphasising the specific sign systems that mathematics has developed to deal with its ideas and concepts, and that are relevant for general education. The role of symbol systems is characteristic of mathematics (Dörfler 2016). However, we can turn it around and regard this aspect of mathematics as part of its contribution to the culture at large. A good example of this emphasis is provided by Whitehead (1929) book where he justifies why students (in general) should learn to solve quadratic equations:

Quadratic equations are part of algebra, and algebra is the intellectual instrument which has been created for rendering clear the quantitative aspects of the world. (ibid., p. 7)

Despite these critical remarks, we have to put Heymann's book into perspective. From his analysis of the normative function of mathematics for general education, he concluded that contemporary mathematics education had deficiencies in many respects. For instance, he argued for a more significant role of aspects of estimation and approximation of magnitudes, of interpretations with graphs and tables with data, simple forms of mathematical modelling, and the use of mathematics as a means of communication instead of using it only as a calculation tool. This is necessary because of changes in society and the living environment of students. Contributing to the understanding of the world requires mathematical modelling with authentic examples and reflection about the role of mathematics. The cultural coherence should be achieved by focusing on the main ideas of mathematics. The development of critical thinking, entailing a willingness to assume responsibility, practice in communication and cooperation requires a new, student-oriented, culture of teaching and learning.

Heymann became a consultant of the state government of North Rhine-Westphalia, where he influenced the emerging new curricula. In general, the public debate on mathematics education soon became weaker. It was the TIMSS and the PISA shock in the late 1990s and the beginning of the twenty-first century that had a more lasting effect on mathematics at school level.

\subsubsection{Allgemeinbildung and Mathematical Literacy, Competence Orientation Since the Late 1990s Due to the TIMSS and PISA 'Shocks'}

\section{Mathematical Literacy and Competence Orientation}

Since the German results in TIMSS and PISA, which were considered to be too much below average, mathematics and science education have become a broad political and public concern again, similarly to the big educational reforms in the 1960s. One of the differences to the late 1960s and the beginning of the 1970s was the specific focus on mathematics and science education, whereas, in the earlier 'crisis of education', the focus was the educational system in general. 
The diagnosis that mathematics and science education had to be improved led to countless initiatives, development projects, and efforts in the professional development of mathematics and science teachers, which cannot be discussed here. 'Output orientation' became an influential concept, and since that time the expected outcome of school mathematics education regarding students' knowledge became more specified, and students' achievements vis-à-vis the newly specified output goals are being checked.

The notion of 'competencies' then became the royal way to specify the required outputs of the school system. Moreover, PISA also introduced its particular notions of 'mathematical literacy' and the notion of 'big ideas' into the German debate on mathematics education and initiated a discussion on how these notions are related to German conceptions of Allgemeinbildung and to traditional general goals for mathematics education at school level.

PISA is based on a conception of mathematical literacy. The following quotes provide the definition for the PISA 2000 and the PISA 2012 framework:

Mathematical literacy is an individual's capacity to identify and understand the role mathematics plays in the world, to make well-founded mathematical judgements and to engage in mathematics, in ways that meet the needs of that individual's current and future life as a constructive, concerned and reflective citizen. (OECD 1999, p. 41)

Mathematical literacy is an individual's capacity to formulate, employ, and interpret mathematics in a variety of contexts. It includes reasoning mathematically and using mathematical concepts, procedures, facts and tools to describe, explain and predict phenomena. It assists individuals to recognise the role that mathematics plays in the world and to make the wellfounded judgments and decisions needed by constructive, engaged and reflective citizens. (OECD 2013, p. 25)

On an abstract level, the PISA approach to mathematics in general education is surprisingly similar to that of Allgemeinbildung in that it stresses the function of mathematics education for the future life of students. In a first approximation, Allgemeinbildung is more general than mathematical literacy because it does not view the individual as just a citizen. A conception of Allgemeinbildung would probably include mathematical literacy. However, what exactly is a constructive, concerned, and reflective citizen in the sense of PISA? The answer to this question determines how the relation to conceptions of Allgemeinbildung with their different views of the subject can be analysed.

The concept of mathematical literacy is similarly complex and variable as Allgemeinbildung. Jablonka (2003) distinguishes different interpretations of mathematical literacy. Mathematical literacy may aim at developing the following aspects that she uses as section headings:

- Human Capital

- Cultural Identity

- Social Change

- Environmental Awareness

- Evaluating Mathematics. 
She mainly identifies PISA's conception with the 'human capital interpretation', but being very general and abstract at the same time.

Thus a conception of mathematical literacy as behaving mathematically - a definition not intrinsically related to the social community in which this behaviour is to be performed may equally be underpinned by educational arguments advocating critical citizenship for participation in the public life of an economically advanced society as well as by workforce demands in underdeveloped countries. (Jablonka 2003, p. 81)

In PISA's meaning of the notion of mathematical literacy, two further aspects are relevant - mathematical competencies and big ideas:

Mathematical competencies are general skills and competencies such as problem-solving, the use of mathematical language and mathematical modelling.

Mathematical big ideas represent clusters of relevant, connected mathematical concepts that appear in real situations and contexts. Some of these big ideas are well established, such as chance, change and growth, dependency and relationships and shape. "Big ideas" are chosen because they do not result in the artificial approach of separating mathematics into different topics. (OECD 1999, p. 42)

The eight competencies are mathematical thinking skills, mathematical argumentation skills, modelling skills, problem posing and solving skills, representation skills, symbolic, formal and technical skills, communication skills, and aids and tool skills (ibid., p. 43). The six big ideas are chance, change and growth, space and shape, quantitative reasoning, uncertainty, dependency and relationships (ibid., p. 48). These aspects are important; of course, though the definition alone does not cover the meaning of 'mathematical literacy'.

If we compare this perspective to Heymann, we note that the approach to identify big ideas is similar to Heymann's identification of main ideas in that their contextual and cultural role is taken into account and they also cross boundaries of traditional curricular topics. However, PISA's resulting ideas are different. The analysis of competencies is based on a much broader and differentiated view of what constitutes mathematics as a scientific discipline in terms of mathematical activities than in Heymann's approach.

The aspect to "understand the role mathematics plays in the world" in the PISA definition is a reflective dimension. The phrasing in the PISA 2012 framework is weaker in that mathematical literacy should only 'assist' in judging the role mathematics plays in the world. PISA's test items also do not assess this understanding directly.

It is very interesting to compare the PISA approach to the KOM project (Niss and Højgaard 2011) that significantly influenced the competencies of PISA. In addition to the competencies, the authors state:

The above-mentioned competencies are all characterised by being action orientated in that they are directed towards handling different types of challenging mathematical situations. Besides the mathematical mastery we have tried to capture with these competencies, we have also found it desirable to operate with types of "active insights" into the nature and role of mathematics in the world, and which are not directly behavioural in nature. (ibid., p. 74) 
The authors distinguish and elaborate on three forms of 'overview and judgment': "The actual application of mathematics in other subject and practice areas"; "The historical development of mathematics, both internally and from a social point of view"; and "The nature of mathematics as a subject" (ibid., p. 75).

These aspects constitute one way to specify the meaning of "understanding the role mathematics plays in the world", but they are not systematically developed in the PISA framework. Competencies focus on behavioural aspects ("mathematical mastery') and do not explicitly cover reflective knowledge about mathematics and its cultural and societal role. The holistic view of developing individuals' personalities as is expressed in most conceptions of Allgemeinbildung is also more general than mathematical mastery.

On the other hand, it is unclear how these more general desirable outputs of education can be assessed. Advocates of competence orientation would argue that the general educational goals found in preambles of syllabi often do not succeed in effectively influencing the practice of mathematics education, which often focuses on technical mathematical skills. Competence orientation aims at a much broader spectrum of mathematical behaviours to be assessed, which is moving mathematics education in the direction of important behavioural parts of mathematical Allgemeinbildung without exhausting this notion.

\subsubsection{Mathematical Literacy, Allgemeinbildung and National Standards for Mathematics in Germany}

The designers of PISA never claimed that national curricula are validly assessed in their totality and regard their assessments as a kind of 'partial assessment'.

The term literacy has been chosen to emphasise that mathematical knowledge and skills as defined within the traditional school mathematics curriculum do not constitute the primary focus of OECD/PISA. Instead, the emphasis is on mathematical knowledge put to functional use in a multitude of different contexts and a variety of ways that call for reflection and insight. (OECD 1999, p. 41)

It should also not be forgotten that the designers of PISA deliberately did not include important components of general mathematics education and mathematical Allgemeinbildung:

Attitudes and emotions, such as self-confidence, curiosity, a feeling of interest and relevance, and a desire to do or understand things, to name but a few, are not components of the OECD/PISA definition of mathematical literacy but nevertheless are important prerequisites for it. (OECD 1999, p. 42)

However, the PISA results supported advocates who argued for strengthening the mathematical literacy aspect in German curricula, campaigning for a more prominent place for applications and mathematical modelling in the curriculum than before, but the influence was more general. 
From its very beginnings, however—internationally, but especially in Germany—PISA also pursued a kind of meta-goal: to stimulate thinking about the objectives of the tested domains within an education system. This meta-goal was made more or less explicit, at least in the domain of mathematics, where the conceptualisation of the domain as "mathematical literacy" was a signal to the community of mathematics educators to restructure their thinking about how mathematics is addressed in schools, and how the outcomes of mathematics education should be evaluated. (Neubrand 2013, p. 39)

The influence PISA had on the German mathematics education on various levels is complex, and of course, some interactions with specific German conceptions of mathematical Allgemeinbildung and traditional ways of expressing curricular goals were sparked off.

It is remarkable that from the beginning of PISA testing in Germany, even in the German PISA team, it was clear that PISA's mathematical literacy covers only a part of the goals of mathematics education in general education. Thus, the advisory board of German mathematics educators for the PISA 2000 project created a supplementary German test, which was based on the notion of 'Mathematische Grundbildung', from which mathematical literacy is only a proper subset (Neubrand et al. 2001, 2004).

The paper by Neubrand (2003) characterises the relations and differences between mathematical literacy and 'Mathematische Grundbildung'. 'Mathematische Grundbildung' gives an independent value to mathematical techniques and conceptual thinking in mathematics. Neubrand points out that PISA's framework was influenced by Freudenthal, as quoted in OECD (1999, p. 41): "Our mathematical concepts, structures and ideas have been invented as tools to organise the phenomena of the physical, social and mental world" (Freudenthal 1983, p. ix). This also influenced the selection of the conceptual modelling in PISA. However, Freudenthal is also arguing for the reorganisation and constitution/construction of mathematical concepts as mental objects that give an independent value to mathematics itself. Neubrand gives credit to these features as well as to the notion of 'mathematical proficiency' (Kilpatrick 2001) and Schoenfeld's interpretation of quantitative literacy (Schoenfeld 2001) as akin to the broader German approach to 'Mathematische Grundbildung'. "The PISA definition for 'mathematical literacy' — in contrast - is more specific in that it explicitly includes the role of the citizen in (Western, developed) societies in its definition and in that it gives less emphasis to the abilities to structure and restructure within mathematics itself." (Neubrand 2003, p. 344. transl. R.B.)

Neubrand characterises the ambitions expressed in the notion of Allgemeinbildung as going far beyond 'Mathematische Grundbildung', referring to Winter (1995) and the educational philosophy of mathematics that was published in BLK (1997), the latter an expertise reaction to the poor TIMSS results in Germany. He summarises:

Applications are interesting and really indispensable only if it is experienced, how mathematical modelling is functioning, and which kind of elucidation can be achieved thereby. The model character of mathematical problem solutions should not be disguised or remain obscure $[\ldots]$

Each student should experience that human beings are capable of constructing concepts and whole architectures of them, or, differently put, that stringent science is possible. (Neubrand 2003, p. 345. transl. R.B.) 
These aspects are of course very akin to the 'overview and judgment' aspects of the KOM project that were cited above. Fischer (2001) provides a specific elaboration and interpretation of these reflective dimensions for education up to the final grade 12/13 that concludes with the Abitur (see Vohns 2017a for more details). He postulates that students should have been educated as well-informed laypeople who can communicate with experts in modern society rather than doing expert work on a small scale themselves. This requires mathematical mastery and mathematical competencies, but this is not sufficient on its own and has to be supplemented by reflective knowledge rather than more 'operative knowledge'. Instead of gaining accessible modelling competencies in oversimplified situations, students should be able to critically question assumptions made in societal applications of mathematics in dialogues with experts.

Beyond this conceptual debate, the discussions among administrators, politicians, and mathematics educators following the PISA shock had enormous consequences on the level of curriculum standards. One of the most important results was the creation of national standards in mathematics for grade 9/10 in 2004 and for grade 12/13 (Abitur) in 2012 for the first time in the history of West Germany (KMK 2012, 2004). The standards specify the function of mathematics education in schools by specifying competencies that should be achieved by students. According to these standards, the mathematical content should be organised and structured around 'leading ideas', the latter approach constituting an influence by PISA, the NCTM standards, and the German debate on fundamental or central ideas for mathematics, which were discussed, among others, by Heymann.

The new national standards are called Bildungsstandards although the notion of Bildung or Allgemeinbildung as such is hardly mentioned in them (only the standards of 2012 quote Winter's (1995) three basic experiences). They define the goals of secondary mathematics education by a three-dimensional framework with the dimensions of Leitideen (leading ideas), (process oriented) mathematical competencies, and the level of complexity. The leading ideas are number (and algorithm), measurement, space and shape, functional relations, data and chance. The competencies are:

- Arguing mathematically

- Mathematical problem solving

- Mathematical modelling

- Use of mathematical representations

- Working with symbolic, formal and technical elements of mathematics

- Communicating (mathematically).

The standards are a result of a complex process of negotiations, which were of course influenced by PISA, the NCTM standards, and the German discussion on Allgemeinbildung.

Quoting Winter does not mean that the standards also share the detailed elaboration of his three experiences. A more concrete notion of Allgemeinbildung in the German tradition is not elaborated in the standards, nor can we identify a clear educational philosophy of mathematics. Competence orientation is focusing on the behavioural 
side and not on the 'three forms of overview and judgment' that can be detected in the KOM project, for instance. This has been the object of criticism in the German community itself, arguing from various perspectives. We are unable to go into further details here.

\subsubsection{Further Developments}

The theoretical debate on Allgemeinbildung and mathematics education in Germany continues. The historical and actual discussion on fundamental ideas is well analysed in the paper by Vohns (2016). Moreover, Neubrand (2015) contributed a chapter in the German handbook on mathematics education on the foundations of mathematics education rooted in a theory of Bildung. He also argues for elaborating an educational philosophy of mathematics and compares the different approaches: Freudenthal's mathematics as an educational task, the approach from identifying fundamental ideas, general learning goals in the sense of Winter (1975), as well as the notions of mathematical literacy and mathematical proficiency. Winter's (1995) three experiences are considered as a synthesis, a challenge for future research that has to elaborate and fill these ideas. Using them as a superficial justification of current curricula and standards by just quoting the three experiences is something different and does not convey the critical stance that notions of Allgemeinbildung have always had in the further development of mathematics education.

\subsection{Allgemeinbildung, Mathematical Competencies and Mathematical Literacy: Conflict or Compatibility? (Reaction by Mogens Niss)}

\subsubsection{The Concept of Allgemeinbildung}

Let us begin by noting that the German word 'Allgemeinbildung' hardly has any suitable counterpart in English (neither 'general formation' nor 'general education' carries quite the same meaning but may serve as a first approximation). Moreover, the term is certainly used in Scandinavian languages ('almendannelse' in Danish and Norwegian, 'allmän bildning' in Swedish), but it seems that a corresponding notion doesn't really exist in other European languages. This should not be taken to mean that other languages and cultures do not nurture similar ideas, only that these haven't been coined into one short term with all the connotations of Allgemeinbildung, which, as Rolf Biehler and Hans Niels Jahnke have convincingly shown in their presentations, is a very rich and complex concept.

As I see it, three important dualities—not to be mistaken for dichotomies-generated by the notion of Allgemeinbildung, deserve further attention. 
The first duality emerges from the fact that in educational contexts, the word 'allgemein' ('general' in English) can have two different targets. Either it can refer to the 'general population' in a given society, so that, in principle, all citizens constitute the intended subjects of formation or education. Or it can refer to the general nature of the 'substance' of the formation or education to be received by the members of the intended recipient group. Or-of course-allgemein might refer both to the population addressed and to the substance of formation/education at issue. In either case, any sensible discussion of the nature and role of Allgemeinbildung requires clarification of which of the possible targets are in focus. When it comes to the recipient population, it is not usually that clear whether this population is, in fact, meant to encompass literally all 'normal' citizens in society, and if not, who should then be included or excluded, respectively, as recipients? If instead, we are focusing on the generality of the substance of formation/education, many issues need further clarification. What exactly is it that is meant to be allgemein regarding substance? Is it substance that is supposed to be common to all domains of knowledge? Is it substance that is considered universally useful or valuable in the lives of every member of the intended category of recipients? Is it substance that underpins our understanding of the fundamentals of the world? Is it substance of an overarching (meta) nature, above and beyond scientific and scholarly disciplines? Is it substance that deals with the formation of the moral, mental, intellectual and aesthetic capacities of the individual, his or her character? Or is it...?

The second duality occurs in the case where the target of Allgemeinbildung is substance pertaining to formation/education. The question then arises of whether this substance is primarily defined in terms of content, i.e. what people should know and understand and the ways in which they should do so, or whether it primarily involves processes, i.e. what people should be able to do with their knowledge, and in what contexts, circumstances and situations.

The third duality has to do with the ultimate purpose of Allgemeinbildung. For whose sake should it be pursued? For the personal benefit of the individual, so that he or she can thrive and develop as a person in the world and surroundings in which he or she lives? Or for the sake of the community or society at large, which is supposed to benefit from having several knowledgeable, thoughtful, as well as intellectually, morally and aesthetically cultured citizens?

As I see it, we haven't really specified what we mean by Allgemeinbildung before we have specified how to take a stance related to each of these dualities. My own position-however, I certainly realise that others are possible and defendable-is that Allgemeinbildung should have the vast majority of citizens as its population target, not just a small elite, 'the happy few', and that its substance should be focused on the fundamentals of our understanding of nature, culture and society and on the ways this understanding has come into being and has developed and grown, whilst involving analytic and critical perspectives on this understanding and its outcomes, especially with regard to what it means and takes to know something. I am more sceptical about the possibility of generating general-content and context-free-intellectual and moral faculties that go beyond the basics of logical reasoning and appreciation of universal human rights. Finally, as regards the purpose of Allgemeinbildung, I 
emphasise the need for society to consist of allgemeingebildete citizens, who are able and willing to engage in discussions and activities that can foster the development of a just, equal, free, humanistic, sustainable and democratic society, in which it is not the case that "few have too much and fewer too little" (Grundtvig 1820).

Now, in most definitions and conceptualisations of Allgemeinbildung it is a point in itself that no disciplines or school subjects, mathematics included, are referred to in the conceptualisation. What then, does Allgemeinbildung have to do with mathematics education? Well, as I perceive it, mathematics does play a crucial role in several of the aspects mentioned above, simply because mathematics permeates the fundamentals of our understanding of nature, culture and society, as it does with logical and formal reasoning. Hence, in my view, mathematics should enjoy 'civil rights' as a key component of Allgemeinbildung. Conversely, Allgemeinbildung is indeed of relevance in the context of mathematics education by offering general formative and educational perspectives to its pursuit.

\subsubsection{False or Genuine Dichotomies?}

I fully share Rolf Biehler's and Niels Jahnke's insistence (Chap. 5 of this book) on the relevance, value and necessity of Allgemeinbildung also in today's societies and education systems. It goes without saying-even though Rolf Biehler actually says it - that this requires continuous updating of our understanding of the concept in order to relate it to the economic, technological, cultural, ideological and political developments that our societies undergo. The original point of departure of Allgemeinbildung in humanistic ideals based on classical languages, literature, philosophy and art in antiquity, as the prototypical point at infinity setting the standards for our formative and educational endeavors, is no longer adequate or sufficient, despite the indisputable value of the intellectual, societal and artistic accomplishments of antiquity.

Today, it seems that some modern defenders and active supporters of Allgemeinbildung (amongst whom I count myself) see that there are antagonistic relationships between Allgemeinbildung and a number of other ideas and notions that have been put forward and have gained momentum during the last two to three decades. More specifically, some establish a contradiction between Allgemeinbildung and utilitarianism, others between Allgemeinbildung and (mathematical) literacy, and still others between Allgemeinbildung and (mathematical) competencies.

In what follows, I shall argue that there is indeed a dichotomy between Allgemeinbildung and utilitarianism, at least if utilitarianism is understood in its traditional-rather narrow-sense. I shall further argue that there is no contradiction between Allgemeinbildung and competencies and literacy, respectively. On the contrary, they are highly compatible, albeit not identical.

The everyday, non-philosophical (as with Mill 1863) understanding of utilitarianism focuses on the practical utility (usefulness) of objects, processes and undertakings for life, work, occupations and professions, business and industry, technology, econ- 
omy, infrastructure, and the running of society, etc. More often than not, such utility is required to be rather direct (i.e. displaying clear causality) and effective within a relative short time span. It was on the basis of this narrow understanding of utility that Heymann (1996) in Germany was misinterpreted by the public when he made his famous claim that seven years of school mathematics would be enough if we only considered direct applications in everyday life (see Sect. 6.1.3).

Irrespective of which specific interpretation of Allgemeinbildung one adheres to, it is pretty obvious that it cannot be reduced to utilitarianism in the sense just outlined. By focusing on complex insights and reflectiveness going far beyond the needs of the day, both in scope and in time, the perspectives offered by Allgemeinbildung are entirely different from those of utilitarianism. To be sure, Allgemeinbildung implies no discarding or downgrading of everyday utility — that would be insane-it just insists that there is much more to be said about and done for individual and communal life in culture and society than just pursuing direct and short-term usefulness.

If, however, utilitarianism is given a much broader meaning than everyday utility, such as to comprise the fostering and furthering of a balanced and inclusive development of culture, science, art, technology, society, and democracy, Allgemeinbildung is eminently compatible with utilitarianism. As a matter of fact, one might go as far as to say that the ultimate purpose of Allgemeinbildung is to be utilitarian in this much wider sense.

Mathematical competencies are to do with the enactment, practice and exercise of mathematics, i.e. doing mathematics. Even if this does indeed presuppose a lot of content knowledge and theoretical understanding of the edifice of mathematics, mathematical competencies go beyond such knowledge by being action-orientated. Since Allgemeinbildung in almost any conceptualisation of it places emphasis on knowledge and understanding in their own right, it follows that mathematical competencies and Allgemeinbildung are not identical, nor is one a subset of the other. They have different foci. However, they are by no means incompatible let alone contradictory; on the contrary, they complement each other. Moreover, as mathematical competencies were conceived as a way of liberating the enactment of mathematics from specific mathematical topics and specific educational levels or settings, mathematical competencies are meant to be of a general nature in analogy with the way in which Allgemeinbildung is intended to be of a general nature transgressing specific disciplines, educational levels and contexts, vocations and professions. So, the fact that there are indeed significant distinctions between competencies and Allgemeinbildung does not at all imply that these notions are antagonistic. That is simply a false dichotomy.

In much the same way, there is certainly no antagonistic relationship between Allgemeinbildung and mathematical literacy. Mathematical literacy is to do with individuals' ability to put mathematics to functional use in extra- and intra-mathematical contexts and situations that are of significance to the individuals' actual and future lives as active, concerned and reflective citizens. One might well claim that this ought to be an element of Allgemeinbildung, but even if it isn't accepted as such an element, there is indeed no contradiction between the two. They will then simply have different foci and emphases. Moreover, by its very definition, mathematical literacy 
goes far beyond narrow utilitarianism as outlined above. By the way, mathematical competencies and mathematical literacy are not identical either. Mathematical competencies do in fact underpin mathematical literacy, but mathematical competencies are much more than mathematical literacy (Niss 2015). Once again, a dichotomy between Allgemeinbildung and mathematical literacy is yet another false dichotomy.

\subsubsection{Conclusion}

I very much agree with those-including Rolf Biehler and Niels Jahnke-who are making a strong case for the importance of Allgemeinbildung, both in general and in the context of mathematics education. This, however, requires a clear conceptualisation of the notion of Allgemeinbildung. As I see it, dichotomies between Allgemeinbildung and mathematical competencies, respectively, are nothing but false dichotomies and hence should be abandoned.

Acknowledgements We are very grateful to an anonymous reviewer and to Andreas Vohns, who reviewed an earlier draft non-anonymously, for providing very helpful and constructive comments, clarifications and pointed to further literature, most relevant for this section. The analysis of Winter's contribution was jointly done with Niels Jahnke (see Chap. 5 of this book). In the oral versions of this paper, Winter was mentioned in both presentations, but we decided to elaborate on Winter's position only in this chapter to make it easier for the reader. Many thanks go to Birgit Griese from Paderborn University who helped to improve the English language and clarity of this text.

\section{References}

Biehler, R. (1994). History and epistemology of mathematics and mathematics education. Introduction. In R. Biehler, R. W. Scholz, R. Straesser, \& B. Winkelmann (Eds.), Didactics of mathematics as a scientific discipline (pp. 327-333). Dordrecht: Kluwer.

Biehler, R., Heymann, H. W., \& Winkelmann, B. (Eds.). (1995). Mathematik allgemeinbildend unterrichten: Impulse für Lehrerbildung und Schule. Köln: Aulis.

Biehler, R., \& Jahnke, H. N. (Eds.). (1997). Mathematische Allgemeinbildung in der Kontroverse-Materialien eines Symposiums am 24. Juni 1996 im ZiF der Universität Bielefeld. IDM Occasional Paper 163. Bielefeld: Universität Bielefeld.

BLK. (1997). Gutachten zur Vorbereitung des Programms „,Steigerung der Effizienz desmathematischnaturwissenschaftlichen Unterrichts“. Bonn: Bund-Länder-Kommission für Bildungsplanung und Forschungsförderung.

Bloom, B. S. (1956). Taxonomy of educational objectives; The classification of educational goals (1st ed.). New York: Longmans, Green.

Bosse, D. (Ed.). (2009). Gymnasiale Bildung zwischen Kompetenzorientierung und Kulturarbeit. Wiesbaden: VS Verlag für Sozialwissenschaften.

Bruner, J. S. (1960). The process of education. Cambridge: Harvard University Press.

Burrill, G., \& Biehler, R. (2011). Fundamental statistical ideas in the school curriculum and in training teachers. In C. Batanero, G. Burrill, \& C. Reading (Eds.), Teaching statistics in school mathematics-challenges for teaching and teacher education-A joint ICMI/IASE study: The 18th ICMI study (pp. 57-69). Dordrecht: Springer. 
Damerow, P., Elwitz, U., Keitel, C., \& Zimmer, J. (1974). Elementarmathematik Lernen für die Praxis? Ein exemplarischer Versuch zur Bestimmung fachüberschreitender Curriculumziele. Stuttgart: Klett.

Dohmen, G. (1964). Bildung und Schule. Die Entstehung des deutschen Bildungsbegriffs und die Entwicklung seines Verhältnisses zur Schule. Bd. 1: Der religiöse und der organologische Bildungsbegriff. Weinheim: Beltz.

Dörfler, W. (2016). Signs and their use: Peirce and Wittgenstein. In A. Bikner-Ahsbahs, A. Vohns, R. Bruder, O. Schmidt, \& W. Dörfler (Eds.), Theories in and of mathematics education (pp. 21-31). Springer.

Fischer, R. (2001). Höhere Allgemeinbildung. In A. Fischer, A. Fischer-Buck, K.-H. Schäfer, \& D. Zöllner (Eds.), Situation-Ursprung der Bildung. Franz-Fischer-Jahrbuch der Philosophie und Pädagogik (Vol. 6, pp. 151-161). Leipzig: Universitätsverlag.

Freudenthal, H. (1983). Didactical phenomenology of mathematical structures. Dordrecht, The Netherlands: Reidel.

Gagné, R. M. (1970). The conditions of learning (2nd ed.). New York: Holt.

Gagné, R. M., \& Briggs, L. J. (1974). Principles of instructional design. New York: Holt.

Gates, P., \& Vistro-Yu, C. P. (2003). Is mathematics for all? In A. J. Bishop, M. A. Clements, C. Keitel, J. Kilpatrick, \& F. K. S. Leung (Eds.), Second international handbook of mathematics education (pp. 31-73). Dordrecht: Springer, The Netherlands.

Grundtvig, N. F. S. (1820). Lang højere bjerge så vide på jord [poem]. In R. Nyerup (Ed.) Sange til den 10de April 1820, til Trykken befordrede af R. Nyerup. Copenhagen.

Heymann, H. W. (1996). Allgemeinbildung und Mathematik. Weinheim: Beltz.

Heymann, H. W. (2003). Why teach mathematics? A focus on general education. Dordrecht, Boston: Kluwer Academic Publishers.

Horlacher, R. (2004). Bildung-A construction of a history of philosophy of education. Studies in Philosophy and Education, 23(5), 409-426. https://doi.org/10.1007/s11217-004-4452-1.

Horlacher, R. (2016). The educated subject and the German concept of Bildung. A comparative cultural history. New York: Routledge Taylor \& Francis Group.

Huber, L. (2009). Von „basalen Fähigkeiten” bis ,,vertiefte Allgemeinbildung”: Was sollen Abiturientinnen und Abiturienten für das Studium mitbringen? In D. Bosse (Ed.), Gymnasiale Bildung zwischen Kompetenzorientierung und Kulturarbeit (pp. 107-124). Wiesbaden: VS Verlag für Sozialwissenschaften.

Jablonka, E. (2003). Mathematical literacy. In A. J. Bishop, M. A. Clements, C. Keitel, J. Kilpatrick, \& F. K. S. Leung (Eds.), Second international handbook of mathematics education (pp. 75-102). Dordrecht: Kluwer.

Jahnke, H. N. (1990). Mathematik und Bildung in der Humboldtschen Reform. Göttingen: Vandenhoeck \& Ruprecht.

Kilpatrick, J. (2001). Understanding mathematical literacy: The contribution of research. Educational Studies in Mathematics, 47(1), 101-116. https://doi.org/10.1023/a:1017973827514.

Klafki, W. (1963). Studien zur Bildungstheorie und Didaktik. Weinheim: Beltz.

Klafki, W. (1974). Didaktische Analyse (11th ed.). Hannover: Schroedel.

Klafki, W. (1995). Didactic analysis as the core of preparation of instruction. Journal of Curriculum Studies, 27(1), 13-30.

Klafki, W. (2000). The significance of classical theories of Bildung for a contemporary concept of Allgemeinbildung. In I. Westbury, S. Hopmann, \& K. Riquarts (Eds.), Teaching as a reflective practice. The German Didaktik tradition (pp. 85-107). Mahwah, NJ: Erlbaum.

KMK. (2012). Bildungsstandards im Fach Mathematik für die Allgemeine Hochschulreife (Beschluss der Kultusministerkonferenz vom 18.10.2012). https://www.kmk.org/fileadmin/ veroeffentlichungen_beschluesse/2012/2012_10_18-Bildungsstandards-Mathe-Abi.pdf.

KMK. (2004). Bildungsstandards im Fach Mathematik fürden Mittleren Schulabschluss_Beschluss der Kultusministerkonferenz vom 4.12.2003. München: Wolters Kluwer.

Krüger, K. (2000). Erziehung zum funktionalen Denken-Zur Begriffsgeschichte eines didaktischen Prinzips. Berlin: Logos Verlag. 
Lenné, H. (1969). Analyse der Mathematikdidaktik in Deutschland. Stuttgart: Klett.

Malecki, A. (2016). Schulen auf einen Blick. Ausgabe 2016. Wiesbaden: Statistisches Bundesamt. Mill, J. S. (1863). Utilitarianism (1st ed.). London: Parker, Son \& Bourn, West Strand.

Neubrand, M. (2003). "Mathematical literacy”/,Mathematische Grundbildung”. Zeitschrift für Erziehungswissenschaft, 6(3), 338-356. https://doi.org/10.1007/s11618-003-0039-9.

Neubrand, M. (2013). PISA mathematics in Germany: Extending the conceptual framework to enable a more differentiated assessment. In M. Prenzel, M. Kobarg, K. Schöps, \& Rönnebeck (Eds.), Research on PISA: Research Outcomes of the PISA Research Conference 2009 (pp. 39-49). Dordrecht: Springer.

Neubrand, M. (2015). Bildungstheoretische Grundlagen des Mathematikunterrichts. In R. Bruder, L. Hefendehl-Hebeker, B. Schmidt-Thieme, \& H.-G. Weigand (Eds.), Handbuch der Mathematikdidaktik (pp. 51-73). Berlin, Heidelberg: Springer.

Neubrand, M., Biehler, R., Blum, W., Cohors-Fresenborg, Flade, L., Knoche, N., et al. (2001). Grundlagen der Ergänzung des internationalen PISA-Mathematik-Tests in der deutschen Zusatzerhebnung. ZDM, 33(2), 45-59.

Neubrand, M., Biehler, R., Blum, W., Cohors-Fresenborg, E., Flade, L., Knoche, N., et al. (2004). Der Prozess der Itementwicklung bei der nationalen Ergänzungsuntersuchung von PISA 2000: Vom theoretischen Rahmen zu den konkreten Aufgaben. In M. Neubrand (Ed.), Mathematische Kompetenzen von Schülerinnen und Schülern in Deutschland: Vertiefende Analysen im Rahmen von PISA-2000 (pp. 31-50). Wiesbaden: VS - Verlag für Sozialwissenschaften.

Niss, M. (1994). Mathematics in Society. In R. Biehler, R. W. Scholz, R. Sträßer, \& B. Winkelmann (Eds.), Didactics of mathematics as a scientific discipline (pp. 367-378). Dordrecht: Kluwer.

Niss, M. (2015). Mathematical literacy. In S. J. Cho (Ed.), The Proceedings of the 12th International Congress on Mathematical Education (pp. 409-414). Heidelberg, New York, Dordrecht, London: Springer

Niss, M., \& Højgaard, T. (Eds.). (2011). Competencies and mathematical learning: Ideas and inspiration for the development of mathematics teaching and learning in Denmark. Roskilde: Roskilde University, IMFUFA.

OECD. (1999). Measuring student knowledge and skills a new framework for assessment. Paris: OECD Publishing.

OECD. (2013). PISA 2012 assessment and analytical framework. Mathematics, reading, science, problem solving and financial literacy. OECD Publishing.

Robinsohn, S. B. (1969a). Bildungsreform als revision des curriculum (2nd ed.). Neuwied: Luchterhand.

Robinsohn, S. B. (1969b). Educational reform through curriculum revision. Western European Education, 1(1), 20-29. https://doi.org/10.2753/eue1056-4934010120.

Schoenfeld, A. H. (2001). Reflections on an impoverished education. In L. A. Steen (Ed.), Mathematics and democracy: The case for quantitative literacy (pp. 49-54). Princeton: NCED.

Skovsmose, O. (1994). Towards a philosophy of critical mathematics education. Dordrecht: Kluwer.

Thom, R. (1973). Modern mathematics: Does it exist? In A. G. Howson (Ed.), Developments in mathematical education (pp. 194-209). Cambridge: Cambridge University Press.

Vohns, A. (2016). Fundamental ideas as a guiding category in mathematics education-Early understandings, developments in German-speaking countries and relations to subject matter didactics. Journal für Mathematik-Didaktik, 37(Suppl 1), 193-223. https://doi.org/10.1007/s13138-0160086-4.

Vohns, A. (2017a). Bildung, mathematical literacy and civic education: The (strange?) case of contemporary Austria and Germany. In A. Chronaki (Ed.), Mathematics Education and Life at Times of Crisis. Proceedings of the Ninth International Mathematics Education and Society Conference (Vol. 2, pp. 968-978). Volos: University of Thessaly Press.

Vohns, A. (2017b). Einkommensteuertarife mit Schulmathematik erkunden—Ein Zugang aus bildungstheoretischer. Perspektive. Der Mathematikunterricht, 63(3), 25-35. 
Vollrath, H.-J. (2007). Towards an authentic teaching of mathematics: Hans-Georg Steiner's contribution to the reform of mathematics teaching. ZDM Mathematics Education, 39(1), 39-50. https://doi.org/10.1007/s11858-006-0013-0.

Wagenschein, M. (1965). Ursprüngliches Verstehen und exaktes Denken (1st ed.). Stuttgart: Klett. Whitehead, A. N. (1929). The aims of education \& other essays. New York: The Macmillan Company.

Winter, H. (1975). Allgemeine Lernziele für den Mathematikunterricht? Zentralblatt für Didaktik der Mathematik, 7, 106-116.

Winter, H. (1990). Bürger und Mathematik. Zentralblatt der Didaktik der Mathematik (ZDM), 22(4), $106-116$.

Winter, H. (1995). Mathematikunterricht und Allgemeinbildung. Mitteilungen der Gesellschaft für Didaktik der Mathematik, 61, 37-46.

Wittenberg, A. I. (1963). Bildung und Mathematik Mathematik als exemplarisches Gymnasialfach (2nd ed.). Stuttgart: Klett.

Open Access This chapter is licensed under the terms of the Creative Commons Attribution 4.0 International License (http://creativecommons.org/licenses/by/4.0/), which permits use, sharing, adaptation, distribution and reproduction in any medium or format, as long as you give appropriate credit to the original author(s) and the source, provide a link to the Creative Commons licence and indicate if changes were made.

The images or other third party material in this chapter are included in the chapter's Creative Commons licence, unless indicated otherwise in a credit line to the material. If material is not included in the chapter's Creative Commons licence and your intended use is not permitted by statutory regulation or exceeds the permitted use, you will need to obtain permission directly from the copyright holder. 


\title{
Chapter 7 \\ Theories of and in Mathematics Education
}

\author{
Angelika Bikner-Ahsbahs and Andreas Vohns
}

\begin{abstract}
How far has the didactics of mathematics developed as a scientific discipline? This question was discussed intensively in Germany during the 1980s, with both affirmative and critical reference to Kuhn and Masterman. In 1984, Hans-Georg Steiner inaugurated a series of international conferences on 'Theories of Mathematics Education' (TME), pursuing a scientific program that aimed at founding and developing didactics of mathematics as a scientific discipline. Today, a more bottom-up meta-theoretical approach, the networking of theories, has emerged which has roots in the early days of discussing the developmental of mathematics education as a scientific discipline. This article presents an overview of this thread of development and a brief description of the TME program. Two theories from German-speaking countries are outlined and networked in the analysis of an empirical example that shows their complementary nature traced back to the TME program.
\end{abstract}

Keywords Theories - Theory of mathematics education (TME) - Networking theories - Mathematics education as a scientific discipline $\cdot$ Learning activity Sign use $\cdot$ Semiotic game

\footnotetext{
A. Bikner-Ahsbahs ( $\square)$

University of Bremen, Bremen, Germany

e-mail: bikner@math.uni-bremen.de
}

\author{
A. Vohns \\ Alpen-Adria-University Klagenfurt, Klagenfurt, Austria \\ e-mail: Andreas.Vohns@aau.at




\subsection{Introduction}

This chapter ${ }^{1}$ begins with a description of the historical situation of the community of mathematics education in German-speaking countries. The historical development and discussions surrounding the concept of theory related to mathematics education as a scientific discipline are traced from the 1970s up to the beginning of the twentyfirst century, in the German-speaking countries as well as internationally. We will describe the main points of the Theory of Mathematics Education (TME) program as introduced by Hans-Georg Steiner. Two theoretical approaches, the theory of Learning Activity developed by Joachim Lompscher and Willi Dörfler's semiotic view of doing mathematics related to diagrammatic reasoning and its semiotic game, are summarized and concretized through the application of them to the analysis of an empirical example, a students' group solution of a mathematical task. Based on this example, we depict the networking of theories and the subsequent contribution to the TME program.

\subsection{The Role of Theories in Relation to Mathematics Education as a Scientific Discipline: A Discussion in the 1980s}

On an institutional and organizational level, the time span from the 1970s until the early 1980s had been a period of considerable change for mathematics education in former West Germany ${ }^{2}$ - both in school and as a research domain. The Institute for Didactics of Mathematics (Institut für Didaktik der Mathematik, IDM) was founded in 1973 in Bielefeld as the first research institute in the German-speaking countries specifically dedicated to mathematics education research; 1975 saw the inception of the Society of Didactics of Mathematics (Gesellschaft für Didaktik der Mathematik, $G D M)$ as the scientific society of mathematics educators in the German-speaking countries (cf. Bauersfeld et al. 1984, pp. 169-197; Toepell 2004).

The teacher colleges ('Pädagogische Hochschulen'), being the home of many mathematics educators at that time, were either integrated into full universities or developed into universities of education entitled to award doctorates. The Hamburg Treaty ('Hamburger Abkommen', KMK 1964/71), adopted in 1964 by the Standing Conference of Ministers of Education and Cultural Affairs (KMK), led to considerable organizational changes within the German school system. Although

\footnotetext{
${ }^{1}$ This chapter presents the ICME-13 Topical Survey 'Theories in and of Mathematics Education' (Bikner-Ahsbahs et al. 2016) in a shorter, partly reworked version: Sects. 7.1 and 7.2 are slightly revised versions (see ibid. pp. 1-9), Sect. 7.3 has been reworked and expanded (see ibid. pp. 10-11). Sections 7.4 and 7.5 present a summary and intensified rework of Bikner-Ahsbahs et al. (2016, pp. 13-42).

${ }^{2}$ For an overview including the development in Austria c.f. Dörfler 2013b; for an account on the development in Eastern Germany c.f. Walsch 2003.
} 
the traditional, more vocationally oriented 'Volksschule' (a common school covering both primary and secondary education, grades 1-8) was abolished, a new track called 'Hauptschule' was instituted for grades 5-8, reinstating a third track besides 'Realschule' and 'Gymnasium' for the years to come. In 1968, the Standing Conference's 'Recommendations and Guidelines for the Modernization of Mathematics Teaching' introduced profound changes to the content of mathematics education at all ages. Along with this, the traditional designation of the school subject as 'Rechnen' (translated as 'practical arithmetic') was also abandoned for primary school education in favour of the subject designation 'Mathematik' (cf. Griesel 2001; Müller and Wittmann 1984, pp. 146-170).

Likewise, there was a vivid interest in discussing how far mathematics education had developed as a scientific discipline, as documented in both of the German language journals on mathematics education founded at that time: Zentralblatt für Didaktik der Mathematik (ZDM, founded in 1969) and Journal für MathematikDidaktik (JMD, founded in 1980). These discussions mainly addressed two aspects: the role and suitable concept of theories for mathematics education, and the question of how mathematics education was to be founded as a scientific discipline and how it could be further developed. Of course, both aspects are deeply intertwined.

Issue 6 (1974) of ZDM was dedicated to a broad discussion about the current state of the field of 'Didactics of Mathematics'/mathematics education. The issue was edited by Hans-Georg Steiner. It comprised contributions from Bigalke (1974), Freudenthal (1974), Griesel (1974), Otte (1974) and Wittmann (1974), among others. These articles were focused around the questions of (1) how to conceptualize the subject area or domain of discourse of mathematics education as a scientific discipline; (2) how mathematics education may substantiate its scientific character; and (3) how to frame its relation to reference disciplines, especially mathematics, psychology and educational science. While there was a rich variety in the approaches to these questions, and, likewise, to the definitions of 'Didactics of Mathematics' given by the various authors, cautioning against reductionist approaches seemed to be a common topic of these papers. That is, the authors agreed upon the view that mathematics education cannot be meaningfully conceptualized as a subdomain of either mathematics, psychology, or educational science alone.

The role of theory was more explicitly discussed about 10 years later in two papers (Burscheid 1983; Bigalke 1984) and in two comments (Fischer 1983; Steiner 1983) published in the 'Journal für Mathematik-Didaktik' (JMD). As an example of the discussion about theory of that time, we will convey the different positions in these papers in more detail.

In 1983, Burscheid used the model from Kuhn and Masterman (cf. Kuhn 1970; Masterman 1970, 1974) to explore the developmental stage of mathematics education as a scientific discipline. He justified this approach by claiming that every science represents its results through theories and therefore mathematics education as a science is obliged to develop theories and make its results testable (Burscheid 1983, p. 222). This model describes scientific communities and their development by paradigms. By investigating mainly natural sciences, Kuhn has characterized a 
paradigm by four components - symbolic generalizations, models of thought, values and attitudes, and exemplars:

(1) symbolic generalizations as "expressions, deployed without question or dissent [...], which can readily be cast in a logical form" (Kuhn 1970, p. 182) or a mathematical model-in other words: scientific laws, e.g. Newton's law of motion;

(2) metaphysical presumptions as faith in specific models of thought "shared commitment to beliefs", such as "heat is the kinetic energy of the constituent parts of bodies" (p. 184);

(3) values and attitudes "more widely shared among different communities" (p. 184) than the first two components;

(4) exemplars, such as "concrete problem-solutions that students encounter from the start of their scientific education" (p. 187)—in other words: textbook or laboratory examples.

Masterman (1970,p. 65) categorized these components with respect to three types of paradigms:

(a) metaphysical or meta-paradigms (refers to 2);

(b) sociological paradigms (refers to 3 );

(c) artifact or constructed paradigms (refers to 1 and 4).

Each paradigm shapes a disciplinary matrix according to which new knowledge can be structured, legitimized, and embedded into the discipline's body of knowledge. Referring to Masterman, Burscheid used these types of paradigms to identify the scientific state of mathematics education with respect to four development stages of a scientific discipline (see Burscheid pp. 224-227):

Burscheid described the first stage (Table 7.1) as a founding stage of a scientific discipline where scientists are identifying the discipline's core problems, establishing typical solutions and developing methods to be used. In this stage, scientists struggle with the discipline's basic assumptions and kernel of ideas; for instance, with the methodological questions of how validity can be justified and which thought models are relevant. In this stage, paradigms begin to develop, resulting in the building of scientific schools and shaping a multi-paradigm discipline. The schools' specific paradigms unfold locally within the single scientific group but do not affect the discipline as a whole. In stage three, mature paradigms compete to gain scientific hegemony in the field (Burscheid 1983, p. 226). The final stage is that of a mature scientific discipline in which the whole community shares more or less the same paradigm (p. 226).

Following the disciplinary matrix, Burscheid (pp. 226-236) identified paradigms in mathematics education and features at that time, according to which different scientific schools emerged and could be distinguished from one another, e.g. according to forms, levels and types of schools, or according to reference disciplines such as mathematics, psychology, pedagogy, and sociology. The constructed paradigms dealt in principle with establishing adequate theories in a discipline. Concerning building theories, however, the transfer of the model of Masterman and Kuhn was 
Table 7.1 Stage-model of the development of a scientific discipline (p. 224, translated $)^{\mathrm{a}}$

\begin{tabular}{l|l|l}
\hline Stage & $\begin{array}{l}\text { Paradigm } \\
\text { characteristics }\end{array}$ & Core description \\
\hline 1 & Non-paradigmatic & $\begin{array}{l}\text { Founding phase of the } \\
\text { scientific discipline }\end{array}$ \\
\hline 2 & $\begin{array}{l}\text { Multi-paradigmatic } \\
\text { science }\end{array}$ & $\begin{array}{l}\text { Scientific schools based } \\
\text { on paradigms emerge }\end{array}$ \\
\hline 3 & $\begin{array}{l}\text { Dual-paradigmatic } \\
\text { science }\end{array}$ & $\begin{array}{l}\text { Mature paradigms } \\
\text { compete }\end{array}$ \\
\hline 4 & $\begin{array}{l}\text { Mono-paradigmatic } \\
\text { science }\end{array}$ & $\begin{array}{l}\text { A mature paradigm } \\
\text { determines the } \\
\text { scientific discipline }\end{array}$ \\
\hline
\end{tabular}

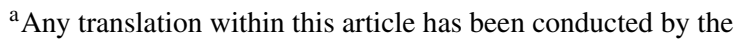
authors unless stated otherwise

difficult to achieve because symbolic generalizations and/or scientific laws can be built more easily in the natural sciences than in mathematics education. This is because mathematics education is concerned with human beings who are able to creatively decide and act in the teaching and learning processes. Burscheid doubted that a general theory such as those in physics could ever be developed in mathematics education (p. 233). However, his considerations led to the conclusion that "there are single groups in the scientific community of mathematics education which are determined by a disciplinary matrix. [...] That means that mathematics education is [still] heading to a multi-paradigm science" (translated, p. 234).

Burscheid's analysis was immediately criticized from two perspectives. Fischer $(1983)^{3}$ claimed that pitting mathematics education against the scientific development of natural science is almost absurd because mathematics education has to do with human beings (p. 241). In his view "theory deficit" (translated, p. 242) should not be regarded as a shortcoming but as a chance for all people involved in education to emancipate themselves. The lack of impact to practice should not be overcome by top-down measures from the outside but by involving mathematics teachers from the bottom-up to develop their lessons linked to the development of their personality and their schools (p. 242). Fischer did not criticize Burscheid's analysis per se, but rather the application of a model postulating that all sciences must develop in the same way as the natural sciences towards a unifying paradigm (Fischer 1983).

Steiner (1983) also criticized the use of the models developed by Kuhn and Masterman. He considered them to be not applicable to mathematics education in principle, claiming that even for physics these models do not address specific domains in suitable ways, and, in his view, domain specificity is in the core of mathematics education (p. 246). Even more than Fischer, Steiner doubted that mathematics education will develop towards a unifying single paradigm science. According to him,

\footnotetext{
${ }^{3}$ Fischer also feared that once mathematics education would develop towards a unifying paradigm, the field of mathematics education were more concerned with its own problems like physics and, finally, would develop separating its issues from societal concerns.
} 
Table 7.2 Views on mathematics education as a scientific discipline

\begin{tabular}{l|l}
\hline Discussant & View on mathematics education as a scientific discipline and its development \\
\hline Burscheid & $\begin{array}{l}\text { Theories and theorizing are in the core of mathematics education as a scientific } \\
\text { discipline. Taking the development of natural science as a role model, Burscheid } \\
\text { assumes that the development of mathematics education advances by a process } \\
\text { of maturing and competing paradigms }\end{array}$ \\
\hline Fischer & $\begin{array}{l}\text { Fischer dismisses to take natural science as role model for scientific } \\
\text { development since mathematics education has to do with human beings and it is } \\
\text { practice based. It develops from practice bottom-up by the development and } \\
\text { emancipation of teachers }\end{array}$ \\
\hline Steiner & $\begin{array}{l}\text { Steiner dismisses to take natural science as role model for scientific } \\
\text { development of mathematics education because not even physics fits this model } \\
\text { in all respects. Mathematics education as a scientific discipline is systemic and } \\
\text { interdisciplinary at its core. It develops from the inside as a system of } \\
\text { interrelations among mathematics, further disciplines and through the relation } \\
\text { of theory and practice }\end{array}$ \\
\hline Bigalke & $\begin{array}{l}\text { The nature of mathematics education as a scientific discipline follows scientific } \\
\text { principles. Its theory concept consists of an unimpeachable kernel and an } \\
\text { empirical surrounding. From the contextual nature of the scientific knowledge of } \\
\text { mathematics education Bigalke infers the necessity to accept multiple principles } \\
\text { and theories. This knowledge develops from the inside while theories are } \\
\text { inspired by practice and have to prove being successful in research and practice }\end{array}$ \\
\hline
\end{tabular}

mathematics education has many facets and a systemic character with a responsibility to society. It is deeply connected to other disciplines and in contrast to physics, mathematics education must be thought of as being interdisciplinary at its core. The scientific development of mathematics education should not rely upon external categories of description and acceptance standards, but should develop such categories itself (pp. 246-247); and, moreover, it should consider the relation between theory and practice (p. 248) (Table 7.2).

One year later, Bigalke (1984) proposed exactly such an analysis from the inside. He analyzed the development of mathematics education as a scientific discipline as well, but this time without using an external developmental model. He proposed a "suitable theory concept" (translated, p. 133) for mathematics education on the basis of nine theses. Bigalke urged a theoretical discussion, and reflection on epistemological issues of theory development. Mathematics education should establish the principles and heuristics of its practice, specifically of its research practice and theory development on its own terms. Bigalke specifically regarded it as a science that is committed to mathematics as a core area with relations to other disciplines. He claimed that its scientific principles should be created by "philosophical and theoretical reflections from tacit agreements about the purpose, aims, and the style of learning mathematics as well as the problematization of its pre-requisites" (translated; p. 142), and he emphasized that such principles are deeply intertwined with research programs and their theorizing processes. 
Many examples taken from the German didactics of mathematics substantiate that Sneed's and Stegmüller's understanding of theory ${ }^{4}$ (cf. Jahnke 1978, pp. 70-90) fits mathematics education much better than the restrictive notion of theory according to Masterman and Kuhn, specifically when theories are regarded to inform practice. Referring to Sneed and Stegmüller, Bigalke (1984, p. 147) investigated the suitability of their theory concept for theoretical approaches in mathematics education and summarized this theory concept in the subsequent way:

\begin{abstract}
A theory in mathematics education is a structured entity shaped by propositions, values and norms about learning mathematics. It consists of a kernel, that encompasses the unimpeachable foundations and norms of the theory, and an empirical component which contains all possible expansions of the kernel and all intended applications that arise from the kernel and its expansions. This understanding of theory fosters scientific insight and scientific practice in the area of mathematics education. (translated, p. 152)
\end{abstract}

Bigalke (1984) himself pointed out that this understanding of theory allows many theories to exist side by side providing a frame for a diversity of theories. It was clear to him that no collection of scientific principles for mathematics education would result in a 'canon' agreed across the whole scientific community. On the contrary, he considered a certain degree of pluralism and diversity of principles and theories to be desirable or even necessary (p. 142). Bigalke regarded theories as being inspired by the practice of teaching and learning of mathematics thus providing the link to this practice, founding mathematics education as a scientific discipline in which theories may prove themselves successful in research as well as in practice (Bigalke 1984). Progress of the scientific discipline results from the challenge to overcome the tension between the scientific principles and the values and norms in the practice of teaching and learning mathematics. Theories are the tools to overcome this challenge (p. 159), hence, allowing various forms of theories to be developed.

\title{
7.3 Theories of Mathematics Education (TME): A Program for Developing Mathematics Education as a Scientific Discipline
}

Out of the previous presentation arose the result that the development of theories in mathematics education cannot be cut off from clarifying the notion of theory and its epistemological ground related to the scientific foundation of the field. Steiner (1983) construed this kind of self-reflection as a genuine task in any scientific discipline (cf. Steiner 1986) when he addressed the comprehensive task of founding and further developing mathematics education as a scientific discipline (cf. Steiner 1987c). At a post-conference meeting of ICME-5 in Adelaide in 1984, the first of five conferences on the topic "Theories of Mathematics Education" (TME) took place (Steiner et al.

\footnotetext{
${ }^{4}$ We will not further elaborate on the theory concept by Stegmüller and Sneed as we wish to focus on the debate conducted at that time.
} 
1984; Steiner 1985, 1986). This topic is a developmental program consisting of three partly overlapping components ${ }^{5}$ :

- "Development of the dynamic regulating role of mathematics education as a discipline with respect to the theory-practice interplay and interdisciplinary cooperation.

- Development of a comprehensive view of mathematics education comprising research, development, and practice by means of a systems approach.

- Meta-research and development of meta-knowledge with respect to mathematics education as a discipline" (emphasis in the original; Steiner 1985, p. 16).

Steiner characterized mathematics education as a complex referential system in relation to the aim of implementing and optimizing teaching and learning of mathematics in different social contexts (p. 11). He proposed taking this view as a metaparadigm for the field (Steiner 1985, p. 11; Steiner 1987a, p. 46), addressing the necessity of meta-research in the field. According to Steiner, the field's inherent complexity evokes reduction of its complexity in favor of focusing on specific aspects, such as curriculum development, classroom interaction, or content analysis. According to Steiner, this complexity also creates a differential classification of mathematics education as a "field of mathematics, as a special branch of epistemology, as an engineering science, as a sub-domain of pedagogy or general didactics, as a social science, as a borderline science, as an applied science, as a foundational science, etc." (Steiner 1985, p. 11). Steiner required clarification of the relations among all these views, including the principle of complementarity on all layers, which means considering research and meta-research, concepts as objects and concepts as tools (Steiner 1987a, p. 48, 1985, p. 15). He proposed understanding mathematics education as a human activity, hence, he added an activity theory view to organize and order the field (Steiner 1985, p. 15). The interesting point here is that Steiner implicitly adopted a specific theoretical view of the field but points to the multiple perspectives in the field which should be acknowledged as its interdisciplinary core.

Steiner (1985) emphasized the need for the field to become aware of its own processes of development of theories and models and investigate its means, representations and instruments. Epistemological considerations seemed important for him, specifically concerning the role of theory and its application. In line with Bigalke, he proposed considering Sneed's and Stegmüller's view on theory as suitable for mathematics education, since it encompasses a kernel of theory and an area of intended

${ }^{5}$ This program was later reformulated by Steiner (1987a, p. 46; emphasis in the original):

- Identification and elaboration of basic problems in the orientation, foundation, methodology, and organization of mathematics education as a discipline.

- The development of a comprehensive approach to mathematics education in its totality when viewed as an interactive system comprising research, development, and practice.

- Self-referent research and meta-research related to mathematics education that provides information about the state of the art-the situation, problems, and needs of the discipline while respecting national and regional differences. 
applications to conceptualize applicability being a part of the very nature of theories in mathematics education (p. 12).

In the first TME conference, theory was an important topic, especially the distinction between so-called borrowed and home-grown theories. Borrowed theories are taken from outside mathematics education whereas home-grown theories are those developed within mathematics education. With respect to this distinction, Steiner's complementary view made him point to the danger of one-sidedness. In his view, borrowed theories are not just transferred and used but rather adapted to the needs of mathematics education and its specific contexts. Home-grown theories, however, are able to address domain-specific needs but are subjected to the difficulty of establishing suitable research methodologies on their own authority. The interdisciplinary nature of mathematics education requires regulation among the different perspectives but also regulation of the balance between home-grown and borrowed theories (Steiner 1985; Steiner et al. 1984).

So, what is Steiner's specific contribution to the discussion of theories and theory development? Like other colleagues, such as Bigalke, he has pointed to the role of theories as being in the core of mathematics education as a scientific discipline, and he proposed the notion of theory developed by Sneed and Stegmüller (cf. Jahnke 1978; pp. 70-90; see also Bigalke in this article) as being suitable for such an applied science. Steiner proposed complementarity to be a guiding principle for the scientific field and required investigating what complementarity means in each case of the field's topics. In this respect, the dialectic between borrowed theories and homegrown theories is an integral part of the field that allows the discipline to develop from its core and to be challenged from its periphery. In addition, Steiner emphasized that mathematics education as a system (see Steiner 1987b) should reflect on its own epistemological basis, its own theory concepts and theory development, the relation between theory and practice, and the interrelation among all its perspectives. He has added that the specific view of mathematics education always incorporates some epistemological model of how mathematics and teaching and learning of mathematics are understood, and that this is especially relevant for theories in mathematics education.

If we consider the research (practice) in mathematics education as an activity of the discipline, then Steiner has addressed two intertwined sub-activities to be relevant for the foundation and development of mathematics education as a scientific discipline: theorizing in research develops theories, and reflecting on and in the system develops the system of mathematics education; however both activities are related. The following diagram tries to capture Steiner's view on the two activities developing mathematics educations as a scientific discipline (Fig. 7.1):

\subsection{Post-TME Period}

In the following decade, from 1992 up to the beginning of the twenty-first century, the discussion on theory concepts died down in the German community of mathe- 


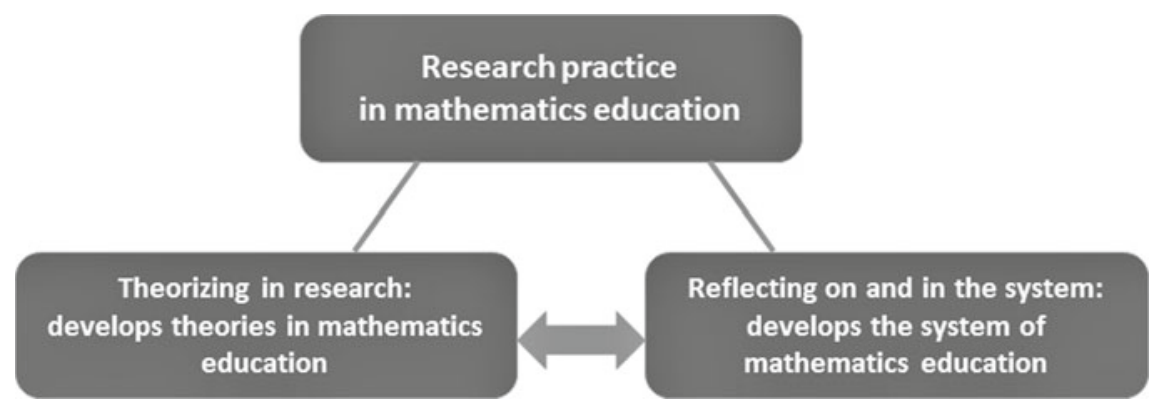

Fig. 7.1 A tentative diagram of Steiner's view on two necessary and related activities in mathematics education as a scientific discipline

matics educators while the theoretical diversity in the field grew. A comprehensive overview of theories used within different (and ever-evolving) strands of mathematics education research in the German-speaking countries over the last 30 years would necessarily go beyond the scope of this paper. We can only give a few cursory examples here, and any selection of such examples is at least prone to subjective selectiveness and personal bias. Therefore, the reader is highly encouraged to consider the other articles in this volume for a more complete picture of the theoretical backgrounds referenced in the respective strands of mathematics education research. Considering the two main scientific journals, we identified scientific contributions from several theoretical communities addressing three topics related to the TME program (without any claim to completeness):

(1) Methodology: methodological and thus theoretical aspects in interpretative research (Beck and Jungwirth 1999), interviews in empirical research (Beck and Maier 1993), multi-methods (Wellenreuther 1997); explaining in research (Maier 1998), methodological considerations on large scale assessments such as e.g. Third International Mathematics and Science Study (TIMSS) (Knoche and Lind 2000);

(2) Methods in empirical research: e.g., two special issues of ZDM in 2003 edited by Kaiser presented a number of methodical frameworks;

(3) Issues on meta-research about what mathematics education is, can, and should include: considerations on paradigms and the notion of theory in interpretative research (Maier and Beck 2001), comparison research (Kaiser 2000; Maier and Steinbring 1998; Brandt and Krummheuer 2000; Jungwirth 1994), and mathematics education as design science (Wittmann 1995) and as a text science (Beck and Maier 1994).

This short list indicates that-at that time-distinct theoretical communities seemed to share the need for methodological and meta-theoretical reflection. In some cases, these theoretical considerations transcended the borders of the distinct theoretical community and led to critical response and discussion: 
- Kirsch (1977/2000) and Becker (1978) are some of the rather sparse examples of meta-theoretical reflection on Stoffdidaktik ("subject matter analysis") from proponents of this traditional strand of mathematics education research in Germanspeaking countries. Both the notion of "concentration on the mathematical heart of the matter" (Kirsch 1977, 2000) and the sense and purpose of working out mathematically elaborated background theories for school mathematics (Becker 1978) have been questioned from a systems theory perspective in Steinbring (1998) and Steinbring (2011).

- In their discussion of the use of interviews in interpretative research, Beck and Maier (1993) also presented an account of 'understanding' in mathematics classrooms (as process and product) developed according to the interpretative paradigm. Weigand (1995) contrasts this view with more traditional, normative accounts of 'understanding' developed just within the aforementioned framework of Stoffdidaktik. Weigand raises the question whether interpretative notions of 'understanding', originally developed in social science and cultural contexts, can in principle meet the particularities of mathematical thinking and learning, and stresses the complementarity of interpretative and Stoffdidaktik-approaches.

- Knoche and Lind (2000) introduced models of item response theory which were used within the TIMS-Study (Trends in International Mathematics and Science Study) and subsequently were and are used in the Programme for International Student Assessment (PISA) to a broader audience of mathematics education researchers in German speaking countries. Since then, these models have become more widely adopted, and their benefits for assessing and analyzing students' mathematical competence have been discussed, e.g. in Knoche et al. (2002), Büchter and Pallack (2012) and Leuders (2014). On the other hand, the appropriateness of these models for conceptualizing mathematical learning and the theoretical assumptions related to mathematical learning and student performance underlying these models have been challenged fundamentally, e.g. in Meyerhöfer (2004), Bender (2005), Vohns (2012) and Wuttke (2014)—some of the articles leading to rebuttals and rejoinders.

To reiterate, these are just some cursory examples of theoretical discussions across different strands of mathematics education research, and the reader may again be referred to the other articles in this volume for a more complete and balanced view on theoretical issues that have arisen and been discussed within and between the respective strands.

In order to provide a deeper insight into theory strands of German-speaking countries, we summarize two examples presented during the ICME-13. Both theoretical approaches are then reconsidered and linked in an analysis of an empirical example, as it is usually done in the Networking of Theory strands to show how different theories may be used to better grasp the complexity of teaching and learning mathematics. Referring back to Steiner and his TME program, we will use the insight gained from this exercise to describe how mathematics education as a scientific discipline could reflect on its own epistemological basis, and do meta-research as Steiner proposed to clarify the specificities and roles of its theories and their relations to practice. 


\subsection{Two Theories, Their Origins and Their Purposes}

In the survey on theory strands in German-speaking countries (Bikner-Ahsbahs and Vohns 2016), two theories are described in detail and used for the analysis of an empirical example. The first theory, presented by Bruder and Schmitt (2016), is that of Learning Activity, originally developed by Joachim Lompscher in the German Democratic Republic (GDR). The second approach, presented in the same survey by Dörfler (2016), is an example of theorizing mathematics as a semiotic way of doing mathematics by referring to the concept of diagram introduced by Peirce and relating this to the idea of semiotic games by Wittgenstein (1999). For the purpose of this article, we will give a brief overview of both approaches.

\subsubsection{Learning Activity}

Bruder and Schmitt (2016) discuss the theory of Learning Activity developed by Lompscher within the theory culture of activity theory introduced by soviet psychologists, e.g. Vygotski, Leont'jev and Luria (Lompscher 2006). This theory culture takes activities as meaningful, purposeful, culturally and historically coined components of an activity system. Driven by a general motive, an activity brings itself about collectively by actions which are goal oriented and linked to the individuals' psychological development. These actions are influenced by the social and cultural environment in which they are conducted. They are mediated by practical or mental tools available in the cultural environment and directed towards goals; they consist of operations determined by the specific situated conditions (Giest and Lompscher 2006, p. 39), and are often conducted unconsciously (Hasan and Kazlauskas 2014, p. 10). The relation between subject and object is at the core of any activity. This relation, together with actions, goals and available means, structure the activity (Giest and Lompscher 2006, pp. 37-41). Through activities, the subject actively acquires cultural knowledge and knowing, and in the same process this cultural knowledge and knowing is transformed by the individual. Thus, internalisation and externalisation are mutual processes of transformation (Lompscher 1985a, p. 25). Examples of activities are playing activity, learning activity, and working activity (Giest and Lompscher 2006, p. 55).

Lompscher has applied this theoretical view on teaching and learning in school (see Bruder and Schmitt 2016; Lompscher 1985a, b, 1989a, pp. 23-32; Giest and Lompscher 2006, pp. 67-106). Through a learning activity, a student acquires societal knowledge and cognitive competencies by interacting with other individuals and the environmental conditions. Lompscher (1989a) emphasizes that knowledge and competencies are related to "segments of societal experience of the world" (p. 29, translated). The general motive of a learning activity is self-development according to the specific cultural requirements (Giest and Lompscher 2006, p. 83), an aspect that distinguishes learning activity from other activities (p. 93). The teacher is crucial 
for constituting a learning activity: he/she arranges the learning conditions as tasks and provides the means to solve them. The learning activity on a topic is achieved by learning actions. These are arranged in steps, building a pathway for a learning trajectory to shape suitable learning conditions, providing resources for a sequence of learning actions which are supposed to lead to the desired learning goal. Sub-tasks are to be arranged in a way that the learner can adopt these tasks and their sub-goals as his/her own. As Lompscher puts it: The outcomes of the individual learning is only achieved by "the intensity and quality of the learner's own activity on and with the learning object, the adequately using resp. shaping or transforming of the learning conditions, the employment of available learning means resp. changes according to adequate aims and conditions" (Lompscher 1989a, p. 32, translated, emphasis in the original).

According to Bruder and Schmitt (2016), Giest and Lompscher (2006) distinguish three parts of a learning action: the orientation, the performance and the control part (p. 197), and three types of orientations a student may be able to conduct (Giest and Lompscher 2006, p. 192; see also Bruder and Schmitt 2016, pp. 16-18): trial orientation (driven by some kind of trial and error), pattern orientation (a sensitivity to patterns can be followed in a focused area), and field orientation (knowledge can be acquired and transferred in a complete knowledge field). A general motive for a learning activity is the development of field orientation, but this is not so easy to achieve. Bruder and Schmitt (2016, p. 16) refer to Davydov's (1990) idea to start within an initial abstract feature as a means for orientating, exploring and enriching the abstract with the concrete. Ascending from the abstract to the concrete is regarded as a strong approach to reach field orientation as early as possible (see Lompscher 2006, 131-205, 1989b).

Lompscher's research group has undertaken empirical studies in close connection with the teaching and learning practice in several school domains (Giest and Lompscher 2006). Mathematics was just one of them. The theory of learning activity has been intensively applied, adapted and further developed in research and development for teaching and learning mathematics in various directions (see Bruder and Schmitt 2016): for example, specifying elementary mental operations by Bruder and Brückner (1989), developing a comprehensive model for competence development for modelling, problem solving and argumentation (Bruder et al. 2003), investigating mathematical problem solving (Collet and Bruder 2008; Bruder and Collet 2011), developing learning tasks (Bruder 2010), and difficulties in representing functions (Nitsch 2015), to name just four.

\subsubsection{A Semiotic View on Mathematics: Sign Use and Semiotic Game}

The second example, presented by Dörfler (2016), is a specific semiotic view referring to Charles Sanders Peirce and Ludwig Wittgenstein. In the 1990s, Michael Otte 
introduced Peirce's semiotics as an important view on mathematics to the German community of mathematics educators (see for example Fischer 2005, p. 375; Dörfler 2016, p. 23; Otte 1997). In the subsequent years, Peirce's theory of semiotics has also been taken up by several researchers for different purposes, for example to develop a semiotic theory on learning (Hoffmann 2001), to illustrate its epistemological nature (Hoffmann 2005), to include the view on diagrams in the mathematics classroom (Dörfler 2006), for analysing chat-communication (Schreiber 2006) or investigating the epistemic role of gestures (Krause 2016).

Dörfler's theoretical view is rooted in a dynamic understanding of mathematics itself (Dörfler 2004, 2006, 2008, 2013a, 2016). Similar to Hoffmann (2005), Dörfler takes the concept of diagram introduced by Peirce as a starting point and describes doing mathematics as diagrammatic reasoning. However, the specificity in Dörfler's elaboration is abstaining from the view on mathematical activity as a mental activity building abstract objects in the individual learner.

In Peirce's semiotics, each sign is embedded in a triadic relation between the sign (as a representamen), an object the sign stands for, and an interpretant-which is an effect of the sign allotting meaning to it. For example the interpretant may be produced by an interpreter regarding the sign as standing for an object in some way, like $\pi$ may be regarded as an irrational number, the limit of a specific infinite sum or as representing the proportional relation between the circumference of a circle and its diameter. The following quote by Peirce (1931-1958) depicts this triadic relation of signs:

A sign, or representamen, is something which stands to somebody for something in some respect or capacity. It addresses somebody, that is, creates in the mind of that person an equivalent sign, or perhaps a more developed sign. That sign which it creates I call the interpretant of the first sign. The sign stands for something, its object. It stands for that object, not in all respects, but in reference to a sort of idea, ... (CP 2.228, emphasis in the original)

However, an interpretant does not necessarily need to be produced by a human being, it can also be produced in the physical world (Nöth 2000, p. 227). But in any case, the interpretant is the part of the sign that points to meaning. Peirce distinguishes between three kinds of signs in relation to the object: a sign can be an icon, an index, or a symbol. An icon, such as a photo of a person, is a sign that resembles the object: the material person. An index is a sign that refers to another sign because of its direct connection to it, like smoke refers to fire. A symbol is a conventionalized sign or a habitualized sign like the equivalent sign. It links the sign to the object by some kind of regularity or law (Nöth 2000, p. 66).

Referring to Peirce, a diagram, such as an equation, is built by signs of a representation system that provides conventionalized rules. It may include all three kinds of signs described above. A variable in the equation may be viewed as an index referring to another sign, e.g. a measure. The equal sign may represent the rule that two things are regarded the same in a specific manner, as an iconic sign it may refer to a balance scale. In general, a diagram is an inscription representing iconic relations between different signs: that is, it is a complex sign made of other signs and their relations as possibilities to be focused on in an interpretant. While all signs in the 
semiotics of Peirce refer to an object, this is not necessarily the case for a diagram (see Dörfler 2016, p. 23). A diagram may just refer to an area of collateral knowledge. Experimenting with a diagram, observing it, and perceiving some new relations may lead "us to suspect that something is true" (CP 5.162). Peirce describes:

All necessary reasoning without exception is diagrammatic. That is, we construct an icon of our hypothetical state of things and proceed to observe it. This observation leads us to suspect that something is true, which we may or may not be able to formulate with precision, and we proceed to inquire whether it is true or not. (CP 5.162)

Diagrammatic reasoning has been worked out more clearly by Bakker and Hoffmann (2005) for mathematics education. As indicated in the quote from Peirce (CP 5.162), they distinguish three steps of diagrammatic reasoning (pp. 340-341): (1) constructing a diagram to represent relations (diagrammatization); (2) experimenting with diagrams based on rules of the specific sign system, rules that tell us what can and what cannot be done with the diagram; and (3) observing the results of the experimentation and reflecting on them (cf. Hoffmann 2005, p. 129). The latter may lead to the discovery of patterns of relations, "which we may or may not be able to formulate with precision, and proceed to inquire whether it is true or not" (CP 5.162).

Dörfler (2016, p. 23) precisely describes how his theoretical view on working with mathematical diagrams represents doing mathematics. He argues that language is a sign system that just mediates between individuals and diagrams. In his view, diagrams are "extra-linguistic signs" (Dörfler 2006, p. 27) with a spatial structure representing relations and providing rules for inventing, exploring and transforming them. As these rules are taken to be without contradictions, mathematical inferences appear consistent and strict. Mathematical meanings are at stake in these transformations as transforming rules. These rules can be exposed linguistically, but their meanings are more directly expressed in the relations of the diagrammatic inscriptions. However, individuals can build a relationship with these diagrams, while exploring, perceiving or talking about them. According to Dörfler, diagrammatic reasoning expresses the nature of doing mathematics, and it is highly creative. Dörfler rejects the existence of mathematical objects as abstract mental objects. Instead, mathematical objects, in his view, manifest in the relations of the diagrams and the rules of their transformations. Thus, "Diagrammatic reasoning is a rule-based but inventive and constructive manipulation of diagrams for investigating their properties and relationships" (Dörfler 2016, p. 26). Hence, it is at the core of the dynamic semiotic view on mathematics, for example when equations are produced they can be transformed into other equations by transformation rules and allow features to be observed and rules to be identified in the diagrams.

Referring to Wittgenstein (1999, according to Dörfler 2016, p. 27), Dörfler strengthens his theoretical view on diagrammatic reasoning by describing mathematics as a semiotic game. This way he sharpens the notion of mathematical meanings: they are in the rules that are the basis for establishing the semiotic game and for building relationships among the signs. Mathematical diagrams are the "essential 
and constitutive" (p. 30) means in this game and meanings are in the use of rules. Consequent ensues Dörfler's view on learning mathematics:

Thus for Peirce, to learn mathematics would be to acquire expertise in diagrammatic reasoning, and for Wittgenstein, it would be to participate in the many various sign games and their techniques. In both cases, which are closely related, it is of great importance to stick meticulously to establish rules... mathematics is thereby fundamentally shown to be a deeply social and socially shared cultural activity and product: sign activity can be executed with others and shown to others in public form. This is very different from imagining mathematics as a kind of abstract and mental activity. (Dörfler 2016, p. 30)

\subsection{Reconsidering the TME Program by Networking the Two Theoretical Views}

In line with the TME-program, we will now present a piece of meta-research to clarify the nature of the two theories above and their relation to inform practice and to raise the awareness of the epistemology on hand. "(...) Steiner (1985) has emphasized the need for the field to become aware of its own processes of development of theories and models and investigate its means, representations, and instruments" (Bikner-Ahsbahs and Vohns 2016, p. 9). This kind of awareness can be achieved by meta-research: that is, research on the research. To do so, we will use the Networking of Theories approach developed since 2006 (see Bikner-Ahsbahs et al. 2014, 2017; Dreyfus 2009). The Networking of Theories approach also emphasizes metaresearch. However, it does not explicitly want to advance the field, although this may happen in small steps during the practical process in research. Its main aim is to show a way to solve complex problems for which more than one theory is needed, and reflect on the very process. In order to include meta-research as an additional practice into research, research practices have to be broadened to address also the theories themselves, their methodologies, and the research practices as research objects. The purpose for this kind of meta-research may vary, for example it may be important to obtain methodological or theoretical clarity in a multi-theoretical approach (Kidron et al. 2014; Bikner-Ahsbahs and Kidron 2015), to solve an apparently contradicting problem (Sabena et al. 2014), to clarify the nature of research results or the specificity of the particular epistemology in the study. A nice example for exploring the complementary relation of individual and social processes in an inquiry-based classroom has been presented by Tabach et al. (2017).

In the following section, we will explain what we mean by networking theories. To undertake a networking case, we will present a small piece of data: a students' group solution for a mathematical problem. This data set will be analysed from Lompscher's perspective of Learning Activity and from Dörfler's perspective of semiotic game and diagrammatic reasoning according to the common question of how the process of problem solving yields the result. By comparing and contrasting the two theoretical views rooted in the analyses, and the analyses presented, we want to contribute to the TME program and show the added value of the networking of theories for obtaining 
an in-depth understanding of the two theories as well as the manner in which they inform teaching and learning practice.

\subsubsection{Networking Theories Approach}

The Networking of Theories is a research practice of relating different theoretical approaches to each other and uncovering underlying assumptions, describing their particular identities and boundaries and, beyond this, contributing to an in-depth dialogue among theory cultures of mathematics education (see Bikner-Ahsbahs and Prediger 2014; Prediger et al. 2008), and achieving new kinds of results. For such an approach, pairs of networking strategies have been developed and ordered according to their integration potential (Fig. 7.2).

Each theory provides particular knowledge to the field, paying attention to some aspects while leaving other aspects aside. Therefore, the main assumption in the Networking of Theories approach is to respect the diversity of the theories in the field as richness (Bikner-Ahsbahs 2009). Neither unifying theories nor ignoring other theories should be part of this practice. The Networking of Theories, say for example the two approaches above, is more a dialogue between theory cultures in multi-theoretical research. This 'dialogue' (Kidron and Monaghan 2012) can be approached by the four pairs of networking strategies (Prediger et al. 2008) positioned in between the two poles of the landscape in Fig. 7.2 and ordered according to their degree of integration. Networking of theories begins with understanding the other theory and making one's own theory understandable. What does this mean? For example, it means that assumptions which often are implicit should be explicated, or that historical roots as well as paradigmatic empirical cases can offer access to clarify the essential concepts of the theory (cf. Bikner-Ahsbahs and Prediger 2014). However, sometimes there are limits. If concepts emerge within an educational culture, it may be difficult or even impossible to explain them to another culture (Bikner-Ahsbahs et al. 2017, p. 2689). By comparing and contrasting theories, their similarities, commonalities and differences can be identified, hence, contribute to deepening the understanding of both theories. The intermediate step to integration is combining and coordinating

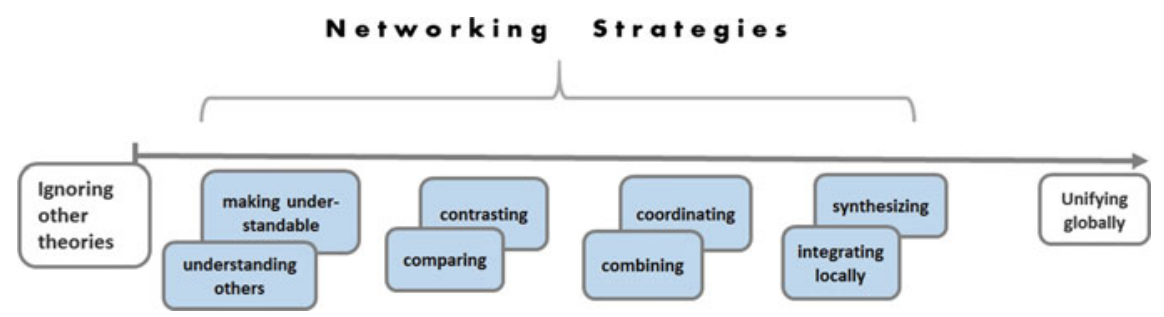

Fig. 7.2 Networking strategies (Prediger et al. 2008, p. 170; Bikner-Ahsbahs and Prediger 2010, p. 492) 
the theories. This step is not always possible; for instance, when theories cannot be combined in a compatible way because this would lead to contradictory results in research. But for instance if the theories address complementary views on the teaching and learning processes (Tabach et al. 2017), the process of improving mutual understanding may progress. The final step is the strategy pair of local integration and synthesizing. Local integration sometimes can be achieved when boundary concepts (cf. Akkerman and Bakker 2011), which can be understood from both theories, are identified (Sabena et al. 2014), or when theoretical concepts of two theories can be integrated into a new theoretical framework (Shinno 2017). As Shinno has shown, the step of integration may have losses and gains: the concepts in the integrated framework may change their notion, but open up new directions of research.

This landscape of networking strategies will now be used to network the two theories, Learning Activity and doing mathematics as a semiotic game of diagrammatic reasoning.

\subsubsection{Try to Find a Fraction Representing $\sqrt{2}$}

Figure 7.3 represents the solution of the task to try to represent $\sqrt{2}$ as a fraction, done by a pair of students at grade 9 . The initial task of the lesson before was to construct $\sqrt{2}$ on the number line by the length of the diagonal of the square with a side length of 1 unit. This was done in a whole class discussion. In the following lesson, the teacher posed the task: Work in pairs and try to represent $\sqrt{2}$ by a fraction. His aim was to prepare the students for the subsequent proof on the irrationality of $\sqrt{2}$ as an initial step to expand the rational numbers towards the real numbers.

\subsubsection{The Semiotic Game Analysis}

We first theorize the solution process in Fig. 7.3 by applying Dörfler's elaboration on doing mathematics as a semiotic game of diagrammatic reasoning and learning mathematics as gaining expertise therein. To do so, we have to analyse the diagrams as they are transformed step by step, and identify the rules represented explicitly or implicitly in the transformations and relations expressed in the diagrams.

The students begin solving the task with the statement that $\sqrt{2}$ has to be bigger than 1 but it is not clear where this comes from. They start with the fraction $\frac{5}{4}$ being bigger than one (line 1), as a kind of tentative true rule that 'this is taken as being equal to $\sqrt{2}$.

In step 1 the tentative equation is transposed by conventionalized transformation rules of equations. The equation obtained is $32=25$, which is wrong. The inequality is recognized by the students; but their inference 'the fraction is too big' is also wrong (line 2), since the original fraction is smaller than $\sqrt{2}$. The implicit rule 'taken as equal' was too vague. This kind of reasoning 'building a tentative equation for $\sqrt{2}$, 


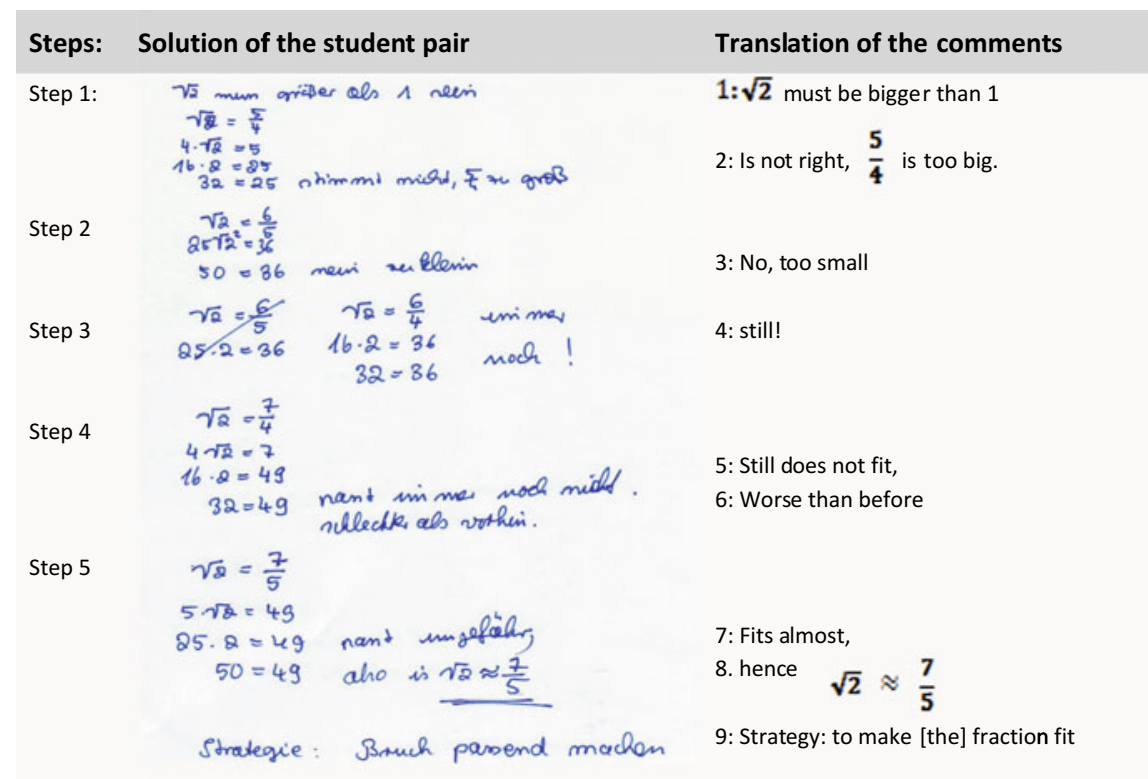

Fig. 7.3 A case of diagrammatic reasoning

changing it to remove the square root and interpreting the result' is repeated in the following steps but with creative changes in constructing arithmetic equations as diagrams.

In step 2, both the nominator and the denominator are changed at the same time by increasing both by 1 . Since the nominator is bigger than the denominator, the new fraction has become smaller, but we cannot assume that the students know this. The new inference from the resulting equation $50=36$, that the fraction is "too small", is now correct (line 3 ).

In step 3, the diagram is worked out according to the same rules as before, but this time only the denominator is reduced by 1 . If we take this as an interpretant of the previous inference, then the underlying rule is to make the next fraction slightly bigger. From the resulting equation $32=36$, the students infer now that it is "still" too small (line 4), but this is wrong. The new fraction has indeed become bigger than $\sqrt{2}$.

Step 4 reacts to the previous false inference, since the fraction is now made even bigger by increasing only the nominator by 1 . The result $32=49$ "still does not fit" (line 5) and it is even "worse than before" (line 6). "Worse" seems to indicate that the difference between 32 and 49 is bigger than the one between 32 and 36 taken from step 3. That the fraction now is bigger than $\sqrt{2}$ does not appear as an interpretant.

Meanwhile a number of rules have emerged: increasing the nominator of the fraction by 1 and reducing the denominator of the fraction by 1 make the fraction bigger, reducing the nominator by 1 and increasing the denominator by 1 make 
the fraction smaller. The tentative rule 'take the two numbers as being equal' is a pragmatic rule which can be falsified by the inequality of the result. However, the inferences about the kind of inequality are inconsistent. From step 3 onwards, the rule for changing the fractions seems to be 'change either the nominator or the denominator by 1 according to the previous result'.

In step 5, we would expect that either the nominator is reduced by 1 or the denominator is increased by 1 . Reducing the nominator would reveal the previous fraction, hence, this transformation does not make sense. In fact, the students increase the denominator by 1 . Since the manipulation of the equation now leads to the two numbers 50 and 49 close to each other the students' result is $\sqrt{2} \approx \frac{7}{5}$. The approximately-equal sign and doubling the underlining indicate that an approximate result is accepted.

Through diagrammatic reasoning, two kinds of rules are put into effect: (1) if the equation is true, then the manipulation of it will lead to an equation which is also true. Otherwise the result will indicate how to approach the next iteration. (2) Finding an iteration of fractions to box $\sqrt{2}$ is a quasi-systematic way to determine a fraction close to $\sqrt{2}$.

The students' interpretations are expressed in linguistic terms, taken as inferences or interpretants, which show that they sometimes interact with the diagrams in an ambiguous way (line 2 to line 4 ). The visible transformations, the rules used and produced, are not precisely expressed. Conventionalized rules for transforming equations are used as routine actions not addressed in the students' comments. Only the results are interpreted, but partly ambiguously. It turns out that the mistakes in steps 3 and 4 are not relevant because the underlying rule to change either the nominator or the denominator in an opposite direction revealed a result where the mistakes did not harm the process. The final strategy of approximating $\sqrt{2}$ by boxing it through an iteration of fractions emerged as a heuristic rule that resonates well with the students' overall strategy "to make [the] fraction fit" (line 9).

\subsubsection{The Learning Activity Analysis}

Let us now add the analysis from the perspective of the theory of Learning Activity. In contrast to Dörfler's semiotic approach, this theory addresses the complete course of learning, from the teacher's planning to the goals, whether they are achieved and what comes next. This planning already starts with the question of which cultural-historical knowledge should be learned, whether this knowledge is already accessible, and how the goal should be approached. Specifically the history of teaching and learning in the class has to be considered in the preparation of this course. The teacher in our example has initially constructed $\sqrt{2}$ on the number line. His next goal is the proof of the irrationality of $\sqrt{2}$ as a prerequisite for achieving his final goal: the introduction of real numbers. In this teaching course, the task above is a sub-task with the sub-goal yielding the insight that a fraction which exactly represents $\sqrt{2}$ cannot possibly exist. 
Lompscher has emphasized the mutual dependency of the leaning actions, the learning goals, and the learning objects in the learning conditions that together provide an arrangement in which the students may constitute their own learning activity. Not surprisingly, this open task has produced three more types of solutions in the class. One student pair used their calculator to find an approximate fraction. A second pair tried to find a finite decimal fraction to represent $\sqrt{2}$ but failed, and therefore showed by the last digits that this does not work: they got stuck. A third pair used the factorizing of prime numbers in a fraction to find a representation for: they also failed, but tried to find a reason why. Given this situation, only the solution above would prepare the teacher's intended proof, although at this stage the proof-lesson could be prepared in a way that also builds on the students' diverse solutions.

In contrast to Dörfler's view, the interplay of the subject and the object is at the core of the learning activity leading to the individual student's personal development. Therefore, we have to ask, what kind of knowledge and competencies have the students previously built, and prospectively are to build in the future. In the solution presented in Fig. 7.3, two elementary acquisition actions (stressed by Lompscher) are shown, identifying and realizing: The students identify a fraction close to $\sqrt{2}$, they realize transpositions of equations and build an iteration of fractions for approximating $\sqrt{2}$. They use heuristic strategies and transforming equations as heuristic means, and thus realize an argumentation similar to that of a proof of contradiction. In their task solution, the two students show trial orientation at the beginning including errors. But through heuristic strategies (equations as heuristic means and systematically changing the starting conditions of the next step) they quickly begin to systematically build an approximation boxing $\sqrt{2}$ into subsequent fractions, probably not yet conducted quite consciously. However, the way they transform the diagrams systematically depicts their ability of pattern orientation in the way boxing is realized, based on the interpretation of previous inequality. Field orientation does not seem to be touched yet because the theme of irrational numbers has just started to be in the scope of learning.

Can we finally confirm that the students have built their own learning activity through changing the conditions and resources given? We cannot exactly answer this question, but we may find indicators for this outcome. The students used heuristic strategies that are not required, such as equations as heuristic means, and as-if-actions as a heuristic strategy to reveal necessary conditions. They systematically scrutinized the manipulation of equations and checked the results to continue with a slight change of the conditions in the next step. Through heuristics, they constructed conditions which enabled them to proceed in the solving of the problem. In fact they show quite proficient problem solving actions leading to a result that could raise the question as to whether it would be possible to represent $\sqrt{2}$ by a fraction, and whether or not a final solution could be reached algorithmically. All these aspects indicate that the students really have established their own learning activity yielding their solution of the task. However, they might not be aware yet that representing $\sqrt{2}$ by a fraction is impossible. The theory of Learning Activity would now focus on the teacher's actions of how to systematize all the students' results and provide further tasks and resources to prepare the intended proof. 


\subsubsection{Undertaking a Networking Analysis}

Networking both theories based on the empirical analyses confirms the results already achieved by the analyses done with another empirical case presented in the ICME-13 survey (Bikner-Ahsbahs 2016).

The semiotic approach elaborated by Dörfler starts from a specific home-grown account of the dynamics of doing mathematics and presents an approach which describes this doing, however, by adapting the work of two philosophers. The theory of Learning Activity is a more comprehensive theory elaborated for many subjects, borrowed and applied to mathematics to develop students' competencies in doing mathematics. It explicitly includes learning goals to be achieved. In terms of the semiotic game view, the students and their mental activities are not at the core of the analysis. The process of diagrammatic reasoning and the transformation rules expressed in the diagrams are addressed rather independently of the students' individual way of interpreting the situation. The inferences can be taken as a mathematical part of the diagrams, thus, of diagrammatic reasoning. We may even state that the relationships shown in the diagrams, in which the next step can be regarded as an interpretant to the previous one, advance the transformation process and constitute the rules. In contrast, the Learning Activity analysis focuses more on the learners, the cultural-historical conditions and the context in the course of teaching and learning in which the students may be able to develop themselves by creating an own learning activity.

Whereas diagrammatic reasoning and the rules obtained belong to the kernel of the theory's identity of Dörfler's semiotic approach, the individual students and their abilities belong to the theory's periphery. In Lompscher's theoretical view, this is the other way round: the students' development is at the core of the theory of Learning Activity, whereas the diagrams are resources belonging to the conditions of this development. This has considerable consequences for research: the research question posed must be interpreted differently by the two approaches, and the methodological and conceptual tools used to gain scientific knowledge in research also differ. However, the two approaches could be used in a complementary way.

This complementarity (see Steiner 1985, 1987a) can be described with the metaphor of "zooming-out and zooming-in" (Prediger et al. 2010, p. 1533, referring to Jungwirth) when looking at the grain sizes of relevant processes. This is possible because both approaches share a certain sensitivity towards acting or doing. Coming from the teacher's long term planning, we would zoom in on Dörfler's view to observe and analyze the diagrammatic reasoning on a micro level, in order to reconstruct the rules shown in the semiosis. The students' interpretation may indicate aspects of their development when the Learning Activity theory is considered. We then would have to zoom out again in order to take the whole course of teaching and learning as a complementary view into account. If Lompscher's view is considered, we would ask what was learned before the task is posed, what kinds of resources are available, and which resources have to be made available for the students to reach the sub-goals, which conditions are to be met, and how they can be changed to accomplish the 
overall goal. Most importantly, the aim would be to construct the course of sub-goals and sub-actions in a way that constitutes a suitable learning activity for reaching the learning goal and revealing field orientation.

\subsection{Conclusions}

What can be learnt from this networking case for advancing the field by meta-research in the sense of the TME program?

The debate surrounding the developmental stage of mathematics education as a scientific field in the 1980s already showed contrasting views. While the analysis of Burscheid based on the model of Kuhn and Masterman indicates that a monotheoretical view was desirable for advancing the field, Bigalke and Steiner emphasized the multi-theoretical or even the interdisciplinary character of mathematics education as a scientific field with a specific focus on complementarity, in which the practice of teaching and learning of mathematics plays a significant role. If research is used to inform the practice of teaching and learning or to address diverse cultures, multi-theoretical views may be much more useful to grasp the complex nature of the settings in the field. Such an approach could help to gain complementary knowledge to inform practice regarded from different angles, as Steiner has pointed out. In this sense, the networking of theories is a kind of meta-research and a challenging way of research practice, when added to normal research. Its purpose is to contribute to the improvement of solving problems in the field of mathematics education. For that, it is necessary to advance theoretical and methodological clarity on the one hand, and the communication among the theory cultures and among theory and practice on the other. The previously presented networking example shows that the metaphor of 'zooming in and zooming out' may guide research with complementary theoretical approaches of different grain sizes heuristically.

In the TME program, Steiner has elaborated a more general top-down view for advancing the field but it does not show how this program can be implemented; that is, how meta-research can be conducted in a way to advance the field. The TME program could rather serve as an orientation scheme, whereas the Networking of Theories regarded as an additional research practice provides examples of concrete meta-research showing how it improves solving problems in the field and why this kind of meta-research is useful. The Networking of Theories approach has been predominantly developed by several European researchers (see Bikner-Ahsbahs and Prediger 2014), but there are forerunners in the theory tradition of German-speaking countries, for example interesting cases of the networking of theories were presented by Bauersfeld (1992a, b) and Maier and Steinbring (1998). Advancing the field as a scientific domain as Steiner has attempted may be the byproduct of such deep and careful case-based meta-research.

The Networking of Theories strand has started to provide concrete examples for such a research practice, pointing to its benefit and being at the same time sensitive 
about the difficulties and limits a multi-theoretical approach may bring with it (see for example Bikner-Ahsbahs et al. 2017).

\section{References}

Akkerman, S., \& Bakker, A. (2011). Boundary crossing and boundary objects. Review of Educational Research June 2011, 81(2), 132-169.

Bakker, A., \& Hoffmann, M. (2005). Diagrammatic reasoning as the basis for developing concepts: A semiotic analysis of students' learning about statistical distributions. Educational Studies in Mathematics, 60, 333-358. https://doi.org/10.1007/s10649-005-5536-8.

Bauersfeld, H. (1992a). Activity theory and radical constructivism-What do they have in common and how do they differ? Cybernetics and Human Knowing, 1(2/3), 15-25.

Bauersfeld, H. (1992b). Integrating theories for mathematics education. For the Learning of Mathematics, 12(2), 19-28.

Bauersfeld, H., Otte, M., \& Steiner, H.-G. (Eds.). (1984). Schriftenreihe des IDM: 30/1984. Zum 10jährigen Bestehen des IDM. Bielefeld: Universität Bielefeld.

Beck, Ch., \& Jungwirth, H. (1999). Deutungshypothesen in der interpretativen Forschung. Journal für Mathematik-Didaktik, 20(4), 231-259.

Beck, Ch., \& Maier, H. (1993). Das Interview in der mathematikdidaktischen Forschung. Journal für Mathematik-Didaktik, 14(2), 147-180.

Beck, Ch., \& Maier, H. (1994). Mathematikdidaktik als Textwissenschaft. Zum Status von Texten als Grundlage empirischer mathematikdidaktischer Forschung. Journal für Mathematik-Didaktik, 15(1/2), 35-78.

Becker, G. (1978). Über Hintergrundtheorien geometrischer Schulkurse. Mathematica Didactica, 1(1), 13-20.

Bender, P. (2005). PISA, Kompetenzstufen und Mathematik-Didaktik. Journal für MathematikDidaktik, 26(3), 274-281.

Bigalke, H.-G. (1974). Sinn und Bedeutung der Mathematikdidaktik. ZDM, 6(3), 109-115.

Bigalke, H.-G. (1984). Thesen zur Theoriendiskussion in der Mathematikdidaktik. Journal für Mathematik-Didaktik, 5(3), 133-165.

Bikner-Ahsbahs, A. (2009). Networking of theories-Why and how? Special plenary lecture. In V. Durand-Guerrier, S. Soury-Lavergne, \& S. Lecluse (Eds.), Proceedings of CERME 6, Lyon, France. http://www.inrp.fr/publications/edition-electronique/cerme6/plenary-01-bikner. pdf. Accessed: July 23, 2010.

Bikner-Ahsbahs, A. (2016). Networking of theories in the tradition of TME. In A. Bikner-Ahsbahs, A. Vohns, R. Bruder, O. Schmitt, \& W. Dörfler (Eds.), Theories in and of mathematics education. ICME-13 Topical Surveys (pp. 33-42). Switzerland: SpringerOpen.

Bikner-Ahsbahs, A., \& Kidron, I. (2015). A cross-methodology for the networking of theories: The general epistemic need (GEN) as a new concept at the boundary of two theories. In A. BiknerAhsbahs, Ch. Knipping, \& N. Presmeg (Eds.), Approaches to qualitative methods in mathematics education-Examples of methodology and methods (pp. 233-250). New York: Springer.

Bikner-Ahsbahs, A., \& Prediger, S. (2010). Networking of theories-An approach for exploiting the diversity of theoretical approaches; with a preface by T. Dreyfus and a commentary by F. Arzarello. In B. Sriraman, \& L. English (Eds.), Theories of mathematics education: Seeking new frontiers (Vol. 1, pp. 479-512). New York: Springer.

Bikner-Ahsbahs, A., Prediger, S., \& The Networking Theories Group (Eds.). (2014). Networking of theories as a research practice in mathematics education. New York: Springer.

Bikner-Ahsbahs, A., \& Vohns, A. (2016). Theories in mathematics education as a scientific discipline. In A. Bikner-Ahsbahs, A. Vohns, R. Bruder, O. Schmitt, \& W. Dörfler (Eds.), Theories in and of mathematics education. ICME-13 Topical Surveys (pp. 3-11). Switzerland: SpringerOpen. 
Bikner-Ahsbahs, A., Bakker, A., Haspekian, M., \& Maracci, M. (2017). Introduction to the thematic working group 17 on theoretical perspectives in mathematics education research. In T. Dooley \& G. Gueudet (Eds.), Proceedings of the Tenth Congress of the European Society for Research in Mathematics Education (CERME10, February 1-5, 2017) (pp. 2683-2690). Dublin, Ireland: DCU Institute of Education and ERME Dublin (Ireland). http://www.mathematik.uni-dortmund. de/ prediger/ERME/CERME10_Proceedings_2017.pdf. Accessed: May 2, 2018.

Bikner-Ahsbahs, A., Vohns, A., Bruder, R., Schmitt, O., \& Dörfler, W. (Eds.). (2016). Theories in and of mathematics education. ICME-13 Topical Surveys (pp. 3-11). Switzerland: SpringerOpen.

Brandt, B., \& Krummheuer, G. (2000). Das Prinzip der Komparation im Rahmen der Interpretativen Unterrichtsforschung in der Mathematikdidaktik. Journal für Mathematik-Didaktik, 21(23/4), 193-226.

Bruder, R. (2010). Lernaufgaben im Mathematikunterricht. In H. Kiper, W. Meints, S. Peters, S. Schlump, \& S. Schmit (Eds.), Lernaufgaben und Lernmaterialien im kompetenzorientierten Unterricht (pp. 114-124). Stuttgart: W. Kohlhammer Verlag.

Bruder, R., \& Brückner, A. (1989). Zur Beschreibung von Schülertätigkeiten im Mathematikunterricht - ein allgemeiner Ansatz. Pädagogische Forschung, 30(6), 72-82.

Bruder, R., \& Collet, C. (2011). Problemlösen lernen im Mathematikunterricht. Berlin: Cornelsen Scriptor.

Bruder, R., \& Schmitt, O. (2016). Joachim Lompscher and his activity theory approach focusing on the concept of learning activity and how it influences contemporary research in Germany. In A. Bikner-Ahsbahs, A. Vohns, R. Bruder, O. Schmitt, \& W. Dörfler (Eds.), Theories in and of mathematics education. ICME-13 Topical Surveys (pp. 13-20). Switzerland: SpringerOpen.

Bruder, R., Krüger, U.-H., \& Bergmann, L. (2003). LEMAMOP - ein Kompetenzentwicklungsmodell für Argumentieren, Modellieren und Problemlösen wird umgesetzt. https://eldorado.tudortmund.de/bitstream/2003/33436/1/BzMU14-4ES-Bruder-191.pdf. Accessed: April 28, 2017.

Büchter, A., \& Pallack, A. (2012). Methodische Überlegungen und empirische Analysen zur impliziten Standardsetzung durch zentrale Prüfungen. Journal für Mathematik-Didaktik, 33(1), 59-85.

Burscheid, H. J. (1983). Formen der wissenschaftlichen Organisation in der Mathematikdidaktik. Journal für Mathematik-Didaktik, 3, 219-240.

Collet, C., \& Bruder, R. (2008). Longterm-study of an intervention in the learning of problemsolving in connection with self-regulation. In O. Figueras, J L. Cortina, S. Alatorre, T. Rojano, \& A. Sepúlveda (Eds.), Proceedings of the Joint Meeting of PME 32 and PME-NA XXX (Vol. 2, pp. 353-360). Morelia: Cinvestav-UMSNH.

Davydov, V. V. (1990). Types of generalization in instruction: Logical and psychological problems in the structuring of school curricula. Soviet studies in mathematics education (Vol. 2). Reston, VA: National Council of Teachers of Mathematics.

Dörfler, W. (2004). Diagrams as means and objects of mathematical reasoning. In H.-G. Weigand (Ed.), Developments in mathematics education in German-Speaking countries. Selected Papers from the Annual Conference on Didactics of Mathematics 2001 (pp. 39-49). Hildesheim: Verlag Franzbecker.

Dörfler, W. (2006). Diagramme und Mathematikunterricht. Journal für Mathematik-Didaktik, 27(3/4), 200-219.

Dörfler, W. (2008). Mathematical reasoning: Mental activity or practice with diagrams. In M. Niss (Ed.), ICME 10 Proceedings, Regular Lectures, CD-Rom. Roskilde: IMFUFA, Roskilde University.

Dörfler, W. (2013a). Bedeutung und das Operieren mit Zeichen. In M. Meyer, E. Müller-Hill, \& I. Witzke (Eds.), Wissenschaftlichkeit und Theorieentwicklung in der Mathematikdidaktik (pp. 165-182). Hildesheim: Franzbecker.

Dörfler, W. (2013b). Impressionen aus (fast) vier Jahrzehnten Mathematikdidaktik. Mitteilungen der Gesellschaft für Didaktik der Mathematik, 95, 8-14. 
Dörfler, W. (2016). Signs and their use: Peirce and Wittgenstein. In A. Bikner-Ahsbahs, A. Vohns, R. Bruder, O. Schmitt, \& W. Dörfler (Eds.), Theories in and of mathematics education. ICME-13 Topical Survey (pp. 21-31). Switzerland: SpringerOpen.

Dreyfus, T. (2009). Ways of working with different theoretical approaches in mathematics education research: An introduction. In V. Durand-Guerrier, S. Soury-Lavergne, \& S. Lecluse (Eds.), Proceedings of CERME 6, Lyon, France. http://www.inrp.fr/publications/edition-electronique/ cerme6/plenary-01-bikner.pdf. Accessed: March 18, 2016.

Fischer, R. (1983). Wie groß ist die Gefahr, daß die Mathematikdidaktik bald so ist wie die Physik? - Bemerkungen zu einem Aufsatz von Hans Joachim Burscheid. Journal für MathematikDidaktik, 3, 241-253.

Fischer, R. (2005). An interview with Michael Otte. In M. Hoffmann, J. Lenhart, \& F. Seeger (Eds.), Activity and sign. Grounding mathematics education (pp. 361-378). New York: Springer Science + Business Media.

Freudenthal, H. (1974). Sinn und Bedeutung der Didaktik der Mathematik. ZDM Mathematics Education, 6(3), 122-124.

Giest, H., \& Lompscher, J. (2006). Lerntätigkeit - Lernen aus kultur-historischer Perspektive. Ein Beitrag zur Entwicklung einer neuen Lernkultur im Unterricht. In H. Giest \& G. Rückriem (Eds.), International Cultural-historical Human Sciences (ICHS), Band 15. Berlin: Lehmanns Media.

Griesel, H. (1974). Überlegungen zur Didaktik der Mathematik als Wissenschaft. ZDM Mathematics Education, 6(3), 115-119.

Griesel, H. (2001). Scientific orientation of mathematical instruction-History and chance of a guiding principle in East and West Germany. In H.-G. Weigand (Ed.), Developments in mathematics education in Germany. Selected papers from the Annual Conference on Didactics of Mathematics Leipzig, 1997 (pp. 75-83). Hildesheim: Franzbecker.

Hasan, H. \& Kazlauskas, A. (2014). Activity theory: Who is doing what, why and how. In H. Hasan (Ed.), Being practical with theory: A window into business research (pp. 9-14). Wollongong, Australia: THEORI. http://eurekaconnection.files.wordpress.com/2014/02/p-09-14-activity-theorytheori-ebook-2014.pdf. Accessed: May 5, 2017.

Hoffmann, M. H.-G. (2001). Skizze einer semiotischen Theorie des Lernens. Journal für Mathematik-Didaktik, 22(3/4), 231-251.

Hoffmann, M. H.-G. (2005). Erkenntnisentwicklung. Ein semiotischer-pragmatischer Ansatz. Frankfurt a. M.: Klostermann.

Jahnke, H. N. (1978). Zum Verhältnis von Wissensentwicklung und Begründung in der Mathematik - Beweisen als didaktisches Problem. Bielefeld: Universität Bielefeld.

Jungwirth, H. (1994). Die Forschung zu Frauen und Mathematik: Versuch einer Paradigmenklärung. Journal für Mathematik-Didaktik, 15(3/4), 253-276.

Kaiser, G. (2000). Internationale Vergleichsuntersuchungen - eine Auseinandersetzung mit ihren Möglichkeiten und Grenzen. Journal für Mathematik-Didaktik, 21(3/4), 171-192.

Kaiser. (Ed.) (2003). Qualitative empirical methods in mathematics education-Discussions and reflections. Zentralblatt für Didaktik der Mathematik, 35 (5 and 6).

Kidron, I., \& Monaghan, J. (2012). Complexity of dialogue between theories: Difficulties and benefits. In Pre-proceedings of the 12th International Congress on Mathematical Education. Paper presented in the Topic Study Group 37. (pp. 7078-7084). COEX, Seoul (Korea): ICME.

Kidron, I., Artigue, M., Bosch, M., Dreyfus, T, \& Haspekian, M. (2014). Context, milieu and mediamilieus dialectic: A case study on networking of AiC, TDS, and ATD. In A. Bikner-Ahsbahs, S. Prediger (Eds.) \& The Networking Theories Group, Networking of theories as a research practice in mathematics education (pp. 153-177). New York: Springer.

Kirsch, A. (2000). Aspects of simplification in mathematics teaching. In I. Westbury, S. Hopmann, \& K. Riquarts (Eds.), Teaching as a reflective practice-The German didactic tradition (pp. 267-284). Mahwah: Lawrence Erlbaum Associates. (Reprinted from: Proceedings of the third international congress on mathematical education (pp. 98-120), by H. Athen, \& H. Kunle (Eds.), 1977, Karlsruhe: Zentralblatt für Didaktik der Mathematik. 
KMK - Kultusministerkonferenz der Länder. (1964/71). Abkommen zwischen den Ländern der Bundesrepublik zur Vereinheitlichung auf dem Gebiete des Schulwesens. Beschluss der KMK vom 28.10.1964 in der Fassung vom 14.10.1971. http://www.kmk.org/fileadmin/Dateien/ veroeffentlichungen_beschluesse/1964/1964_10_28-Hamburger_Abkommen.pdf. Accessed: 10 March 2016.

Knoche, N., \& Lind, D. (2000). Eine Analyse der Aussagen und Interpretationen von TIMSS unter Betonung methodologischer Aspekte. Journal für Mathematik-Didaktik, 21(1), 3-27.

Knoche, N., Lind, D., Blum, W., Cohors-Fresenborg, E., Flade, L., Löding, W., et al. (2002). (Deutsche PISA-Expertengruppe Mathematik, PISA-2000) Die PISA-2000-Studie, einige Ergebnisse und Analysen. Journal für Mathematik-Didaktik, 23(3), 159-202.

Krause, C. M. (2016). The mathematics in our hands: How gestures contribute to constructing mathematical knowledge. Wiesbaden, Germany: Springer Spektrum.

Kuhn, T. S. (1970). The structure of scientific revolutions (2nd ed.). Chicago: University of Chicago Press.

Leuders, T. (2014). Modellierungen mathematischer Kompetenzen - Kriterien für eine Validitätsprüfung aus fachdidaktischer Sicht. Journal für Mathematik-Didaktik, 35(1), 7-48.

Lompscher, J. (1985a). Die Lerntätigkeit als dominierende Tätigkeit des jüngeren Schulkindes. In J. Lompscher, L. Irrlitz, W. Jantos, E. Köster, H. Kühn, G. Matthes, \& G. Witzlack (Eds.), Persönlichkeitsentwicklung in der Lerntätigkeit (pp. 23-52). Ein Lehrbuch für die pädagogische Psychologie an Instituten für Lehrerbildung. Berlin: Volk und Wissen.

Lompscher, J. (1985b). Die Ausbildung von Lernhandlungen. In J. Lompscher, L. Irrlitz, W. Jantos, E. Köster, H. Kühn, G. Matthes, \& G. Witzlack (Eds.), Persönlichkeitsentwicklung in der Lerntätigkeit (pp. 53-78). Ein Lehrbuch für die pädagogische Psychologie an Instituten für Lehrerbildung. Berlin: Volk und Wissen.

Lompscher, J. (1989a). Aktuelle Probleme der pädagogisch-psychologischen Analyse der Lerntätigkeit. In Psychologische Analysen der Lerntätigkeit. Beiträge zur Psychologie. In J. Lompscher, G. Hinz, W. Jantos, B. Jülisch, L. Komarowa, I.-P. Scheibe, \& C. Wagner (Eds.), Psychologische Analyse der Lerntätigkeit. Beiträge zur Psychologie (pp. 21-50). Berlin: Volk und Wissen, Volkseigener Verlag.

Lompscher, J. (1989b). Lehrstrategie des Aufsteigens vom Abstrakten zum Konkreten. In J. Lompscher, G. Hinz, W. Jantos, B. Jülisch, L. Komarowa, I.-P. Scheibe, \& C. Wagner (Eds.), Psychologische Analyse der Lerntätigkeit. Beiträge zur Psychologie (pp. 51-90). Berlin: Volk und Wissen, Volkseigener Verlag.

Lompscher, J. (2006). Tätigkeit. Lerntätigkeit. Lehrstrategie. Theorie der Lerntätigkeit und ihre empirische Erforschung. In H. Giest \& G. Rückriem (Eds.), International Cultural-Historical Human Sciences (ICHS), Band 19. Berlin: Lehmanns Media.

Maier, H. (1998). „Erklären“: Ziel mathematikdidaktischer Forschung? Journal für MathematikDidaktik, 18(2/3), 239-241.

Maier, H., \& Beck, Ch. (2001). Zur Theoriebildung in der Interpretativen mathematikdidaktischen Forschung. Journal für Mathematik-Didaktik, 22(1), 29-50.

Maier, H., \& Steinbring, H. (1998). Begriffsbildung im alltäglichen Mathematikunterricht - Darstellung und Vergleich zweier Theorieansätze zur Analyse von Verstehensprozessen. Journal für Mathematik-Didaktik, 19(4), 292-330.

Masterman, M. (1970). The nature of a paradigm. In I.-A. Lakatos \& A. Musgrave (Eds.), Criticism and the growth of knowledge. Proceedings of the International Colloquium in the Philosophy of Science, London, 1965 (pp. 59-90). London: Cambridge U.P.

Masterman, M. (1974). Die Natur des Paradigmas. In I.-A. Lakatos \& A. Musgrave (Eds.), Kritik und Erkenntnisfortschritt (pp. 59-88). Braunschweig: Vieweg \& Sohn.

Meyerhöfer, W. (2004). Zum Kompetenzstufenmodell von PISA. Journal für Mathematik-Didaktik, 25(3/4), 294-305.

Müller, G. N., \& Wittmann, E. (1984). Der Mathematikunterricht in der Primarstufe: Ziele. Inhalte. Prinzipien. Beispiele (3rd ed.). Wiesbaden: Vieweg + Teubner. 
Nitsch, R. (2015). Diagnose von Lernschwierigkeiten im Bereich funktionaler Zusammenhänge. Wiesbaden: Springer Spektrum.

Nöth, W. (2000). Handbuch der Semiotik. Stuttgart und Weimar: Metzler.

Otte, M. (1974). Didaktik der Mathematik als Wissenschaft. Zentralblatt für Didaktik der Mathematik (ZDM), 6(3), 125-128.

Otte, M. (1997). Mathematik und Verallgemeinerung - Peirce' semiotisch-pragmatische Sicht. Philosophia naturalis, 34(2), 175-222.

Peirce, C. S. (1931-1958). Collected papers (Vol. I-VIII). Cambridge: Harvard University Press.

Prediger, S., Bikner-Ahsbahs, A., \& Arzarello, F. (2008). Networking strategies and methods for connecting theoretical approaches-First steps towards a conceptual framework. ZDM-The International Journal on Mathematics Education, 40(2), 165-178.

Prediger, S., Bosch, M., Kidron, I., Monaghan, J., \& Sensevy, G. (2010) Different theoretical perspectives and approaches in mathematics education research-Strategies and difficulties when connecting theories. In V. Durand-Guerrier, S. Soury-Lavergne, \& F. Arzarello Lecluse (Eds.), Proceedings of the 6th Congress of the European Society for Research in Mathematics Education (pp. 1529-1544). Lyon: Institut national de recherche pédagogique.

Sabena, C., Arzarello, A., Bikner-Ahsbahs, A., \& Schäfer, I. (2014). The epistemological gap-A case study on networking of APC and IDS. In A. Bikner-Ahsbahs, S. Prediger (Eds.) \& The Networking Theories Group, Networking of theories as a research practice in mathematics education (pp. 165-183). New York: Springer.

Schreiber, C. (2006). Die Peirce'sche Zeichentriade zur Analyse mathematischer ChatKommunikation. Journal für Mathematik-Didaktik, 27(3/4), 240-264.

Shinno, Y. (2017). Meta-theoretical aspects of the two case studies of networking theoretical perspectives: Focusing on the treatments of theoretical terms in different networking strategies. In T. Dooley \& G. Gueudet (Eds.), Proceedings of the Tenth Congress of the European Society for Research in Mathematics Education (CERME10, February 1-5, 2017) (pp. 2670-2571). Dublin, Ireland: DCU Institute of Education and ERME Dublin (Ireland). http://www.mathematik.unidortmund.de/ prediger/ERME/CERME10_Proceedings_2017.pdf. Accessed: May 2, 2018.

Steinbring, H. (1998). Mathematikdidaktik: Die Erforschung theoretischen Wissens in sozialen Kontexten des Lernens und Lehrens. Zentralblatt für Didaktik der Mathematik (ZDM), 30(5), 161-167.

Steinbring, H. (2011). Changed views on mathematical knowledge in the course of didactical theory development: Independent corpus of scientific knowledge or result of social constructions? In T. Rowland \& K. Ruthven (Eds.), Mathematical knowledge in teaching (pp. 43-64). New York: Springer.

Steiner, H.-G. (1983). Zur Diskussion um den Wissenschaftscharakter der Mathematikdidaktik. Journal für Mathematik-Didaktik, 3, 245-251.

Steiner, H.-G. (1984). Topic areas: Theory of mathematics education. In M. Carss (Ed.), Proceedings of the Fifth International Congress on Mathematics Education (pp. 293-298). Boston, Basel, Stuttgart: Birkhäuser.

Steiner, H.-G. (1985). Theory of mathematics education (TME): An introduction. For the Learning of Mathematics, 5(2), 11-17.

Steiner, H.-G. (1986). Topic areas: Theory of mathematics education (TME). In M. Carss (Ed.), Proceedings of the Fifth International Congress on Mathematical Education (pp. 293-299). Boston, Basel, Stuttgart: Birkhäuser.

Steiner, H.-G. (1987a). A systems approach to mathematics education. Journal for Research in Mathematics Education, 18(1), 46-52.

Steiner, H.-G. (1987b). Philosophical and epistemological aspects of mathematics and their intersection with theory and practice in mathematics education. For the Learning of Mathematics, $7(1), 7-13$.

Steiner, H.-G. (1987c). Implication for scholarship of a theory of mathematics education. Zentralblatt der Didaktik der Mathematik, Informationen, 8(4), 162-167. 
Steiner, H. G., Balacheff, N., Mason, J., Steinbring, H., Steffe, L. P., Cooney, T. J., \& Christiansen, B. (1984). Theory of mathematics education (TME). ICME 5-Topic Area and Mini-conference. Occasional Paper 54, Arbeiten aus dem Institut für Didaktik der Mathematik der Universität Bielefeld. Bielefeld: IDM. http://www.uni-bielefeld.de/idm/serv/dokubib/occ54.pdf. Accessed: April 8, 2016.

Tabach, M., Rasmussen, C., Dreyfus, T., \& Hershkowitz, R. (2017). Abstraction in context and documenting collective activity. In T. Dooley \& G. Gueudet (Eds.), Proceedings of the Tenth Congress of the European Society for Research in Mathematics Education (CERME10, February 1-5, 2017) (pp 2692-2699). Dublin, Ireland: DCU Institute of Education and ERME Dublin (Ireland): http://www.mathematik.uni-dortmund.de/ prediger/ERME/CERME10_Proceedings_ 2017.pdf. Accessed: May 2, 2018.

Toepell, M. (2004). Zur Gründung und Entwicklung der Gesellschaft für Didaktik der Mathematik (GDM). Mitteilungen der Gesellschaft für Didaktik der Mathematik, 30(78), 147-152.

Vohns, A. (2012). Zur Rekonstruierbarkeit impliziter Standardsetzungen zentraler Prüfungen mit Hilfe des Rasch-Modells. Journal für Mathematik-Didaktik, 33(2), 339-349.

Walsch, W. (2003). Methodik des Mathematikunterrichts als Lehr- und Wissenschaftsdisziplin. Zentralblatt für Didaktik der Mathematik (ZDM), 35(4), 153-156.

Weigand, H.-G. (1995). Interpretatives oder normatives Paradigma? - Anmerkungen zum Artikel von Chr. Beck u. H. Maier: Das Interview in der mathematikdidaktischen Forschung, JMD, 14 (1993), H. 2, S. 147-179. Journal für Mathematik-Didaktik, 16(1), 145-148.

Wellenreuther, M. (1997). Hypothesenbildung, Theorieentwicklung und Erkenntnisfortschritt in der Mathematikdidaktik: Ein Plädoyer für Methodenvielfalt. Journal für Mathematik-Didaktik, $18(2 / 3), 186-216$.

Wittgenstein, L. (1999). Bemerkungen über die Grundlagen der Mathematik. Werkausgabe Vol. 6. Frankfurt: Suhrkamp.

Wittmann, E. Chr. (1974). Didaktik der Mathematik als Ingenieurwissenschaft. Zentralblatt für Didaktik der Mathematik (ZDM), 6(3), 119-121.

Wittmann, E. C. (1995). Mathematics education as a 'design science'. Educational Studies in Mathematics, 29(4), 355-374.

Wuttke, J. (2014). Rasch-Modell, suffiziente Statistik, Transformationsgruppen und Methodenkritik: Anmerkungen zu Büchter \& Pallack (2012/13) und Vohns (2012). Journal für MathematikDidaktik, 35(2), 283-293.

\section{List of References for Further Reading}

Batanero, M. C., Godino, J. D., Steiner, H. G., \& Wenzelburger, E. (1992). An international TME survey: Preparation of researchers in mathematics education. Occasional Paper 135, Arbeiten aus dem Institut für Didaktik der Mathematik der Universität Bielefeld. Bielefeld: IDM.

Giest, H., \& Lompscher, J. (2003). Formation of learning activity and theoretical thinking in science teaching. In A. Kozulin, B. Gindis, V. S. Ageyev, \& S. M. Miller (Eds.), Vygotsky's educational theory in cultural context (pp. 267-288). Cambridge: Cambridge University Press.

Lompscher, J. (1999a). Activity formation as an alternative strategy of instruction. In Y. Engeström, R. Miettinen, \& R.-L. Punamäki (Eds.), Perspectives on activity theory (pp. 264-281). Cambridge: Cambridge University Press.

Lompscher, J. (1999b). Learning activity and its formation: Ascending from the abstract to the concrete. In M. Hedegaard \& J. Lompscher (Eds.), Learning activity theory (pp. 139-166). Aarhus: Aarhus University Press.

Lompscher, J. (2002). The category of activity-A principal constituent of cultural-historical psychology. In D. Robbins \& A. Stetsenko (Eds.), Vygotsky's psychology: Voices from the past and present (pp. 79-99). New York: Nova Science Press. 
Mühlhölzer, F. (2010). Braucht die Mathematik eine Grundlegung? Ein Kommentar des Teil III von Wittgensteins Bemerkungen über die Grundlagen der Mathematik. Frankfurt: Vittorio Klostermann.

Steiner, H.-G., \& Vermandel, A. (Eds.). (1988). Foundations and methodology of the discipline mathematics education. Didactics of mathematics. Proceedings of the second TME-conference. Antwerp: University of Antwerp.

Vermandel, A. (1988). Theory of mathematics education. Proceedings of the third international conference. Antwerp: University of Antwerp.

Open Access This chapter is licensed under the terms of the Creative Commons Attribution 4.0 International License (http://creativecommons.org/licenses/by/4.0/), which permits use, sharing, adaptation, distribution and reproduction in any medium or format, as long as you give appropriate credit to the original author(s) and the source, provide a link to the Creative Commons licence and indicate if changes were made.

The images or other third party material in this chapter are included in the chapter's Creative Commons licence, unless indicated otherwise in a credit line to the material. If material is not included in the chapter's Creative Commons licence and your intended use is not permitted by statutory regulation or exceeds the permitted use, you will need to obtain permission directly from the copyright holder. 


\title{
Chapter 8 \\ Classroom Studies-Sociological Perspectives
}

\author{
Uwe Gellert and Götz Krummheuer
}

\begin{abstract}
The specific aspects of Classroom Studies, as a focus within the German Speaking Traditions in Mathematics Education Research, rest on the fundamental sociological orientation on mathematics lessons. Initiated by the works of Heinrich Bauersfeld, the first sociological perspective unfolds its power of description by reconstructing social processes regarding the negotiation of meaning and the social constitution of shared knowledge through collective argumentation in the daily practice of mathematic lessons. A second sociological perspective aims at the reconstruction of the conditions and the structure surrounding the construction of performance and success in mathematics lessons.
\end{abstract}

Keywords Access $\cdot$ Argumentation $\cdot$ Interpretative studies $\cdot$ Negotiation of meaning $\cdot$ Participation $\cdot$ Performance

\subsection{Introduction}

The specificity of classroom studies as a focus within the German-speaking traditions in mathematics education research is due to the fundamental sociological orientation of the view into mathematics teaching and learning. Two sociological points of view are distinguished: (a) the constituents and effects of learning in mathematics classroom activities; and (b) the effects and constituents of stratification in mathematics teaching and learning. We do not attempt to provide an inclusive overview of classroom studies in German-speaking countries, but rather point out the special nature of the sociology-based tradition.

\footnotetext{
U. Gellert $(\varangle)$

Freie Universität Berlin, Berlin, Germany

e-mail: ugellert@zedat.fu-berlin.de

G. Krummheuer

Goethe University Frankfurt, Frankfurt, Germany

e-mail: krummheuer@math.uni-frankfurt.de 
(a) Initiated by the work of Heinrich Bauersfeld, the first sociological perspective unfolds a considerable descriptive power in the reconstruction of social processes of the negotiation of meaning and the social constitution of takenas-shared knowledge. The modus operandi here is collective argumentation in the everyday practice of mathematics teaching and learning. With respect to the sociological reference to Symbolic Interactionism, Conversation Analysis and Ethnomethodology, a microsociology of the teaching and learning of mathematics in school is constructed. In the first section, Götz Krummheuer reports on "Interpretative Classroom Research: Origins, Insights, Developments".

(b) The second sociological perspective aims at reconstructing the conditions and structures of the construction of achievement and success in mathematics education. In this respect, the mechanisms of interaction and their (often indirect) social effects are the focus of attention. In doing this, the microsociology of the teaching and learning of mathematics in school is systematically related to meso-sociological and macro-sociological, institutional and societal structures. For this purpose, theories of the sociology of education serve as a central reference. In the second section, Uwe Gellert describes "Classroom Research as Part of the Social-Political Agenda".

\subsection{Interpretative Classroom Research: Origins, Insights, Developments}

\subsubsection{Introduction ${ }^{1}$}

The process of the development of an interactional theory of learning mathematics reaches back to the years between 1970 and 1980. In these years, the foundations were laid for the basic concepts for a theory of interaction of mathematics learning and teaching in the work group around Heinrich Bauersfeld at the IDM of the University of Bielefeld (Krummheuer and Voigt 1991). This theoretical approach was further expanded (Jungwirth and Krummheuer 2008) and in time efforts were undertaken to make these concepts and the typical way of thinking behind this approach known

\footnotetext{
${ }^{1}$ As the sole author, I alone am responsible for this part of the paper. However, without the intensive work with other colleagues, the presented results would not be possible. I would like to especially mention:

- At the Purdue University in West-Lafayette, Indiana USA: Terry Wood, Erna Yackel und Paul Cobb, and in Germany,

- at the Institute for Didactic of Mathematics at the University of Bielefeld: Heinrich Bauersfeld and Jörg Voigt,

- at the Free University Berlin: Natascha Naujok, Birgit Brandt and Uwe Gellert, and

- at the Goethe University Frankfurt am Main: Marei Fetzer, Christof Schreiber, Marcus Schütte, Anne Fellmann, Anne Vogler, Ergi Acar Bayraktar, Melani Beck, as well as my colleagues Birgit Brandt, Helga Jungwirth and Rose Vogel.
} 
to practicing teachers (Fellmann 2014; Fetzer and Krummheuer 2007; Krummheuer and Fetzer 2005). The theory development as well as the endeavour to make the results available to teachers were usually funded by grants, for example the German Science Foundation. Most of the projects deal with mathematics teaching in grade school. More recent projects involve also preschool as well as familial settings.

In the following the development of the theory (Sect. 8.2.2), its practical relevance (Sect. 8.2.3) and the practice of research (Sect. 8.2.4) are described. Due to space constraints, the methodological foundation of this approach is not outlined. This is unfortunate in so far as its name "interpretative classroom research" refers to its usual methodological classification. It should be mentioned that there are more approaches that apply interpretative methods. Usually, their theoretical perspective is not a genuine sociological one as in Steinbring's epistemological work or in the research of the group around Nührenbörger (Schwarzkopf et al. 2018; Steinbring 2005).

\subsubsection{Theory}

The theoretical approach that is referred to here as interactionist is based on three basic assumptions:

1. The subject matter to be learned as well as the learning conditions that are necessary for its acquisition are situationally bound in interactive exchange between the participants in the process of the negotiation of meaning.

2. The constitutive social condition of the possibility of learning of a mathematical content, term or procedure is the participation in a process of collective argumentation concerning the content, terms or other procedures.

3. The indication of a successful process of learning of a pupil is the increased autonomous participation in such collective argumentation in the process of a current interaction and/or in the following interaction that is thematically imbedded in the actual situation.

In the following these three points are outlined in more detail.

\subsubsection{Emergent Interactional Processes: Negotiation of Meaning and Conditions of Learning}

Basically, this approach refers to symbolic interactionism and ethnomethodology. Below a twofold hypothesis is stated, whereby the first one represents the other reason why this approach is interpretative.

In the sequence of interaction during a process of teaching, a situational meaning of the content at stake is negotiated by acts of speech and accompanying actions and is based on processes of interpretation conducted by the participants. Thus, one can differentiate between the intended content as exemplarily presented in the teaching material and the 
situationally emerging themes as they emerge by the process of negotiation (Krummheuer 1995; Krummheuer and Brandt 2001).

The cognitive processes of the pupils refer to these interactively produced and situationally bound themes and not to the provided mathematical content.

Through previous experiences in similar processes of negotiation, often the interpretations by the participants are routinized and standardized. Alluding to Goffman (1974) Krummheuer calls these ways of interpretation "framing". These are structured individual processes of interpreting that through adjustment to previous processes of negotiation have found a certain routine in their recall as well as a certain standardization in their use (Krummheuer 1995, 2007).

On the interactive level, routinized processes of negotiation have been reconstructed above all in teacher guided situations. Voigt (1995) introduces the terms of "pattern of interaction" and "thematic procedures" for these phenomena. He understands here a specific, thematically focused rule in the process of interaction. It is essential for him that these patterns refer to the process of negotiation and thus contain a subject matter component. This distinguishes his definition from those which do not concern themselves with interaction structures that are content-bound, as for example (Mehan 1979) with his interaction pattern ,initiation-reply-evaluation“ (p. 54). Furthermore, Voigt's work refers to Bauersfeld's concept of the „funnel pattern" (1980). In his later research this led him to speak of "thematic procedures", a more exact terminology. In the Sect. 8.3.2.2 the concept of pattern of interaction will be mentioned again.

Beside this empirical research on teacher-guided instruction, several studies have dealt with interaction processes in group work of pupils in mathematics classes. Naujok (2000) reconstructs work phases of different types of cooperation, such as helping, collaborating and parallel forms of work. Lange (2013) was able to reconstruct further types of cooperation in a study on the processes of problem solving in mathematics group work in the secondary school. Krummheuer and Brandt (2001) differentiate in groups of pupils between "stable, collective work processes" and the "parallel handling of problems" (pp. 66ff).

In considering the mathematical aspects in the attempts at theory building, the following two characteristics have been more exactly examined in corresponding empirical studies:

(a) the dependency on language

(b) the specific inscriptionality of mathematics and mathematics education

Here a short discussion of these two points:

(a) With reference to the dependency on language that distinguishes itself among others through a specificity of the subject matter, Bauersfeld (1995) speaks of "language games" in allusion to Wittgenstein (1963). Here Bauersfeld expresses the idea that the language in the mathematics teaching interaction is characterized by specific forms, ways of expression and means of dealing with each other that, taken together, build "a culture of a mathematical classroom" (ibid., p. 282). 
A similar idea is expressed in the term ,mathematics discourse“ (Moschkovich 2007; Sfard 2008).

Schütte (2009) states the following hypothesis about this classroom culture based on his socio-linguistic oriented analysis of mathematics teaching: In the introductory situations in mathematics classrooms the mathematics contents that are to be learned are often presented in oral everyday language, while the later required achievement tests in the class and written papers are conducted in a formal subject-matter language of mathematics and mathematics education which most of the pupils do not have at their disposal (p. 195). This everyday classroom practice follows an "implicit pedagogy" (p. 196) in which pupils learn the contents that are to be negotiated more on the basis of their out-of-school mathematics and language competencies rather than through a mathematics specific language game developed in the interaction of the classroom. These linguistic and the above-mentioned frame analyses both point to the qualitative difference in the use of language and the habits of interpretation between the teacher and the mathematically more competent pupils. Conversely, other pupils interpret with everyday language the happenings in the classroom by a way of framing that is not appropriately adapted to the treated mathematics contents. Krummheuer (1995) characterizes such phenomena as "framing differences".

(b) Besides the special mathematics language, other specific graphic signs and/or symbols are used in mathematics lessons that can be communicated only in a written or drawn form. These place special demands on the interactive negotiation of meaning in mathematics lessons. It should be remembered that also from a perspective of mathematics education, even more inscriptional elements flow into the teaching interaction in form of learning materials and visual aids. Fetzer (2003a, b) studies these specific content and didactically motivated inscriptions in mathematics classes. For her analyses, she refers to the model of a twodimensionality framework of orality and literacy from Koch and Oesterreicher (Oesterreicher 1997). It is important to mention that the inscriptional elaborations of the pupils are a blending of their current mathematical ideas and their anticipated expectations about what effect their publication might have on the class. Hereby, a second level enters the processes of negotiation. Fetzer speaks here of a "double interactionism" of mathematics teaching processes (2003a, p. 86).

Schreiber (2004) adapts the semiotics approach of Peirce (1978) in order to theoretically encompass the inscription aspects of mathematics interaction. Thus, an alternative semiotic-oriented understanding of the inscriptional processes in mathematics teaching is developed in addition to Fetzer's linguistics-based approach. Schreiber reconstructs semiotic processes that are characterized by a chain of signs and attributed meanings and which within these meanings again becomes signs in a negotiation by interactive turns. With reference to the construction of a term of Presmeg (2002) he speaks here of a "chaining" i.e. of "complex semiotic processes" (Schreiber 2010, p. 40). Further Schreiber takes up Peirce's concept of "diagram" of such semiotic processes: Diagrams are inscriptions, which are constituted by a system of rules concerning their 
generation, use and transformation (Bauersfeld and Seeger 2003; Dörfler 2006; Kadunz 2006; Morgan 1998). Thus, processes of thought do not (only) take place internally in the cognition of the learner; much more these processes can take place also in the external manipulation of diagrams, guided by certain rules and, at the same time, with "reduced speech". Schreiber expands here an up to now mostly non-researched field at the juncture of semiotics and interactionism.

\subsubsection{The Condition of the Possibility of Learning: Collective Argumentation in Formats}

The second premise of the interactionist approach says that the constitutive condition for the possibility of learning of mathematics is the participation in a collective argumentation (see above). In Sect. 8.3.2.1 the term argumentation is dealt with. Then in Sect. 8.3.2.2 the learning theoretical content of this premise is explained.

\section{The Concept of Argumentation}

The mathematics discourse among mathematicians is distinguished by a specific "accounting practice" (Garfinkel 1967, p. 1) that is determined by strictly logical argumentation as in the mathematical proof as a special form of argumentation. We also speak of mathematics discourse referring to interactions in mathematics classes. Here, the accounting practice might look different, especially if one thinks of grade school, kindergarten and preschool. In general, by an argumentation " $a$ " a process of negotiation is accomplished in such a way, that "a" supports an utterance "b" so that the participants agree with the correctness of " $b$ " (Kopperschmidt 1989). Usually an argument consists of several utterances that assume various functions. Some of them take over the function of summarizing these statements in the current situation that are unequivocally accepted by the members of a group. Toulmin (1969) speaks here of "data". The general idea of an argumentation is that one can refer back from the current utterance (b) to other undoubted statements (a), the data. Then (b) appears as a "conclusion". If necessary, such an inference from (a) to (b) has to be legitimated. Toulmin categorizes such comments as "warrants" (ibid., p. 98). Other utterances have the function of referring to the acceptability of such warrants. Toulmin (1969) calls them "backings". They represent undoubtable basic convictions.

According to Toulmin (1969), "analytic" or "substantial" types of argumentation can be accomplished. To the analytic type of argumentation belongs deduction and thereby the mathematical proof. The information of the backing is transferred to the conclusion. An argument is called "substantial" when the backing does not contain the complete information that is transferred to the conclusion. In them a convincing 
soundness between statements, references to other statements and/or modification of statements is established (ibid., p. 125). ${ }^{2}$

Toulmin (1969) emphasizes in his writing that the term argumentation should not be reserved only for analytic argumentations. Human undertakings are in a much broader sense argumentative, i.e. grounded on rationality. If one accepts Toulmin's differentiation between types of argumentation, one can expect to find (mostly) substantial argumentation already in the mathematics discourse in the preschool and grade school. Exemplarily, two types of substantial argumentation might illustrate this approach: the narrative argumentation (a) and the diagrammatic argumentation (b).

(a) Empirically, it is possible to reconstruct a narrative (substantial) argumentation with reference to early learning process of mathematics above all in arithmetical problem solving situations among preschool and grade school children (Krummheuer 1997). The here asserted narrativity is seen in the typical patterned sequences of action in the interaction. In such an argumentation, the claimed solution of a mathematics problem is placed in relationship to a familiar solving routine, like counting that has been accomplished before. The participation skills in such a "narrative discourse" (Tomasello 2003, p. 244) are grounded on the mastery of processes of basic language acquisition and interactive competences, that usually are developed at the end of the process of language acquisition, that is in the fifth to sixth year (ibid., pp. 266ff).

(b) Typical for mathematics discourse is, as has already been mentioned, the common use of inscriptions. Such inscriptions can be the conventional presentation of numbers in the decimal system, illustrations that are didactically motivated and much more. In view of the mathematics learning processes in preschool and grade school lessons, it can also involve presentations with concrete materials as with wooden blocks, wooden beads, a ten-frame etc. (Krummheuer 2009; Latour and Woolgar 1986; Roth and Mc Ginn 1998; Schreiber 2010). Such notes, sketches, drawings, presentations based on materials etc. are here of interest when they are used for the demonstration, clarification, backing and consolidation in an oral(-vocal) interaction process. The intentional manipulation of diagrams can also assume the function of an argumentation. Van Oers (1997) shows that such inscriptions like diagrams demonstrate not only objects but also interpretations of the situation for the child that is drawing. As such, diagrams as well as the process of their construction are generally connected with verbal talk in a process of a negotiation.

Krummheuer (2013) reconstructs that in the childhood development of mathematics argumentation the relationship between diagrammatic argumentation and narrative argumentation is complex. While at preschool age apparently both types of argumentation are relatively unrelated to each other, narrative types of narration seem to dominate in first grade, at least in the content area of arithmetic. Hereby not necessarily

\footnotetext{
${ }^{2}$ Among others, Toulmin's functional analysis of argumentation is also used by Schwarzkopf (2000) and Meyer (2015).
} 
mathematically elaborate arguments are developed. These narrative argumentations are often bound to counting strategies but express furthermore an adequate level of language development (see above Sect. 8.3.2.1 and Tomasello 2003).

\section{Application in a Theory of Learning Mathematics: The Term "Format of Argumentation"}

As with the reference to Tomasello above, it has been inferred that the acquisition of the mother tongue represents something like a paradigmatic example for any kind of learning- and developmental process. For the successful development of the acquisition of the mother tongue the necessity of a "Language Acquisition Support System" (LASS) is postulated, by which, in combination with the genetically inherited Language Acquisition Device (LAD), it is possible for the child to acquire its mother tongue (Bruner 1983, p. 19). Empirically, Bruner reconstructs specifically structured patterns of interaction which he calls "formats". Formats are similar, structured patterns of interaction in which over time a switch takes place in the roles, allowing and demonstrating the child's increased autonomy in its language performance (ibid., p. 39).

Besides these considerations that have to do more with the structure of an interaction process that makes learning possible. Miller (1987) is concerned with the question which thematic aspects of an interactive negotiation process can be seen as the condition for the possibility of learning. In an almost seemingly inevitable logical conclusion, he emphasizes that this can only be in the form of the "collective argumentation". Collective argumentation represents thereby a specific form of negotiation that allows for the possibility of learning. In such a process of meaningmaking the participating individuals cannot experience a systematic transcendence of their own possibilities for the construction of meaning. Furthermore, it also influences the triggered cognitive processes in two respects:

1. The experienced genesis of a collective argumentation functions as an orientation for the cognitive restructuring of the individual. The orientation is more effective, the more rational and plausible these argumentations are for the individual since it then can anticipate more easily the further development of this argumentation.

2. The negotiated collective argumentation allows also a function of convergence between the different definitions of the situation by the participants so that the developing individual definitions show a better fit to the results of the commonly negotiated meaning. Also here, it is again the mentioned rationality by means of the collective argumentation that allows the fitting of the new individual constructions of meaning (for both points see Krummheuer 2007).

Both of these aspects of the socially constituted conditions for the possibility of learning (format and collective argumentation) are brought together by Krummheuer in the concept of the "format of argumentation" (ibid.). These formats are to be understood as specific, argumentatively shaped thematic procedures supporting the learning of mathematics (see above Sect. 8.3.1). 


\subsubsection{Indicator for Successful Learning: The Increasing Degree of Autonomy in Participation}

Under an interactive perspective learning is not conceptualized exclusively as an inner, cognitive process, but as a process that concomitantly takes place internally in the individual in the sense of a cognitive reconstruction, as well as in the interaction processes in which the individual participates. Cobb and Bauersfeld (1995) argue that these two constituents are complementary to each other and should be treated in analogy to Heisenberg's uncertainty principle: "When the focus is on the individual, the social fades into the background, and vice versa" (p. 8).

The play that is difficult to grasp between individual and social constituents can be described as follows: if the participation on a collective argumentation functions for the mathematical thinking as orientation and convergence, then the success of learning is expressed in an increasingly good fit of the individual definition of the results of the interactively negotiated meaning. On the level of interaction this fit appears as an increase in the activities of the learners in an established format of argumentation throughout several situations of interaction. The fit of the actions and interpretations of the individual can be empirically reconstructed as an increasingly autonomous adoption of steps of action within such a format. Learning can be described as an "improvement" of participation. Sfard (2008) suggests substituting the concept of learning of "learning-as-acquisition" with one of "learning-as-participation" (p. 92).

Lave and Wenger (1991) characterize the beginning of such a process of acquisition as "legitimate peripheral participation (ibid., p. 35). A learning process can then be described on the interactive level as the way from legitimate peripheral participation to full participation (ibid., p. 37). Krummheuer (2011) argues that the typical polyadic interaction during teaching requires a further differentiation of this terminology. Thus, the legitimate peripheral participation can be filled by different recipient statuses. It can, for example, be an accepted listener who is spoken to by full participants or just a listener who is not spoken to. Furthermore, the legitimate peripheral participation can also be understood as a first step toward participation by which the learner attempts to copy partial steps and parts of the vocal remarks of the full participants.

From the interactionist perspective, mathematical learning and the development of mathematical thinking — as mentioned — can be understood as an increasing degree of autonomy in participation on formats of argumentation. This leads to the two following questions:

1. At the interactive level: in which way does the interaction system make it possible for the participants, who in the beginning are still in the status of the legitimate peripheral participation, to adopt a growing degree of participation?

2. At the individual level: in which way does the individual make use of his opportunity to change his status of participation offered to him by the interaction system?

Both questions are interdependent. Brandt (2004) introduces for this the term "Partizipationsspielraum", which can be translated into English as "leeway of participation". It describes under which particular emerging conditions in the interaction 
a person can shape his participation. Such conditions can be limited so that, for example, no other offer of participation exists other than imitating the teacher's actions. If these conditions are more open, then the participants have the chance to construct their participation in different statuses. If it is possible to reconstruct stability and regularity within different situations of interaction with the same participants, as is the case, for example in school classes, then it is possible to describe participatory types of the individual. Brandt summarizes these types with the term of "profiles of participation" ("Partizipationsprofil”, ibid., p. 147).

\subsubsection{Conditions of the Possibility of Mathematics Learning Processes}

Krummheuer and Brandt (2001) developed a multi-dimensional model that describes components for the reconstruction of the conditions of the possibility of learning mathematics in social settings. The above text mentions this model and further discusses new research results. The conditions of the possibility of mathematics learning are dependent on:

- the quality of the development of the theme

- the characteristic of the practice of rationalization (explicitness of the arguments as in Toulmin, emergence of a format of argumentation) and

- the flexibility of the leeway of participation (active and receptive participation).

With this model, more and less optimal conditions of the possibility of learning can be described:

For an improvement of the social conditions of the possibility of learning mathematics, it is necessary that a development of themes is made possible not within inflexible interaction patterns, but that, step by step, the learner can assume flexible roles with varying degrees of originality and responsibility until finally evolving his own responsibility for the production of a complete mathematical argumentation. The process of argumentation that develops should not "flatten", but include the production of argumentative components that are concerned with deeper insights in the legitimacy of a negotiated conclusion of given statements about the claim that is to be justified. This is of great significance for learning through active doing, as well as through recipient participation, for example, in legitimate peripheral participation. If characteristics of structuring of this description are evident, then we call the interaction process a "condensed course of interaction". In the opposite case, we speak of a "smooth course of interaction" (Krummheuer 2007).

The smooth course of interaction is characterized by a minimal amount of energy and conflict potential and refers to passages of interaction that are almost without friction and conflict (see Bauersfeld 2000). The possibilities for learning that emerge here, however, cannot be seen as optimal. The condensed course of interaction presents an improvement of these possibilities. Their processes of interaction are rather filled with more crisis and friction. Formats of argumentation portray an interactive "crisis management" by which, through the production of a certain 
interactively structured collective argumentation, the interaction is foreseeable thus making a cognitive adaptation possible (Krummheuer 2007).

\subsubsection{Summary}

In the above the results of an empirically based development of theories has been presented. They were successively developed in a series of research projects. In the following these results are once more summarized in a short overview.

Holding to the premises of interactionism, the mentioned empirical studies enabled the following insights:

Interactive processes of negotiation represent the starting point for the development of mathematically specific language games, on which the participating pupils become increasingly competent. In these processes of negotiation, the situationallybound thematic development as well as the situationally-bound conditions of the possibility of learning mathematics are accomplished. This condition is the participation in collective argumentation. At least in mathematics lessons in grade school, these arguments are generally of a substantial nature.

- The processes of negotiation are characterized by differences in framing and qualitative differences in the use of language among the participants. These differences can be understood as a constitutive condition for the possibility of learning mathematics.

- Interaction in mathematics classes is characterized by content-relevant patterns of interaction. Teaching outside such patterns is not feasible in the long term.

- Patterns that are supportive of learning are formats of argumentation. In them the differences of framings are constructively taken up and the autonomous acts of the pupils are supported with argumentative means. The learners take part in a process of development from legitimate peripheral participation to a full participation.

Favourable conditions for the learning of mathematic in teaching situations are interaction processes that are characterized by a condensed course of interaction. They are, first of all, characterized by a collective argumentation in which explicit warrants and if necessary also backings of an argument are used. Furthermore, the pupils act in the demanding status of participation, which are seen as intermediary stages toward full participation.

These participatory intermediate stages are filled more or less successfully by the pupils depending on the leeway of participation that emerges and on the profile of participation that was established for them over several situations.

Courses of condensed interaction emerge from a course of smooth interaction and usually fade back in time into a smoother interaction. At least in the empirical studies on which this article is based, permanent courses of condensed interaction could not be constructed as processes of negotiation in mathematics classrooms. Such everyday situations seem not to be characterized by a continual improvement of the conditions of learning. Possibly this expectation is too high and unrealistic for the everyday mathematics classroom. Often an implicit pedagogy is in effect in 
everyday teaching in which, for example, the differences of frames in the class are not explicitly spoken of and those pupils have an advantage who have formal language competencies from their familial background.

To summarize, the discussed approach focuses on the situationally-bound aspects of mathematics learning. It is concerned with the theoretical exploration of social situations in which mathematics learning processes are initiated, supported and consolidated. The perspective is on the here and now where persons are interacting with each other. The empirical analyses are directed at the reconstruction of such interactively accomplished products such as the negotiation of meaning, argumentation and the structure of interaction etc. In the terms of Schütz and Luckmann (1979), it has to do here with the emerging "everyday worlds" in mathematics classrooms and the conditions of learning that are produced in them.

\subsubsection{Practice Relevance}

The interactionist theory approach allows the relationship of everyday teaching to the changing of teaching to define in a specific way. "To teach" and "changing teaching" can be understood as two different realizations of classroom interaction along these dimensions. In order to improve mathematics teaching, condensed courses of interaction should be recognized more often and with more certainty. In either case of classroom interaction, everyday teaching is characterized by the fact that one makes decisions under pressure that should maintain the flow of interaction. This is not easy-one should not hesitate too frequently, but make decisions with the other participants, and take some matters to be certainly given. Such assumptions in everyday mathematics lessons, for example, are the use of patterns of interaction processes with a less elaborated accounting practice in the sense of a smooth course of interaction.

It is this everyday practice that should be changed. This modified practice would again become everyday but naturally another, in which the course of condensed interaction can not only take place more often but also be methodically better developed. One can understand this development as a cycle: from being everyday to a modified everyday practice with a phase of change in between (Gellert 2003). This cycle can reoccur several times.

With reference to the possibilities of modifying this everyday practice, one can ask how a teacher can learn to accomplish-her own perceptions of change in this everyday setting and to critically reflect on it. A teacher will be more successful in these matters when she assumes more autonomy in her own decisions and actions. An increase in autonomy means the teacher does not attempt to exactly copy suggestions made by other teachers or researchers, but that she can be enabled to develop and experiment on her own alternative visions about the condensed course of interaction. Gellert (2003) distinguishes here between a conception of education that aims at directions about action and those that enable the (future) teachers to develop their 
own approaches for alternative action (p. 139). These alternative actions should aim at the production of a condensed course of interaction.

The ability of the autonomous development and trial of such alternative teaching is most likely encouraged when the participants are able to interpret interaction in classroom episodes in new alternative ways by means of an improved perception. Inevitably, the possibility of the alternative structuring is based on the ability of interpreting in divergent ways. As a motto, it could be phrased: "changing through interpreting" (Fetzer and Krummheuer 2007).

In the teaching situation, the teacher generally acts rationally based on her definition of the situation. If we wish that she acts differently, this too should be a rational undertaking. This can arise more often when she is able to perceive aspects of interaction that lie outside the horizon of her definition of the current situation. In shaping a more developed competency of interpretation lies the foundation for any possibility of changing everyday teaching. On this basis then new assignments, new access to contents of teaching, new contents on the whole or even completely new cultures of lessons with the chance of a permanently effective change of teaching can be introduced. In teacher education as in further education seminars of currently practicing teachers, an essential element is the initiation of a practice of joint interpretation of classroom episodes in the sense of the above goal. On given classroom documents or on participants' own documented teaching episodes, interpretations of these scenes of everyday teaching are generated together based on the above described theoretical approach. Hereby innovative teaching concepts can be already demonstrated in these documents (Krummheuer 2008).

Exactly in the sense of interpretative classroom research, it is not attempted to conduct quantitative studies on effectiveness. It rather tries to reconstruct teachers' interpretations of classroom interaction. Fellmann (2014) reconstructs in a qualitative comparative study the professional self-concepts of the three common professional groups (students in the school of education, practice teachers in their preparatory seminars and practicing teachers), who attempt to use an innovative concept of teaching of cooperative learning in mathematics classes in grade school. She further generated a wealth of alternative interpretations in practice organized by the author of commonly interpreting episodes of their realized practice. Fellmann could assign different interpretations of the participants to certain professional roles (pp. 184ff). These types allow an evaluation of the scope or the generalization of innovative approaches and demands in different professional groups.

\subsubsection{Summary-A Reflection on Research Practice}

An empirically grounded theory of mathematics classroom interaction is presented. It rests on many separate empirical research projects in which due to the necessity of the reduction of complexity in the implementation of each single project, it was necessary to concentrate in each project only on certain facets. Likewise, in the course of over 30 years of research, certain aspects could be stated more precisely 
or were enriched. Especially in the broad theory complex concerning the format of argumentation new theoretical approaches were integrated with reference to the works of Bruner and Toulmin.

All in all, an approach involving an interactionist theory of mathematics learning in the context of school classrooms has been described with the goal of the development of an empirically rich theory of middle range. It places a clear emphasis on the effectiveness of collective argumentation for the learning of mathematics and relies on the idea that the most "rational" of all sciences, namely mathematics, is learned through the participation of pupils in argumentative processes of negotiation about the rationality of their mathematics actions in the classroom.

\subsection{Classroom Research as Part of the Social-Political Agenda}

\subsubsection{Introduction}

This chapter sketches the accumulating body of classroom research in Germany that explicitly relates the interpretations of classroom interaction to the macrosociological or institutional conditions of its production. It aims at complementing Krummheuer's description of the development of an interpretative theory of learning mathematics in the preceding chapter. ${ }^{3}$

Interpretative studies of interaction in German primary and secondary mathematics classrooms (Bauersfeld 1978; Krummheuer 1997; Voigt 1984) have focussed, and continue to focus, on the reconstruction of interaction patterns and formats of argumentation. These are seen as the social building blocks for mathematical activity in the classroom. The results of interactionist research, taken together, yield a rather coherent picture of mathematics classroom micro-cultures. In a nutshell, interactionist studies regard communication in the mathematics classroom as "a process of mutual adaptation wherein individuals negotiate meanings by continually modifying their interpretations" (Cobb and Bauersfeld 1995, p. 8). The 'social' in interactionist studies of mathematics classroom micro-culture is firmly located in the interpersonal space of those who interact. This space is considered a contingent sphere in which mathematical meaning emerges as the product of processes of negotiation. Methodologically, the reconstructivist paradigm, to which most studies subscribe, refers to the textual data of classroom interaction (in which videotape is considered as textual data, too) as the inescapable ground for all interpretation. What cannot be evidenced by the data, cannot form part of the interpretation. As an example, the social or cultural background of individual students involved in a collaborative activity is only taken into consideration once the collaborating students refer explicitly

\footnotetext{
${ }^{3}$ I am indebted to Götz Krummheuer as my mentor when introducing me to interpretative analyses of classroom interaction years ago.
} 
to their social or cultural backgrounds. The students' 'social condition' is irrelevant for the interactionist's analysis unless the participants of the interaction refer to it.

This paradigmatic decision of excluding everything invisible in the interaction from the interpretative analysis is essentially facilitating reconstructions of the emergence of meaning in the classroom. A different sociological perspective considers schools and classrooms not only as places in which learning occurs (qualification), but also as institutional loci in which further societal functions of schooling-allocation, integration, and cultural reproduction - need to be pursued parallel to qualification (cf. Fend 2006). At stake in mathematical activities in the classroom is not only the development of students' knowledge and skills, but also the creation of hierarchies of achievement in mathematics, of differential access to valued forms of mathematics, and of familiarisation with work ethic and norms of comportment. Mathematics, as a school subject, seems to play a particularly important role in this respect. It has been called a 'gate-keeper' for students' career options, and, as Robert Veel (1999, p. 206) has argued from a sociolinguistic perspective, "mathematics is a discipline whose discursive construction through language seems to be unusually closely aligned to the regulative discourse of the classroom and the macro-regulative discourse of the ordering of space and time in the school".

From such a point of view, issues such as the distribution of knowledge, access and the students' resources are crucial ingredients to the forms the interaction in the mathematics classrooms may take. It is of interest, for instance, how mathematics instruction deals "with the correspondence between the hierarchy of social groups and their differential power external to the school and the hierarchies of knowledge, possibility and value within" it (Gellert 2008, p. 216). The interplay of the macroregulative social order and the micro-dynamics of classroom interaction come to the fore in research on mathematics classroom interaction that does not confine its sociological perspective to the micro view.

Based on the extensive experience of micro-sociological interpretative studies of interaction in mathematics classrooms in Germany and, particularly, on the accomplishments in terms of methodological elaboration, several researchers have engaged in extending the analytical framework, with the purpose of getting hold of a variety of macro-sociological or institutional factors. A selection of their work is presented in this chapter in order to illustrate how classroom research as part of the social-political agenda has developed in a close relation to the traditional interactionist research that Krummehuer has reported in the preceding chapter. Of course, the presentation cannot discuss the social issues in-depth, here. Although this presentation is organised chronologically, only some of the examples build explicitly on each other while for others it is more difficult to trace interconnections and development. ${ }^{4}$

\footnotetext{
${ }^{4}$ Some of the research referenced in this section has been published as a book or a Ph.D. thesis in German language and might thus be difficult to access. Anyhow, summaries and selected results of the research in English language can easily be found in international journals and as chapters in edited volumes (e.g. in Gellert et al. 2018).
} 


\subsubsection{Research Issues}

Studies, which interpretatively analyse classroom interaction and go beyond the reconstruction of the emergence of mathematical meaning, have dealt with a variety of issues. This variety falls into three categories. First, the dimension of the students' sex and the gendered formation of mathematical identities has received some attention. Second, the influence of national traditions on classroom interaction has been illuminated through international comparative analysis. Third, the construction of differential performance in mathematics classrooms has been traced to issues of language diversity, openly selective school systems, and to the hidden structures of pedagogic discourse on several levels. It might be interesting not only to consider which issues attention has been paid to. The absence of categories of, for instance, race and ethnicity in research on interaction in mathematics classrooms in Germany might be a fact to be observed.

\subsubsection{The Dimension 'Sex' in Mathematics Classrooms}

The heading of this subsection refers to Helga Jungwirth's (1991) research on the ways in which the sex of the students frames their interaction with the mathematics teacher. In this study, Jungwirth reconstructs differences in the patterns of interaction between teachers and male and female students.

The findings show that the interaction is not coloured by the sex of the participants over many periods. Phases however, in which the basic structure of the interaction is altered, are arranged differently according to the sex of the participating students. This is due to the fact that certain routines of the teachers are modified according to the sex of the students they interact with and the fact that girls and boys have specific ways of acting of their own. In summary boys are more familiar with those methods which enable students to participate successfully in the mathematics classroom. Therefore boys appear to be more competent in mathematics than girls. (p. 87)

Jungwirth concludes that the interaction in the mathematics classroom contributes to the formation of gendered mathematical identities.

\subsubsection{National Traditions Framing Interaction in the Mathematics Classroom}

Christine Knipping (2003) combines the micro-sociological with an international comparative perspective. She reports on proving and application processes in classroom practices in Germany and France, focusing on the Pythagorean theorem as the mathematical content. The comparison of the two national contexts points out two differing curricular tendencies. While, for instance, the observed mathematical lessons in Germany emphasise the application of the Pythagorean theorem in calculations of roofs, distance estimation, etc., the French lessons focus on the activity of proving in geometry. The research exemplifies in which ways the teaching of 
mathematics is not independent from context and culture. The students learn different mathematical knowledge and experience different practices of using this knowledge. Knipping concludes that it is clear and surprising at the same time how much the analysed French and German teaching situations differ.

Although not basing her analyses exclusively on an interactionist methodology, Eva Jablonka's (2004) comparative study of classroom interaction in Germany, Hong Kong and the United States takes up the accomplishments and methodology of German interpretative studies on mathematics education and integrates them into a 'complementary accounts methodology' as the frame of the Learner's Perspective Study. The Learner's Perspective Study context is the context in which her classroom data had been generated. Her methodology combines a zooming into the patterns of interaction at micro-level and a zooming-out to see the structuration of classroom practice. By looking at structures in (national) diversity, the study contributes to our understanding of the practice of learning and teaching mathematics in schools at a very general level. From the international comparative perspective and based on the theoretical foundation of Jablonka's analyses, the learning of mathematics appears primarily as an initiation into the practice of school mathematics. However, as Jablonka points to, "student and teacher practices only have meaning with relation to the organisational forms in which they exist" (p. 6).

\subsubsection{The Construction of Differential Performance in Classroom Interaction}

The differences in the mathematical performance of students in school are usually explained on the basis of different cognitive dispositions, which are mediated by individual performance motivation. From a micro-sociological perspective, however, Uwe Gellert and Anna-Marietha Hümmer (now A.-M. Vogler) (2008) see these differences as intersubjective constructions, thus differences in performance are intersubjective constructions too. These constructions and the mechanisms of their production are the subject of Gellert and Hümmer's study. The theoretical framework is provided by Bernstein's theory of pedagogic discourse, with its emphasis of the regulative principles of classroom interaction. The data of the study is made of video recordings from mathematic lessons at the very start of the fifth school year. The micro-sociological focus is on whether and how teachers clarify to their pupils what they have to achieve to be seen as high performers in mathematics. The study shows that performance expectations are not only related to mathematical abilities. Instead, it concludes, making disparities of performance explicit is linked to a process of coding and decoding of the subject-specific expectations to student participation in the mathematical activities in the classroom.

Marcus Schütte (2009) examines the linguistic organisation of mathematics teaching in primary school. He reconstructs this as a form of implicit pedagogy. The teacher in the lessons observed primarily provides a learning environment to the students, and pursues in the course of the lesson how the students develop their individual skills and talents. Such form of teaching, argues Schütte, can be considered a patho- 
logical form of progressive education. It basically follows the idea that the students can access mathematical meaning simply because of their abilities brought to the classroom, and that the underlying relations of content and language arise by itself.

The discourse in the analysed lessons shows a predominant use of informal everyday language on the side of the teacher. With footing in the work of Bernstein, Cummins, and Halliday, Schütte considers this discourse as characterised by implicitness and contextuality. However, formal language skills, which are not detailed in this everyday discourse, are highly relevant within performance assessments. These formal language skills for understanding and using a kind of vertical discourse are not made accessible in the observed lessons. It can be assumed that for many children the classroom is the only possible space where they can acquire formal language skills. When teachers rely on everyday discourse only in mathematics lessons, the effect on students' language and knowledge acquisition can be detrimental. When this happens, the system of the school fails to provide access particularly for the nonprivileged learners. Structures of privilege and discrimination are then reproduced.

The German school system can be characterised as overtly selective. Traditionally, there is a separation of those with 'intellectual' and those with 'practical talent' at the age of 10. Although the school system has passed substantial changes during the last years, by which its selective character has been downsized, one still finds schools in which the least successful (in terms of academic achievement during the primary school years) students gather. Hauke Straehler-Pohl and Uwe Gellert (2015) are interested in what kind of mathematics was made accessible to the students in these schools and in which form. The focus is on the interaction between teachers and students as well as on the effects that these interactions may have on students' identity formation as learners of mathematics. The study reconstructs how the students become mathematically disempowered by communication patterns that heavily prioritise conformance with the regulative discourse over engagement in the instructional discourse. The mathematics to be transmitted is ridiculously simple, so simple that any classification of students as 'good' or 'bad' could only be built along the students' compliance with the criteria of the regulative discourse. Accordingly, those students that try to resist the low academic expectations they face come quickly into conflict with the teachers and, in several cases, they abandon school at all. StraehlerPohl and Gellert conclude that these pathological moments of pedagogy reveal the true structural condition of how mathematics is taught and learned within the overtly selective school system in Germany.

Nina Bohlmann's (2016) study develops a praxeological model of pedagogic practice which focuses on explication processes in mathematics classrooms. The theoretical ground is provided mainly by Bernstein's theory of pedagogic discourse, especially the concept 'pedagogic device'. The theoretical frame leads to a problematisation of implicitness in the structuring of pedagogic discourse. By analysing the structural specifics of mathematics classroom interaction, consequences for the explication of structures of mathematics classroom interaction are derived. The key assumption is that the implicit structuring of schooling is constitutive of the relationship between performance in school and the social background of students, and operates in a stratifying way. The study investigates by means of analyses of inter- 
action how mathematics teachers attempt to make the structuring of schooling more explicit. It thus reconstructs explication processes in mathematics classrooms. It shows how certain aspects of pedagogic practice - that usually stay implicit—can indeed be explicated. In doing so, differences and commonalities in the setting of priorities and in the realisation of the intended explication processes are made visible.

The results reinforce the claim that explication processes, when systemically, consequentially and consistently implemented, can be seen as an approach to the postulation of equal opportunities in education and by education.

\subsubsection{Conclusion}

When researchers investigate classroom (inter-)activities from sociological perspectives, their particular sociological perspectives entail decisions on what of the social matter is foregrounded and what is kept in the background. It should be mentioned that these decisions are gradual and not dyadic, e.g. in terms of the micro and the macro, and that research studies may relate to several research branches (see, as an example, the positioning of Schütte (2009) in Krummheuer's and Gellert's discussions, in this section). Despite this, an important difference among sociological perspectives on interaction in mathematics classes should be pointed.

Interactionist studies of mathematics classroom activity usually reconstruct the emergence of meaning in negotiations between teachers and students or among students. The mathematics at stake appears as contingent and underdetermined by the social setting in which the negotiation takes place. From this perspective, the mathematics classroom is like a neutral platform on which learning happens. The character of this platform is deliberately blanked out.

Those researchers who acknowledge classroom interaction as the very locus where meaning is constructed, but who conceive the platform not as flat but as a strong relief folded by the tectonic forces of macro-social structures, trace the faulting visible in the construction of meaning in the mathematics classroom back to the structural conditions under which the teaching and learning of mathematics is organised. Needless to say, this is an ambitious expedition into an only roughly charted continent.

\section{References}

Bauersfeld, H. (1978). Kommunikationsmuster im Mathematikunterricht. Eine Analyse am Beispiel der Handlungsverengung durch Antworterwartung. In H. Bauersfeld (Ed.), Fallstudien und Analysen zum Mathematikunterricht (pp. 158-180). Hannover: Schroedel.

Bauersfeld, H. (1980). Hidden dimensions in the so-called reality of mathematics classroom. Educational Studies in Mathematics, 11(1), 23-41.

Bauersfeld, H. (1995). "Language games" in the mathematics classroom: Their function and their effects. In P. Cobb \& H. Bauersfeld (Eds.), The emergence of mathematical meaning: Interaction in classroom cultures (pp. 271-291). Hillsdale, NJ: Lawrence Erlbaum. 
Bauersfeld, H. (2000). Radikaler Konstruktivismus, Interaktionismus und Mathematikunterricht. In E. Begemann (Ed.), Lernen verstehen - Verstehen lernen (pp. 117-145). Frankfurt: Peter Lang.

Bauersfeld, H., \& Seeger, F. (2003). Semiotische Wende. Ein neuer Blick auf das Sprachspiel von Lehren und Lernen. In M. Hoffmann (Ed.), Mathematik verstehen: Semiotische Perspektiven (pp. 20-33). Hildesheim: Franzbecker.

Bohlmann, N. (2016). Implizitheit und Explizitheit. Praxeologische und institutionskritische Analysen zum Mathematikunterricht. Wiesbaden: Springer VS.

Brandt, B. (2004). Kinder als Lernende. Partizipationsspielräume und-profile im Klassenzimmer. Frankfurt: Peter Lang.

Bruner, J. (1983). Child's talk: Learning to use language. Oxford: Oxford University Press.

Cobb, P., \& Bauersfeld, H. (1995). Introduction: The coordination of psychological and sociological perspectives in mathematics education. In P. Cobb \& H. Bauersfeld (Eds.), The emergence of mathematical meaning: Interaction in classroom cultures (pp. 1-16). Hillsdale, NJ: Lawrence Erlbaum.

Dörfler, W. (2006). Diagramme und Mathematikunterricht. Journal für Mathematikdidaktik, 27(3/4), 200-219.

Fellmann, A. (2014). Handlungsleitende Orientierungen und professionelle Entwicklung in der Lehrerbildung. Eine Studie zur Umsetzung eines innovativen Lehr-Lernformats im Mathematikunterricht der Klasen 1 bis 6. Münster: Waxmann.

Fend, H. (2006). Neue Theorie der Schule. Einführung in das Verstehen von Bildungssystemen. Wiesbaden: VS.

Fetzer, M. (2003a). Interaction in collective writing processes in early mathematical learning. Paper presented at CERME 3, Bellaria, Italy.

Fetzer, M. (2003b). Verschriftlichungsprozesse im Mathematikunterricht der Grundschule aus interaktionstheoretischer Sicht. Journal für Mathematik-Didaktik, 24(3/4), 172-189.

Fetzer, M., \& Krummheuer, G. (2007). Gestalten durch Interpretieren. Päd Forum: Unterrichten Erziehen, 35/36(4), 201-204.

Garfinkel, H. (1967). Studies in ethnomethodology. Englewood Cliffs, NJ: Prentice-Hall.

Gellert, U. (2003). Mathematikunterricht und Innovation. Hildesheim: Franzbecker.

Gellert, U. (2008). Validity and relevance: Comparing and combining two sociological perspectives on mathematics classroom practice. ZDM-The International Journal on Mathematics Education, 40(2), 215-224.

Gellert, U., \& Hümmer, A.-M. (2008). Soziale Konstruktion von Leistung im Unterricht. Zeitschrift für Erziehungswissenschaft, 11(2), 288-311.

Gellert, U., Knipping, C., \& Straehler-Pohl, H. (Eds.). (2018). Inside the mathematics class: Sociological perspectives on participation, inclusion, and enhancement. Cham: Springer.

Goffman, E. (1974). Frame analysis: An essay on the organisation of experience. Cambridge, MA: Harvard University Press.

Jablonka, E. (2004). Structure in diversity: Initiation into mathematical practice in classrooms from Germany, Hong Kong and the United States (Unpublished Habilitation thesis). Freie Universität Berlin, Germany.

Jungwirth, H. (1991). Die Dimension "Geschlecht" in der Interaktion des Mathematikunterrichts. Journal für Mathematik-Didaktik, 12(2/3), 133-170.

Jungwirth, H., \& Krummheuer, G. (2008). Interpretative Forschung als Prozess: zu den Denkfiguren einer Forschungsrichtung von ihrem Beginn bis heute. In H. Jungwirth \& G. Krummheuer (Eds.), Der Blick nach innen: Aspekte der alltäglichen Lebenswelt Mathematikunterricht (Vol. 2, pp. 145-172). Münster: Waxmann.

Kadunz, G. (2006). Schrift und Diagramm. Journal für Mathematikdidaktik, 27(3/4), 220-239.

Knipping, C. (2003). Beweisprozesse in der Unterrichtspraxis. Vergleichende Analysen von Mathematikunterricht in Deutschland und Frankreich. Hildesheim: Franzbecker.

Kopperschmidt, J. (1989). Methodik der Argumentationsanalyse. Stuttgart-Bad Cannstatt: Frommann-Holzboog. 
Krummheuer, G. (1995). The ethnography of argumentation. In P. Cobb \& H. Bauersfeld (Eds.), The emergence of mathematical meaning: Interaction in classroom cultures (pp. 229-269). Hillsdale, NJ: Lawrence Erlbaum.

Krummheuer, G. (1997). Narrativität und Lernen. Mikrosoziologische Studien zur sozialen Konstitution schulischen Lernens. Weinheim: Beltz.

Krummheuer, G. (2007). Argumentation and participation in the primary mathematics classroom: Two episodes and related theoretical abductions. Journal of Mathematical Behavior, 26(1), 60-82.

Krummheuer, G. (2008). Bedingungen des Lernens von Mathematik in der lehrergelenkten Unterrichtsinteraktion. Zeitschrift für Grundschulforschung, 1(1), 97-109.

Krummheuer, G. (2009). Inscription, narration and diagrammatically based argumentation: The narrative accounting practices in the primary school mathematics lesson. In W.-M. Roth (Ed.), Mathematical representation at the interface of the body and culture (pp. 219-243). Charlotte, NC: IAP.

Krummheuer, G. (2011). Representation of the notion "learning-as-participation" in everyday situations of mathematics classes. Zentralblatt für Didaktik der Mathematik, 43(1/2), 81-90.

Krummheuer, G. (2013). The relationship between diagrammatic argumentation and narrative argumentation in the context of the development of mathematical thinking in the early years. Educational Studies in Mathematics, 84(2), 249-265.

Krummheuer, G., \& Brandt, B. (2001). Paraphrase und Traduktion. Partizipationstheoretische Elemente einer Interaktionstheorie des Mathematiklernens in der Grundschule. Weinheim: Beltz.

Krummheuer, G., \& Fetzer, M. (2005). Der Alltag im Mathematikunterricht. Beobachten, Verstehen, Gestalten. München: Elsevier.

Krummheuer, G., \& Voigt, J. (1991). Interaktionsanalysen von Mathematikunterricht. Ein Überblick über Bielefelder Arbeiten. In H. Maier \& J. Voigt (Eds.), Interpretative Unterrichtsforschung (pp. 13-32). Köln: Aulis.

Lange, D. (2013). Inhaltsanalytische Untersuchung zur Kooperation beim Bearbeiten mathematischer Problemaufgaben. Münster: Waxmann.

Latour, B., \& Woolgar, S. (1986). Laboratory life: The construction of scientific facts. Princeton, NJ: Princton University Press.

Lave, W., \& Wenger, E. (1991). Situated learning: Legitimate peripheral participation. Cambridge: Cambridge University Press.

Mehan, H. (1979). Learning lessons. Cambridge, MA: Harvard University Press.

Meyer, M. (2015). Vom Satz zum Begriff. Philosophisch-logische Perspektiven auf das Entdecken, Prüfen und Begründen im Mathematikunterricht. Berlin: Springer.

Miller, M. (1987). Argumentation and cognition. In M. Hickmann (Ed.), Social and functional approaches to language and thought (pp. 225-249). San Diego, CA: Academic.

Morgan, C. (1998). Writing mathematically. The discourse of investigation. London: Falmer.

Moschkovich, J. (2007). Examining mathematical discourse practices. For the Learning of Mathematics, 27(1), 24-30.

Naujok, N. (2000). Schülerkooperation im Rahmen von Wochenplanunterricht. Analyse von Unterrichtsausschnitten aus der Grundschule. Weinheim: Beltz.

Oesterreicher, W. (1997). Types of orality in text. In E. Bakker \& A. Kahane (Eds.), Written voices, spoken signs: Tradition, performance, and the epic text (pp. 190-214). Cambridge, MA: Harvard University Press.

Peirce, C. S. (1978). Collected papers of Charles Sanders Peirce (4th ed., Vol. 1). Cambridge, MA: Harvard University Press.

Presmeg, N. (2002). Transitions in emergent modeling. In K. Gravemeijer, R. Lehrer, B. van Oers, \& L. Verschaffel (Eds.), Symbolizing, modeling and tool use in mathematics education (pp. 131-138). Dordrecht: Kluwer.

Roth, W.-M., \& Mc Ginn, M. (1998). Inscriptions: Toward a theory of representing as social practice. Review of Educational Research, 68(1), 35-59. 
Schreiber, C. (2004). The interactive development of mathematical inscriptions-A semiotic perspective on pupils' externalisation in an internet chat about mathematical problems. Zentralblatt für Didaktik der Mathematik, 36(6), 185-195.

Schreiber, C. (2010). Semiotische Prozesskarten. Chatbasierte Inskriptionen in mathematischen Problemlöseprozessen. Münster: Waxmann.

Schütte, M. (2009). Sprache und Interaktion im Mathematikunterricht der Grundschule. Münster: Waxmann.

Schütz, A., \& Luckmann, T. (1979). Strukturen der Lebenswelt (Vol. 1). Frankfurt: Suhrkamp.

Schwarzkopf, R. (2000). Argumentationsprozesse im Mathematikunterricht: Theoretische Grundlagen und Fallstudien. Hildesheim: Franzbecker.

Schwarzkopf, R., Nührenbörger, M., \& Mayer, C. (2018). Algebraic understanding of equalities in primary classes. In C. Kieran (Ed.), Early algebra (pp. 195-212). Rotterdam: Springer.

Sfard, A. (2008). Thinking as communicating. Human development, the growth of discourses, and mathematizing. Cambridge: Cambridge University Press.

Steinbring, H. (2005). The construction of new mathematical knowledge in classroom interaction. An epistemological perspective. Berlin: Springer.

Straehler-Pohl, H., \& Gellert, U. (2015). Pathologie oder Struktur? Selektive Einsichten zur Theorie und Empirie des Mathematikunterrichts. Wiesbaden: Springer VS.

Tomasello, M. (2003). Constructing a language: A usage-based theory of language acquisition. Cambridge, MA: Harvard University Press.

Toulmin, S. E. (1969). The uses of argument. Cambridge: Cambridge University Press.

Van Oers, B. (1997). On the narrative nature of young children's iconic representations: Some evidence and implication. International Journal of Early Years Education, 5(3), 237-245.

Veel, R. (1999). Language, knowledge and authority in school mathematics. In F. Christie (Ed.), Pedagogy and the shaping of consciousness: Linguistic and social processes (pp. 185-216). London: Continuum.

Voigt, J. (1984). Interaktionsmuster und Routinen im Mathematikunterricht. Weinheim: Beltz.

Voigt, J. (1995). Thematic patterns of interaction and sociomathematical norms. In P. Cobb \& H. Bauersfeld (Eds.), The emergence of mathematical meaning: interaction in classroom cultures (pp. 163-201). Hillsdale, NJ: Lawrence Erlbaum.

Wittgenstein, L. (1963). Tractatus logico-philosophicus (D. F. Pears \& B. F. McGuiners, Trans.). London: Routledge \& Kegan Paul.

Open Access This chapter is licensed under the terms of the Creative Commons Attribution 4.0 International License (http://creativecommons.org/licenses/by/4.0/), which permits use, sharing, adaptation, distribution and reproduction in any medium or format, as long as you give appropriate credit to the original author(s) and the source, provide a link to the Creative Commons licence and indicate if changes were made.

The images or other third party material in this chapter are included in the chapter's Creative Commons licence, unless indicated otherwise in a credit line to the material. If material is not included in the chapter's Creative Commons licence and your intended use is not permitted by statutory regulation or exceeds the permitted use, you will need to obtain permission directly from the copyright holder. 


\title{
Chapter 9 \\ Educational Research on Learning and Teaching Mathematics
}

\author{
Timo Leuders and Andreas Schulz
}

\begin{abstract}
One of the main goals of research in (mathematics) education is the generation of knowledge on processes of teaching and learning. The approaches of many research projects in German-speaking countries that contributed to achieving this goal during recent decades are diverse. Many of these projects are characterized by narrowly focusing on distinctive phenomena within learning and teaching mathematics, by taking a multi-step approach that develops theory in a series of consecutive studies (often one area of interest is pursued over many years) and by a mixed-method research strategy that integrates different methodological practices. This chapter provides exemplary insight into these kinds of research in mathematics education in German-speaking countries over the last few decades. After a brief glimpse into the beginnings, we deliver four examples that illustrate the features of these kinds of research and also describe the perspectives of researchers by way of short interview excerpts.
\end{abstract}

Keywords Educational research - Interdisciplinary research • Mixed-methods • Research strategies $\cdot$ Problem solving $\cdot$ Mathematical proof $\cdot$ Experimental thinking $\cdot$ Fractions

\subsection{Introduction}

As early as the 1980s, mathematics education in Germany was already actively using and developing research strategies focusing on distinctive phenomena of mathemat-

\footnotetext{
T. Leuders $(\bowtie)$

Institute for Mathematics Education, Pädagogische Hochschule (University of Education), Freiburg, Germany

e-mail: leuders@ph-freiburg.de
}

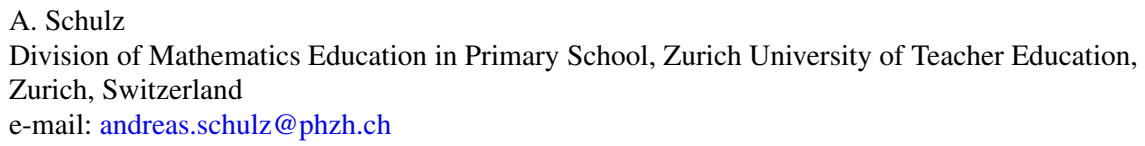


ics learning and teaching and combining and developing methods that were expected to support these research goals. Ursula Viet's investigation of the cognitive development of fifth- and sixth-grade students in arithmetic and geometry (Viet et al. 1982) can serve as an example of such research: Viet and colleagues (1982) emphasized that, while in empirical research on mathematics subject case studies and interventions with pre-post designs dominated, their project aimed to study long-term learning processes. Furthermore, their focus was not on mathematics achievement in general, but on the development of knowledge in focused areas such as "counting and calculating in (non-decimal) place-value-systems" or "geometric mappings in situations with axial symmetry". In a multi-step design, the project investigated the learning trajectories and learning obstacles of students while working within a "programmed instruction"-environment, i.e., standardized teaching material that excluded teachers and social interaction. Their analysis of clinical interviews and of errors in students' solutions produced knowledge that is specific for the areas under investigation, such as the prevalence and effectiveness of different strategies in calculating in place-value systems.

Their early study already illustrates core features of the type of empirical research that eventually became a specific feature of mathematics education research: The interest in content-specific learning processes, the development of adequate research strategies, a multi-step long-term research strategy, and the use and adaptation of theories from psychology (cf. "borrowed theories" in Bikner-Ahsbahs and Vohns in this volume).

Many more studies working in a similar vein were launched during the following years, and several thereof were supported by grants from the German Research Foundation (Deutsche Forschungsgemeinschaft-DFG), such as in the 1990s:

- E. Cohors-Fresenborg: Individual Differences in the Mental Representation of Term Rewriting (Cohors-Fresenborg and Striethorst 2003).

- M. Franke: Solution strategies of students in primary school during work on picture-text-integrating tasks. Qualitative empirical investigations on word problems (Franke 1998).

- K. Hasemann: Categories of students' mathematical thinking processes (Hasemann 1997).

- G. Krummheuer: Reconstruction of "formats of collective argumentation" in primary school mathematics lessons (Krummheuer 1998).

- K. Reiss: Problem solving strategies in spatial-geometric tasks with concrete and computer-simulated material (Reiss 1999; Burchartz and Stein 1998).

- M. Stein: Pupils work on problems with a goal that cannot be reached.

- H. Steinbring: Epistemological and social-interactive conditions for the construction of mathematical knowledge structures (Steinbring 1997).

- B. Wollring: Qualitative empirical investigations on the understanding of probability of children in kindergarten and primary school (Wollring 1994).

Since it is hardly possible to report comprehensively on this strand of research found throughout mathematics education research in German-speaking countries, we present four more recent examples of projects that illustrate how these features 
were expanded upon during subsequent decades — and omit many others that would also be worth mentioning. The reader who is interested in the breadth of research in German-speaking countries during recent decades can get a fairly good impression by browsing the content of Journal für Mathematik-Didaktik (JMD): all articles since the first issue in 1980 have been retro-digitalized and offer abstracts in English. For specific types of empirical research that are quite different (e.g., design science, classroom studies or large-scale studies), we refer to the respective chapters in this book.

Within the following four research projects in the next two sections, we discuss key aspects of research strategies in mathematics education from a general point of view. Furthermore, we insert excerpts from video interviews with the researchers in which they explain their research goals and strategies when designing and conducting such research in the field of mathematics education. These interviews were presented in a session at ICME-13 in Hamburg. They were discussed by international participants and contain the spontaneous reactions from the interviewed researchers. Their statements have been slightly revised and abridged but are intended to maintain their spontaneous and subjective character.

\subsection{Interdisciplinary Research}

In 2000-2006, the German Research Foundation set up a six-year priority program for empirical educational research ,The Educational Quality of Schools“ (Bildungsqualität von Schulen-BiQua), with a multiple-strategy focus (Prenzel and Schöps 2007) and with the following goals:

- to investigate mathematics and science teaching, since this was the area of concern after the TIMS-Study's findings-aiming to generate explanations for the mediocre results

- to motivate analysis of domain-specific and cross-curricula learning within and outside school—a rather broad scope

- to initiate interdisciplinary cooperation and methodological development in empirical educational research.

The three-step program was designed to initiate projects ranging from foundational research to implementation. Quantitatively speaking, this resulted in 32 projects, and 80 doctoral studies from all areas of educational research, including mathematics education. Qualitatively speaking, many researches profited from collaborations that led to new approaches, interesting findings, the advancement of empirical research in mathematics and science education, and the development and fruitful integration of theories that had previously not been considered to be interconnected. Some of the projects that inspired mathematics education research were:

- R. Pekrun, R. vom Hofe, W. Blum, S. Wartha, and others: PALMA—development of mathematical competence and motivation over 6 school years 
- M. Kunter, J. Baumert, W. Blum, A. Jordan, S. Krauss, M. Neubrand, and others: COACTIV: Linking teacher knowledge and student achievement

- E. Klieme, B. Drollinger-Vetter, F. Lipowsky, C. Pauli, K. Reusser and K. Rakoczy: PYTHAGORAS: Instructional quality in classroom (also: subject-specific) and learning outcome

- R. Bruder, B. Schmitz, F, Perels, E. Komorek, C. Collet and others: Fostering problem solving and self-regulation, and a subsequent teacher-training program

- A. Renkl, S. Schworm, K. Reiss, A. Heinze and others: Learning to prove-The idea of heuristic examples.

\subsubsection{Example 1: Problem Solving and Self-regulation}

Should general learning skills and mathematical skills be taught in a separate or an integrated way? This quite general question was investigated in a concrete manner within the project of Bruder, Schmitz and colleagues (Bruder et al. 2007; Perels et al. 2007). Educational psychology considers content-related goals as helpful within training programs that aim to promote students' subject-independent self-regulatory skills (e.g., Hasselhorn and Hager 2001; de Corte et al. 2000). Furthermore, when discussing theories that describe self-regulatory behavior, such as the model by Schmitz and Wiese (2006), mathematics educators recognize many core elements of problemsolving behavior, as already described for example by Polya (1949) (see Fig. 9.1).

It thus would appear plausible to devise training programs that combine instructional elements with respect to problem-solving strategies and those that foster selfregulation strategies in different phases.

The program as shown in Fig. 9.2 was implemented in various ways with students of different ages and including elements that trained teachers and parents to support the learning process. Experimentally-controlled variation yielded many interesting findings with respect to the effect of the various parameters. One interesting finding was that the training of self-regulation skills also boosts problem-solving competence, but not vice versa. When adding support by teachers and/or parents, another of the interesting findings was that teacher support enhances the training's effect while teacher training alone has no effect.

This of course cannot be generalized, and there may be more efficient ways to train teachers. Bruder et al. (2007) developed such a training program that started by transforming the extracurricular program into a teaching concept that could be "hardwired" into the everyday mathematics classroom. It was implemented and tested in field studies in three phases with pre-service teachers, with teachers in the induction phase, and with regular teachers. Again, problem-solving elements were combined with self-regulation elements.

Unfortunately, no control group design was possible, meaning that the considerable increase in heuristic use and mathematics achievement cannot be identified as an effect of the intervention. However, the researchers demonstrated the impact of 


\section{Preaction Phase}

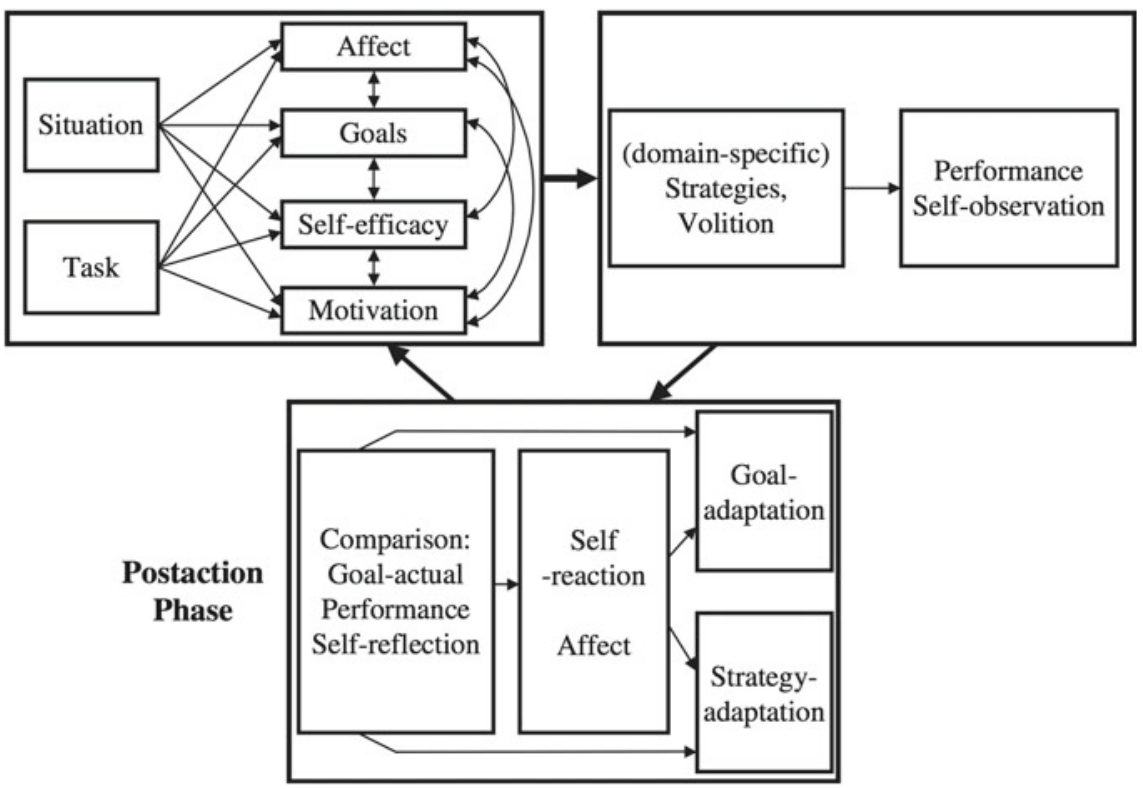

Fig. 9.1 This "process model of self-regulation" (according to Schmitz and Wiese 2006) bears much resemblance to the phases of mathematical problem-solving

Contents of the combined training programme

\begin{tabular}{|c|c|c|}
\hline Unit & Problem solving & Self-regulation \\
\hline $1^{\text {st }}$ unit & working forwards & strategy reflection, attention \\
\hline $2^{\text {nd }}$ unit & $\begin{array}{l}\text { tables, figures, equations } \\
\text { working forwards and backwards }\end{array}$ & goals \\
\hline $3^{\text {rd }}$ unit & $\begin{array}{l}\text { working forwards and backwards } \\
\text { principle of invariance } \\
\text { exercise }\end{array}$ & volitional strategies \\
\hline $4^{\text {th }}$ unit & $\begin{array}{l}\text { tables, figures, equations } \\
\text { exercise }\end{array}$ & goals, self-reflection, motivation \\
\hline $5^{\text {th }}$ unit & $\begin{array}{l}\text { principle of invariance } \\
\text { exercise }\end{array}$ & volitional strategies \\
\hline $6^{\text {th }}$ unit & integration & self-reflection/handling errors \\
\hline
\end{tabular}

Fig. 9.2 A training program for problem solving and self-regulation (from Perels et al. 2007)

the training on many facets on the teacher and classroom level, such as the ability of teachers to analyze problem-solving situations.

\section{Interview with Regina Bruder about her experiences in the collaboration:}

Bernhard Schmitz and I met at a psychologist meeting in Darmstadt. He was seeking a domain for his current research on self-regulation. I saw an opportunity to profit from the psychological expertise. My goal was an empirical study with respect to my theoretical work on learning and problem solving. I learned from problem-solving training in mathematics 
competitions that mental flexibility can be increased by making pupils aware of heuristic principles and strategies. The question was whether this impressive effect was also achievable in everyday lessons.

One target of the six-year research project funded by the DFG was to prove empirically the validity of theoretically-postulated connections between problem solving and self-regulation. It was also clear from the beginning that a sustainable effect was intended to help us develop lessons with a carefully developed intervention. Three stages were needed for this. First, I had to be sure that problem solving and self-regulation abilities are achievable by most students. In a pilot-study during special courses outside the regular classroom, we ensured that combining training in problem solving and self-regulation produces benefits when compared to pure problem-solving training sessions or pure self-regulation training sessions. In the next step, a teaching concept was developed together with dedicated teachers for how to integrate the strategy training sessions from the pilot study within normal lessons. The effects of this implementation were evaluated again, confirming our pilot study's results. The third step was to transport this lesson concept to teacher teams from various schools. This concept's implementation by the more than fifty teachers involved was monitored via standardized lesson reports. The pupils' problem-solving and self-regulation results were assessed via tests and interviews. In the follow-up study we demonstrated that the classes taught with the combination still possessed stable knowledge on heuristics one year later.

What have I learned for further research? In this project I realized that it is not only helpful but necessary to have a strong theoretical background when hypotheses should be reviewed quantitatively. The attempt to generate new theories from quantitative empirical data will not succeed - you cannot get out more than you have put into it. Furthermore, there were differences in the researchers' view on the project, especially regarding what is still part of the research and what is not. I believe that subject-specific didactic research must not be limited to the generation of general theories: it must develop concepts for transferring the scientific insights into practice as well. We continued to develop further training courses even after the funding ended. The question that remains unanswered is: to what extent are we as researchers also responsible for the results we achieve being put into practice?

\subsubsection{Example 2: Proof of Competence and Worked Examples}

Mathematical proof is a central but difficult topic in school mathematics. It has been intensively addressed in mathematics education (e.g., Hanna and Jahnke 1996; Healy and Hoyles 1998; Reid and Knipping 2010). Many different approaches to teaching proof have been suggested. Since mathematics educators tend to take their own discipline as a starting point, such suggestions may ask for simplifications of the proof concept that are ,intellectually honest' but appropriate for the students' cognitive level. Going back to Branford (1913) and Freudenthal (1978), this has been done in German Stoffdidaktik, for example by Wittmann and Müller (1988) by Inhaltlich-anschauliche Beweise (visual proof) or by Blum and Kirsch $(1989,1991)$ by „preformal proof“. However-although these concepts had a substantial impact on the classroom, mostly via teaching materials-they have not been empirically investigated with respect to their effectiveness.

Cooperation between mathematics education and educational psychology, however, yielded a new approach — one that interconnected a substantial mathematical viewpoint with state-of-the-art learning theory: in the aforementioned priority pro- 
gram, Kristina Reiss (München) and Alexander Renkl (Freiburg) came up with the following idea: Among many theories that describe the process of proof generation, Boero's (1999) six steps-conjecturing, formulating, exploring, deductive organization, formal presentation and discussion within the community-offered a framework that could be translated, with enough adaptations, to the classroom, yielding a heuristic for generating proofs. For learning new concepts, especially in well-structured domains, many experiments revealed the benefit of learning with worked-out examples, thus reducing the cognitive load of executing problem-solving processes in unfamiliar areas.

Both researchers had intensively investigated their respective areas of interest: Reiss and coworkers developed a test to capture levels of proof competence, while Renkl and his team investigated the processes and conditions relevant for learning with worked-out examples.

However, these approaches had to be adapted to the case of proving, since the learning goal was not a well-structured concept but rather a heuristic process (with many vaguely-defined decisions on the way). Several features were implemented to enhance cognitive activity and reduce unwanted cognitive load: (1) blanks within the examples, (2) prompted self-explanations (why certain steps are taken in a proof) or (3) discussion of necessary knowledge (in geometry). Figure 9.3 illustrates the beginning section of a worked example for learning proof.

This approach proved successful in several ways: Students exhibited a moderate increase in proof competence, and less fear of making mistakes. However, it was predominantly the lower-achieving students that profited, while students with solid understanding of the domain may have been bothered by the intervention-a typical phenomenon when using worked examples. A specific teacher-training session could even enhance the effects.

\section{Interview Alexander Renkl about his experiences in the collaboration:}

How did the research question emerge?

AR: Kristina Reiss and I were both involved in the same research priority program. And of course I was always interested in Kristina's project because my interests were always in how to foster students understanding in mathematics and Kristina was also always interested in psychological theories that can be applied to mathematics. Mathematics educators often told me that a drawback of worked examples is that you cannot teach heuristics or creative thinking skills to students. Kristina was working on the project to foster proving skills, so it was quite natural that we would cooperate.

What was the relevance of mathematical educational theories and educational theories for your project?

AR: Kristina had this Boero model of proof generation in mind, namely, a background for how to teach proving or argumentation to the students. It was also important from the math-education perspective to feel good about the mathematical materials you can use. We had to choose some geometry problems to solve. I couldn't have done that as a psychologist. On the other hand, at that time there were, I think, three important theoretical models related to worked-out-example learning, namely the cognitive load theory approach, Chi's self-explanation model - because we always emphasize that students should not just breeze through worked-out examples but rather also explain the rationale of the worked-out examples to themselves - and finally the skill acquisition model of VanLehn. And so these three 


\section{The Problem:}

Florian and Nina have drawn and measured parallelograms. In doing so, they have observed that opposing sides are always of equal length. Also, the opposing angles always were commensurate.

Florian guesses: "Now we have measured so many parallelograms:

We have drawn all kinds of quadrangles and in all cases we have recognized that the opposing sides were of equal length. Each time, the sides and the angles were commensurate. I think, it is always like this!"

Nina: "Actually I also think this is true, but I don't know why. Couldn't it be that by chance, we have only drawn parallelograms for which this was true? And we cannot exactly measure the angles and sides. Perhaps they were only approximately of the same size. "

Florian: "So let's try to prove this like real mathematicians!"

Thus, Florian and Nina try to prove the following mathematical assumption:
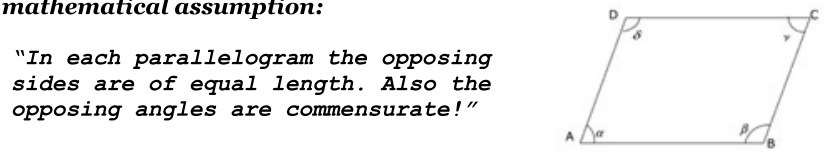

In the following we will have a look at how they solved

this mathematical problem. Do try not only to read this solution, but to complete the particular steps on your own.

II. Examination of the Problem:

First we want to reproduce the measurements of Florian and Nina. You will need a set square, paper and pencils.

II - a) Use the following box to draw a parallelogram ABCD and mark the angles with $\alpha, \beta, \gamma, \delta$. Afterwards measure and note the sizes of the sides and angles.

Draw here: [[Space for individual drawings]]

II - b) The experiments indicate that the opposing sides and angles in all parallelograms are of equal size. You mayremember that this is called congruent. In the 7 th grade you have learned that congruent sides and angles can be transformed on one another by using congruency mappings.

Nina and Florian try to remember:

Nina: "When did we hear of angles and sides that have the same size?"

Florian:"In the 7 th grade."

Nina: „Yes, when we learned about congruency mappings."

What kind of congruency mappings do you remember?

Answer:

Fig. 9.3 Worked example for teaching proof (only beginning section, illustrative pictures removed, source: teaching material supplied by A. Renkl)

psychological models were important as guidelines to design the student environment as an example-based environment.

Did you experience problems with, or any limitations due to the close connection between mathematics and psychology?

AR, I had carried out many interdisciplinary projects in the meantime, and I had also experienced the usual problems in projects like this, but in this specific case there were no real barriers. Kristina is a math educator who is very familiar with psychology, and I'm not too distant from mathematics education. I was always somewhat interested in mathematics 
education even before then. And as our perspectives were not that divergent, there was a lot of productive cooperation; it's also helps when there's mutual affinity, as things then go relatively easily.

What consequences did this close cooperation have for the results or for the way you tackle the problems?

AR: We conducted some shorter controlled studies managed primarily by us and by the psychologists, and that were inspired by the math-education perspective. On the other hand, the more complex classroom studies were done by math educators. Thus everyone's contribution was in his or her field of expertise. This went quite well, and we also benefited from the advantage of obtaining findings from the lab, from more controlled lab-type studies, as well as from the classroom - that's ideal if you want robust findings.

In the second step, I also always need to know what works in the classroom setting, so this cooperation also had the advantage of satisfying this desire of an educational psychologist, namely what I find in the lab can be applied in the classroom.

Could you also claim there was an influence on math education in general or educational psychology coming from your project?

AR: I would say yes, at least in the German math-education community. I got the feeling that worked-out examples didn't play a genuine role initially. Most of the math educators have absorbed a bit of old-fashioned pedagogy. And the idea developed in psychology of using worked examples as specific means of fostering understanding was sometimes hard to get across to math educators. At least I found it hard to explain - to convince those colleagues; however, this project and our results made the math educators more curious about the potential of worked examples for fostering understanding and so it was a kind of door-opener for this idea to those educator communities.

Would you say that there has even been an impact on the classroom, in the German mathematics classroom?

AR: Perhaps, some ideas from our research are included in some mathematics textbooks. So there may be a minor influence, but I would guess that it is primarily evident in the design of textbooks. I would not say that the typical German math teacher knows much about the theory of example-based learning.

How would you say that this specific project influenced your own further studies, your own research later?

AR: I think it had a huge influence, because we grew to realize that worked examples can be applied for algorithmic content as well as other fields. And so we used structurally similar worked examples for non-mathematical areas, and they worked well in those areas, which opened up a totally new field of application possibilities for worked examples. That was a strong influence.

The second benefit was connected to mathematics. I was then also interested in whether I could set aside other restrictions of typical worked-out examples that math educators often pointed out, for example multiple solutions. We then devised worked examples with multiple solutions. And they work if you use them in a good way. We aso devised worked-out examples containing typical errors and guided students to process, to listen in a beneficial way.

Finally over the last several years I have written theoretical papers about what I call focused information processing. Many of these basic ideas originated from this project on proof finding.

The two examples from research demonstrate how empirical research profits from combining theoretical and methodological perspectives of general education research (educational psychology) and of research in mathematics education. It is important to note that, in both examples the "binding force" in the collaboration was not a simple 
sort of work sharing, such as. bringing content expertise and methodological expertise into a project. It was rather the complementary theoretical perspective of a relevant situation in teaching and learning: The commonalities of (subject-independent) selfregulation and (subject-specific) problem solving made it fruitful to combine the two aspects and seek parallels or synergies in their combined instruction. Furthermore, it was the partners' goal in both examples to extend the knowledge in their respective area of interest, e.g., taking the step from worked examples to heuristic worked examples. This step was generated in a productive struggle between the researchers' field of general learning and mathematical proving with respect to the meaning of each of their theories for their partner's field.

Furthermore, one also notes in both projects a certain degree of circumspection in developing and implementing an intervention: The researchers carefully plan the interventions not only considering their power to (dis)prove a hypothesis empirically but also to accommodate an everyday classroom environment, e.g., via a multi-step approach - the research presented here builds upon many studies that the researchers conducted already (on their own) to develop and validate their theories.

The aforementioned projects are inspiring examples of research in (mathematics) education in Germany, and many more researchers have had similar experiences. However, while multi-step research focusing on central phenomena of mathematics learning and teaching are quite prevalent in mathematics education research in German-speaking countries, interdisciplinary research is still the exception, since researchers in subject-matter education and general education often tend to have different backgrounds and belong to different university faculties.

\subsection{Mixed-Methods Research}

The second section introduces two research projects that draw equally from qualitative and quantitative methods in a mixed-method design. As an introduction, a condensed theoretical framework is presented that we refer to again in the discussion of the two research projects.

In recent decades, researchers in mathematics education have expanded their repertoire with research designs that suffice for and can tackle especially multifaceted research problems by integrating different methodological practices, eventually with a mixture of qualitative and quantitative research questions suitable for a complex empirical and theoretical research topic (Johnson and Onwuegbuzie 2004; Hart et al. 2009). However, a review of the latest literature reveals many different theoretical justifications for and definitions of mixed-methods research (MMR), some of which are contradictory (cf. Kelle 2008; Teddlie and Tashakkori 2009).

Although Denzin (1970) originally referred to a combination of multiple forms of qualitative research methods only (Denzin 2012), especially his concept of triangulation has often been referred to in German-speaking countries as a theoretical research background for integrating and employing several (i) data sources, (ii) investigators, (iii) theories, and (iv) methodological practices-both qualitative and quan- 
titative - within a single research design. Remote from its original understanding, the term triangulation is frequently referred to with two different meanings (Schulz 2010; Kelle and Buchholtz 2015, p. 331): (a) "triangulation as a mutual validation of research results" and (b) "triangulation as an integration of complementary perspectives on the subject being investigated to create a more complete image of the research domain."

Being suitable for both of these meanings, the importance of MMR can be justified by taking a closer look at the specific strengths and weaknesses of qualitative and quantitative methods, and how a balance can be struck by different types of MMR designs (Kelle 2008; cf. Schulz 2011): Qualitative research is restricted to the careful choice of a few cases. Moreover, the analysis of unstandardized data is highly dependent on the individual researcher. This "immediately raises questions about the generalizability of findings and about the intersubjectivity of interpretations" (Kelle and Buchholtz 2015, p. 336). On the other hand, qualitative methods are often useful for exploration, detection, and discovery. They help us "construct new theoretical concepts, categories, and sometimes even whole theories about the domain under study" (ibid.). Quantitative research relies on standardization and requires reliable and objective (observer-neutral) data. This enables the investigation of many cases, which contributes to a theoretically grounded basis for generalizations. Quantitative methods are ideally suited for a theory-driven approach, "whereby precise hypotheses are formulated at the onset, then operational definitions are formulated for the concepts these hypotheses comprise, measurement instruments are constructed, and data are collected and analyzed subsequently" (ibid., p. 334). They are therefore appropriate tools to examine clear-cut causal statements. However, the researchers' theoretical knowledge or that of the corresponding discipline may be limited. Furthermore, context-bound patterns, structures and rules may form an integral part of particular life worlds under investigation that may be unknown to the researchers, especially if the socio-cultural background of researchers and respondents differs. Such a lack of knowledge may cause severe problems when formulating hypotheses, defining variables, and creating research instruments. Specifically, when examining causal statements, important variables may be "omitted with low levels of explained variance as a consequence", intervening variables may be overlooked, or functional relations between certain variables may be incorrectly specified "so that causal processes underlying the investigated phenomena are not adequately understood" (ibid., p. 335; cf. Kelle 2008; Schulz and Wirtz 2012).

Being driven by awareness of the specific strengths and shortcomings of monomethodological research designs, MMR designs may be used as strategies "for overcoming each method's weaknesses and limitations by deliberately combining different types of methods" (Brewer and Hunter 1989, p. 11). Meanwhile, various designs and manifold categorizations for MMR designs exist and are discussed in Germanspeaking countries (e.g., Kelle 2008; Kuckartz 2014; Kelle and Buchholtz 2015; Burzan 2016). To discuss many of them would clearly go beyond the scope of this chapter. Instead, we present a concise view into the world of MMR designs that suffices as a framework for discussing the MMR design examples discussed later in this chapter. We concentrate on four prototypical MMR designs: 
(a) In a sequential qualitative-quantitative design, a qualitative study is first used to develop theoretical concepts and hypotheses. Their generalizability is then examined in a quantitative study. A widely used example for this kind of MMR design is when measurement instruments or interventions are developed on the foundation of existing qualitative findings, which enable their operationalization in a quantitative study.

(b) In a sequential quantitative-qualitative design, for example, incomprehensible statistics may lead to their further investigation with the help of qualitative data and methods. Another example is that a quantitative pre-study may support the selection of cases for a qualitative study.

(c) In a parallel qualitative-quantitative design, for example, researchers may interview or observe the same individuals simultaneously while applying different methods. In an experimental setting, a learning progress might be examined in a summative assessment via quantitative methods while the underlying learning processes could be validated or identified via qualitative methods.

(d) A complex qualitative-quantitative design integrates the partial qualitative and quantitative studies systematically, eventually by performing several research cycles altogether. This allows researchers to benefit from the many advantages of both sequential and parallel designs.

Complex designs require extraordinary effort that often can be coped with by wellcoordinated teams only. If individual researchers hope to create a MMR design, they will require expertise in both qualitative and quantitative research methods. Furthermore, they should be aware of the specific strengths and weaknesses of qualitative and quantitative research methods so as to combine and integrate them productively and well targeted.

In the following, we present and discuss two examples of MMR designs from Germany: Kathleen Philipp made use of a sequential mixed-methods design (Philipp 2012; Philipp and Leuders 2012). She analyzed students' strategies while solving several mathematical problems and developed a competence model about experimental thinking in mathematics. This laid the groundwork for an intervention study that confirmed that experimental skills in mathematics can be fostered effectively.

Prediger and Wessel (2013) and Wessel (2014) implemented an integrated, parallel mixed-methods design. They fostered students' understanding of fractions, and scaffolded the learning processes by facilitating students' abilities to talk about fractions and their meaning. Their intervention's efficacy was investigated by a randomized controlled trial and qualitative analyses of the videotaped teaching-learning processes. 


\subsubsection{Example 3: Understanding and Teaching Experimental Thinking in Mathematics}

Knowledge acquisition in the natural sciences is based on experiments. Experimental thinking includes the generation and confirmation of hypotheses. There are similar processes of knowledge generation in mathematics: relationships between different kinds of objects are explored, hypotheses are generated and examined by producing and analyzing examples - as described by e.g. Euler or Pólya. This is the starting point of the project by Philipp et al. (2012) described below.

Despite the analogy, knowledge acquisition in mathematics is quite seldom associated with experimentation (e.g., Bartolini Bussi 2009). Proof and the axiomatic method dominate when establishing mathematical knowledge is discussed. However, that neglects the essential role that experimental thinking in mathematics plays in (i) generating and confirming hypotheses by examining examples before coming to any final proposition, and (ii) in arriving at a mathematical proof.

Concerning the natural sciences, scientific discovery can be described as a process of Dual Search (SDDS, Klahr and Dunbar 1988). The search in two problem spaces (one hypothetical, the other experimental) shapes hypothesis generation, experimental design, and the evaluation of hypotheses.

In their first study, Philipp et al. analyzed the experimental activities of pupils in mathematical problem situations (Leuders et al. 2011). A theory about experimental thinking in mathematics was developed relying on those findings while keeping the theoretical background of experimental thinking in mind. In the following study, experimental thinking skills in mathematics were identified and operationalized. This measurement was used in a pre-post test design to assess the learning effect of an intervention that fostered students' skills in experimental thinking.

The first study's cohort consisted of nine students (prospective teachers) and twelve pupils (grades 3 and 4). They were videotaped while solving mathematical problems. The problems had been chosen to be open-ended and to trigger many hypotheses and examples to solve the problem. One of those problems was the "sums of consecutive numbers" (see Fig. 9.4: "stair numbers").

The analysis made use of Grounded Theory. Procedures were identified and coded. The system below of four core procedural categories became apparent via axial coding: (1) generating examples, (2) structuring examples, (3) generating hypotheses, and (4) testing hypotheses. These four core categories are interrelated in the experimental-thinking process while trying to solve a problem (Fig. 9.5).

In the next quantitative study, the intervention was developed according to approved design principles for fostering problem-solving strategies (Bruder 2003) and included four phases: the introduction of problems, explaining problem-solving procedures, reflecting on procedures and applying them to other situations. Participants were sixth graders (middle school): 126 students were assigned to the intervention group, and 101 students to the control group. The intervention lasted about three weeks. A pre- and post-test with a control group were administered immediately before and after the intervention, a follow-up test about six weeks later. The pre-, 
Fig. 9.4 Sums of consecutive numbers-example problem (cf. Philipp 2012, Abb. 16.1.)

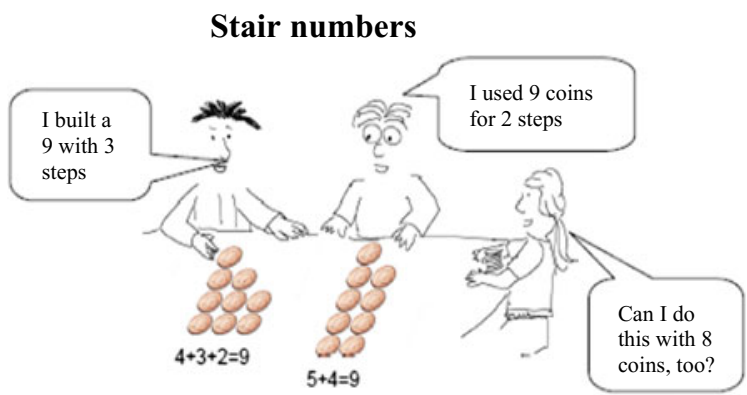

The number researchers (Till, Ole and Maria) investigate stair numbers.

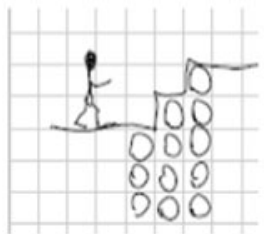

What can you find about stair numbers?

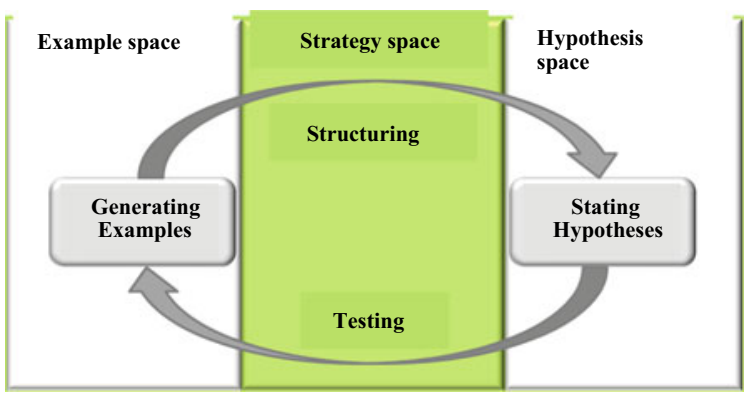

Fig. 9.5 Model of experimental thinking in mathematics (cf. Philipp 2012, p. 289)

post- and follow-up-tests included items for measuring "structuring examples" and "testing hypotheses". The analysis revealed a significant increase in large effects in both areas, which remained stable over 6 weeks. The large effect sizes support the authors' claim that such procedures can be fostered effectively in regular mathematics classrooms.

Interview with Kathleen Philipp (KP), about her experiences within the MMR design described above:

How did you come up with your research question?

KP: "When I was a teacher instructing my pupils in class, I often observed curiosity in children's mathematical thinking. I was given the chance to take part in a large research project as a PhD student on the topic of "experimentation" in mathematics or natural sciences. Being embedded in that research context, our research goal was to analyze the significance 
of experimentation in mathematics, and I was pleased to be able to take a closer look at the experimental thinking of students in the mathematics classroom."

\section{How did your theoretical background influence the research design?}

KP: "The theoretical background concerning processes that are characterizable as experimental approaches was very helpful for me to understand the importance of such processes. When Euler, and later Polya, described experimental processes, I realized it was worth trying to see whether children can do mathematics in a similar manner. One of the challenges in the beginning was to find tasks for students that allowed them to find their own ways to solve a problem, even when they were unfamiliar with such tasks. It was also clear that the interesting processes are internal ones and that it would be hard to observe and analyze them, in particular when young children are involved. To overcome these challenges, I used different methods to collect data.

The theoretical background of the two problem spaces from Klahr and Dunbar helped me understand the complex processes many students demonstrated in these settings. It was very obvious that examples and hypotheses play an important role in mathematical experimentation. But there was something else we needed to understand. I refined the existing theory about two problem spaces and identified a third space that characterizes the kind of strategies used to switch between the two spaces, i.e., between examples and hypotheses."

How did you choose and develop your research strategies?

KP: "First I identified the experimental strategies students use when exploring mathematical problems. When I noticed that students do mathematics in a manner resembling that of mathematicians, I wondered if it would be possible to teach such experimental strategies in class. To investigate this, I had to think about a means of measuring such strategies. Then I developed tasks that would reveal whether experimental strategies were being applied to find a solution. The third step was to develop a teaching unit in the standard curriculum in which I could integrate the training of experimental strategies. Finally, I had the teaching unit taught in several classes. All classes were taught by their regular mathematics teachers. At the end, I compared how frequently the respective students used experimental strategies successfully with classes that had not participated in the training session but who had been taught the same contents by relying on the school textbooks."

Which kinds of triangulation(s) did you implement in your mixed-method design?

KP: "I triangulated several theories and data sources. To generate and analyze my data, I applied both qualitative and quantitative methods."

Why did you implement those kinds of triangulation? Can you describe the interplay of or roles of 'theory development' and 'theory confirmation' in your study?

KP: "The development of my research project required different methods. To identify experimental strategies, I had to take a qualitative approach, because the aim was to investigate and understand students' approaches in depth, and to create a foundation for developing a theory of experimentation while learning mathematics. I therefore applied the Grounded Theory to analyze the students' approaches, which has the advantage of enabling you to develop a theory from your data. Thus, as is typical when using Grounded Theory, it was feasible to identify core strategies that students apply in experimentation.

Quantitative methods were necessary to measure the use of such experimental strategies, which made it possible to investigate a larger group of students (about 230) and make comparisons with a control group.

On the one hand, different methods were necessary to find answers to the specific research questions. On the other hand, the measuring and fostering of experimental strategies validated the theory. I relied on different data sources to observe and assess experimental strategies." Was implementation in the classroom important from the start? 
KP: "Yes, implementation in the classroom was important for me personally. Working as a teacher for many years, it was my research concern to link my research findings to actual practice. In my opinion, it is crucial that research results in our field be relevant in mathematics education."

How did the project influence your later research projects personally?

KP: "For me, this research project was fundamental to the evolution of my research interests. It is still important to me that research results be closely associated with practice. Another aspect is that I have a deep interest in understanding people's thinking and their thought processes."

\subsubsection{Understanding and Teaching Fractions}

Our description of the fourth project example follows Prediger and Wessel (2013) and Wessel (2014) who work on language challenges and conceptual mathematical challenges for students with low language proficiency. Language proficiency is the key determinant of mathematics achievement-not immigrant status or being multilingual (Heinze et al. 2009; Prediger et al. 2018). Students with low language proficiency encounter reading obstacles as well as difficulty in developing conceptual understanding (Prediger et al. 2018).

To support students' constructions of meanings for new mental objects and relationships (Steinbring 2005), the authors draw upon the principle of relating verbal, symbolic, graphic, and concrete representations (Duval 2006; Lesh 1979; Bruner 1967). Conceptual learning processes involve the acquisition of new linguistic, graphic, and symbolic means for expressing mathematical concepts and their meanings (Schleppegrell 2010). This illustrates how deeply interwoven mathematics learning and language learning are (Pimm 1987).

The principles of relating representations has been extended to relating different linguistic registers also, such as establishing first- and second-language registers, mathematical technical registers, a school language register, and the students' everyday registers (see Fig. 9.6: Prediger and Wessel 2013). "A register can be defined as the configuration of semantic resources that a member of a culture typically associates with the situation type... in a given social context" (Halliday 1978, p. 111).

The school register is characterized by context-reduced and complex linguistic means. It differs from the everyday register by appearing conceptually written even if medially oral. Unlike the technical register, the school register is seldom taught explicitly in school. In particular, this is problematic for underprivileged language learners who acquire only everyday language and vocabulary at home but nevertheless require the school register for higher thinking skills (Clarkson 2009), while privileged (first- or second-) language learners are exposed to the school register already at home (Schleppegrell 2004; Cummins 2000).

An intervention was designed that included translations between all registers and related them to each other. The choice of suitable activities for each moment in the 


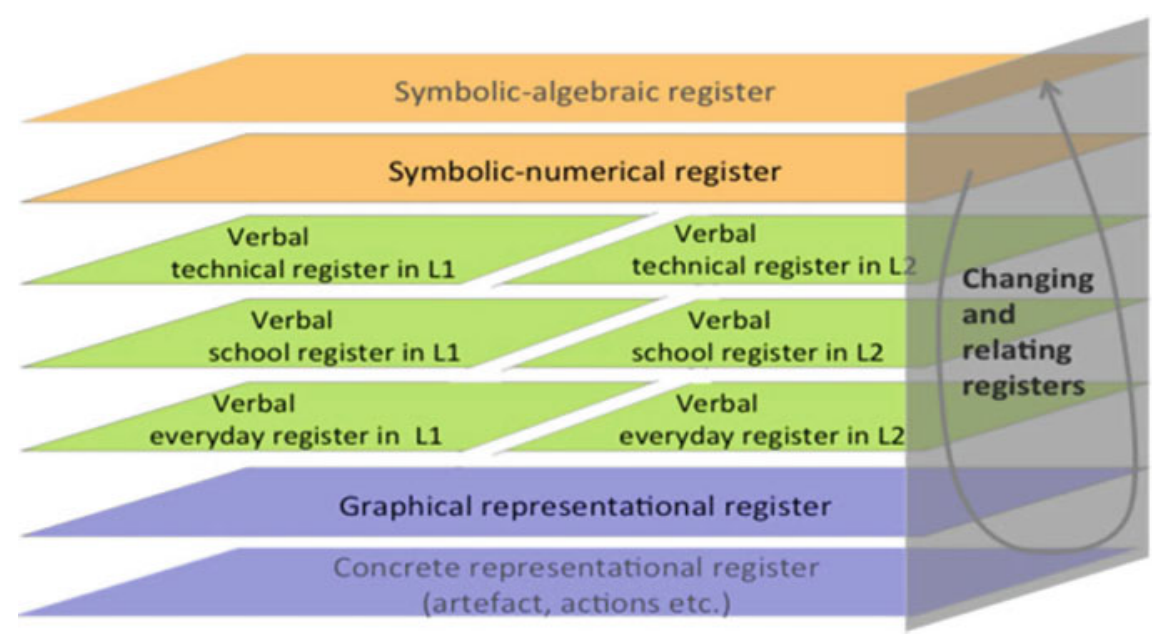

Fig. 9.6 Registers and representations (Prediger and Wessel 2013, p. 438)

learning process was guided by the design strategies of "pushed output" (Swain 1985) and scaffolding (Hammond and Gibbons 2005). The language- and mathematicsintegrated intervention aimed to initiate the construction of mathematical meaning in combination with opportunities to establish the required language means (Prediger and Wessel 2013: Fig. 9.7):

The intervention study took the mixed-methods approach to investigate effects from two research questions in a triangulating manner (Prediger and Wessel 2013, p. 443): “(1) To what extent do students who participate in the language- and mathematics-integrated intervention improve their achievement in the fraction test? (2) What is the situational potential of the intervention activities to initiate students' constructing of meanings and activating of linguistic means in the school and technical register?"

The study sample consisted of 72 seventh-grade second-language learners with below average math performance and limited German language proficiency. The intervention consisted of six lessons lasting $90 \mathrm{~min}$ in 2-to-1 sessions (two students with one teacher). A pre- and post-test randomized controlled trial design with a control group was realized (Fig. 9.8).

The control group was taught by their regular teacher with the usual fraction textbook repetition program. The $18 \times 540 \mathrm{~min}$ were video-taped, and relevant episodes were selected according to research question 2 . The data corpus for the qualitative analysis comprised selected videos, all written materials from the interventions, and the teachers' lesson plans.

The quantitative analysis of the learning gains revealed a low-to-medium effect (intra-group effect size measured by $\mathrm{d}=0.42$ ) in the control group, but a very strong effect $(\mathrm{d}=1.22)$ in the intervention group. Those differences became significant in a later study with a larger cohort (Prediger and Wessel 2018). 


\section{More and more fifth}

c) Now Kenan produces fifths with fraction bars. Complete the table.

\begin{tabular}{l|l|}
$\begin{array}{l}\text { Anteil that } \\
\text { Kenan wants } \\
\text { to draw: }\end{array}$ & My Picture \\
\hline$\frac{1}{5}$ & \\
\hline$\frac{2}{5}$ & \\
\hline$\ldots$ & [the original work sheet has lines for $\frac{3}{5}$ and $\frac{4}{5}$ he \\
\hline & \\
\hline & \\
\hline 5 & \\
\hline Examine the table precisely and consider the following: \\
- What happens with the coloured part of the fraction bar? \\
- Why does the coloured part change?
\end{tabular}

e) Your research:

- How and why does the Anteil change?

- Write down your findings so that another student can understand what is happening with the Anteil and why the Anteil changes.

- You can use the following words:

What changes?

- the numerator

- the denominator

- the number of friends

- the number of chocolate bars
How does it change?

- more

- less

- bigger

- smaller

- the same

Fig. 9.7 Macro scaffolding (Prediger and Wessel 2013, p. 444); "Anteil” in (e) is used deliberately by the authors in their translation of the task. It signifies the mental image connected to a fraction as a part of a whole

Quantitative analysis of learning effects was complemented by a qualitative analysis to exploratively reconstruct the situational potential of the design strategies and instructional activities in the learning processes (Prediger and Wessel 2013: Fig. 9.8). The qualitative analysis included in-depth analysis of the videotaped teaching-learning processes: (1) the aim of sequential analysis was to reconstruct individual and interactional processes of meaning construction for fractions, (2) several qualitative coding procedures for students' utterances were conducted to capture different linguistic aspects, and (3) students' development of mathematical meaning and lin- 


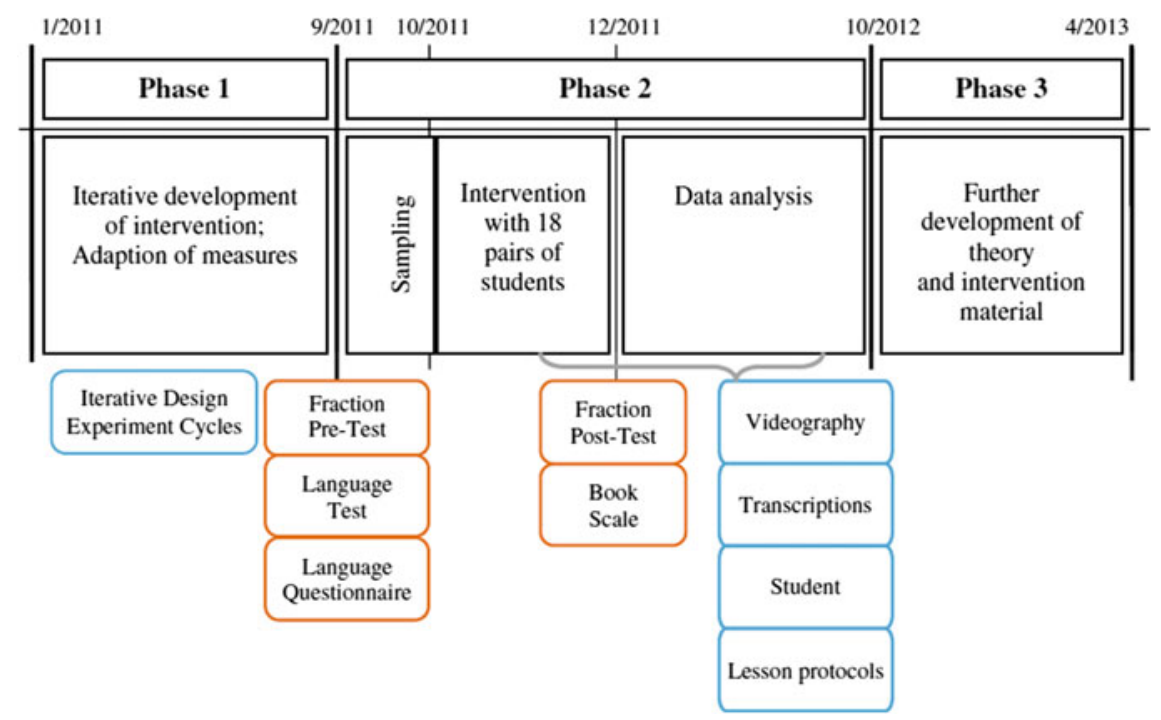

Fig. 9.8 Mixed-methods design (Prediger and Wessel 2013, p. 445)

guistic means were reconstructed in their interaction with concrete elements of the instructional design.

This qualitative analysis identified the specific potential of macro- and microscaffolding in combination with the design strategy of pushed output.

The MMR design was reflected in the study findings (Prediger and Wessel 2013, p. 453): "Whereas these quantitative results alone might have been explained on the basis of the intensity of individual teaching, the case studies gave some first insights into how the design elements offered fruitful learning opportunities, since they showed the deep interconnection of linguistic and mathematical learning processes: ...With the help of macro and micro scaffolding, low-achieving students successfully proceeded from their everyday language to a language for thinking and talking about structural relationships."

\section{Interview with Susanne Prediger (SP), about her experiences within the above-described MMR design:}

How did the research question emerge? Was it a rational decision?

SP: "A research question is also a matter of personal choices, but it is of course based on a rational decision. Regarding the challenges of language learners in mathematics: by 2011, we had a situation where we had a lot of statistical evidence of connections between language proficiency and mathematics learning. But we did not know much about how to foster language learning. We thus chose to continue to dig deeper and beyond the current descriptive knowledge, to find answers about how to foster language learners and what could work for them."

How did the theoretical background influence the research design?

SP: "That it definitely does. In our case it's how you conceive of the role of language in the learning process. When we consider language only as relevant in its communicative function, 
it might suffice to gather knowledge about how to approach word problems and alleviate language difficulties in word problems. But we start from the assumption that language has a deep cognitive function within mathematical learning processes. If we want to delve deeper into that, we need to study the learning processes, and see how the interplay between language and mathematics really works. That is why we had to initiate mathematics- and language-integrated processes. In everyday classrooms, we observed hardly any conceptual learning opportunities for students with low language proficiency, which created the need to establish an instructional design specifically for those students as a research context for our research questions."

What kinds of triangulations did you implement in your mixed-methods design?

SP: "First of all it is a triangulation of data, because we wanted on the one hand to gather data about the intervention's function to see if it works. To test what works, you need a pre- and a post-test, you need to conduct a randomized controlled trial. But if you want to learn how it works, you really need data on the actual processes, meaning video data and qualitative analysis.

On the theoretical level, we preferred working with networking theories. It is a similar idea, but it is not just about putting the two next to another. You really have to integrate the different theories. Regarding this topic of language and mathematics education, of course you need theories about mathematics learning and you need theories about language and its role, and they have to be combined."

Can you describe the interplay between 'theory development' and 'theory confirmation' in your study?

SP: "In the classical sense we only discuss confirming theories, which is all about hypotheses and validating them. The randomized controlled trial is the research approach of choice for validating hypotheses. In our case, we could validate the hypothesis that students with low language proficiency learn better when they are given language- and mathematics-integrated learning opportunities.

However, before you can validate a hypothesis, you must develop categories to characterize phenomena and to generate hypotheses to be validated. This is where qualitative, explorative research approaches are most suitable.

In our research, we really combined these two approaches: we validated a hypothesis that had been quite general and invested a lot of time and energy to generate a theory on a more fine-grained level. For this, we had to develop the categories in which we could formulate phenomena and refined hypotheses. The importance of generating categories is often underrated.

In the present project the validation of the hypothesis that a language- and content-integrated intervention might be more effective was only a starting point. To elaborate upon our theory, we had to investigate the processes in depth to understand what exactly happened in the learning processes. And this qualitative research enabled us to generate categories that we could use as a starting point and for initial hypotheses for the next project. Within the next project, which is now being funded by the German Research Foundation, we again have some hypotheses that we can validate or reject, and we will generate new questions and new aspects to be studied in greater depth. (Prediger and Wessel 2018)

Thus, there's always interplay between hypothesis generation and its validation. Indeed, the categories are really the most important element in terms of theory generation. There is a worthwhile article by Cobb and diSessa, who talk about ontological innovations. Their article puts emphasis on the generation of categories as the major output of research."

What do you personally prefer: to start with a qualitative study, or take a quantitative approach? 
SP: “(Laughs) Neither nor - it's more like going backward and forward. Sometimes, like in this project, there was quantitative evidence of a problem with language proficiency and mathematics achievement. Thus, we started to understand what the problem was qualitatively, and conducted design research cycles to devise an intervention that we could put to the test in a randomized controlled trial. Yet I would never want to conclude with a randomized controlled trial, because we need to understand how things work and what really happens in these processes. So, it really is a backward-forward movement. I'm really pleased that we have funding for two successive projects, including the one described here. In both we dug deeper and deeper into the details about what students really need, into what kinds of fostering in language terms they require, and into the type of fostering that is genuinely effective.

It's like the question about the hen and the egg - you can't tell where to start, you have to take a combined, cyclical approach."

\section{Summarizing comments on the two MMR projects and the interviews}

Many researchers in mathematics education consider themselves to be engaged in an applied discipline, where research should contribute to improving education. Learning mathematics with understanding is a complex process, and (Hart et al. 2009, p. 39) "mixed methods research may be an appropriate response to calls for greater generalizability of results while maintaining enough detail about the processes of teaching and learning to be valid and useful." This idea on the purpose and use of MMR in mathematics education was expressed clearly by the two researchers we interviewed, Kathleen Philipp and Susanne Prediger. It goes together with the concern expressed by Hart et al. (ibid.), that research in mathematics education does not only need to know "if particular educational experiments improve learning with understanding but also how those results are achieved and why we can expect them to be replicated elsewhere."

The two examples above and the interviews with the researchers illustrate how MMR in particular can contribute a great deal of both scientific and practical knowledge to the evidence on "what works" (cf. Chatterji 2005): in particular, the MMR project discussed by Kathleen Philipp (cf. Philipp 2012; Philipp and Leuders 2012) exemplified how the use of systemic, contextually-grounded studies in early phases may be followed by more sharpened, analytic experimental studies in later research phases. The MMR project discussed by Prediger and Wessel (2013) and Wessel (2014) underscored that the combined use of more than one research method may help us reveal patterns, develop new constructs and deepen the understanding of relationships between constructs, especially causal relationships. However, as Prediger expressed it in her interview, it is not necessary "to end with a randomized controlled trial, because we want to understand how the things work and what really happens in the processes." 


\subsection{Conclusion}

The four examples of research presented here can by no means claim to be representative for educational research in mathematics in German-speaking countries. However, they do illustrate several of the characteristics and strategies of research often encountered and explicitly discussed within the research community-in many other countries beyond German-speaking Europe.

\section{References}

Bartolini Bussi, M. (2009). Experimental mathematics and the teaching and learning of proof. In V. Durand-Guerrier, S. Soury-Lavergne \& F. Arzarello (Eds.), Proceedings of the Sixth Congress of the European Society for Research in Mathematics Education. Working Group 2. Argumentation and proof (pp. 221-230). Lyon (France).

Blum, W., \& Kirsch, A. (1989). Warum haben nichttriviale Lösungen von f' $=\mathrm{f}$ keine Nullstellen? Beobachtungen und Bemerkungen zum inhaltlich-anschaulichen Beweisen. In H. Kautschitsch \& W. Metzler (Hrsg.), Anschauliches Beweisen (pp. 199-209). Wien, Stuttgart: Hölder-PichlerTempsky, Teubner.

Blum, W., \& Kirsch, A. (1991). Preformal proving: Examples and reflections. Educational Studies in Mathematics, 22, 183-203.

Boero, P. (1999). Argumentation and mathematical proof: A complex, productive, unavoidable relationship in mathematics and mathematics education. International Newsletter on the Teaching and Learning of Mathematical Proof, 7(8).

Branford, B. (1913). Betrachtungen über mathematische Erziehung vom Kindergarten bis zur Universität. Leipzig, Berlin: Teubner.

Brewer, J., \& Hunter, A. (1989). Multimethod research: A synthesis of styles. Sage Publications, Inc.

Bruder, R. (2003). Methoden und Techniken des Problemlösenlernens. Material im Rahmen des BLK-Programms „Sinus “zur,, Steigerung der Effizienz des mathematischnaturwissenschaftlichen Unterrichts “. Kiel: IPN.

Bruder, R., Komorek, E., Collet, C., \& Schmitz, B. (2007). Contents and results of an intervention study in mathematics lessons at secondary level with a teaching concept to support mathematical problem-solving and self-regulative competencies. In M. Prenzel (Ed.), Studies on the educational quality of schools (pp. 197-219). Münster: Waxmann.

Bruner, J. S. (1967). Toward a theory of instruction. Cambridge: Harvard University Press.

Burchartz, B., \& Stein, M. (1998). The invisible wall project: Problem-solving processes of pupils who work on problems with a goal which cannot be reached. Münster: Wilhelms-Universität.

Burzan, N. (2016). Methodenplurale Forschung: Chancen und Probleme von Mixed Methods. Weinheim/ Basel: Beltz Juventa.

Chatterji, M. (2005). Evidence on "what works": An argument for extended-term mixed-method (ETMM) evaluation designs. Educational Researcher, 34(5), 14-24.

Clarkson, P. (2009). Mathematics teaching in Australian multilingual classrooms. In R. Barwell (Ed.), Multilingualism in mathematics classrooms-Global perspectives (pp. 145-160). Bristol: Multilingual Matters.

Cohors-Fresenborg, E., \& Striethorst, A. (2003). Untersuchung individueller Unterschiede in der mentalen Repräsentation von symbol verarbeitenden Regelsystemen [Investigating individual differences in the mental representation of symbol processing rule systems]. ZDM, Zentralblatt für Didaktik der Mathematik, 35(3), 94-101. 
Cummins, J. (2000). Language, power, and pedagogy: Bilingual children in the crossfire (Vol. 23). Clevedon: Multilingual Matters.

De Corte, E., Verschaffel, L., \& Op't Eynde, P. (2000). Self-regulation: A characteristic and a goal of mathematics education. In M. Boekaerts, P. R. Pintrich, \& M. Zeidner (Eds.), Handbook of self-regulation (pp. 687-725). San Diego: Academic Press.

Denzin, N. K. (1970). The research act. Chicago, IL: Aldine.

Denzin, N. K. (2012). Triangulation 2.0. Journal of Mixed Methods Research, 6(2), 80-88.

Duval, R. (2006). A cognitive analysis of problems of comprehension in a learning of mathematics. Educational Studies in Mathematics, 61(1-2), 103-131.

Franke, M. (1998). Kinder bearbeiten Sachsituationen in Bild-Text Darstellung [Solving multiplicative word problems in a picture-text combination]. Journal für Mathematik-Didaktik, 19(2-3), 89-122.

Freudenthal, H. (1978). Vorrede zu einer Wissenschaft vom Mathematikunterricht. München: Oldenbourg.

Halliday, M. A. (1978). Language as social semiotic. London: Arnold.

Hammond, J., \& Gibbons, P. (2005). Putting scaffolding to work: The contribution of scaffolding in articulating ESL education. Prospect, Special Issue, 20(1), 6-30.

Hanna, G., \& Jahnke, H. N. (1996). Proof and proving. In A. J. Bishop (Ed.), International handbook of mathematics education (pp. 877-908). New York: Kluwer Academic Publishers.

Hart, L. C., Smith, S. Z., Swars, S. L., \& Smith, M. E. (2009). An examination of research methods in mathematics education (1995-2005). Journal of Mixed Methods Research, 3(1), 26-41.

Hasemann, K. (1997). The use of concept maps for evaluating students' arithmetical understanding. In J. Hamers, M. Overtoom (Eds.), Inventory of European programmes for teaching thinking (pp. 189-196). Doetichem/Rapallo.

Hasselhorn, M., \& Hager, W. (2001). Kognitives training. In D. H. Rost (Ed.), Handbuch Pädagogische Psychologie (pp. 343-351). Weinheim: Psychologie Verlags Union.

Healy, L., \& Hoyles, C. (1998). Justifying and proving in school mathematics. Technical report on the nationwide survey. Mathematical science. London: Institute of Education, University of London.

Heinze, A., Reiss, K., Rudolph-Albert, F., Herwartz-Emden, L., \& Braun, C. (2009). The development of mathematical competence of migrant children in German primary schools. Proceedings of the 33rd PME, 3, 145-152.

Johnson, R. B., \& Onwuegbuzie, A. J. (2004). Mixed methods research: A research paradigm whose time has come. Educational Researcher, 33(7), 14-26.

Kelle, U. (2008). Die Integration qualitativer und quantitativer Methoden in der empirischen Sozialforschung. Ort: Vs Verlag.

Kelle, U., \& Buchholtz, N. (2015). The combination of qualitative and quantitative research methods in mathematics education: A "mixed methods" study on the development of the professional knowledge of teachers. In A. Bikner-Ahsbahs, C. Knipping, \& N. Presmeg (Eds.), Approaches to qualitative research in mathematics education (pp. 321-361). Dordrecht, Heidelberg, New York, London: Springer.

Klahr, D., \& Dunbar, K. (1988). Dual space search during scientific reasoning. Cognitive Science, 12(1), 1-48.

Krummheuer, G. (1998). Formats of argumentation in the mathematics classroom. In: H. Steinbring, M. G. Bartolini Bussi, \& A. Sierpinska, (Hrsg.), Language and communication in the mathematics classroom. Reston: NCTM.

Kuckartz, U. (2014). Mixed methods: Methodologie, Forschungsdesigns und Analyseverfahren. Wiesbaden: Springer.

Lesh, R. (1979). Mathematical learning disabilities. In R. Lesh, D. Mierkiewicz, \& M. G. Kantowski (Eds.), Applied mathematical problem solving (pp. 111-180). Columbus: Ericismeac.

Leuders, T., Naccarella, D., \& Philipp, K. (2011). Experimentelles Denken - Vorgehensweisen beim innermathematischen Experimentieren. Journal für Mathematik-Didaktik, 32(2), 205-231. 
Perels, F., Otto, B., Schmitz, B., \& Bruder, R. (2007). Evaluation of a training programme to improve mathematical as well as self-regulatory competences. In M. Prenzel (Ed.), Studies on the educational quality of schools (pp. 197-219). Münster: Waxmann.

Polya, G. (1949). Preliminary remarks on a logic of plausible inference. Dialectica, 3(1-2), 28-35.

Philipp, K. (2012). Experimentelles Denken: theoretische und empirische Konkretisierung einer mathematischen Kompetenz. Wiesbaden: Springer.

Philipp, K., \& Leuders, T. (2012). Innermathematisches Experimentieren - empiriegestützte Entwicklung eines Kompetenzmodells und Evaluation eines Förderkonzepts. In W. Riess, M. Wirtz, B. Barzel, \& A. Schulz (Eds.), Experimentieren im mathematisch-naturwissenschaftlichen Unterricht: Schüler lernen wissenschaftlich denken und arbeiten (pp. 285-300). Münster: Waxmann.

Pimm, D. (1987). Speaking mathematically. London: Routledge.

Prediger, S., \& Wessel, L. (2013). Fostering German-language learners' constructions of meanings for fractions-Design and effects of a language-and mathematics-integrated intervention. Mathematics Education Research Journal, 25(3), 435-456.

Prediger, S., \& Wessel, L. (2018). Brauchen mehrsprachige Jugendliche eine andere fach- und sprachintegrierte Förderung als einsprachige? Zeitschrift für Erziehungswissenschaft, 21(2), 361-382. https://doi.org/10.1007/s11618-017-0785-8.

Prediger, S., Wilhelm, N., Büchter, A., Gürsoy, E., \& Benholz, C. (2018). Language proficiency and mathematics achievement-Empirical study of language-induced obstacles in a high stakes test, the central exam ZP10 [Authorized English translation of Sprachkompetenz und Mathematikleistung]. Journal für Mathematik-Didaktik, 36(1), 77-104. https://doi.org/10.1007/s13138-0180126-3.

Prenzel, M. \& Schöps, K. (2007). The educational quality of schools (BiQua): A priority programme of the German Research Foundation (DFG). In M. Prenzel (Ed.), Studies on the educational quality of schools: The final report on the DFG Priority Programme (S. 7-18). Münster: Waxmann.

Reid, D. A., \& Knipping, C. (2010). Proof in mathematics education. Research, learning and teaching. Rotterdam: Sense Publisher.

Reiss, K. (1999). Spatial ability and declarative knowledge in a geometry problem-solving context. In O. Zaslavsky (Ed.), Proceedings of the 23rd International Conference for the Psychology of Mathematics Education (Vol. I, p. 303). Haifa (Israel): Technion.

Schleppegrell, M. J. (2004). The language of schooling. A functional linguistics perspective. Mahwah, NJ: Erlbaum.

Schleppegrell, M. J. (2010). Language in mathematics teaching and learning. A research review. In J. Moschkovich (Ed.), Language and mathematics education (pp. 73-112). Charlotte: Information Age Publishing.

Schmitz, B., \& Wiese, B. S. (2006). New perspectives for the evaluation of training sessions in selfregulated learning: Time-series analyses of diary data. Contemporary Educational Psychology, 31, 64-96.

Schulz, A. (2010). Ergebnisorientierung als Chance für den Mathematikunterricht?: Innovationsprozesse qualitativ und quantitativ erfassen (Vol. 17). München: Herbert Utz Verlag.

Schulz, A. (2011). Konkrete wissenschaftliche Erkenntnisprozesse in qualitativen und quantitativen Studien haben mehr Gemeinsamkeiten als Unterschiede .... In R. Haug \& L. Holzäpfel (Eds.), Beiträge zum Mathematikunterricht 2011 (pp. 783-786). Münster: WTM Verlag.

Schulz, A., \& Wirtz, M. (2012). Analyse kausaler Zusammenhänge als Ziel des Experimentierens. Werner Rieß, Markus Wirtz, Bärbel Barzel und Andreas Schulz (Hg.): Experimentieren im mathematisch-naturwissenschaftlichen Unterricht (pp. 39-56). Münster: Waxmann.

Steinbring, H. (1997). Epistemological investigation of classroom interaction in elementary mathematics teaching. Educational Studies in Mathematics, 32(1), 49-92.

Steinbring, H. (2005). The construction of new mathematical knowledge in classroom interaction: An epistemological perspective (Vol. 38). Berlin, New York: Springer Science \& Business Media.

Swain, M. (1985). Communicative competence: Some roles of comprehensible input and comprehensible output in its development. Input in Second Language Acquisition, 15, 165-179. 
Teddlie, C., \& Tashakkori, A. (2009). Foundations of mixed methods research: Integrating quantitative and qualitative approaches in the social and behavioral sciences. Thousand Oaks, California, USA: Sage.

Viet, U., Schmidt, V., Sommer, N., \& Grommelt, U. (1982). Changes in the cognitive level of development of 5th-grade school-children (Orientierungsstufe) in mathematics classes. Zeitschrift für Pädagogik, 28(3), 365-380.

Wessel, L. (2014). Fach-und sprachintegrierte Förderung durch Darstellungsvernetzung und Scaffolding: Ein Entwicklungsforschungsprojekt zum Anteilbegriff (Vol. 19). Wiesbaden: Springer.

Wittmann, E. C., \& Müller, G. (1988). Wann ist ein Beweis ein Beweis? In P. Bender (Ed.), Mathematikdidaktik: Theorie und Praxis (pp. 237-257). Berlin: Cornelsen.

Wollring, B. (1994). Animistische Vorstellungen von Vor- und Grundschulkindern in stochastischen Situationen [Animistic thinking of pre-school children and children in primary school in stochatstic situations] Journal für Mathematikdidaktik, 15(1-2), S.3-34.

Open Access This chapter is licensed under the terms of the Creative Commons Attribution 4.0 International License (http://creativecommons.org/licenses/by/4.0/), which permits use, sharing, adaptation, distribution and reproduction in any medium or format, as long as you give appropriate credit to the original author(s) and the source, provide a link to the Creative Commons licence and indicate if changes were made.

The images or other third party material in this chapter are included in the chapter's Creative Commons licence, unless indicated otherwise in a credit line to the material. If material is not included in the chapter's Creative Commons licence and your intended use is not permitted by statutory regulation or exceeds the permitted use, you will need to obtain permission directly from the copyright holder.

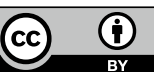




\title{
Chapter 10 \\ Large-Scale Studies in Mathematics Education Research
}

\author{
Kristina Reiss, Andreas Obersteiner, Aiso Heinze, \\ Ursula Itzlinger-Bruneforth and Fou-Lai Lin
}

\begin{abstract}
Large-scale studies assess mathematical competence in large samples. They often compare mathematical competence between groups of individuals within or between countries. Although large-scale research is part of empirical educational research more generally, it is also linked to more genuine mathematics education research traditions, because sophisticated methods allow for empirical verifications of theoretical models of mathematical competence, and because results from largescale assessments have influenced mathematics education practices. This chapter provides an overview of large-scale research in mathematics education in German speaking countries over the last decades. After a brief review of historical developments of large-scale assessments in Germany, we focus on the development of competence models in Germany and Austria. At the end of this chapter, we reflect on recent developments and discuss issues of large-scale assessments more generally, including an international perspective.
\end{abstract}

Keywords Large-scale assessment $\cdot$ Mathematical competence $\cdot$ Competence models · PISA study

K. Reiss $(\bowtie)$

TUM School of Education, Technical University of Munich, Munich, Germany e-mail: kristina.reiss@tum.de

A. Obersteiner

Freiburg University of Education, Freiburg im Breisgau, Germany

A. Heinze

Leibniz Institute for Science and Mathematics Education, Kiel, Germany

U. Itzlinger-Bruneforth

Federal Institute for Educational Research, Innovation \& Development of the

Austrian School System, Salzburg, Austria

F.-L. Lin

National Taiwan Normal University, Taipei, Taiwan

(C) The Author(s) 2019

H. N. Jahnke and L. Hefendehl-Hebeker (eds.), Traditions in German-Speaking

Mathematics Education Research, ICME-13 Monographs,

https://doi.org/10.1007/978-3-030-11069-7_10 


\subsection{Introduction}

In recent years, researchers have assessed mathematical competence in large samples using sophisticated statistical methods. Large-scale assessment of mathematical competences requires close collaboration between researchers from mathematics education, statistics, and psychology. Accordingly, the lines of research presented in this chapter are linked to both mathematics education research traditions and, more broadly, large-scale empirical educational research. The chapter is structured into five sections. The following paragraphs provide an introduction to the contents of the five sections.

Popular large-scale studies such as PISA (Programme for International Student Assessment) have received much public attention and have led to a stronger focus on the outcome of school education in general and of mathematics education in particular. In Germany, international large-scale studies did not receive much attention before 1995, when Germany took part in the Third International Mathematics and Science Studies (TIMSS) for the first time. The results showed that German lower and upper secondary school students' mathematical performance did not meet the expectations of teachers, educators, and the general public. German students performed below the international average and showed acceptable results only for routine problems (Baumert et al. 1997). The results of PISA 2000 (Baumert et al. 2001) were again disappointing. Consequences from these studies were intensive debates among educators and stakeholders, and the launch of educational programs to improve mathematics instruction at school. Another consequence was the agreement to use large-scale assessments on a regular basis to monitor the outcome of school education. We elaborate on these developments in Sect. 10.2.

The developments in large-scale empirical educational research are related to mathematics education research because assessing mathematical competence in large samples was accompanied by the development and the empirical verification of theoretical models of mathematical competence. Assessing students' mathematical competences requires models of what mathematical competence should be. Initial models were predominantly based on theoretical and normative considerations but rarely on empirical evidence. Reiss and colleagues (e.g., Reiss et al. 2007a, b; Reiss et al. 2012) developed a model for primary mathematics education that took into account theoretical and normative perspectives and was continuously refined on the basis of empirical evidence. The model suggests five levels of mathematical competence ranging from technical background knowledge and routine procedures to complex mathematical modelling. Section 10.3 of this chapter provides an overview of this model of mathematical competence.

To monitor the outcome of education on a regular basis, new institutions were founded in Germany, such as the Institute for Educational Quality Improvement (IQB, Berlin) and the Center for International Student Assessment (ZIB, Munich). The idea of system monitoring is, however, not specific to Germany. Other countries founded similar institutions and developed similar models of mathematical competence to assess students' competences on a regular basis. In Austria, the Federal Institute for 
Educational Research, Innovation and Development of the Austrian School System (BIFIE) was founded on a similar basis as institutions in Germany. One core function of the institute was to establish and disseminate knowledge about educational standards in mathematics. These standards were based on a theoretical framework which included a model of mathematical competence with three dimensions (process, content, and complexity). This model is based on the existing mathematics curriculum and represents a new structure for teaching, learning and assessment of mathematics. In Sect. 10.4, we elaborate on this model of mathematical competence and its development in Austria.

In conclusion, large-scale studies allow monitoring the outcome of mathematics education on the system level. The broad data these studies provide have been used to empirically validate theoretical models of mathematical competence and have contributed to a more realistic view on what students are capable of learning at school. However, there are several general issues of large-scale studies such as their purpose and their risks that need to be discussed. At the end of this chapter, in Sect. 10.5, we reflect on recent developments and discuss more general issues of large-scale assessments that reach beyond the traditions in German-Speaking countries.

\subsection{Large-Scale Assessment: Impact on Mathematics Educational Research and Practice in Germany}

The aim of this section is to provide an overview of the impact of large-scale assessment (LSA) studies on mathematics educational research and practice in Germany. The section is structured into four subsections. The first subsection provides some historical background information about the public discussion of the LSA results from TIMSS 1995 and PISA 2000 in Germany. In the next three subsections, we describe the impact of LSA on mathematics educational research, on mathematics education as a scientific discipline, and on schools and mathematics teachers, respectively.

\subsubsection{LSA of Mathematical Competence in Germany: How It Started (TIMSS 1995 and PISA 2000)}

The history of (international) LSA of mathematical competence started in Germany in 1995. Until then, Germany did not take part in international comparison studies on outcomes of mathematics education. Moreover, until 2000 there were no comparisons between the 16 federal states in Germany. The latter is particularly interesting because in the 1970s and 1980s there were heated (political) debates within and between the federal states about the most effective school system, the educational goals, and the preferred teaching styles. Although there was disagreement among 
the federal states, politicians were convinced that Germany in general had a highlevel educational system. Hence, many were disappointed by the results of TIMSS 1995 for lower and upper secondary students in mathematics. Germany scored below the international average and the performance level was only acceptable for routine problems (Baumert et al. 1997). The consequence was a discussion within the educational sciences and educational administrations (Blum and Neubrand 1998) but there was hardly any discussion in the public. The results of TIMSS 1995 were supplemented by the findings of TIMSS Video 1995. This study confirmed findings from earlier case studies (e.g., Bauersfeld 1978) describing a typical teaching style in German mathematics classrooms (Stigler et al. 1999; Neubrand 2002). A feature of this teaching style was a low variation of teaching methods, which often meant direct instruction accompanied by low-level question-answer-sequences (so-called "funnel pattern", Bauersfeld 1978). Moreover, a low quality of tasks and task implementation was reported. As a consequence, the responsible politicians decided in 1997 to participate in international comparisons and to compare educational outcomes of the 16 federal states on a regular basis.

In 2000, Germany took part in the first PISA study. Like the results of TIMSS, the results of PISA were again relatively weak, from both a criterion-oriented and an international comparative perspective (Deutsches PISA-Konsortium 2001). For mathematics, the study identified a large group of low-performing students (about $25 \%$ ) and only a small group of high-performing students (about 2\%). Moreover, there was a strong relation between students' achievement and their socio-economic background, and there were large differences between the 16 German federal states. A specific weakness of German students was the ability to use their mathematical knowledge in real-life situations. In contrast to the TIMSS 1995 results, the PISA results were debated in the broader public. For example, the fact that German students and students from the U.S. were quite similar with respect to the level of mathematics competence and the relation between achievement and socio-economic background was discussed intensively.

\subsubsection{Impact on (Mathematics) Educational Research in Germany}

The political decision to participate in international LSA provided various opportunities for educational research. Accordingly, the LSA itself as well as the results of the LSA had an impact on (mathematics) educational research in Germany. On the one hand, it influenced descriptive research, and on the other hand, it induced studies aiming at explanations for the descriptive LSA findings.

The motivation for further descriptive research studies relied on the mission of educational research to provide a basis for political decisions to improve the educational system. With TIMSS 1995 and PISA 2000 it became clear that educational policy in Germany was based on insufficient information about the educational real- 
ity. Hence, subsequent to the first international LSA on the secondary level, educational research used the opportunities of national extensions of the follow-up cycles as well as of additional LSA in other age groups. For example, in PISA 2003, the German sample was supplemented by an additional sample of students with migration background (so-called oversampling). It turned out that language skills and socio-economic status (SES) were the main factors for the comparatively low mathematics performance of students with migration background. Moreover, the PISA 2003 sample was tested again one year later to collect information about students' learning progress in mathematics. The findings indicated that there was large variation in mathematics competence development between school classes. Only $58 \%$ of students showed a significant increase of mathematical competence from grade 9 to grade 10 on the mathematics PISA scale (for more details on how mathematical competence was conceptualized, see Sect. 10.3.1).

Several additional LSA studies were conducted with respect to mathematical competence in other populations than secondary students, such as:

- TIMSS in grade 4 at the end of German primary school. The findings for mathematics competence were similar to those observed in secondary school. This means that many problems already evolve in primary schools.

- TEDS (Teacher Education and Development Study) — the study on professional knowledge of mathematics pre-service teachers (Blömeke et al. 2010). One of the striking results was that non-certified mathematics teachers show very low professional knowledge.

- PIAAC (Programme for the International Assessment of Adult Competencies) - the study of adults' competence in various domains including mathematics. The mathematical competence of German adults is on an average level in comparison to the OECD countries. However, about $17 \%$ of the German adults show very poor mathematical competence, which corresponds to the PISA results (Rammstedt 2013). Typically, adults master mathematical procedures they need in their every-day or professional live (the "use it or loose it phenomenon", Duchhardt et al. 2017).

- NEPS (National Educational Panel Study). This project started in 2008 with the goal of creating a panel of longitudinal data of competence development (mathematics, science, language) and specific conditions of learning environments (www. neps-data.de). The data collection is based on a multi-cohort-sequence-design which follows cohorts starting with babies, kindergarten children, 5th-graders, 9th-graders, university students, and adults. The panel provides data for the scientific community which allows examining longitudinal competence development in mathematics (Neumann et al. 2013).

In addition to descriptive research several explanatory research studies and study programs were conducted. In essence, the aim of these projects was to explain the previously obtained descriptive results and to generate knowledge which might help to improve mathematics education in schools. Examples for research programs are the priority programs "Educational Quality of Schools" and "Competence Models", supported by the German Science Foundation (DFG), or the framework program 
"Empirical Educational Research", supported by the Federal Ministry of Education and Research. Examples of studies that were conducted within these programs are:

- The Pythagoras video study (Lipowsky et al. 2009) focusing on lessons about the Pythagorean Theorem. This study combined data on the quality of mathematics instruction with data on students' learning progress.

- Projects on reasoning and proof in geometry classroom (Reiss et al. 2007a) or teaching problem solving (Komorek et al. 2007). These projects analyzed conditions for successful mathematics instruction fostering students' competences in geometric proof and in problem solving. They also developed teaching concepts and material and evaluated them in intervention studies.

- The COACTIV study (Professional Competence of Teachers, Cognitively Activating Instruction, and Development of Students' Mathematical Literacy), which investigated professional competence of mathematics teachers and aspects of their mathematics instruction in the PISA 2003 follow-up sample (Kunter et al. 2013). This study provided evidence for the influence of mathematics teachers' content knowledge (CK) and pedagogical content knowledge (PCK) on instructional quality and students' learning progress. In particular, the complexity of mathematical problems used in German mathematics classrooms within one school year was examined (Jordan et al. 2008). The researchers evaluated 47,500 problems from 260 secondary teachers and found an overall low complexity, even though the problems met the curricular level.

\subsubsection{Impact on Mathematics Education as a Discipline}

The international LSA studies had different kinds of impact on the mathematics education community. As described in the previous section, LSA studies induced further research studies. However, there was and still is an additional impact on a meta-level, especially on the research content and research methods as well as on the discussion about the specific role of mathematics education research in the broader field of educational research.

Regarding the impact on the research content and methods, LSA studies firstly facilitated a normative discussion about the constructs which were addressed in LSA. Among others, there were scientific debates on the conceptualization of mathematical competence, the quality of mathematics instruction, and teacher professional competence. Related to these debates the goals of mathematics education in schools as well as in teacher education were scrutinized.

Secondly, LSA facilitated the "empirical turn" in mathematics education research. As an example, quantitative-empirical research articles in the main German journal on mathematics education (Journal für Mathematik-Didaktik; JMD) published after 2005 appear to be more sensitive to methodological challenges of empirical research than articles published in the 1980s and 1990s. Especially, decisions on adequate research designs, the quality of test items (item development based on 
competence models) or the quality of processing raw data (reliability and objectivity) have become more important in the scientific discussion. In sum, the mathematics education community now has higher scientific standards concerning quantitativeempirical research.

A third important impact of LSA was and is that it raised questions about the features that constitute mathematics education as a scientific discipline. This question was triggered by the fact that the results on students' achievement in mathematics in TIMSS 1995 and PISA 2000 were mainly presented by researchers from educational science and psychology (although a few researchers from mathematics education were involved in these studies). Accordingly, the question came up what the specific contribution of mathematics educational research is in comparison to that of mathematics-related research in educational science. Interestingly, a similar question concerning the status of mathematics education came up again in the context of research on mathematics teachers' professional knowledge. For the conceptualization of the construct pedagogical content knowledge (PCK) and the development of related test items, researchers had to answer the question what mathematics educational knowledge should be. The challenge of this question became even clearer and was triggered by Lee Shulman's notion that PCK is simply an amalgam of content knowledge and pedagogical knowledge (Shulman 1987). This issue is still a matter of discussion within the educational community (Kirschner et al. 2017).

\subsubsection{Impact on Schools and Mathematics Teachers}

In addition to the impact of LSA on the scientific field of mathematics education, the LSA studies have consequences for the educational practice in schools and for mathematics teacher education at universities. The most striking consequence of LSA was the nationwide implementation of educational standards for mathematics combined with a monitoring system. In Germany, since 1945 the federal states are in charge of school education. The organization of the educational system in a decentralized manner was a consequence of the Nazi regime in Germany and was meant to avoid that a central government could control the educational system. Although a standing conference of all 16 ministries of education exists, until 2003 the federal states did not agree on precise goals and desired outcomes of school education (except for the German Abitur, which is the final examination from upper secondary schools and a general university-entrance qualification). In the 1990s, first ideas for educational standards in grade 10 were discussed. The results of TIMSS 1995 and PISA 2000 accelerated this process. In particular, the results of PISA 2000 in general and the huge differences in mathematics achievement between the different German federal states in particular put a lot of pressure on politicians. The German constitution (Grundgesetz) requires that the federal government and the governments of the federal states ensure an equal standard of living in all federal states (which means, in particular, equal educational opportunities). Hence, in 2003, educational standards for mathematics for the lower secondary level (grade 9/10) were implemented. In 
2004, such standards were implemented for the primary level (grade 4), and in 2012 for the Abitur (upper secondary level, grade 12/13). In 2004, the federal "Institute for Educational Quality Improvement (IQB)" at the Humboldt University of Berlin was founded. The IQB is responsible for the evaluation of the educational standards. In 2006, a nationwide test-based monitoring system was implemented with highquality test instruments. Teachers are obliged to administer these tests in grade 3 and grade 8 , that is, one year before students should reach the educational standards for the primary or the secondary level, respectively. One important aspect of the monitoring system is that teachers analyze their students' test results so that they get information about their students' difficulties. Based on this information teachers can prepare specific learning support so that especially low achieving students get a chance to reach the educational standards after grade 4 or 10.

In addition to the above-mentioned changes of the educational system, new ideas were brought into teacher education and teacher professional development. For example, in 1998 the nationwide teachers' professional development (PD) program SINUS $^{1}$ started (and lasted until 2013). It included primary and secondary school teachers from more than 2500 schools. SINUS provided a specific infrastructure for PD (Prenzel et al. 2009). Teachers from different schools worked in local professional learning communities (PLC). The basis for each PLC was a pool of "state of the art material" prepared by researchers, which described topics from mathematics education. The PLC chose material from this pool and worked on the topics. Moreover, representatives of the PLCs met regularly in regional meetings and regional representatives met regularly in national meetings. The SINUS program for primary school teachers was evaluated based on TIMSS instruments. It turned out that students taught by teachers in so-called SINUS schools showed better achievement in mathematics than students taught in comparable schools without SINUS (Dalehefte et al. 2014).

There were also changes in the university-based teacher education system. Firstly, obligatory standards for mathematics teacher education in Germany were established in 2008. Secondly, the poor results of non-certified mathematics teachers in TEDS and the low mathematics achievement of their students in the evaluation of the educational standards had an important influence on the federal states to change the regulations for teacher education. In most federal states, all primary school teachers must now pass a substantial number of mathematics courses at the university. Moreover, all future teachers have to obtain a Master's degree or a comparable qualification before they are allowed to teach in school, regardless of school level (i.e., primary through upper secondary level).

In addition to the consequences on the institutional level described so far, LSA affected genuine mathematics educational research. We illustrate this impact using research on mathematical competence in the following two sections.

\footnotetext{
${ }^{1}$ SINUS $=$ „Steigerung der Effizienz des mathematisch-naturwissenschaftlichen Unterrichts“ (improving the efficiency of mathematics and science teaching).
} 


\subsection{Consequences from Large-Scale Assessment: An Example of Research on Mathematical Competence in Germany}

In this section, we first explain why models of mathematical competence are necessary to implement and evaluate standards for school mathematics. We then describe how models of mathematical competence are developed in a process that takes into account both theories of mathematical development and empirical evidence. We illustrate this process using data from a large-scale national assessment in Germany. Finally, we show how additional qualitative analyses can contribute to our understanding of mathematical development on an individual level.

\subsubsection{Understanding Mathematical Competence}

As described above (Sect. 10.2) standards for school mathematics have been implemented in several countries in the last decades (e.g. Kultusministerkonferenz 2003, 2004, 2012, in Germany; National Council of Teachers of Mathematics 2000, in the U.S.). The influential Common Core State Standards Initiative (2012) asserts that standards "define what students should understand and be able to do" regarding mathematical content like number and quantity, algebra, functions, geometry, statistics and probability, as well as regarding typical mathematical practices like problem solving, reasoning and argumentation, modeling, use of tools, communication, use of structures and regularity. Standard-oriented classroom instruction aims at a profound understanding of mathematics and seeks to support students in applying their knowledge. Accordingly, standards are meant to support students' competence acquisition. This concept plays an important role with regard to standards, and it is also used in the German context. Weinert's (2001, pp. 27-28) definition is broadly accepted; it defines competences as „,cognitive abilities and skills possessed by or able to be learned by individuals that enable them to solve particular problems, as well as the motivational, volitional and social readiness and capacity to utilize the solutions successfully and responsibly in variable situations. "Standards thus refer to a conceptualization of competence that is similar to the concept of literacy on which the framework of PISA is based.

Students' competences may be assigned to mathematical content and practices but this assignment should take into account that students perform at different levels of proficiency. PISA 2012 provides a general description of these different levels based on international test data (OECD 2013). Table 10.1 summarizes six levels of proficiency of 15-year old students according to the OECD report (OECD 2013, p. 61).

This description of proficiency levels is important in order to understand students' performance particularly in the context of international comparisons. However, this description has limitations from a mathematics education point of view and with 
Table 10.1 Levels of proficiency in mathematics in PISA (OECD 2013, p. 61)

Level What students can typically do

6 At Level 6, students can conceptualise, generalise and utilise information based on their investigations and modelling of complex problem situations, and can use their knowledge in relatively non-standard contexts. They can link different information sources and representations and flexibly translate among them. Students at this level are capable of advanced mathematical thinking and reasoning. These students can apply this insight and understanding, along with a mastery of symbolic and formal mathematical operations and relationships, to develop new approaches and strategies for attacking novel situations. Students at this level can reflect on their actions, and can formulate and precisely communicate their actions and reflections regarding their findings, interpretations, arguments, and the appropriateness of these to the original situation

$5 \quad$ At Level 5, students can develop and work with models for complex situations, identifying constraints and specifying assumptions. They can select, compare, and evaluate appropriate problem-solving strategies for dealing with complex problems related to these models. Students at this level can work strategically using broad, well-developed thinking and reasoning skills, appropriate linked representations, symbolic and formal characterisations, and insight pertaining to these situations. They begin to reflect on their work and can formulate and communicate their interpretations and reasoning

4 At Level 4, students can work effectively with explicit models for complex concrete 3 situations that may involve constraints or call for making assumptions. They can select and integrate different representations, including symbolic, linking them directly to aspects of real-world situations. Students at this level can utilise their limited range of skills and can reason with some insight, in straightforward contexts. They can construct and communicate explanations and arguments based on their interpretations, arguments, and actions

3 At Level 3, students can execute clearly described procedures, including those that require sequential decisions. Their interpretations are sufficiently sound to be a base for building a simple model or for selecting and applying simple problem-solving strategies. Students at this level can interpret and use representations based on different information sources and reason directly from them. They typically show some ability to handle percentages, fractions and decimal numbers, and to work with proportional relationships. Their solutions reflect that they have engaged in basic interpretation and reasoning

2 At Level 2, students can interpret and recognise situations in contexts that require no more than direct inference. They can extract relevant information from a single source and make use of a single representational mode. Students at this level can employ basic algorithms, formulae, procedures, or conventions to solve problems involving whole numbers. They are capable of making literal interpretations of the results

1 At Level 1, students can answer questions involving familiar contexts where all relevant information is present and the questions are clearly defined. They are able to identify information and to carry out routine procedures according to direct instructions in explicit situations. They can perform actions that are almost always obvious and follow immediately from the given stimuli 
regard to mathematics classroom practices. The reason is that the levels of proficiency are not "fine-grained" and do not specify details of mathematical processes and products. In particular, as this model is not meant to be a developmental model, it does not explain how learners may proceed from one level of proficiency to the next, or specify students' knowledge gaps when they fail to do so. Including such information in the model would be useful for analyzing student errors on specific items and for understanding learning processes (Vygotskij 1978).

Further refining the model would presuppose a better knowledge of learning processes, which would require detailed studies of students' performance. Moreover, profound theoretical considerations are necessary. It is important to identify the prerequisites for solving a specific problem with regard to the requirements concerning the mathematics behind the problem and with regard to general or everyday knowledge: For example, calculating $37+28$ asks for basic numerical knowledge, and probably the application of various methods of calculation which presupposes knowing and understanding them. Determining the number of legs, which five dogs, eight birds, or seven goldfish have, on the other hand, requires basic numerical knowledge but also "every-day knowledge". Understanding mathematical competence must therefore take into account alternating empirical and theoretical considerations in order to properly describe competences and their development.

\subsubsection{Modeling Mathematical Competence}

Attempts have been made to describe mathematical competence and its development particularly from a theoretical point of view resulting in (mainly) normative models of mathematical competence (Reiss et al. 2007b). Evaluating these models has two aspects. On the one hand, we need empirical studies with an adequate number of tasks and students in order to verify or falsify the theoretical considerations. On the other hand, we need empirical studies, which demonstrate the distinction between levels of competence with regard to typical misunderstandings in order to initiate support in teaching these topics.

In the following, we illustrate how these aspects were addressed in a recent research agenda. First, we present data from a national assessment ("IQBLändervergleich") of a representative sample of 27,000 fourth-graders in Germany (Reiss et al. 2012), which aimed at monitoring the German educational standards in mathematics. Moreover, we describe how data may be used to inform teachers about strengths and weaknesses of their students.

\subsubsection{Modeling Mathematical Competence with Data from a National Assessment}

The test assessed mathematical competence in a variety of subdomains. Data were scaled such that the mean was 500 and the standard deviation 100. The breadth of the 
levels was set to 70; however, with respect to low-performers and high-performers boundaries were open. In the following, we illustrate the model in the domain of numbers.

- Level I ( $\leq 389$ ): Basic technical background (routine procedures on the basis of simple conceptual knowledge)

Students at this level are familiar with simple mathematical terms and procedures. These terms and procedures can be reproduced correctly within a mathematical context, respectively within a context, which is familiar or well-trained. Specifically, students are proficient in exercises that require addition or multiplication of numbers up to ten. They can utilize these concepts during mental calculation exercises, partly written or written-only calculation exercises, if the exercises do not pose any specific difficulties. Additionally, they have to be able to apply these types of calculations in simple word problems correctly. Also, students can compare numbers based on their values and they can interpret numbers on place value panels without problems, especially in the range $1-1000$.

- Level II (390-459): Simple use of basic knowledge (routine procedures within a clearly defined context)

Students are able to utilize their basic knowledge for simple, clearly structured and well-known mathematical problems. For example, problems requiring addition, subtraction, and multiplication can be solved using written or partly written algorithms. The students also conduct rough estimations and correctly recognize the dimensions of their results. In addition, students utilize the structure of the decimal system, and recognize general mathematical principles. These principles are taken into account when continuing simple number sequences, conducting structured counting procedures and engaging in systematic trials. They detect and apply familiar proportional attributes. Students can convert simple numbers into specified units, even when the units differ in value or when numbers have decimals. In addition, students can interpret clearly structured graphs, figures and tables even if they entail a large number of information.

- Level III (460-529 points): Recognition and utilization of relationships within a familiar context (both mathematical and factual)

Students are able to utilize their knowledge flexibly in various problems within a familiar context. Specifically, students handle numbers and operations within the curricular scope securely, and conduct numerical estimations well-even for large numbers. Students can recognize and describe structural aspects-at least when the contents have been practiced well. Students are able to continue number sequences that follow relatively complex rules; in addition, they identify incorrect numbers within straightforward number sequences.

- Level IV (530-599): Secure and flexible utilization of conceptual knowledge and procedures within the curricular scope 
Students can utilize their mathematical knowledge securely, even when the context is not familiar. They correctly describe their own methods for calculation, understand and reflect on the approach of other students and are proficient in all mathematical calculations that are part of the curriculum. Following instructions, students manipulate and systematically change numbers in place value panels, even if the numbers are large (up to one million). They recognize the rules behind even complex number patterns and continue the patterns correctly. Calculations with quantities are performed securely and flexibly, especially calculations that involve approximations and estimations.

- Level V ( $\geq 600$ ): Modeling complex problems involving independent development of adequate strategies

Students can work on mathematical problems in each subject area adequately, securely and flexibly even if the context is unknown. Students are able to work on a highly advanced level both in using adequate strategies and in giving meaningful evaluations and generalizations. They use their in-depth knowledge from the curriculum flexibly even in unfamiliar situations, communicate their methods comprehensibly and explain why they chose their specific method. Mathematical arguments are assessed adequately, and complex situations are modeled and worked upon even if calculations require difficult processes such as the use of tables, compound quantities or numbers in decimal notation.

\subsubsection{Modeling Competence Between Quantitative and Qualitative Approaches}

Models of competence are based on well-defined demands; they identify mathematical tasks with varying difficulty and match students' competences and task characteristics. There is a straightforward scientific paradigm, the correct or wrong answer. However, such a paradigm has limitations because the correctness of answers does not allow immediate conclusions about the cognitive processes underlying these answers. In the following, we describe a study (for further details, see Obersteiner et al. 2015) wherein we tried to analyze students' answers in depth in order to better understand the differences between the various levels of competence with respect to errors and misconceptions. Data come from a sample of 3rd-graders who took part in an annual testing of their mathematical competences ("Vergleichsarbeiten"; VERA). The items addressed mathematical argumentation in the domain of number and operations as well as in the domain of patterns and structures.

Item 1 (see Fig. 10.1) addresses place values. The theoretical level of competence of this item according to the model was II, as was the empirical level. More than half of the students gave correct answers, $23 \%$ did not answer to the question. The most common mistake was referring to the ones only or to the tens only. These children obviously had a preliminary understanding of the place value system but were unable to extend it to this complex situation. 


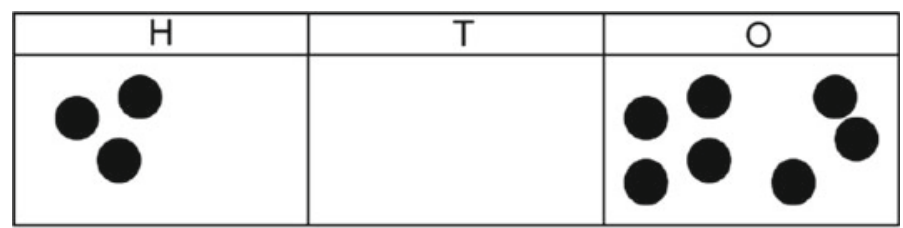

Paul wants to show the number 370 in a place value table. However, he makes a mistake. Explain his mistake.

Fig. 10.1 Item 1: place value

Item 2 (see Fig. 10.2) addresses properties of numbers. In this case, the theoretical level of competence (III) was lower than the empirical level (IV), which means that the students had more problems with solving it correctly than was anticipated. About one third of the students gave correct answers, another third did not answer to the question. The most common mistake was not referring to the magnitude. Children were not able to use their knowledge of numbers in a problem-solving situation.

Item 3 (see Fig. 10.3) addresses number sequences. For this item, the theoretical and empirical levels of competence were identical and both high (IV for part a, V for part b). Only 27\% (part a) and 14\% (part b) of the students, respectively, answered the two questions correctly. The most common mistake was that students did not mention that the magnitudes of each two numbers add up to 100. Children's written work suggested that some were able to identify the correct solution but were unable to communicate their knowledge.
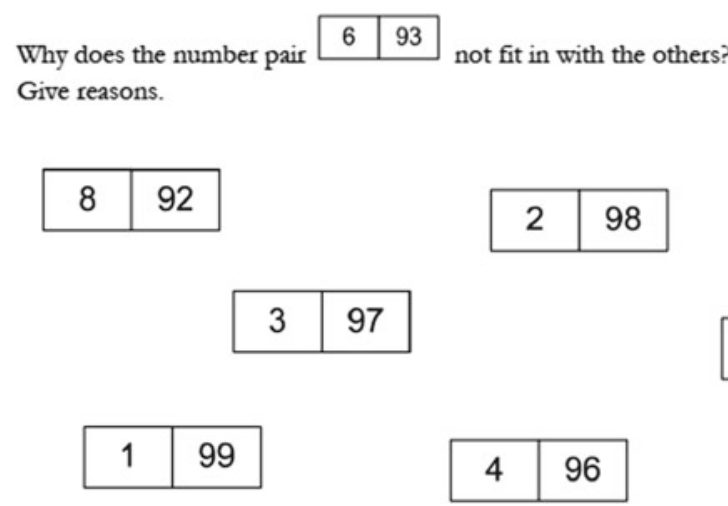

Fig. 10.2 Item 2: numbers pairs 
Fig. 10.3 Item 3: number sequences
Look at the number sequence.

\section{$111 \quad 100 \quad 88$} 61

a) What is the missing number?

b) Write down the rule for calculation!

\subsubsection{Summary}

We have illustrated how international large-scale assessments and the introduction of educational standards for school mathematics had an impact on mathematics education research and practice in Germany. Competence models have been developed that were based on both theoretical considerations and empirical evidence from largescale assessments. To increase our understanding of how we can support students develop from a lower level of competence to a higher one, additional qualitative approaches that include an analysis of where exactly students go wrong at a certain level of competence can be fruitful. Such approaches can eventually lead to more fine-grained models of mathematical competence and its development.

\subsection{Consequences from Large-Scale Assessment: Competence Models and Evaluation of Classroom Practice in Austria}

The current system of LSA in Austria comprises three strands: international assessment as external benchmark, standardized assessment of national education standards (BIST-Ü) as a main lever for school quality development, and informal competence measurement (IKM) as a self-evaluation tool for teachers. This section first provides a brief history of the system and then focuses on the two strands of national assessments. We introduce the competence models and the national education standards, describe briefly the implementation of the assessment, and then explain the reporting system.

\subsubsection{Development of Large-Scale Assessment in Austria}

As in other German speaking countries, LSA are a relatively young phenomenon in Austria. By participating in TIMSS in 1995, Austria, like Germany (see Sect. 10.2), started to participate in international LSAs. The results were mixed: Austria was in the group of top performers on the elementary school level but not on the lower secondary school level. Austria had a very small group of top performers, and there was a 
comparably large gender gap (Beaton et al. 1997; Mullis et al. 1997). However, the results were not of much interest to policy makers or the broader public. This changed in 2001, when the results from PISA 2000 were presented and publicly discussed. Of most concern was (and is) the group of students identified as "students at risk". In mathematics, $22 \%$ of students in Austria currently fall into this category (Suchán and Breit 2016). Moreover, there is a comparably small group of high performing students.

In response to these results, the Ministry of Education of Austria assigned a committee to devise a "master plan". One of the goals of the committee was to change the culture in the school system from input-oriented to output-oriented. In the report (Eder et al. 2005), the committee listed a number of measures intended to augment school quality, amongst others the introduction of national educational standards and the assessment thereof. At about the same time, competence models for the subject domains were developed and empirically validated in pilot studies. In 2009, a law was passed (Bundesgesetzblatt II Nr. 1/2009) that defined national educational standards in mathematics, German (both grades 4 and 8), and English (grade 8 only), which were based on national curricula. The law also mandated regular assessment of the competences and "meaningful feedback" to students, teachers, and school principals as well as a system of monitoring reports in order to foster evidencedriven activities. A baseline study was conducted in 2009 (lower secondary school level, $\mathrm{n}=204$ schools) and 2010 (elementary school level, $\mathrm{n}=267$ schools) in order to measure the level of competences before national education standards were implemented. Since 2012, competences in mathematics, German, and English are assessed, alternating every year in a census in grades 4 and 8 . Feedback is prepared by the BIFIE on several levels for each national LSA (see Table 10.2).

\subsubsection{Mathematics Competence Models in Austria}

For all subjects and grades covered, competence models were devised. In 2007, the Institute for Didactics of Mathematics at the University of Klagenfurt (Austria) pub-

Table 10.2 Feedback recipients

\begin{tabular}{l|l|l}
\hline Recipients & Format & N \\
\hline Students & Online, individualized & About 76',000 per grade \\
\hline Teachers (classes, groups) & Online, for each class taught & $\begin{array}{l}\text { About 4000 in lower } \\
\text { secondary/6000 in elementary }\end{array}$ \\
\hline Schools & Online, per school and class & $\begin{array}{l}\text { About } 1400 \text { in lower } \\
\text { secondary/3000 in elementary }\end{array}$ \\
\hline School authorities & Online and in print & 99 school districts \\
\hline Regional (federal state) & Online and in print & 9 states \\
\hline National & Online and in print & 1 report \\
\hline
\end{tabular}


lished a brochure in which a competence model for mathematics in lower secondary schools was introduced (Institut für Didaktik der Mathematik 2007). In this section, we only describe the model used for grade 8 mathematics. The competence model uses three dimensions to describe mathematical competence: process, content, and level of complexity (see Table 10.3).

The process domains as well as the content domains contain four distinct areas each; the level of complexity is divided into three hierarchical levels. Since these dimensions of content, processes, and complexity are orthogonal to each other (see Fig. 10.4), the model consists of $4 \times 4 \times 3=48$ nodes altogether. For every node, a can-do statement describes students' skills and abilities (Verordnung der Bundesministerin für Unterricht, Kunst und Kultur über Bildungsstandards im Schulwesen 2009), for example "the students are able to describe algebraic, tabular or graphic representations of structures and (functional) relations and interpret both in a given context. In doing so, it is necessary to make connections to other mathematical contents (terms, theorems, representations) or processes" (process 3/content 2/complexity level 2, see grey cube in Fig. 10.4).

Mathematics materials used in school are supposed to use this structure and cover all process and content domains. Test items for national tests are developed on the basis of these nodes; only items that can be classified unambiguously on a node are used in the test, in the sense that the group of test developers and at least one external expert reach consensus on the classification. Since the level of complexity is not equal to empirical difficulty, at reporting stage, empirical difficulty along with the classification according to educational standards (competence level) are also published. As an example, the item in Fig. 10.5 has been classified as follows.

- Process domain: demonstrating, modeling

- Content domain: statistical representation, measures of central tendency and variance

- Competence level: 2 (indicating standards reached, see Table 10.3)

Table 10.3 Dimensions of mathematical competence

\begin{tabular}{l|l|l}
\hline $\begin{array}{l}\text { Process domains } \\
\text { (Handlungsbereiche) }\end{array}$ & $\begin{array}{l}\text { Content domains } \\
\text { (Inhaltsbereiche) }\end{array}$ & $\begin{array}{l}\text { Level of complexity } \\
\text { (Komplexitätsbereiche) }\end{array}$ \\
\hline P1: demonstrating, modeling & C1: numbers and units & $\begin{array}{l}\text { L1: use of basic skills and } \\
\text { knowledge }\end{array}$ \\
\hline P2: calculating, operating & $\begin{array}{l}\text { C2: variable, functional } \\
\text { dependency }\end{array}$ & $\begin{array}{l}\text { L2: build } \\
\text { connections/connect }\end{array}$ \\
\hline P3: interpreting & $\begin{array}{l}\text { C3: geometric figures and } \\
\text { shapes }\end{array}$ & $\begin{array}{l}\text { L3: reflect, use knowledge } \\
\text { of reflection }\end{array}$ \\
\hline P4: explaining, reasoning & $\begin{array}{l}\text { C4: statistical } \\
\text { representations, measures of } \\
\text { central tendency and } \\
\text { variance }\end{array}$ & \\
\hline
\end{tabular}




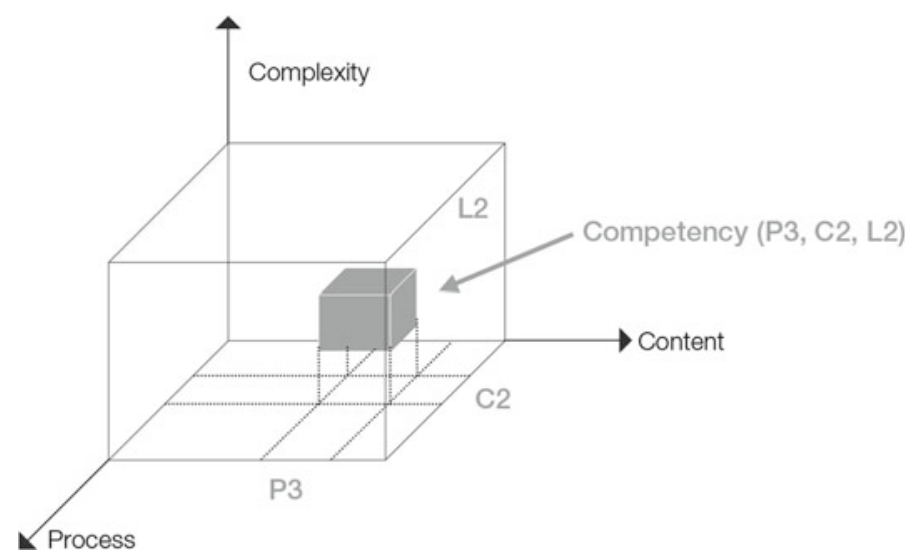

Fig. 10.4 Competence model, mathematics, grade 8. Adapted from Institut für Didaktik der Mathematik (2007)

Example item (translated): A lina and Christoph want to go on a 5-day canoe trip. They plan to do $15 \mathrm{~km}$ per day on average. After 4 days, they have managed to do the following distances:

\begin{tabular}{|l|c|c|c|c|c|}
\hline Day & 1 & 2 & 3 & 4 & 5 \\
\hline Distance & 17 & 12 & 14 & 16 & $?$ \\
\hline
\end{tabular}

How many kilometers do they have to do on day 5 to reach the average of $15 \mathrm{~km}$ per day? Write your answer in the box.

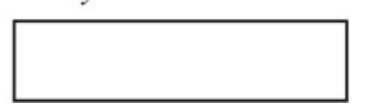

Fig. 10.5 Example item

- Answer: $16 \mathrm{~km}$. Empirical difficulty: $53 \%$ of students in Austria solved this item (BIFIE 2012a).

An expert group consisting of mathematics teachers and mathematics education researchers described in four levels the degree to which the education standards are reached (see Table 10.4).

In contrast to the descriptions used in international assessments, these levels were defined and described using a Standard Setting method called Item-DescriptorMatching method (Freunberger 2013). The method requires comparison of the performance shown on the test items with the theoretical framework (in this case, the national curriculum and national standards). The exercise was undertaken before the main assessment was carried out, using field trial data to sort items by empirical difficulty. As the first national assessment in mathematics was strongly debated, this was necessary to keep the Standard Setting out of political discussion. The performance level descriptors were centered around level 2, "standards reached", as this represents the desired outcome. The competence model and the performance level 
Table 10.4 Levels of competence, mathematics, grade 8

Level 3-standards exceeded

Students possess fundamental knowledge and skills in all parts of the mathematics curriculum and advanced knowledge structures, which exceed the requirements of level 2, specifically more pronounced abilities of abstraction and higher proficiency in combining parts of knowledge, methods or rules. They are able to apply these independently in novel situations in a flexible way

Level 2-standards reached

Students possess fundamental knowledge and skills in all parts of the mathematics curriculum and can use these in a flexible way. They are able to find and apply problem solving strategies, to describe and reason about their approach. They are able to handle verbal, graphical and formal representations of mathematical facts in a flexible way and can apply these appropriately. They are able to extract relevant information from differently represented facts (e.g. texts, data material, graphics) and can interpret them in the respective context. They are able to relate their mathematical knowledge and can check, evaluate and/or reason about mathematical statements

Level 1-standards partially reached

Students possess fundamental knowledge and skills in all parts of the mathematics curriculum and can master reproductive tasks and carry out routine procedures

Below level 1—standards not reached

There is no further description of this level, as students on this level typically show insufficient competences/skills

descriptors represent the core of the feedback to all stake-holders and can be found in all reports (see Table 10.2).

\subsubsection{Reporting of Assessment of National Education Standards}

\subsubsection{Reporting on the System Level}

System monitoring is one of the main goals of the assessment of national education standards. A detailed report is published every year on a national and a regional level (cf. Schreiner and Breit 2012a, b; Schreiner et al. 2018). The outcomes should inform education policy makers about issues and areas for improvement. Since the assessment has only started the second cycle, it is yet too early to identify sustainable development. However, we can state that students have performed better in mathematics in 2017 (national average 542 points) than in 2012 (535 points) and in the baseline assessment in 2009 (500 points). This increase in performance was highest in the content domain of statistics (550 points vs. 544 points vs. 500 points). In part, this might have to do with instructional practices; teachers can choose not to cover all areas of the curriculum. Presumably, statistics had been covered by teachers less often than other areas prior to the assessments: A study among first-year students of mathematics education showed that statistics is also the most unpopular content 
area, and that students complained about "comprehension difficulties", "bad lessons" and "no relation to everyday life" (Süss-Stepancik and George 2016). This probably also affects teaching (Süss-Stepancik and George 2017). In the years preceding more recent assessments, the (dis-)likes for content areas and process domains could have been evened out by the fact that all areas are covered by the national tests because teachers might say "now that you test it, we teach it". Teachers may also be more aware of the assessments because instructional material now contains more references to national education standards and competence models than in 2009.

\subsubsection{Reporting on the School and Class Level}

The feedback to school principals and teachers is designed to foster school development and improvement of instructional practice. Based on a model of factors influencing development of school quality and teaching strategies (Helmke 2004), Wiesner et al. (2015) devised a framework modeling the use of feedback for schools and teachers for development. A central point is the standardized assessment which gives objective feedback, in how far schools and classes are able to convey the competences described in the national education standards. The first step comprises the correct analysis and interpretation of the results in order to identify weaknesses and potentials for improvement. Reflecting the outcomes, teachers and school heads then can design actions for improvement. In an evaluation step, the impact of the implemented actions is scrutinized and the quality development cycle starts again. In order to support analysis and interpretation of results, individualized feedback for each class taught is created for to teachers using standard templates (see Table 10.2). This feedback describes not only the outcomes but also other variables like students' socio-economic background, their wellbeing at school, and their motivational situation. Moreover, it includes a "fair comparison" (Pham and Robitzsch 2014), that is, a comparison with schools/classes showing similar characteristics. In addition to feedback on levels of mathematics competence and feedback in terms of points reached overall as well as feedback on the results of subgroups in the class, teachers get feedback on the results of their class(es) in the process and content domains. In contrast to conventions in many other countries, school or class results are not reported publicly as such reporting is not regarded as helpful in terms of quality development. In order to give schools space to develop and work with the results, no school ranking is published. Aggregated reports on regional and national level are published online without reference to specific schools. School results are reported to schools and school authorities only.

As an example, Fig. 10.6 shows the feedback on the process domains (note: data are fictitious). It contains the Austrian mean for all domains (see flag) as well as the school mean (see punctuated line) and the class mean (dot with confidence interval). Individual students are represented as dots. The higher up the bar, the higher the achievement; the wider spread the dots are, the larger the variance within the class. The table below the chart lists the number of students in school and class and the mean including the confidence interval for each domain. 


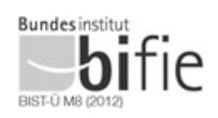

L6
Mathematics: process domains in your class

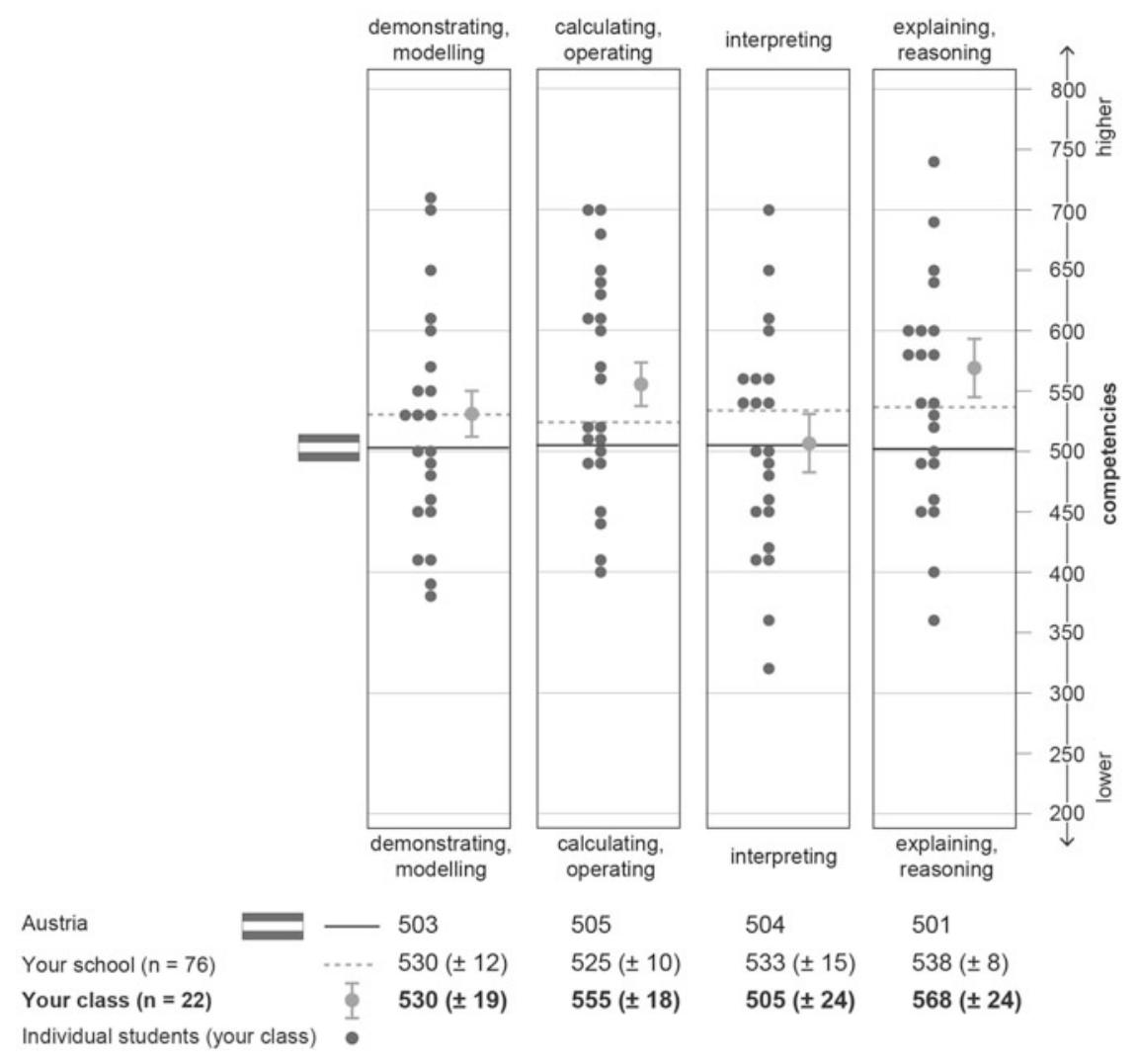

Fig. 10.6 Results on class (group) level by process domain (BIFIE 2012b)

\subsubsection{Other Report Levels}

School authorities receive school results only, without details on the classroom level. In many cases, this level of granularity is acceptable as in Austria the student population within schools tends to be more homogenous than between schools. Therefore, classes within the same school tend to perform more consistently than classes in different schools. By law, students are entitled to their individual feedback. During the test session, they receive a unique code for their individualized feedback available via a secure online platform. Although students are the biggest recipient group, the impact of the feedback on them is probably quite negligible as the results must not be used for grading. The student data is considered confidential and no-one but the student should have access to it. 


\subsubsection{Informal Competence Measurement}

In contrast to the assessment of national education standards, the informal competence measurement is focusing on the classroom level only (Wiesner et al 2017). Teachers can decide whether or not to use this free, web-based tool in their classes. The online platform can score selected response items automatically. Teachers only need to code open response items themselves. The platform instantly generates feedback on the class level and on the level of individual students. It provides feedback for mathematics in general and for process and content domains separately. For each item, national benchmarks stemming from pilot tests are provided. Since the use of the tool is voluntary, the exposure is somewhat hard to measure; roughly $15 \%$ of students take it in grade 6 and about $25 \%$ of students in grade 7 (in mathematics). Teachers may choose to share the results but are not required to.

Table 10.5 Comparison of mandatory national assessment and informal competence measurement

\begin{tabular}{|c|c|c|}
\hline & $\begin{array}{l}\text { Assessment of national education } \\
\text { standards }\end{array}$ & Informal competence measurement \\
\hline Status & - Mandatory & $\begin{array}{l}\text { - Voluntary (mostly, teachers decide } \\
\text { use) }\end{array}$ \\
\hline Grade(s) & - 8 & $\begin{array}{l}\text { - } 6 \text { and } 7 \text { (grade } 5 \text { in preparation, } \\
\text { grade } 8 \text { in planning) }\end{array}$ \\
\hline Cycle & - Every 5 years & - Every year \\
\hline Reach & $\begin{array}{l}\text { - Nearly all students in grade } 8 \\
\text { (about } 76,000 \text { ) } \\
\text { - } 4000 \text { classes in } 1400 \text { schools }\end{array}$ & $\begin{array}{l}\text { - Between } 15 \text { and } 25 \% \text { of students in } \\
\text { around } 40 \% \text { of schools } \\
\text { (mathematics only) }\end{array}$ \\
\hline Administration & $\begin{array}{l}\text { - Highly standardized } \\
\text { - Trained test administrators carry } \\
\text { out test } \\
\text { - Paper-pencil tests only }\end{array}$ & $\begin{array}{l}\text { - Somewhat standardized (e.g., } \\
\text { timing of test, test materials) } \\
\text { - Subject teachers test their students } \\
\text { - Online test administration }\end{array}$ \\
\hline Scoring & $\begin{array}{l}\text { - Materials are collected and are } \\
\text { scored centrally } \\
\text { - Items in open ended format are } \\
\text { coded by trained coders using } \\
\text { standardized coding guide }\end{array}$ & $\begin{array}{l}\text { - Selected response items are scored } \\
\text { automatically } \\
\text { - Open ended format-items are } \\
\text { scored by class teachers; use of } \\
\text { standardized coding guide is } \\
\text { suggested }\end{array}$ \\
\hline $\begin{array}{l}\text { Analysis } \\
\text { methods }\end{array}$ & - IRT models & - Percent correct \\
\hline Feedback & $\begin{array}{l}\text { - Feedback is sent to schools and } \\
\text { teachers months later, students are } \\
\text { anonymous } \\
\text { - On aggregated levels, school } \\
\text { authorities and public are informed }\end{array}$ & $\begin{array}{l}\text { Online tool generates feedback } \\
\text { immediately on class and student } \\
\text { level. Teachers can identify } \\
\text { individual students } \\
\text { - Access to feedback is restricted to } \\
\text { teachers (self-evaluation) }\end{array}$ \\
\hline
\end{tabular}


Table 10.5 (continued)

\begin{tabular}{|c|c|c|}
\hline & $\begin{array}{l}\text { Assessment of national education } \\
\text { standards }\end{array}$ & Informal competence measurement \\
\hline Use & $\begin{array}{l}\text { - Teachers, school heads: Birds-eye } \\
\text { view on educational output, } \\
\text { possibility to identify } \\
\text { weaknesses/strengths } \\
\text { - Comparison with other schools and } \\
\text { classes in similar settings ("fair } \\
\text { comparison") } \\
\text { - School authorities: aggregated } \\
\text { feedback on school level } \\
\text { - System monitoring } \\
\text { - Development of education quality } \\
\text { through developments at schools, } \\
\text { teacher education, education } \\
\text { policy, curricular developments }\end{array}$ & $\begin{array}{l}\text { - Teachers: overview of group as } \\
\text { well as diagnosis of individual } \\
\text { students' achievement levels } \\
\text { - Results must not be used for } \\
\text { grading } \\
\text { - No other users: no reports for } \\
\text { school head, school authorities, } \\
\text { system monitoring. Teachers may } \\
\text { decide to share the results } \\
\text { - Support of individual students by } \\
\text { teachers } \\
\text { - Supporting teachers through } \\
\text { focused and detailed feedback } \\
\text { about class and individuals, in } \\
\text { relation to education standards }\end{array}$ \\
\hline $\begin{array}{l}\text { Contextual } \\
\text { information }\end{array}$ & $\begin{array}{l}\text { - Context questionnaires on student } \\
\text { and school level allow capture of } \\
\text { students and school characteristics }\end{array}$ & $\begin{array}{l}\text { - Minimal context questions } \\
\text { (gender, migration background); } \\
\text { restricted to pilot test }\end{array}$ \\
\hline
\end{tabular}

The competence models used in this tool are the same as the models that are used for the national assessment. The comparison in Table 10.5 is restricted to lower secondary school.

\subsubsection{Summary}

The different strands of large-scale assessment in Austria allow for different viewpoints on students' mathematics competence, depending on the main uses and users. The international LSAs show how students in a specific country perform compared to other countries' students. This is useful feedback for policy makers and interesting for the public. The national assessments allow for comparable and meaningful feedback to teachers and school principals as well as students and parents, school authorities and the broader public about the levels of competence reached as well as areas where there is room for improvement. Figure 10.7 summarizes the intended interactions between curriculum, competency models, national education standards, assessments, and feedback.

As illustrated in this figure, there are many channels for feedback to relevant actors and stakeholders in the system. Further evaluation of the impact of national education standards and their standardized and mandatory assessment will hopefully further clarify the role of education standards. 


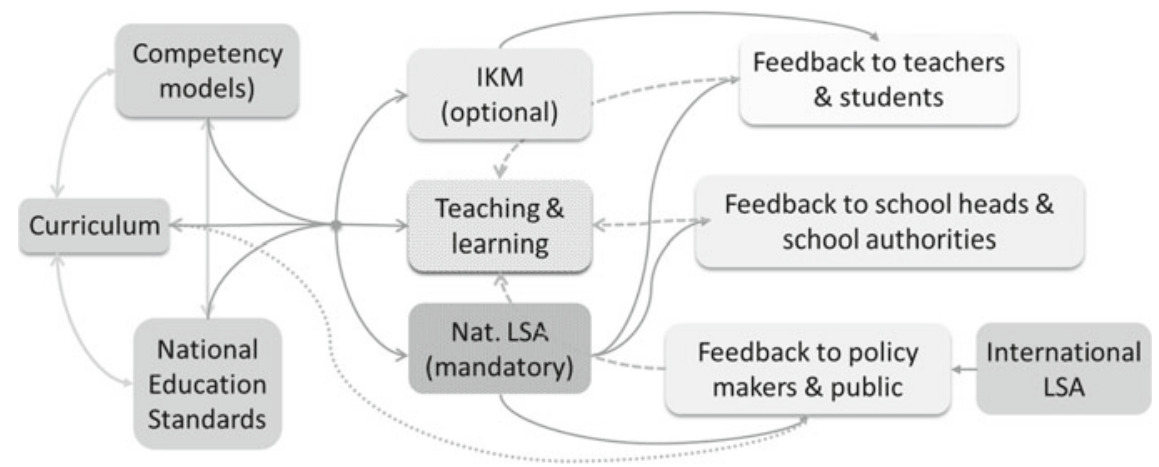

Fig. 10.7 Interactions and embedding of large-scale assessments in Austria

\subsection{Summary and Discussion}

Large-scale assessment plays an increasingly important role on various levels of educational research and practice in German-speaking countries. The developments in Germany and Austria described in this chapter show the potential of LSA in several respects. Large-scale studies have an impact on curriculum development, policy making, and the development of theories of mathematical competence. They also can inspire further research to address issues that large-scale studies have identified as being relevant for competence development. For example, the discussion about what mathematical competence should be has led to the agreement that competence is more than proficiency and encompasses cognitive but also non-cognitive aspects, such as motivation and interest (Weinert 2001). Also, it would be useful if competence models provided information not only on students' competence but also on what students did not yet understand. Such information would be particularly valuable for teachers who need information on students' strengths and weaknesses in order to support their learning. Thus, future research could focus on these aspects.

However, large-scale assessments also have limitations. In the remainder of this section, we first reflect on general issues of large-scale assessments, and then discuss specific limitations and potential risks for research and practice.

\subsubsection{General Issues of Large-Scale Assessments from an International Perspective}

We discuss general issues of large-scale assessments from three perspectives: their purposes, their processes, and their outcomes. 


\subsubsection{Purposes: The Studies Reflect the Needs of a Country}

The decision to conduct large-scale studies is often accompanied by the intention to solve specific educational problems in a country. In the case of Germany and Austria, for example, the starting point of large-scale studies was mainly influenced by the international assessments of students' mathematics performances (i.e., TIMSS and PISA). The results of those studies were disappointing and received much public attention, which in turn pushed stakeholders to improve the situation. Empirical studies provided information about the situation in classrooms. In other words, they enabled investigating certain phenomena more closely to eventually improve the situation for teachers and students, and for developing the curriculum.

In Germany, to support primary and secondary school teachers' professional development, the country started a nationwide teacher professional development program (SINUS). Moreover, there were studies investigating teachers' competencies in teaching mathematics from a national perspective (e.g., COACTIV), as well as from an international perspective (e.g., TEDS-M). In a next step, studies investigated not only school students' and teachers' mathematical competences but also those of adults (e.g., PIAAC). In order to trace the development of competence, the NEPS project was started in 2008. It includes participants of a wide age range to assess their mathematics competence both cross-sectionally and longitudinally.

\subsubsection{Processes: Revealing the Functions of Studies}

To discuss issues related to the aspect of processes, we make an analogy to the TIMSS framework (see Mullis and Martin 2013), which describes how OECD adapts the processes of knowing, applying, and reasoning in designing test items and assessing what students learned in mathematics. We consider these three processes suitable for interpreting how the countries view large-scale studies through the process of (1) knowing what phenomenon they want to investigate, and (2) applying what they have known from precedent studies to explore the new domains they want to investigate further (i.e., a new round of knowing process), or to solve the present educational problems they met. In order to process the application, (3) re-analyzing the collected data with new methods creates opportunities for new studies exploring additional phenomena or outcomes.

The primary data collected from large-scale assessments provide abundant and useful information. The information from these primary data usually contributes directly to educational fields, such as policy making and comparison within a country or between countries. The other potential method to deal with the abundant data is secondary analysis (Glass 1976). Glass introduces the two purposes of this method, one is the re-analysis of data for the purpose of answering the original research question with better statistical techniques, and the other is to answer new questions with old data. An example is the secondary analysis of TIMSS data (Robitaille and Beaton 2002). 
In the example of research on mathematical competence in Germany, the purpose was for example the assessment of fourth-graders' mathematical competence, aiming at developing a competence model. This model is related to competence levels of students' performances in PISA 2012 (OECD 2013). The primary data were collected from the survey of nationwide students with validated items. After analyzing those primary data, the competence model was constructed for specific mathematical content areas. In a next step, students' written responses were investigated to better understand students' errors and misconceptions (see Sect. 10.3).

In Austria, the process was similar to Germany, but the example of Austria shows how competence models can be useful to provide feedback on different levels of the educational system. Data with different ecologies were used to identify new educational phenomena in different schools or classes (King 1997). In this way, large-scale studies can inform policy-makers to make realistic decisions based on empirical data.

\subsubsection{Outcomes of Large-Scale Studies}

As already mentioned, the purpose of large-scale studies is often to solve specific educational problems. The examples from Germany and Austria reported in this chapter showed how the development of competence models benefited from students' performance data from large-scale assessments. Such competence models are dynamic regarding their contents and their participants in related assessments. Moreover, the Austrian study further applied the survey of competence into the system monitoring and suggestions to instructional improvement as the intended outcomes. The example of Germany illustrated how data can be used for another outcome, namely secondary analyses of students' answers to better understand their reasoning and eventually inform instruction concretely and constructively.

\subsubsection{Potential Risks for Research and Practice}

There are potential risks of LSA for research and practice. Although LSA induced progress and changes in mathematics educational research as well as in mathematics classroom, there are some aspects which can be considered as critical.

A first aspect is that LSAs provide a huge amount of empirical data on students' and teachers' mathematics achievement. This can create an imbalance between empirical and theoretical perspectives because it can be tempting to mix up empirical data with empirical evidence. Hence, it is important to keep in mind that generating and interpreting empirical data requires theories, and that theories are also necessary to transform empirical data into empirical evidence. This is particularly important in cases when LSA data develop a "life on their own". Examples are the increasing amounts of purely descriptive empirical results with little scientific impact (i.e. low 
explanatory power) or the illusion of "exact" results due to empirical data-bases and over-interpretation of statistical results.

A second aspect is the norm setting. For example,

- in the research context, we can observe the situation that LSA becomes selfreferential in the sense that LSA becomes an own research topic,

- in the context of educational goals, we can observe that benchmarks for learning outcomes are determined by LSA data instead of normative educational goals,

- in the context of educational policy, we can observe that LSA results promote pragmatic decisions and substitute educational visions as guiding principles.

In conclusion, the research community should critically analyze which role LSA already has and which role LSA should have for research and practice in mathematics education.

\section{References}

Bauersfeld, H. (1978). Kommunikationsmuster im Mathematikunterricht. Eine Analyse am Beispiel der Handlungsverengung durch Antworterwartung. In H. Bauersfeld (Ed.), Fallstudien und Analysen zum Mathematikunterricht (S. 158-170). Hannover: Schroedel.

Baumert, J., Klieme, E., Neubrand, M., Prenzel, M., Schiefele, U., Schneider, W., et al. (Eds.). (2001). PISA 2000. Basiskompetenzen von Schülerinnen und Schülern im internationalen Vergleich. Opladen: Leske + Budrich.

Baumert, J., Lehmann, R., Lehrke, M., Schmitz, B., Clausen, M., Hosenfeld, I., et al. (1997). TIMSS - Mathematisch-naturwissenschaftlicher Unterricht im internationalen Vergleich. Deskriptive Befunde. Opladen: Leske + Budrich.

Beaton, A. E., Mullis, I. V. S., Martin, M. O., Gonzalez, E. J., Kelly, D. L., \& Smith, T. A. (1997). Mathematics achievement in the middle school years: IEA's third international mathematics and science study (TIMSS). Chestnut Hill: Boston College.

BIFIE. (2012a). Beispielitems aus der Standardüberprüfung Mathematik 2012 für die 8. Schulstufe. https://www.bifie.at/system/files/dl/Beispielaufgaben_BIST-UE-M8-2012.pdf. Accessed March 14, 2017.

BIFIE. (2012b). Rückmeldung an die Lehrer/innen. Standardüberprüfung M8-2012. https://www. bifie.at/node/1689. Accessed March 14, 2017.

Blömeke, S., Kaiser, G., \& Lehmann, R. (Eds.). (2010). TEDS-M 2008 - Professionelle Kompetenz und Lerngelegenheiten angehender Primarstufenlehrkräfte im internationalen Vergleich. Münster: Waxmann.

Blum, W., \& Neubrand, M. (Eds.). (1998). TIMSS und der Mathematikunterricht. Informa-tionen, Analysen und Konsequenzen. Hannover: Schroedel.

Common Core State Standards Initiative. (2012). Common core state standards: Mathematics. http://www.corestandards.org/Math. Accessed March 30, 2017.

Dalehefte, I. M., Wendt, H., Köller, O., Wagner, H., Pietsch, M., Döring, B., et al. (2014). Bilanz von neun Jahren SINUS an Grundschulen in Deutschland. Evaluation der mathematikbezogenen Daten im Rahmen von TIMSS 2011. Zeitschrift für Pädagogik, 2(60), S.245-S.263.

Deutsches PISA-Konsortium. (2001). PISA 2000: Basiskompetenzen von Schülerinnen und Schülern im internationalen Vergleich. Opladen: Leske + Budrich.

Duchhardt, C., Jordan, A.-K., \& Ehmke, T. (2017). Adults' use of mathematics and its influence on mathematical competence. International Journal of Science and Mathematics Education, 15(1), $155-174$. 
Eder, F., Haider, G., Specht, W., Spiel, C., \& Wimmer, M. (2005). zukunft:schule. Strategien und Maßnahmen zur Qualitätsentwicklung. Abschlussbericht der Zukunftskommission. https://www. bifie.at/system/files/d1/Reformkonzept\%20zukunft\%20schule\%20II\%20Abschlussbericht\% 202005.pdf. Accessed March 14, 2017.

Freunberger, R. (2013). Standard-Setting Mathematik 8. Schulstufe. Technischer Bericht. https:// www.bifie.at/wp-content/uploads/2017/05/StaSett_M8_TechReport_sV_2013-05-15.pdf. Accessed May 17, 2018.

Glass, G. V. (1976). Primary, secondary, and meta-analysis of research. Educational Researcher, 5(10), 3-8.

Helmke, A. (2004). Von der Evaluation zur Innovation: Pädagogische Nutzbarmachung von Vergleichsarbeiten in der Grundschule. SEMINAR - Lehrerbildung und Schule, 2, 90-112.

Institut für Didaktik der Mathematik. (Eds.). (2007). Standards für die mathematischen Fähigkeiten österreichischer Schülerinnen und Schüler am Ende der 8. Schulstufe. https://www.uni-klu.ac.at/ idm/downloads/Standardkonzept_Version_4-07.pdf. Accessed March 14, 2017.

Jordan, A., Krauss, S., Löwen, K., Blum, W., Neubrand, M., Brunner, M., et al. (2008). Aufgaben im COACTIV-Projekt: Zeugnisse des kognitiven Aktivierungspotentials im deutschen Mathematikunterrichts. Journal fürMathematikdidaktik, 29(2), 83-107.

King, G. (1997). A solution to the ecological inference problem: Reconstructing individual behavior from aggregate data. Princeton, NJ: Princeton University Press.

Kirschner, P. A., Verschaffel, L., Star, J., \& Van Dooren, W. (2017). There is more variation within than across domains: An interview with Paul A. Kirschner about applying cognitive psychologybased instructional design principles in mathematics teaching and learning. ZDM-Mathematics Education, 49(4), 637-643.

Komorek, E., Bruder, R., Collet, C., \& Schmitz, B. (2007). Contents and results of an intervention in maths lessons in secondary level I with a teaching concept to support mathematic problemsolving and self-regulative competencies. In M. Prenzel (Ed.), Studies on the educational quality of schools. The final report on the DFG Priority Programme (pp. 175-196). Münster: Waxmann.

Kultusministerkonferenz. (2003). Bildungsstandards im Fach Mathematik für den mittleren Schulabschluss. Bonn: KMK.

Kultusministerkonferenz. (2004). Bildungsstandards im Fach Mathematik für den Primarbereich. Bonn: KMK.

Kultusministerkonferenz. (2012). Bildungsstandards im Fach Mathematik für die Allgemeine Hochschulreife. Bonn: KMK.

Kunter, M., Baumert, J., Blum, W., Klusmann, U., Krauss, S., \& Neubrand, M. (2013). Cognitive activation in the mathematics classroom and professional competence of teachers. Results from the COACTIV project. New York, NY: Springer.

Lipowsky, F., Rakoczy, K., Drollinger-Vetter, B., Klieme, E., Reusser, K., \& Pauli, C. (2009). Quality of geometry instruction and its short-term impact on students? Understanding of pythagorean theorem. Learning and Instruction, 19(6), 527-537.

Mullis, I. V. S., \& Martin, M. O. (Eds.). (2013). TIMSS 2015 assessment frameworks. Chestnut Hill, MA: TIMSS \& PIRLS International Study Center, Lynch School of Education, Boston College.

Mullis, I. V. S., Martin, M. O., Beaton, A. E., Gonzalez, E. J., Kelly, D. L., \& Smith, T. A. (1997). The mathematics achievement in the primary school years: IEA's third international mathematics and science report. Chestnut Hill: Boston College.

National Council of Teachers of Mathematics. (2000). Principles and standards for school mathematics. Reston, VA: National Council of Teachers of Mathematics.

Neubrand, J. (2002). Eine Klassifikation mathematischer Aufgaben zur Analyse von Unterrichtssituationen - Selbsttätiges Arbeiten in Schülerarbeitsphasen in den Stunden der TIMSS Video-Studie. Hildesheim: Franzbecker.

Neumann, I., Duchhardt, C., Grüßing, M., Heinze, A., Knopp, E., \& Ehmke, T. (2013). Modeling and assessing mathematical competence over the lifespan. Journal of Educational Research Online, 5(2), 80-109. 
Obersteiner, A., Moll, G., Reiss, K., \& Pant, H. A. (2015). Whole number arithmetic-Competency models and individual development. In X. Sun, B. Kaur, \& J. Novotná (Eds.), Proceedings of the 23rd ICMI Study Conference: Primary Mathematics Study on Whole Numbers (pp. 235-242). Macao, China: University of Macau.

OECD. (2013). PISA 2012 results: What students know and can do: Student performance in mathematics, reading and science (Vol. I). Paris: OECD.

Pham, G., \& Robitzsch, A. (2014). „Fairer Vergleich“ [,fair comparison“]. Technische Dokumentation - BIST-Ü Englisch, 8. Schulstufe, 2013. BIFIE: Salzburg. https://www.bifie.at/system/files/ dl/TD_Fairer_Vergleich_E8.pdf. Accessed March 13, 2017.

Prenzel, M., Stadler, M., Friedrich, A., Knickmeier, K., \& Ostermeier, C. (2009). Increasing the efficiency of mathematics and science instruction (SINUS): A large scale teacher professional development programme in Germany. Kiel: Leibniz-Institute for Science Education (IPN). Retrieved from https://www.ntnu.no/wiki/download/attachments/8324749/SINUS_en_fin.pdf.

Rammstedt, B. (2013). Grundlegende Kompetenzen Erwachsener im internationalen Vergleich Ergebnisse von PIAAC 2012. Münster: Waxmann.

Reiss, K., Heinze, A., Kessler, S., Rudolph-Albert, F., \& Renkl, A. (2007). Fostering argumentation and proof competencies in the mathematics classroom. In M. Prenzel (Ed.), Studies on the educational quality of schools. The final report on the DFG Priority Programme (pp. 251-264). Münster: Waxmann.

Reiss, K., Heinze, A., \& Pekrun, R. (2007). Mathematische Kompetenz und ihre Entwicklung in der Grundschule. In M. Prenzel, I. Gogolin, \& H. H. Krüger (Eds.), Kompetenzdiagnostik. Sonderheft 8 der Zeitschrift für Erziehungswissenschaft (S. 107-S. 127). Wiesbaden: Verlag für Sozialwissenschaften.

Reiss, K., Roppelt, A., Haag, N., Pant, H. A., \& Köller, O. (2012). Kompetenzstufenmodelle im Fach Mathematik. In P. Stanat, H. A. Pant, K. Böhme, \& D. Richter (Eds.), Kompetenzen von Schülerinnen und Schülern am Ende der vierten Jahrgangsstufe in den Fächern Deutsch und Mathematik. Ergebnisse des IQB-Ländervergleichs 2011 (S. 72-S. 84). Münster: Waxmann.

Robitaille, D., \& Beaton, A. E. (Eds.). (2002). Secondary analysis of the TIMSS data. Dordrecht: Kluwer Academic Publishers.

Schreiner, C., \& Breit, S. (2012a). Standardüberprüfung 2012. Mathematik, 8. Schulstufe. Bundesergebnisbericht. https://www.bifie.at/system/files/dl/01_BiSt-UE_M8_2012_ Bundesergebnisbericht.pdf. Accessed March 14, 2017.

Schreiner, C., \& Breit, S. (2012b). Standardüberprüfung 2012. Mathematik, 8. Schulstufe. Landesergebnisberichte. https://www.bifie.at/node/1949. Accessed March 14, 2017.

Schreiner, C., Breit, S., Pointinger, M., Pacher, K., Neubacher, M., \& Wiesner, C. (Eds.). (2018). Standardüberprüfung 2017. Mathematik, 8. Schulstufe. Bundesergebnisbericht. https://www. bifie.at/wp-content/uploads/2018/02/BiSt_UE_M8_2017_Bundesergebnisbericht.pdf. Accessed May 17, 2018.

Shulman, L. S. (1987). Knowledge and teaching: Foundations of the new reform. Harvard Educational Review, 57, 1-22.

Stigler, J. W., Gonzales, P., Kawanaka, T., Knoll, S., \& Serrano, A. (1999). The TIMSS videotape classroom study. Methods and findings from an exploratory research project on eighth-grade mathematics instruction in Germany, Japan, and the United States. Washington, D.C.: U.S. Department of Education.

Suchán, B., \& Breit, S. (Eds.). (2016). PISA 2015. Grundkompetenzen am Ende der Pflichtschulzeit im internationalen Vergleich. Graz: Leykam.

Süss-Stepancik, E., \& George, A. C. (2016). Was ich an Mathe mag - oder auch nicht! Epistemologische Beliefs von Studienanfängern/anfängerinnen an der PH NÖ. Open Online Journal for Research and Education, 5(1), 50-62.

Süss-Stepancik, E., \& George, A. C. (2017). Einstellungen von Mathematik-Lehrenden und Lehramtsstudierenden zu mathematischen Teilkompetenzen. In Institut für Mathematik der Universität Potsdam (Ed.), Beiträge zum Mathematikunterricht 2017. Münster: WTM-Verlag. 
Verordnung der Bundesministerin für Unterricht, Kunst und Kultur über Bildungsstandards im Schulwesen. BGB1. II Nr. 1/2009. https://www.ris.bka.gv.at/Dokument.wxe?Abfrage= BgblAuth\&Dokumentnummer=BGBLA_2009_II_1. Accessed March 14, 2017.

Vygotskij, L. S. (1978). Mind in society. Cambridge, MA: Harvard University Press.

Weinert, F. E. (2001). Vergleichende Leistungsmessung in Schulen - eine umstrittene Selbstverständlichkeit. In F. E. Weinert (Ed.), Leistungsmessungen in Schulen (pp. 17-31). Weinheim: Beltz.

Wiesner, C., Schreiner, C., \& Breit, S. (2015). Rahmenmodell zur pädagogischen Nutzung der Kompetenzorientierung durch die Bildungsstandardüberprüfung (Unpublished paper). BIFIE, Salzburg.

Wiesner, C., Schreiner, C., Breit, S., \& Bruneforth, M. (2017). Komplementäres Zusammenwirken von Standardüberprüfung und Informeller Kompetenzmessung. Bifie-Journal. https://www.bifie. at/wp-content/uploads/2018/03/bifie_journal_1-2017-04.pdf. Accessed May 17, 2018.

Open Access This chapter is licensed under the terms of the Creative Commons Attribution 4.0 International License (http://creativecommons.org/licenses/by/4.0/), which permits use, sharing, adaptation, distribution and reproduction in any medium or format, as long as you give appropriate credit to the original author(s) and the source, provide a link to the Creative Commons licence and indicate if changes were made.

The images or other third party material in this chapter are included in the chapter's Creative Commons licence, unless indicated otherwise in a credit line to the material. If material is not included in the chapter's Creative Commons licence and your intended use is not permitted by statutory regulation or exceeds the permitted use, you will need to obtain permission directly from the copyright holder. 